NISTIR 3962

MAGNETIZATION CHANGES IN

LOW-CARBON, Ni-Cr-MO AND

HIGH-STRENGTH-LOW-ALLOY STEELS

AS A FUNCTION OF STRESS

T. W. Petersen

United States Department of Commerce National Institute of Standards and Technology 



\section{MAGNETIZATION CHANGES IN LOW-CARBON, Ni-Cr-Mo AND HIGH-STRENGTH-LOW-ALLOY STEELS AS A FUNCTION OF STRESS}

\section{T. W. Petersen}

Electromagnetic Technology Division Electronics and Electrical Engineering Laboratory National Institute of Standards and Technology Boulder, Colorado 80303

September 1991

Prepared for:

U.S. Department of the Navy David Taylor Research Center Annapolis, MD 21402

and

Defense Advanced Research Projects Agency

Arlington, VA 22209

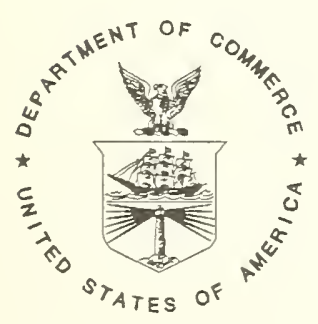

U.S. DEPARTMENT OF COMMERCE, Robert A. Mosbacher, Secretary NATIONAL INSTITUTE OF STANDARDS AND TECHNOLOGY, John W. Lyons, Director 



\section{Contents}

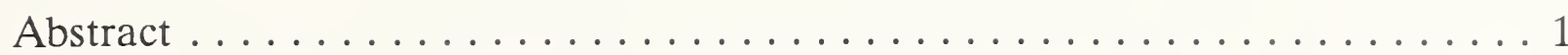

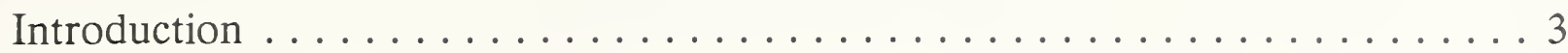

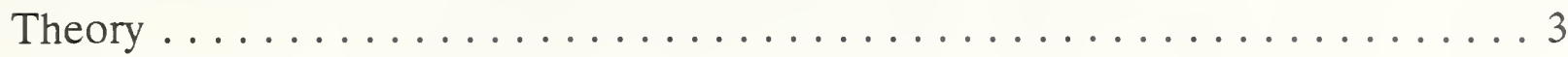

Materials and Sample Geometry .................... 6

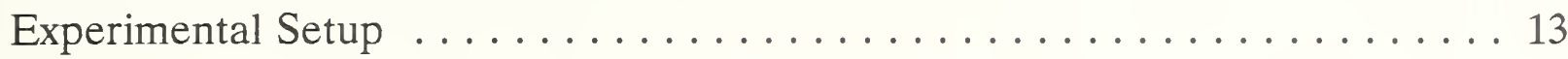

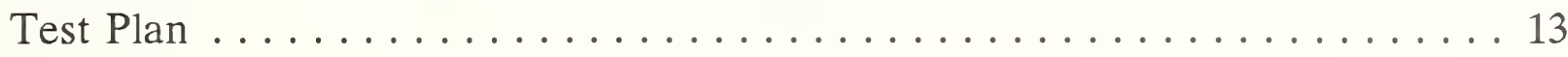

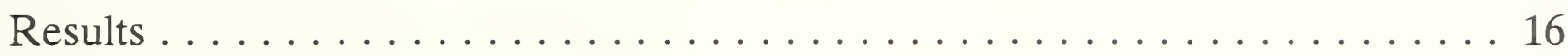

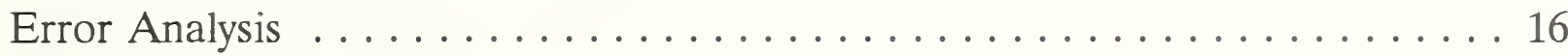

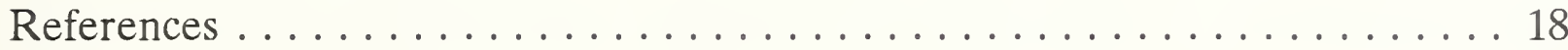

Appendix A . . . . . . . . . . . . . . . . . 19

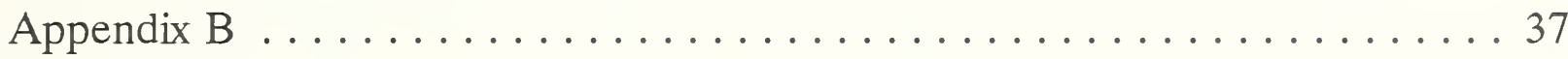

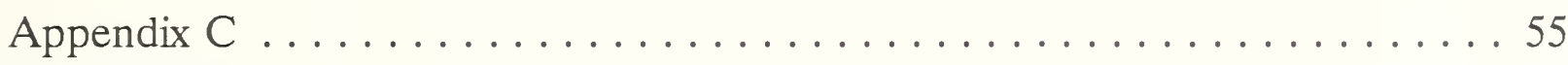

Appendix D . . . . . . . . . . . . . . . . . 73

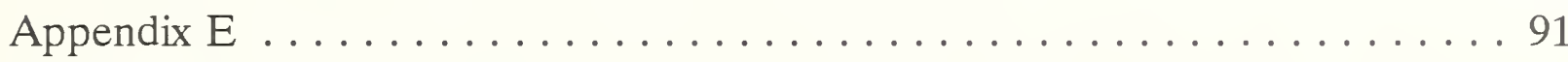

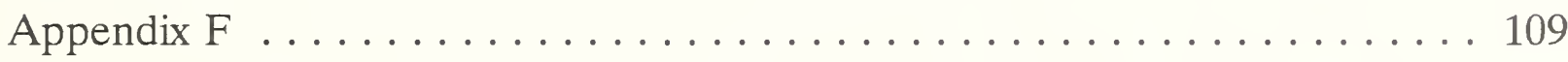

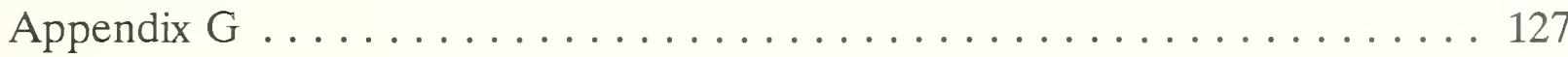

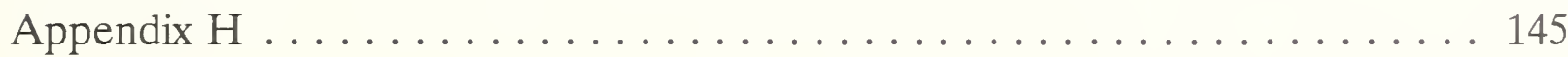





\title{
Magnetization Changes in Low-Carbon, Ni-Cr-Mo and High-Strength-Low-Alloy Steels as a Function of Stress
}

\author{
Timothy W. Petersen \\ Electromagnetic Technology Division \\ Electronics and Electrical Engineering Laboratory \\ National Institute of Standards and Technology \\ Boulder, Colorado 80303
}

\begin{abstract}
The magnetic properties of eight steel alloys and the effect of tensile and compressive stresses on these properties were measured. Experimental samples were designed to allow the application of stress in a direction transverse to that of the applied magnetic field and the measured induction. The measured properties include the differential susceptibility, the normal magnetization curve, symmetric major and minor hysteresis loops, and the anhysteretic magnetization curve for varying stress levels. In addition, the magnetic induction as a function of applied transverse stress was measured for various dc magnetic fields. This report describes the experimental apparatus, the experimental design, and the results of the measurements.
\end{abstract}

Key words: anhysteretic magnetization; compressive stress; ferromagnetism; hysteresis; magnetic induction; magnetic susceptibility; magnetization; magnetoelastic processes; magnetomechanical effects; magnetostriction; steel alloys; stress-induced magnetization; tensile stress. 



\section{Introduction}

The relationship between stress and magnetization has been studied for some

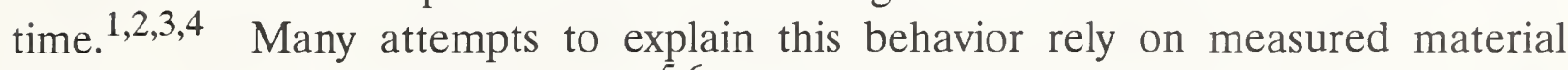
properties to fit theoretical models. 5,6 Several researchers have made measurements of magnetoelastic effects transverse to the applied stress. Schneider and Richardson ${ }^{7}$ used several sample shapes, including a hollow cylinder with azimuthally wound coils threaded through a series of holes, to measure magnetic properties transverse to the applied stress. However, that work was for only one type of material, and the stress was nonuniform through the cross section of the sample, being higher at the edges of the holes. Langman ${ }^{8,9}$ has provided a different approach, using cross-shaped pieces of material sandwiched, along with strain gauges, between ceramic sheets. A four-point bend apparatus provided stress to the material, while a high-permeability yoke provided a magnetic field. The magnetization of the sample was sensed near the center of the sample with secondary coils wound through small holes. However, the sample shape had an unspecified demagnetizing factor and the effect of the Earth's magnetic field was not shielded by the experimental apparatus. In addition to these researchers, Pitman ${ }^{10}$ has made magnetoelastic measurements. These were performed uniaxially, with the stress and the magnetic field in the same direction. A semi-quantitative model was suggested which uses the anhysteretic curve to explain magnetoelastic behavior.

In this work we extend the body of data available for verification of these models. We present a novel method for measuring relationships between stress and magnetic properties of materials. The data gathered from these experiments may be used to extend theoretical models of magnetoelastic effects. In turn, a theoretical model may be used as input to a finite-element model of complex ferromagnetic structures subject to field-stress cycles.

\section{Theory}

Ferromagnetic materials, such as the samples studied, have small magnetic domains. Within each domain the magnetization is saturated. In iron, there are six easy axes along which the magnetization of a domain might lie. A domain wall separates two domains with magnetizations in different directions. In iron, the easy axes are perpendicular so the magnetization change when crossing a domain wall will be either 90 degrees or 180 degrees of arc. These walls are referred to as 90- and 180-degree domain walls. Within the metal as a whole, domains orient themselves to minimize the magnetic energy and the energy contained in the domain walls. With 
no external fields, the magnetization of a sample will depend solely on the material's magnetic history.

There are two processes that change the magnetization of a domain. First, a domain can grow at the expense of another domain by movement of domain walls. Second, an entire domain can rotate its magnetization to one of the other preferred directions. Two factors that affect domain wall motion and domain rotation are stress and magnetic fields.

To study the relationship between magnetization and stress or applied field, we must minimize the energy contained in the domains with respect to the applied field and the applied stress. ${ }^{11}$ The expression for the energy of a magnetic domain has four terms,

$$
\mathrm{E}=\mathrm{E}_{\mathrm{K}}+\mathrm{E}_{\sigma}+\mathrm{E}_{\mathrm{H}}+\mathrm{E}_{\mathrm{D}}
$$

These terms represent the anisotropy energy, the magnetoelastic energy, the magnetic energy, and the demagnetizing energy respectively. The anisotropy energy $\mathrm{E}_{\mathrm{K}}$ can be written

$$
\mathrm{E}_{\mathrm{K}}=\frac{1}{4} \mathrm{~K} \sin ^{2} \theta_{\mathrm{MK}}
$$

where $\mathrm{K}$ is the anisotropy constant for the material, and $\theta_{\mathrm{mk}}$ is the angle between the direction of magnetization in the domain and the easy axis. For the materials studied, this effect was small, since $\theta_{\mathrm{mk}}$ was usually zero. The second term in the energy equation, $\mathrm{E}_{\sigma}$, accounts for the interaction of the domains with stresses in the material and can be written

$$
\mathrm{E}_{\sigma}=\frac{3}{2} \lambda_{\mathrm{s}} \sigma \sin ^{2} \theta_{\mathrm{M} \sigma}
$$

where $\lambda_{\mathrm{s}}$ is the saturation magnetostriction constant for the material, $\sigma$ is the applied stress, and $\theta_{\mathrm{m} \sigma}$ is the angle between the applied stress and the magnetization vector. Some authors account for the variation in $\lambda_{\mathrm{s}}$ with magnetizing field. ${ }^{5,6}$ However, recent experiments ${ }^{7}$ have shown $\mathrm{E}_{\sigma}$ to be linear with stress for positive stresses.

The third term in the energy equation is the mutual energy between $\mathrm{H}$ and $\mathrm{M}$,

$$
\mathrm{E}_{\mathrm{H}}=-\mathrm{H} \mathrm{M}_{\mathrm{s}} \mu_{0} \cos \theta_{\mathrm{MH}} \text {. }
$$

The final term accounts for the interaction between any demagnetizing fields in the 
sample. In the specimens tested, a toroidal geometry was used, so the bulk demagnetizing factor was zero, and hence $\mathrm{E}_{\mathrm{D}}$ was zero. If we consider only the magnetoelastic and magnetic effects on a single domain, the energy equation becomes

$$
\mathrm{E}=\frac{3}{2} \lambda_{\mathrm{s}} \sigma \sin ^{2} \theta-\mathrm{H} \mathrm{M}_{\mathrm{s}} \mu_{0} \cos \left(\theta_{0}-\theta\right),
$$

where $\theta_{0}$ is the angle between the applied field and stress and $\theta$ is the angle between the domain magnetization and stress. The equilibrium position will occur at $\mathrm{dE} / \mathrm{d} \theta$ $=0$. Performing the differentiation and solving for the magnetic field yields

$$
\mathrm{H}=3 \lambda_{\mathrm{s}} \sigma \sin \theta \cos \theta /\left[\mathrm{M}_{\mathrm{s}} \mu_{0} \sin \left(\theta_{0}-\theta\right)\right] .
$$

If the applied field is in the same direction as the stress, $\theta_{0}=0^{\circ}$. Additionally, the cosine dependence may be averaged to $\pm \frac{1}{2}$. The effective field produced by a uniform stress becomes

$$
\mathrm{H}=\mp 3 \lambda_{\mathrm{s}} \sigma /\left(2 \mathrm{M}_{\mathrm{s}} \mu_{0}\right) \text {. }
$$

If the stress and the applied field are perpendicular to one another, $\theta_{0}=90^{\circ}$, and the effective field reduces to

$$
\mathrm{H}= \pm 3 \lambda_{\mathrm{s}} \sigma /\left(2 \mathrm{M}_{\mathrm{s}} \mu_{0}\right) \text {. }
$$

The effective field produced by the stress is the same for both cases, except for the sign. As a result, one expects that measurements with a positive stress along the same axis as the field will produce results identical to measurements with a negative stress along an axis perpendicular to the field.

If one assumes there is no resistance to domain wall motion, then all of the effective fields would add and the resulting magnetization would lie on the anhysteretic curve: the equilibrium domain wall position for a given field. In ferromagnetic materials, there is usually domain wall pinning and, as a result, hysteresis. It is important to note that the normal magnetization curve always asymptotically approaches the anhysteretic curve as the field intensity is increased. At any point on the normal magnetization curve, the effect of a stress cycle or a small magnetic field cycle will be to overcome some of the domain wall pinning and move the magnetization closer to the anhysteretic curve. ${ }^{10}$ The focus of this work was to measure magnetization and susceptibility changes as a function of applied stress along an axis perpendicular to the applied stress. 


\section{Materials and Sample Geometry}

The alloy compositions are listed in Table 1. The sample heat treatments are given in Table 2. Small specimens were measured in a superconducting-quantuminterference-device (SQUID) magnetometer to obtain the saturation magnetization $M_{s}$. Remanent induction $B_{r}$ and intrinsic coercivity $H_{c}$ were obtained from the measured major hysteresis loops, with maximum fields greater than $6 \mathrm{kA} / \mathrm{m}$, for unstressed samples. These quantities are listed in Table 3.

The samples were designed as hollow cylinders threaded at both ends to allow attachments of the grips of a standard stress machine (Fig. 1). The samples were $11.43 \mathrm{~cm}$ in length, with an inner diameter of $1.91 \mathrm{~cm}$. The outer diameter was 3.18 $\mathrm{cm}$ at the ends and necked at the center to $2.22 \mathrm{~cm}$. Each of the eight samples was slotted along both ends to allow primary (field) and secondary (sense) coils to be wound inside the threads. Samples were prepared at the David Taylor Research Center to tolerances of $0.025 \mathrm{~mm}$. Of particular importance was the concentricity of the inner and outer diameters of the cylinders; lack of symmetry could result in plastic deformation at high stresses. Internal stresses introduced into the material as a result of machining were kept to a minimum so measurements of stress dependences would be more indicative of the material. For this reason, slots in the samples were cut using an electrostatic discharge machine (EDM). For the measurements, 80 loops of insulated $30 \mathrm{AWG}$ wire (diameter $0.277 \mathrm{~mm}$ ) were used for the sense coil and 64 loops of insulated AWG 20 wire (diameter $0.848 \mathrm{~mm}$ ) were used for the primary field coil. They were fitted into the eight slots in each sample. The magnetic field provided by the primary coils was calibrated using Ampère's law. The applied field intensity $\mathrm{H}$ as a function of the sample radius and the number of turns $\mathrm{N}_{\mathrm{p}}$ is

$$
\mathrm{H}=\mathrm{N}_{\mathrm{p}} \mathrm{I} /(2 \pi \mathrm{r}) \text {. }
$$

The average field intensity over the radius of the sample may be obtained by integration

$$
\begin{aligned}
\mathrm{H}_{\mathrm{av}}= & \left(\mathrm{r}_{\mathrm{o}}-\mathrm{r}_{\mathrm{i}}\right)^{-1} \int \mathrm{N}_{\mathrm{p}} \mathrm{I}(2 \pi \mathrm{r})^{-1} \mathrm{dr} \\
= & \left(\mathrm{N}_{\mathrm{p}} \mathrm{I} \ln \left(\mathrm{r}_{\mathrm{o}} / \mathrm{r}_{\mathrm{i}}\right)\right] /\left[2 \pi\left(\mathrm{r}_{\mathrm{o}}-\mathrm{r}_{\mathrm{i}}\right)\right],
\end{aligned}
$$

where $r_{0}$ and $r_{i}$ are the outer and inner diameters (Fig. 2).

In a similar fashion, the calibration of the magnetic flux through the sense coils may be obtained using Faraday's law. The sense-coil voltage V can be related to the 


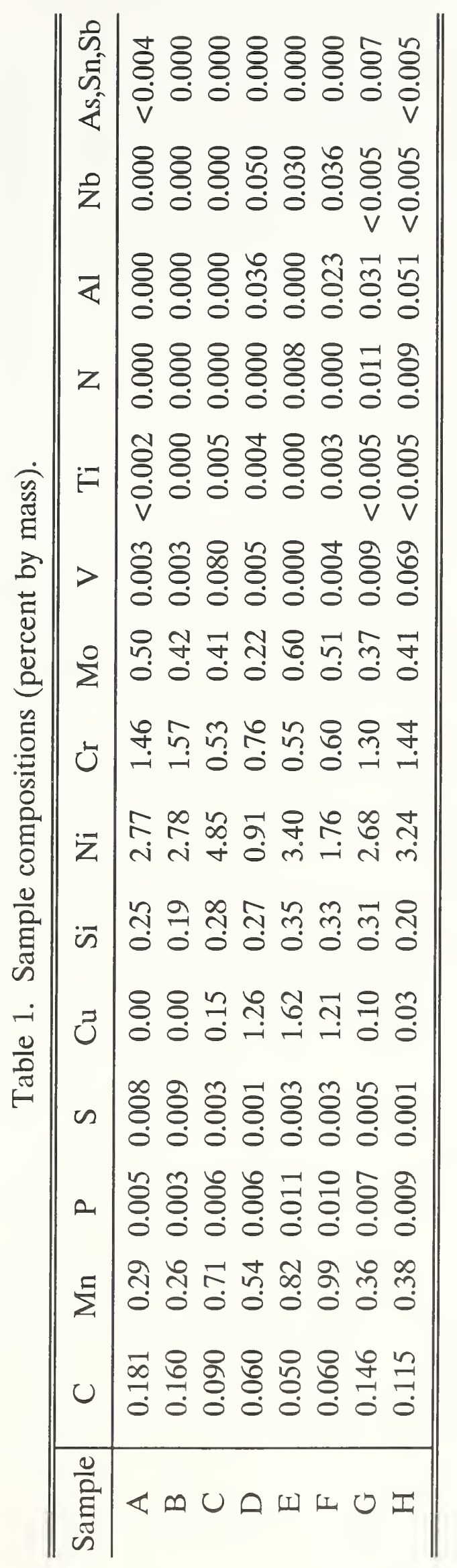




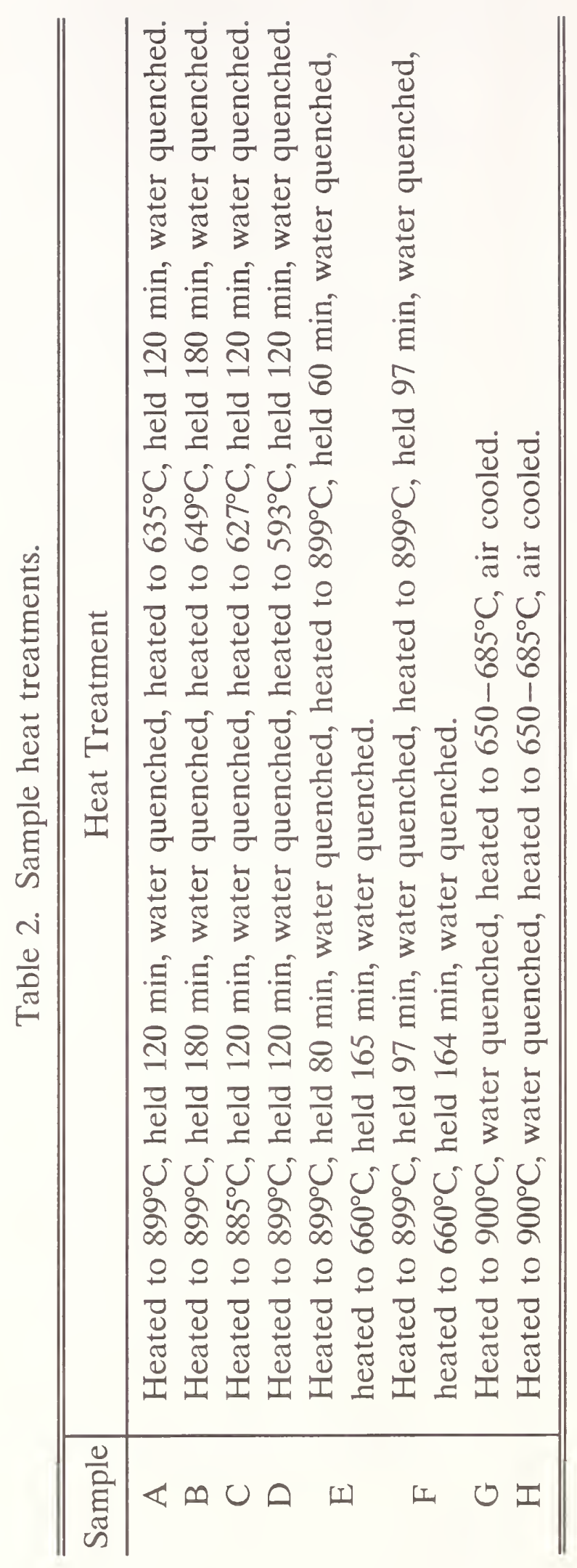


Table 3. Sample magnetic properties.

\begin{tabular}{c|ccc}
\hline \hline Sample & $\mathrm{M}_{\mathrm{S}}(\mathrm{MA} / \mathrm{m})$ & $\mathrm{B}_{\mathrm{r}}(\mathrm{T})$ & $\mathrm{H}_{\mathrm{c}}(\mathrm{A} / \mathrm{m})$ \\
\hline \hline $\mathrm{A}$ & 1.419 & 1.31 & 798 \\
$\mathrm{~B}$ & $1.48^{*}$ & 1.32 & 891 \\
$\mathrm{C}$ & $1.50^{*}$ & 1.23 & 867 \\
$\mathrm{D}$ & 1.507 & 1.12 & 645 \\
$\mathrm{E}$ & 1.438 & 1.21 & 705 \\
$\mathrm{~F}$ & 1.426 & 1.25 & 960 \\
$\mathrm{G}$ & 1.572 & 1.49 & 726 \\
$\mathrm{H}$ & 1.607 & 1.37 & 763 \\
\hline \hline
\end{tabular}

*Determined from major hysteresis loop. 


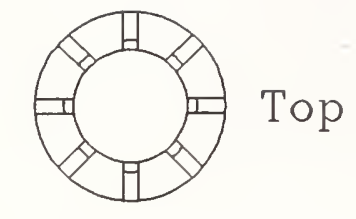

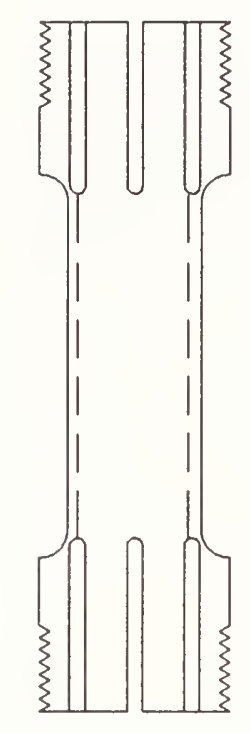

Side View

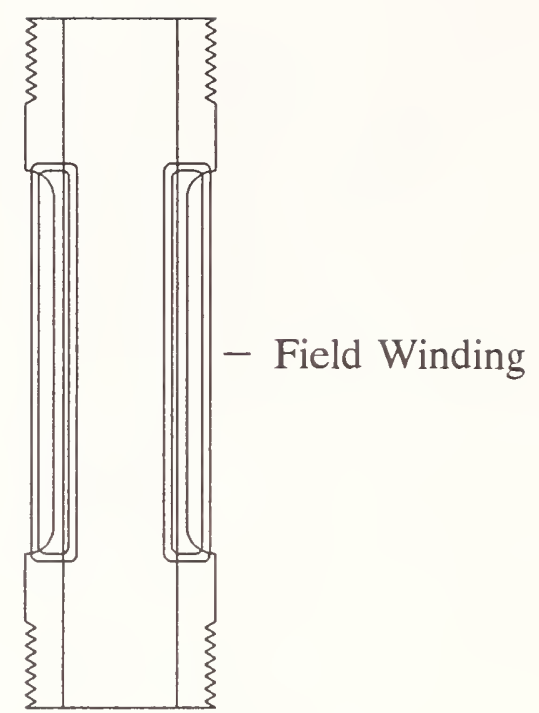

Cross Section

Figure 1. Sample geometry used to measure the magnetoelastic properties of eight steel alloys. The slots in the specimens allowed the primary and sense coils to be wound. 


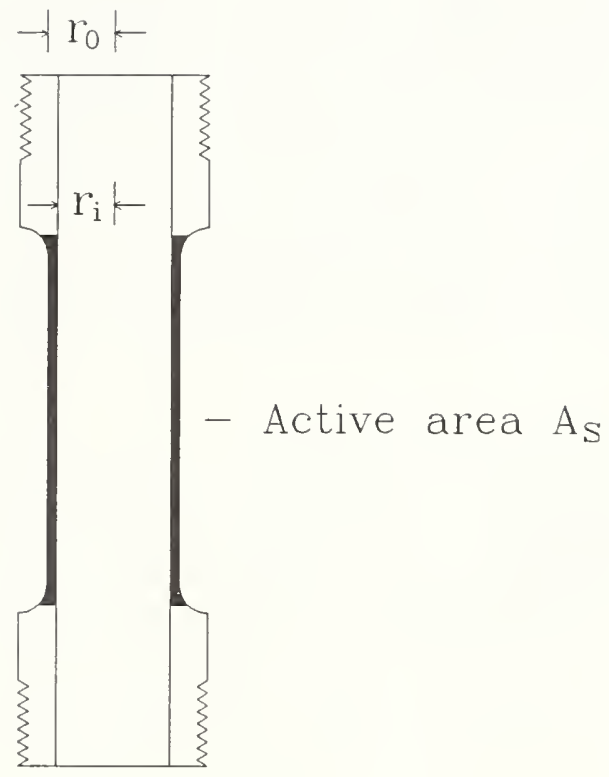

Figure 2. Sample cross section showing active area of the sample. The symbols used in the calibration equations are defined. 
time-differentiated magnetic induction $\mathrm{dB} / \mathrm{dt}$,

$$
\mathrm{V}=-\mathrm{d} \Phi / \mathrm{dt}=-\mathrm{A}_{\mathrm{s}}(\mathrm{dB} / \mathrm{dt})
$$

where $A_{s}$ is the area of the sense coils and $\Phi$ is the total flux through the sense coils.

The voltage is integrated electronically so the total magnetic induction is

$$
\mathrm{B}=-\mathrm{RCV} / \mathrm{A}_{\mathrm{s}},
$$

where $\mathrm{RC}$ is the time constant of the integrator. The integrator used in these experiments was designed with variable resistances and capacitances so the sensitivity of the integrator could be varied. The appropriateness of these toroid calibration equations for this sample geometry has been verified by Cannell. ${ }^{12}$ The applied stress in the active area was calibrated using the cross-sectional area of the sample at its center. In addition, the samples were designed with a slightly greater crosssectional area at the bottoms of the slots to increase the uniformity of the stress in the active area $\mathrm{A}_{\mathrm{s}}$.

The susceptibility of the material may be obtained from the magnetization dependence through differentiation. Alternatively, the susceptibility may be measured directly, due to its proportionality to the unintegrated sense coil voltage, ${ }^{7}$

$$
\begin{aligned}
\chi & =\mathrm{dM} / \mathrm{dH}=(\mathrm{dM} / \mathrm{dt}) /(\mathrm{dH} / \mathrm{dt}) \\
& =\left[\left(1 / \mu_{0}\right) \mathrm{dB} / \mathrm{dt}-\mathrm{dH} / \mathrm{dt}\right] /(\mathrm{dH} / \mathrm{dt}) \\
& =(\mathrm{dB} / \mathrm{dt}) /\left[\mu_{0}(\mathrm{dH} / \mathrm{dt})\right]-1 .
\end{aligned}
$$

The time rate of change of the magnetic induction may be obtained from Eq. (11), and the time rate of change of the magnetic field may be obtained by differentiation of Eq. (10). For susceptibility measurements, the driving wave function chosen was a triangle wave, so $\mathrm{dH} / \mathrm{dt}$ would be a constant over a half cycle. The time rate of change of $\mathrm{H}$ was measured directly from the voltage drop across a resistor in series with the primary coil.

To ensure that the sample was demagnetized in a consistent fashion, the demagnetizing process was computer-controlled using a digitized waveform and a digital-to-analog (D/A) converter. The demagnetizing field was a $1 \mathrm{~Hz}$ sine wave modulated by an exponentially decreasing envelope with an initial value of $5000 \mathrm{~A} / \mathrm{m}$ $(2500 \mathrm{~A} / \mathrm{m}$ for samples $\mathrm{D}, \mathrm{E}$, and $\mathrm{F})$. The envelope was designed so the final amplitude of the sine wave was $10^{-7}$ times the initial amplitude. 


\section{Experimental Setup}

The apparatus shown in Fig. 3 allows a considerable amount of control of the experimental parameters. An eight-channel analog-to-digital (A/D) converter digitizes the data and sends it over the GPIB bus to the computer. The 100-A bipolar power supply has six output ranges, allowing an increase in the current resolution when high currents are not necessary. Not shown in Fig. 3 is a highpermeability shield, coaxial with the sample, used to attenuate stray magnetic noise and shield dc magnetic fields. The leads from the sense coils and those going to the $\mathrm{A} / \mathrm{D}$ converter were braided to prevent flux noise in the circuits.

The 16-bit A/D converter has 8 simultaneous sample-and-hold channels, each capable of storing more than 2500 data points. In addition to monitoring the magnetic field and the magnetic flux, the $\mathrm{A} / \mathrm{D}$ converter also monitored the stress level via an analog voltage output from the stress machine. These stress levels were used in measurements of flux changes with applied stress. The D/A converter also was used to establish repeatable dc bias fields in the sample during measurements of flux changes with applied stress.

\section{Test Plan}

The test plan for the samples consisted of eight types of measurements, each designed to probe a specific property of the alloys. The following notation will be used for the processes:

$\mathrm{D}$ : demagnetize the sample using the $\mathrm{D} / \mathrm{A}$ converter

I: reset the integrator to zero

$\mathrm{H}$ : apply a dc magnetizing field

$\mathrm{H} \sim$ : cycle the magnetizing field

$\sigma+$ : apply a stress

$\sigma-:$ remove a stress

The data obtained were of three types: magnetization as a function of applied field, $\mathrm{B}(\mathrm{H})$ curves; susceptibility as a function of applied field, $\chi(\mathrm{H})$ curves; and magnetic induction as a function of applied stress, $\mathrm{B}(\sigma)$ curves. The measurements performed were as follows: 


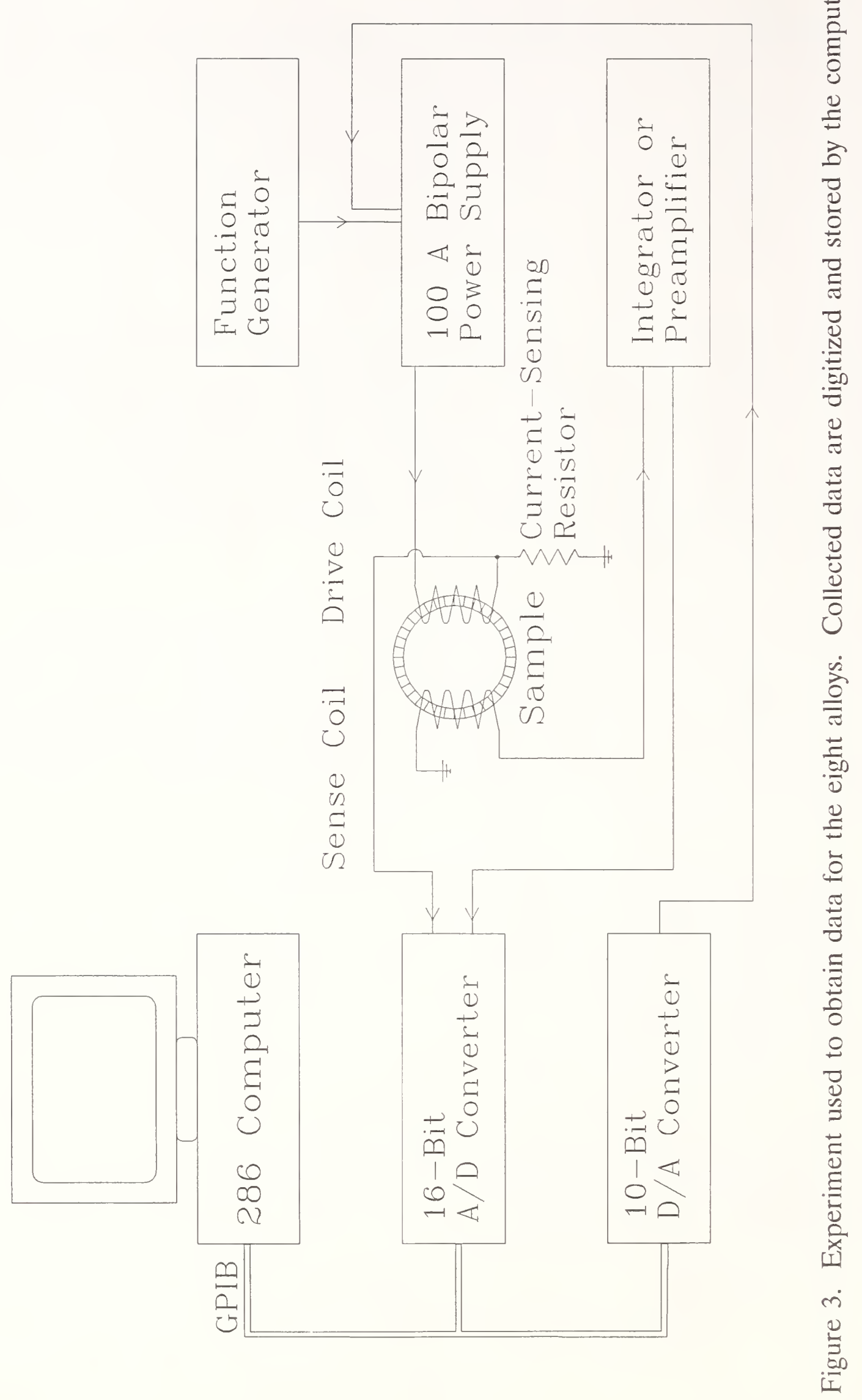


(1) The normal magnetization curve of the sample from $\mathrm{H}=0$ to $5000 \mathrm{~A} / \mathrm{m}$. The data yielded a $\mathrm{B}(\mathrm{H})$ curve, and the process used was $\mathrm{D}$ I $\mathrm{H} \sim$, namely, demagnetize the sample, reset the integrator, and then increase the magnetic field from 0 to $5000 \mathrm{~A} / \mathrm{m}$.

(2) The major hysteresis loop for different stress levels. The data produced $\mathrm{B}(\mathrm{H})$ curves, and the process was $\mathrm{D}$ I $\sigma+\mathrm{H} \sim$. The range of $\mathrm{H}$ was from 0 to 8000 to -8000 to $0 \mathrm{~A} / \mathrm{m}$. The applied stress ranged from -400 to $400 \mathrm{MPa}$ in 17 increments.

(3) Unstressed minor hysteresis loops for maximum fields of 100, 200, and $400 \mathrm{~A} / \mathrm{m}$. The process used was $\mathrm{D}$ I $\mathrm{H} \sim \mathrm{B}(\mathrm{H})$ curves were measured.

(4) Differential susceptibility curves for varying stress levels. The data obtained were $\chi(\mathrm{H})$ curves and the process was $\sigma \mathrm{D} \mathrm{H} \sim$. The applied stress varied between -400 and $400 \mathrm{MPa}$, and data were obtained for maximum fields of 150 and $5000 \mathrm{~A} / \mathrm{m}$. Note that in this measurement an integrator was not used. Instead, a preamplifier was used to amplify the unintegrated voltages from the sense coils. The preamplifier used a low-pass filter typically set at $30 \mathrm{~Hz}$ with a $12 \mathrm{~dB}$ roll-off. The frequency was chosen to eliminate noise at $60 \mathrm{~Hz}$, but to have a bandpass wide enough not to degrade either the peak value of the susceptibility or the initial sharp rise in the susceptibility.

(5) Anhysteretic curves for different stress levels. The resulting data produced a $\mathrm{B}(\mathrm{H})$ curve and the process used was D I $\sigma \mathrm{H} \mathrm{H} \sim$. The stress varied between -400 and $400 \mathrm{MPa}$, and $\mathrm{H}$ was composed of a discrete set of points between 0 and $6400 \mathrm{~A} / \mathrm{m}$. Both the dc bias and the demagnetizing field at each point were controlled by the D/A converter.

(6) Induction as a function of stress for various dc bias fields. The data obtained from this process were $\mathrm{B}(\sigma)$ curves and the process was $\mathrm{D} \mathrm{I} \mathrm{H} \sigma+\sigma-$. The stress was cycled between maxima of $\pm 10, \pm 40, \pm 80, \pm 150$, and $\pm 300 \mathrm{MPa}$. For each of these maxima, the dc bias was varied between 0 and $500 \mathrm{~A} / \mathrm{m}$ in seven increments.

(7) The differential susceptibility curve for the process $\mathrm{D} \sigma+\mathrm{H} \sim$. This process differs from that of measurement (5) in that the order of the stress and the demagnetization is reversed. The stress levels ranged from -400 to $400 \mathrm{MPa}$ in 14 increments, and data were collected for maximum fields of 150 and 1000 $\mathrm{A} / \mathrm{m}$. 
(8) The differential susceptibility curve after the material has experienced the application and release of a stress. The data collected were $\chi(\mathrm{H})$ curves and the process was $\mathrm{D} \sigma+\sigma-\mathrm{H} \sim$. The stress levels ranged from -400 to 400 $\mathrm{MPa}$ in 10 increments, and $\mathrm{H}$ was cycled to maximum fields of 150 and 1000 $\mathrm{A} / \mathrm{m}$.

(9) The saturation magnetization $\mathrm{M}_{\mathrm{S}}$ of small samples was measured using a SQUID magnetometer. The measuring field was typically $5 \mathrm{~T}$. These data appear in Table 3.

\section{Results}

Measurement results for the samples are given in Appendices A through $\mathrm{H}$, where each appendix label indicates a particular sample (Table 1). For all of the data presented, positive stress denotes transverse tensile stress and negative stress denotes transverse compressive stress.

\section{Error Analysis}

One source of error is in the calibration of the magnetic and inductive fields. The sense coils are wound as uniformly as possible over the sample's cross section. However, the area used to calibrate the induction is the area of the sample $A_{s}$. Although the windings do not lie flat against the sample, the error due to flux leakage is small considering the relatively high permeability of the sample when compared to that of the environment. The estimation of $\mathrm{H}$ is more difficult, involving an integration along the path of the radius of the primary coils. The field at the edges of the sample will be higher as a result of the increased local current density produced by the edges of the windings. To address this problem, a three-dimensional finite element analysis was done. ${ }^{12}$ The effect of the nonuniformity of the field through the cross sectional area of the sample and the discrete windings was less than $3 \%$.

A high-permeability shield was placed outside of the sample to minimize fields near the sample. While this method canceled a portion of the background dc magnetic field, the shield could not cancel fields created by the magnetized grips of the stress machine. The dc field may have affected the equilibrium magnetization reached after a demagnetizing cycle. Of greater concern were the dc magnetic fields produced by offset voltages in the electronics. These fields could affect the 
equilibrium magnetization by cycling the demagnetizing field about a dc offset producing a magnetization lying on the anhysteretic curve. The current produced by the voltage-controlled current source with input shorted was less than $1 \mathrm{~mA}$ for all output ranges. This current corresponded to a dc magnetic field of less than $1 \mathrm{~A} / \mathrm{m}$. Other sources of dc offset noise were the D/A converter and the function generator. The dc offset voltages from the function generator and the D/A converter could be nulled to less that $0.1 \mathrm{mV}$, corresponding to an effective magnetic field of $\pm 5 \mathrm{~A} / \mathrm{m}$ at the highest range. However, the resolution of the $\mathrm{D} / \mathrm{A}$ converter was $1 \mathrm{mV}$, so the smallest step size during a demagnetizing cycle was $10 \mathrm{~A} / \mathrm{m}$.

During many of the measurements of magnetic induction, the thermal drift of the integrator affected the data. Ranges on the integrator were chosen to minimize the thermal drift while providing a reasonable sensitivity level. For some measurements, such as the anhysteretic curve, the integrator drift was unavoidable because the measurements lasted 600 seconds. To compensate, the final magnetization value was calculated from the saturated hysteresis loop and the anhysteretic data were linearly corrected for the drift.

During all of the measurements, the lowest output range on the voltagecontrolled current source was chosen. As a result, offset voltages in the function generator and the D/A converter would result in smaller offset magnetic field intensities and the effect of any $60 \mathrm{~Hz}$ noise in the driving wave functions would also be reduced. The filter used to eliminate $60 \mathrm{~Hz}$ noise in the measurements of susceptibility was chosen to reduce noise without degrading either the peak value of the susceptibility or its initial sharp rise.

\section{Acknowledgments}

P. Y. Cannell (David Taylor Research Center) and C. S. Schneider (U.S. Naval Academy) formulated much of the theory presented and suggested many of the measurement techniques. R. B. Goldfarb, R. W. Cross, and M. T. Haskell (National Institute of Standards and Technology) assisted with this project. P. Y. Cannell prepared the figures in the appendices for publication. 


\section{References}

1. R. M. Bozorth and H. J. Williams, Effect of small stresses on magnetic properties, Rev. Mod. Phys. 17, 72-80 (1945).

2. W. F. Brown, Jr., Irreversible magnetic effects of stress, Phys. Rev. 75, 147-154 (1949).

3. J. A. Ewing, Contributions to the molecular theory of induced magnetism, Phil. Mag. 5th Ser. 30, 205-222 (1890).

4. R. R. Birss, Magnetomechanical effects in the Rayleigh region, IEEE Trans. Magn. 7, 113-133 (1971).

5. D. C. Jiles and D. L. Atherton, Theory of the magnetization process in ferromagnets and its application to the magnetomechanical effect, J. Phys. D: Appl. Phys. 17, 1265-1281 (1984).

6. D. C. Jiles and D. L. Atherton, Theory of ferromagnetic hysteresis, J. Magn. Magn. Mater. 61, 48-60 (1986).

7. C. S. Schneider and J. M. Richardson, Biaxial magnetoelasticity in steels, J. Appl. Phys. 53, 8136-8138 (1982).

8. R. Langman, The effect of stress on the magnetization of mild steel at moderate field strengths, IEEE Trans. Magn. 21, 1314-1320 (1985).

9. R. Langman, Magnetic properties of mild steel under conditions of biaxial stress, IEEE Trans. Magn. 26, 1246-1251 (1990).

10. K. C. Pitman, The influence of stress on ferromagnetic hysteresis, IEEE Trans. Magn. 26, 1978-1980 (1990).

11. P. Y. Cannell, David Taylor Research Center, private communication, 1991.

12. P. Y. Cannell, "Design and finite-element analysis of a test sample used to measure the magnetic response of steels to magnetic field and stress," unpublished. 
Appendix A 


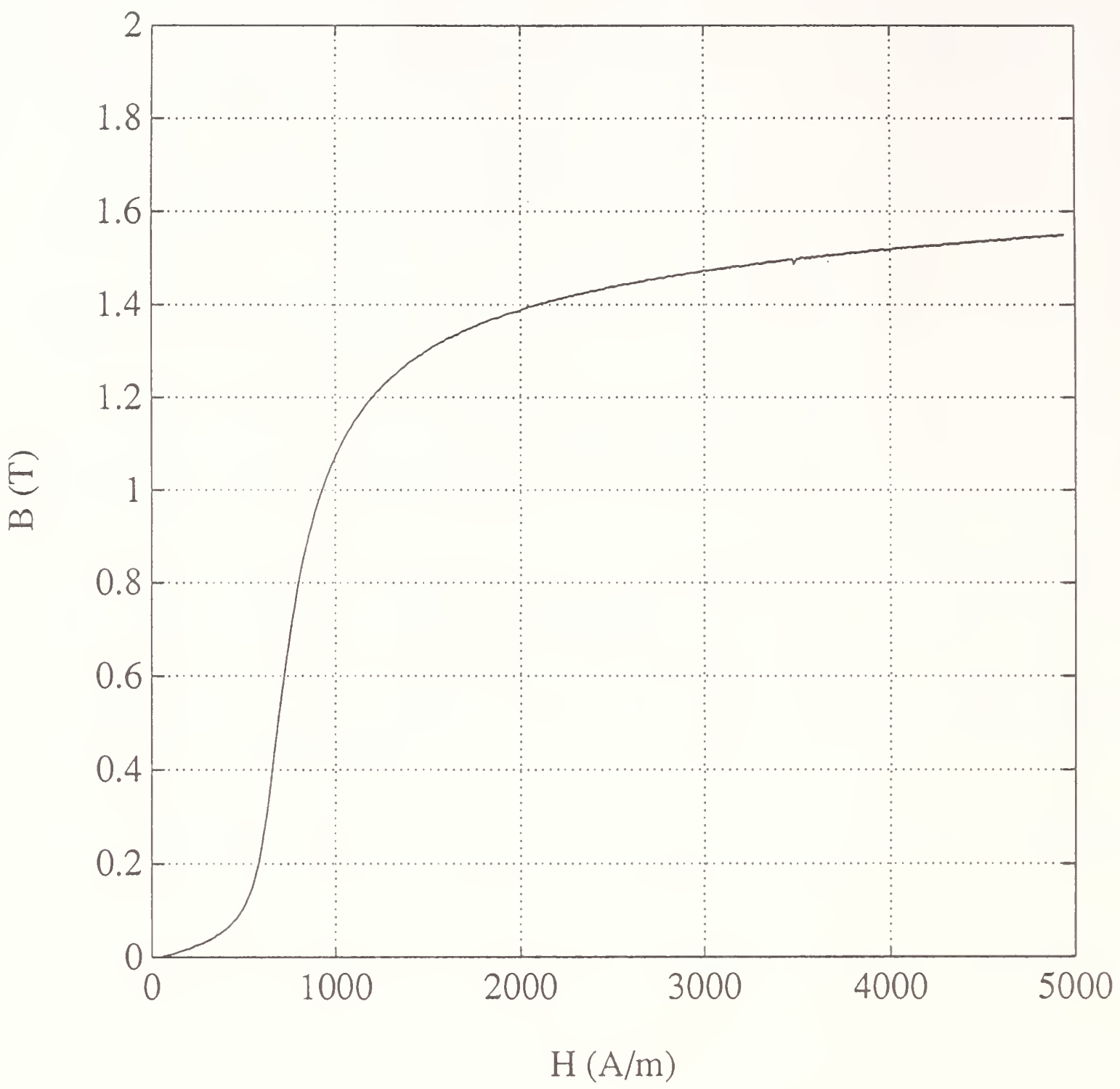

Figure A-1. Normal unstressed magnetization curve as described by (1) in the test plan. 


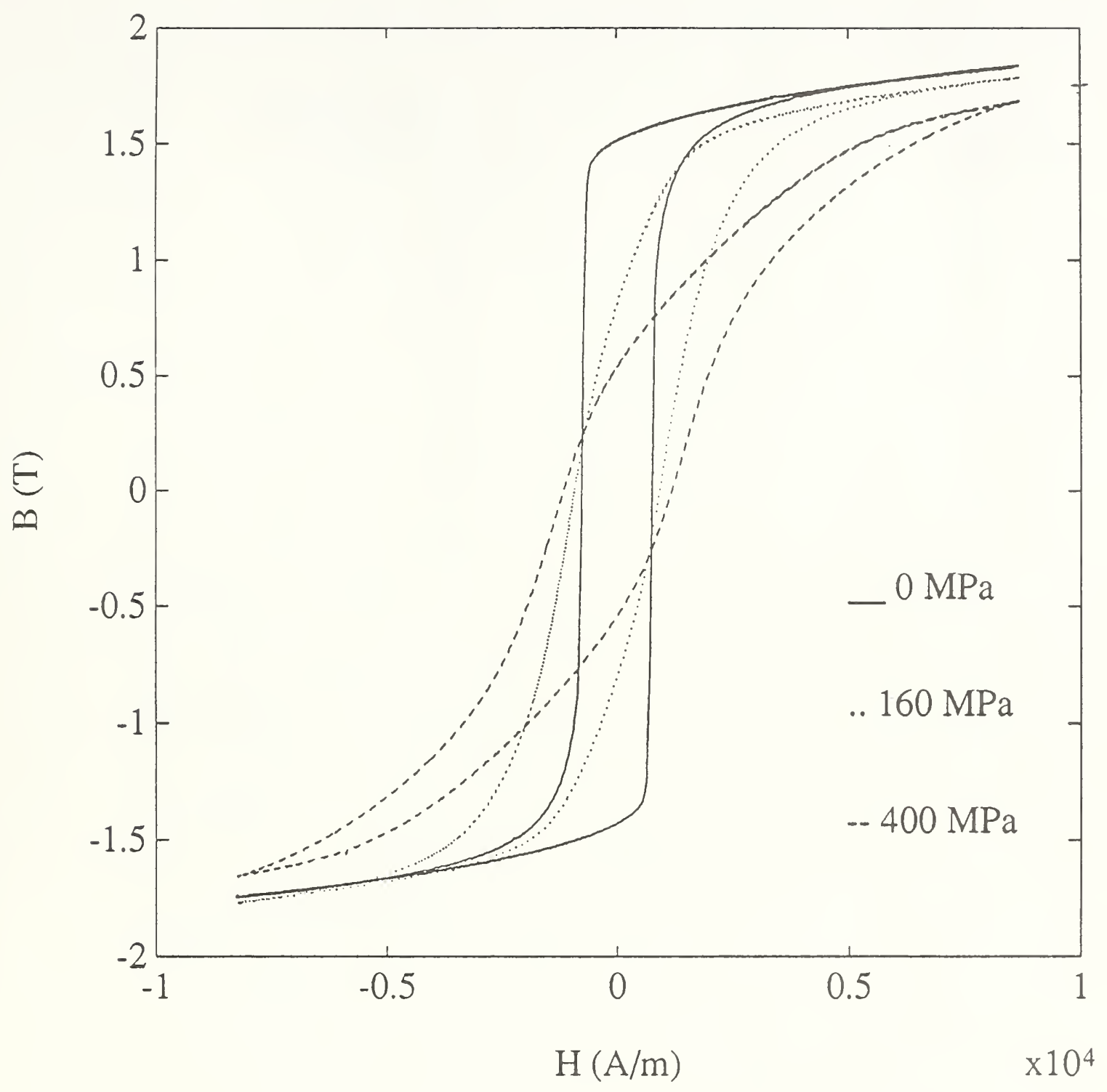

Figure A-2. Magnetic induction as a function of applied magnetic field strength for positive transverse stress (tension) ranging from 0 to $400 \mathrm{MPa}$ as described by (2) in the test plan. The stress results in an effective demagnetizing field which shears the hysteresis loop. 


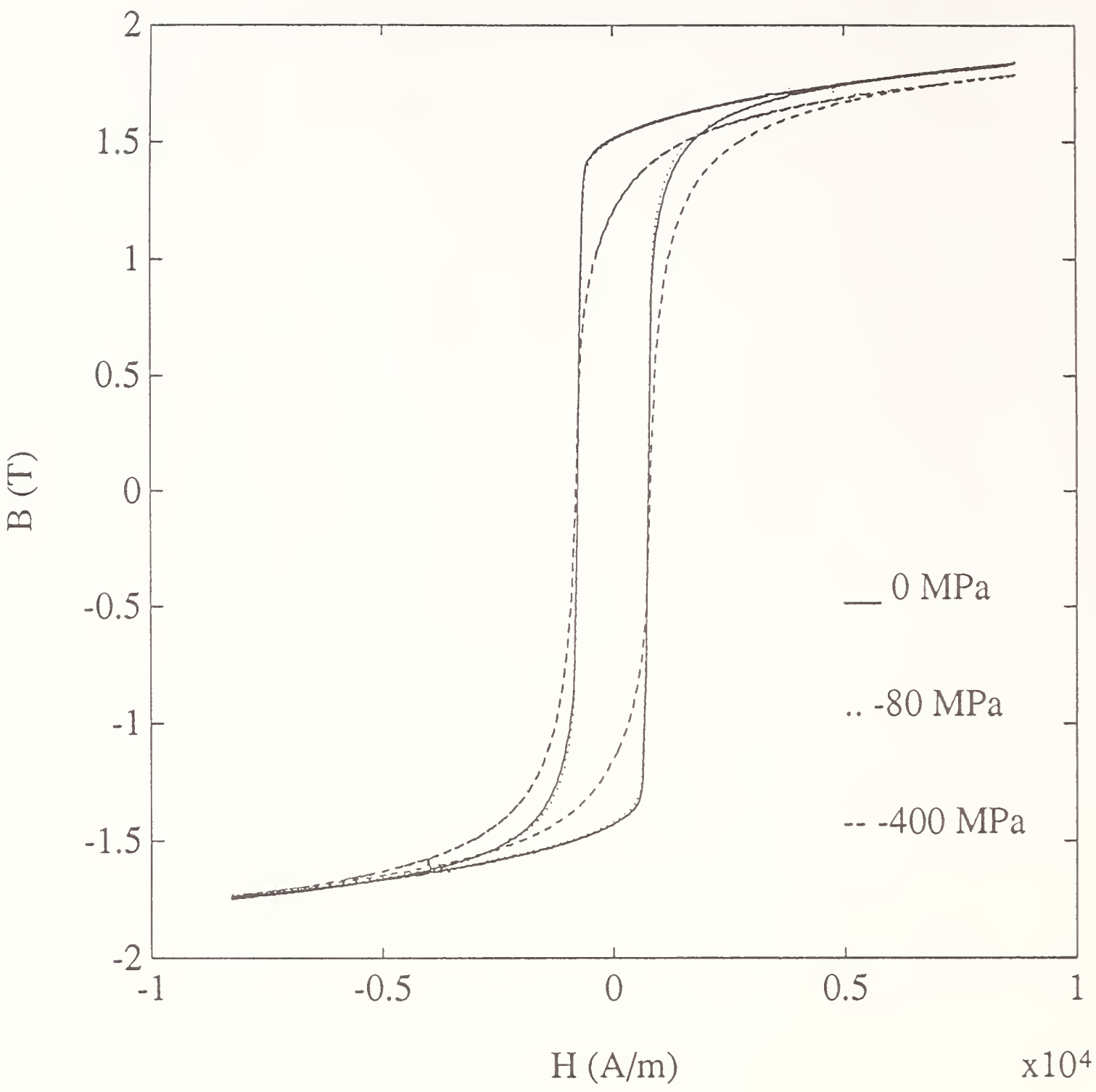

Figure A-3. Magnetic induction as a function of applied magnetic field strength for negative transverse stresses (compression) ranging from 0 to $-400 \mathrm{MPa}$ as described by (2) in the test plan. 


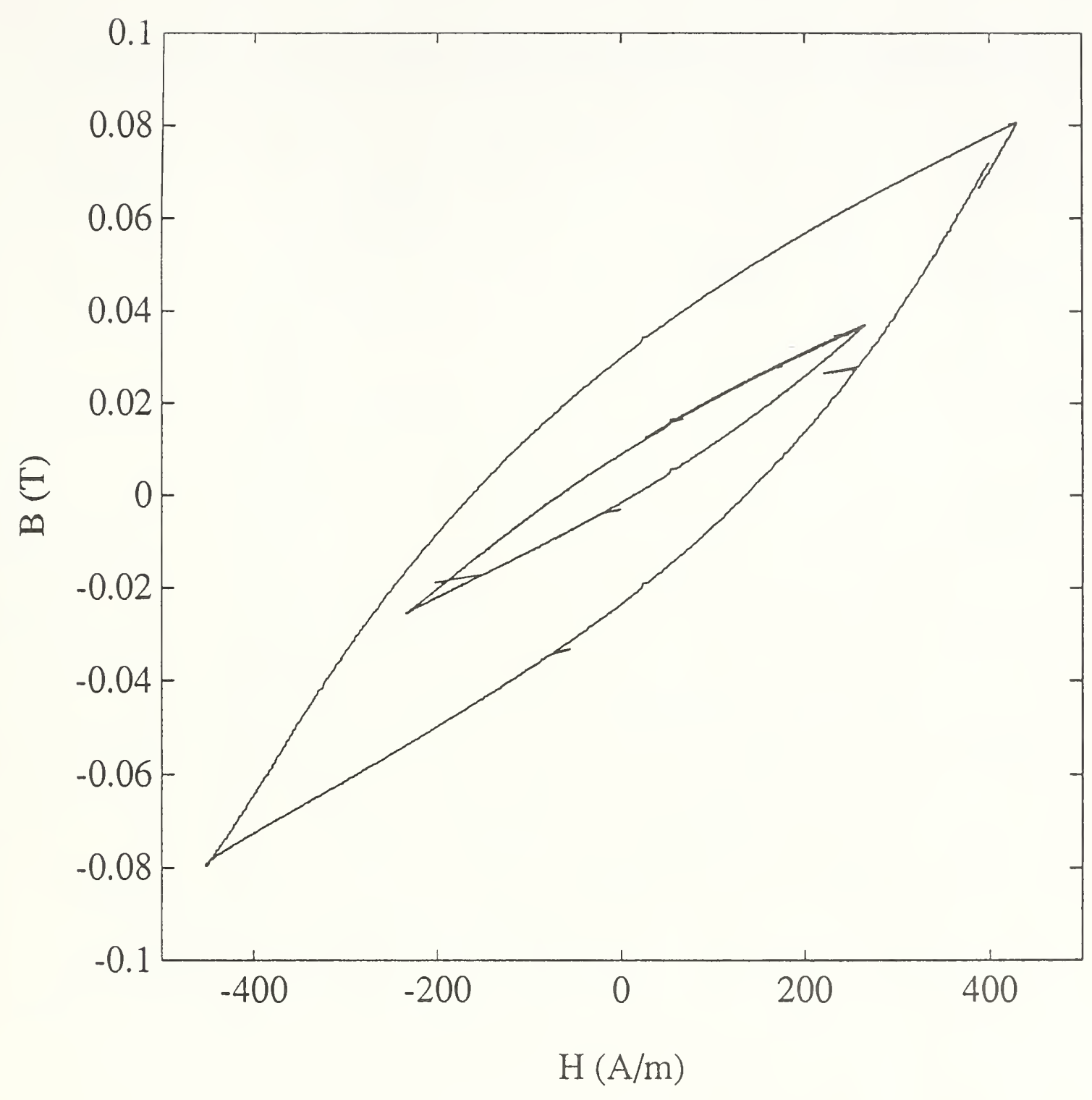

Figure A-4. Magnetic induction as a function of applied magnetic field strength for maximum fields of 200 and $400 \mathrm{~A} / \mathrm{m}$ as described by (3) in the test plan. 


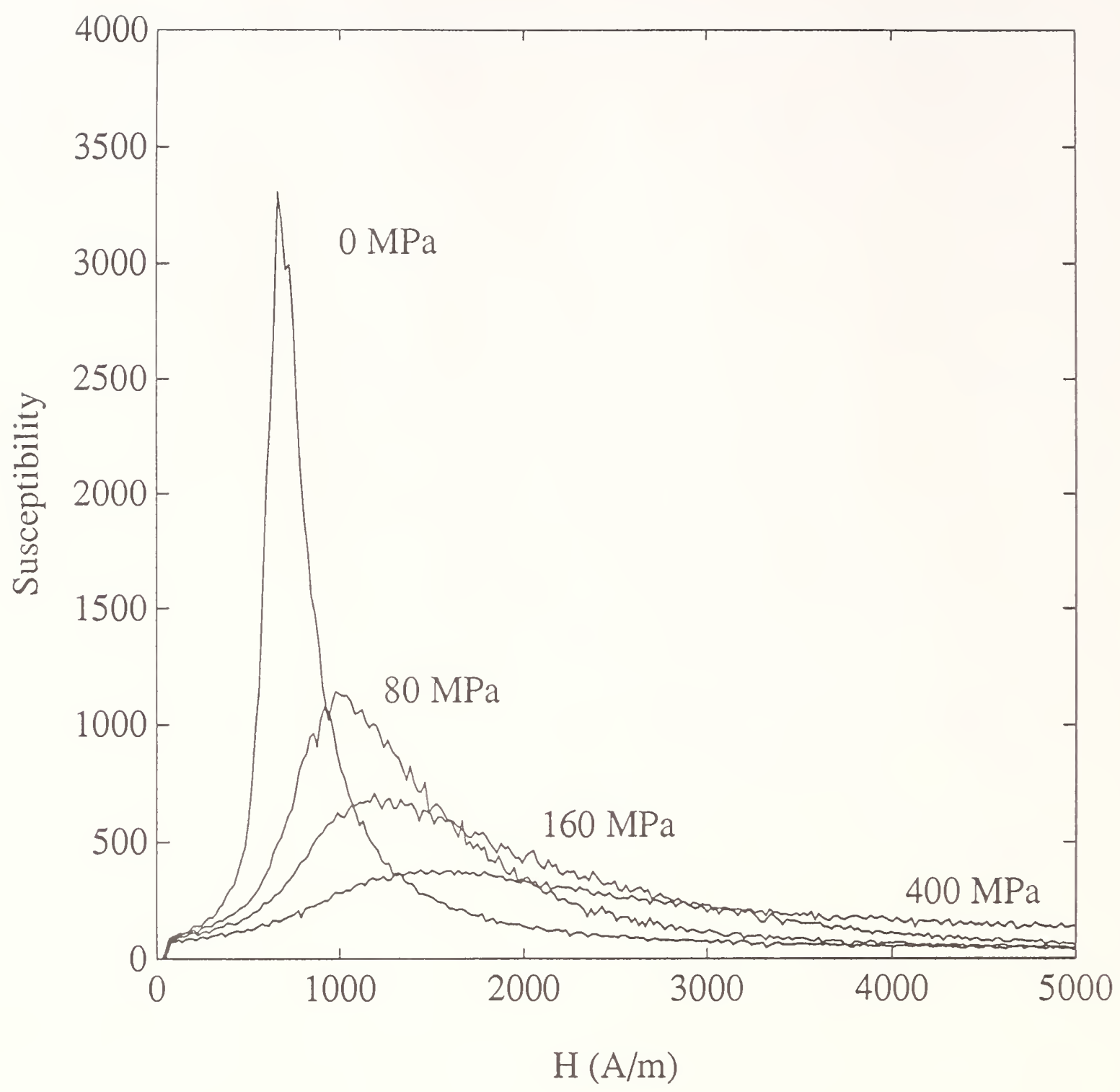

Figure A-5. Susceptibility as a function of applied magnetic field strength for positive transverse stresses (tension) ranging from 0 to $400 \mathrm{MPa}$ as described by (4) in the test plan. 


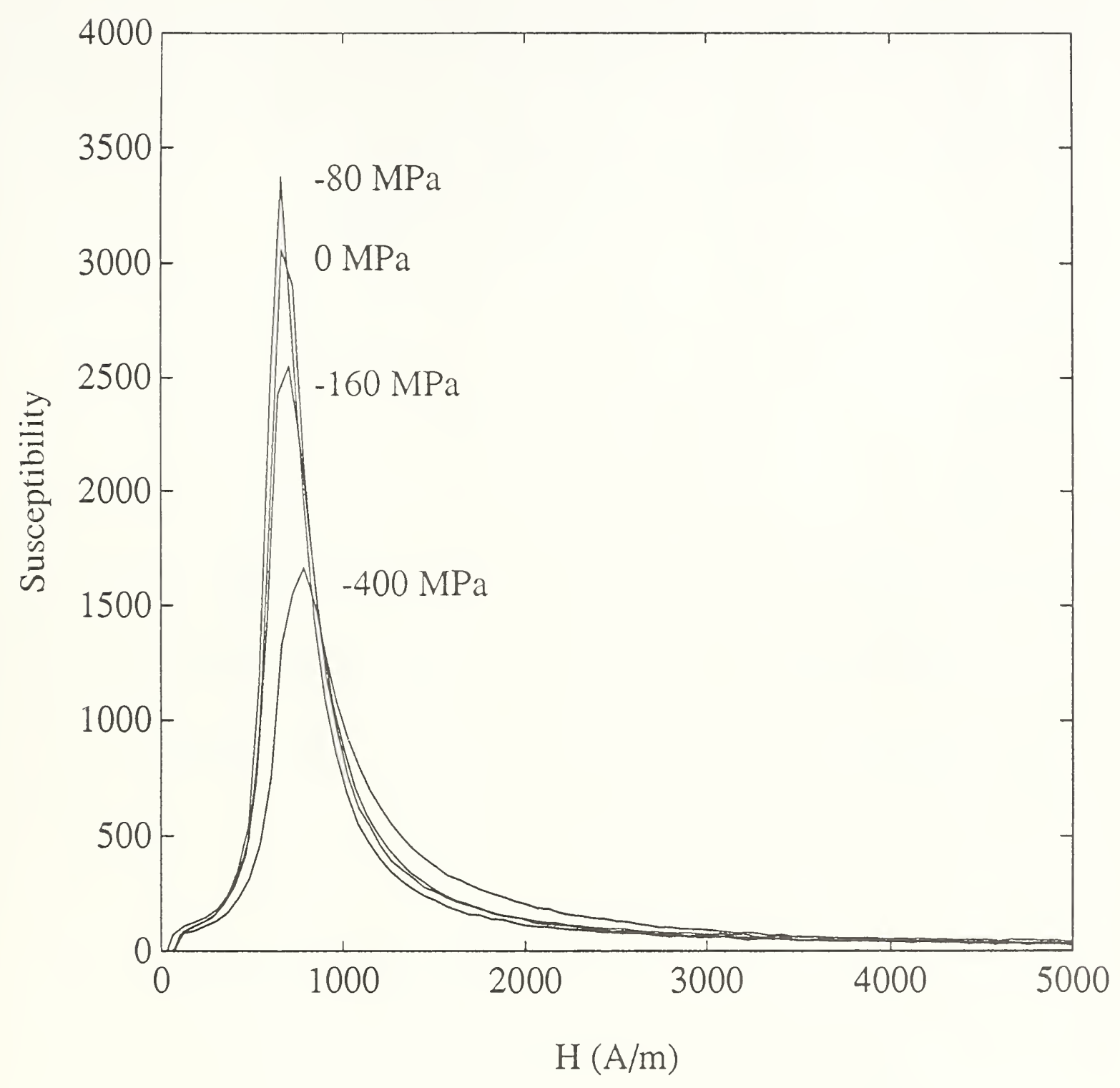

Figure A-6. Susceptibility as a function of applied magnetic field strength for negative transverse stresses (compression) ranging from 0 to $-400 \mathrm{MPa}$ as described by (4) in the test plan. 


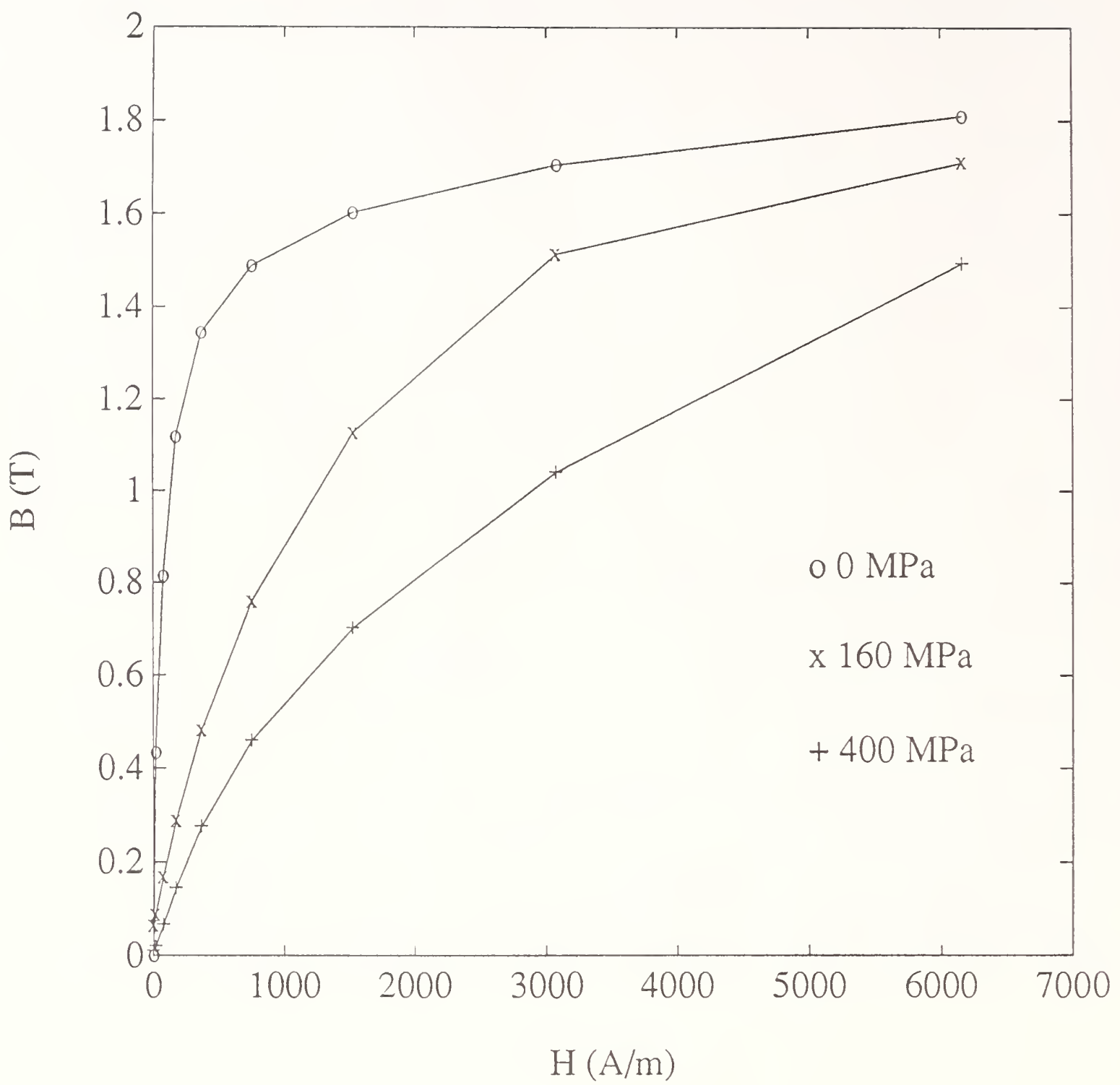

Figure A-7. Anhysteretic magnetization curves for positive transverse stresses (tension) ranging from 0 to $400 \mathrm{MPa}$ as described by (5) in the test plan. 


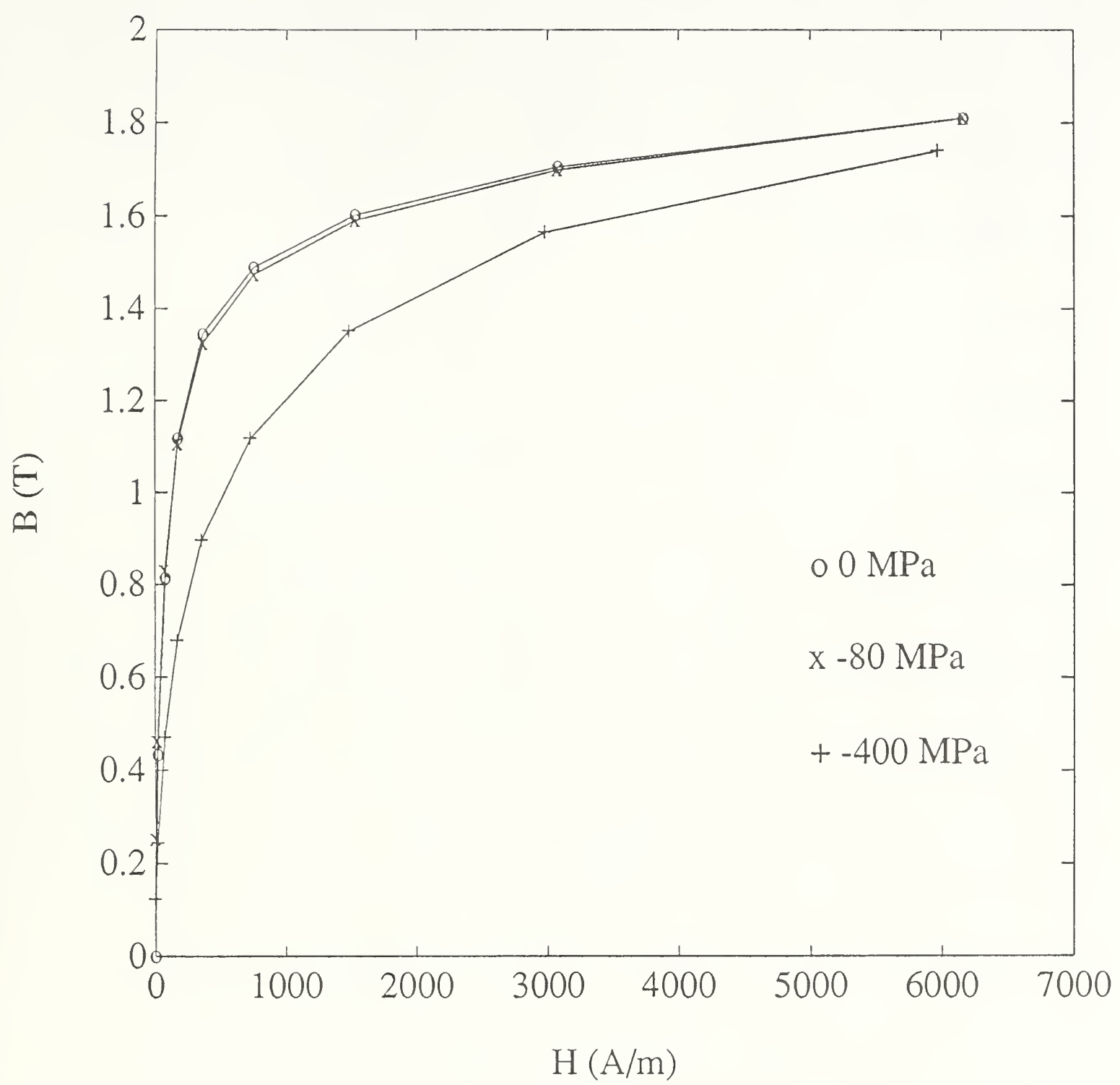

Figure A-8. Anhysteretic magnetization curves for negative transverse stresses (compression) ranging from 0 to $-400 \mathrm{MPa}$ as described by (5) in the test plan. 


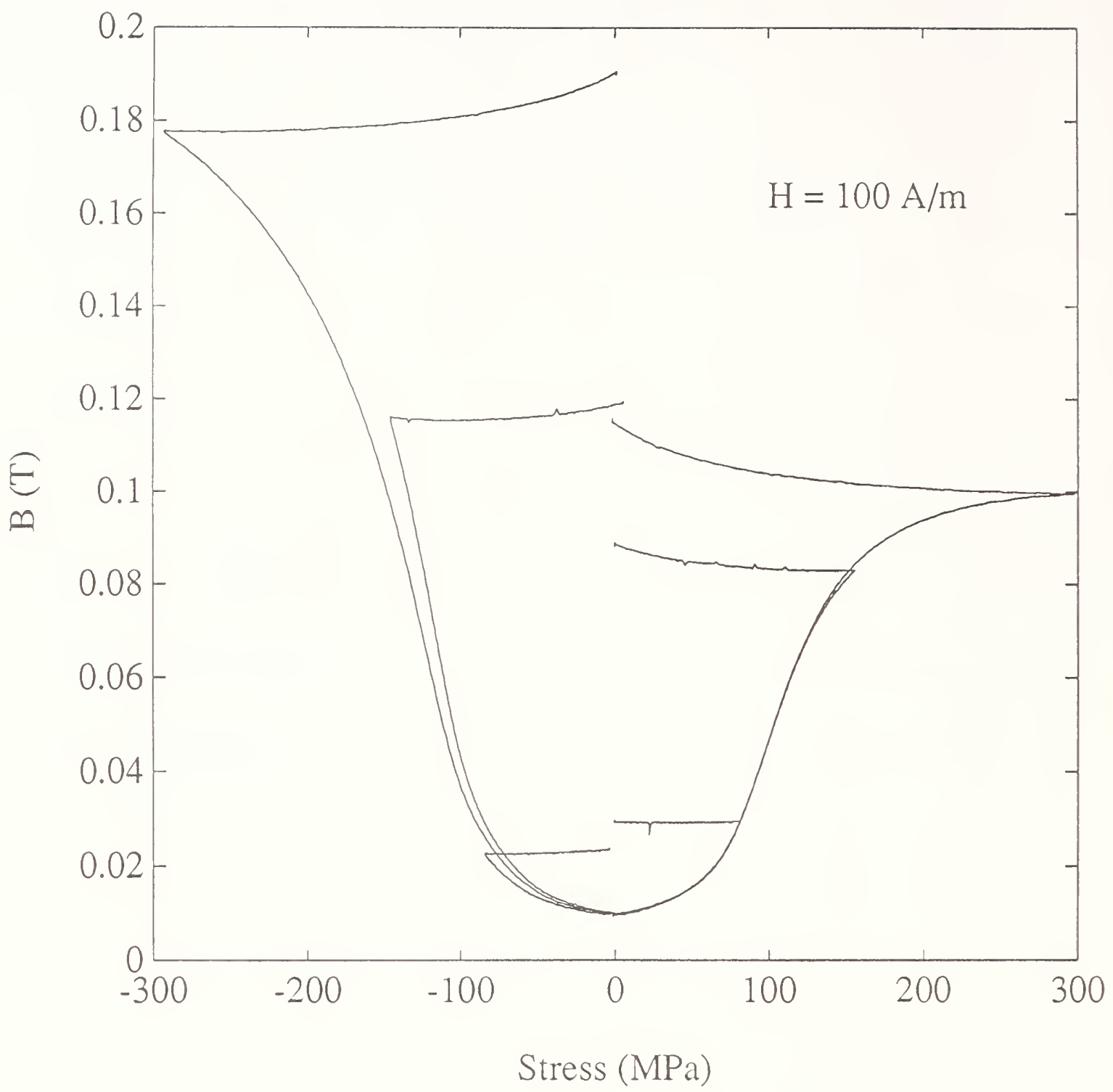

Figure A-9. Magnetic induction as a function of applied transverse stresses ranging from -300 to $300 \mathrm{MPa}$ as described by (6) in the test plan. The dc magnetic field was $100 \mathrm{~A} / \mathrm{m}$. 


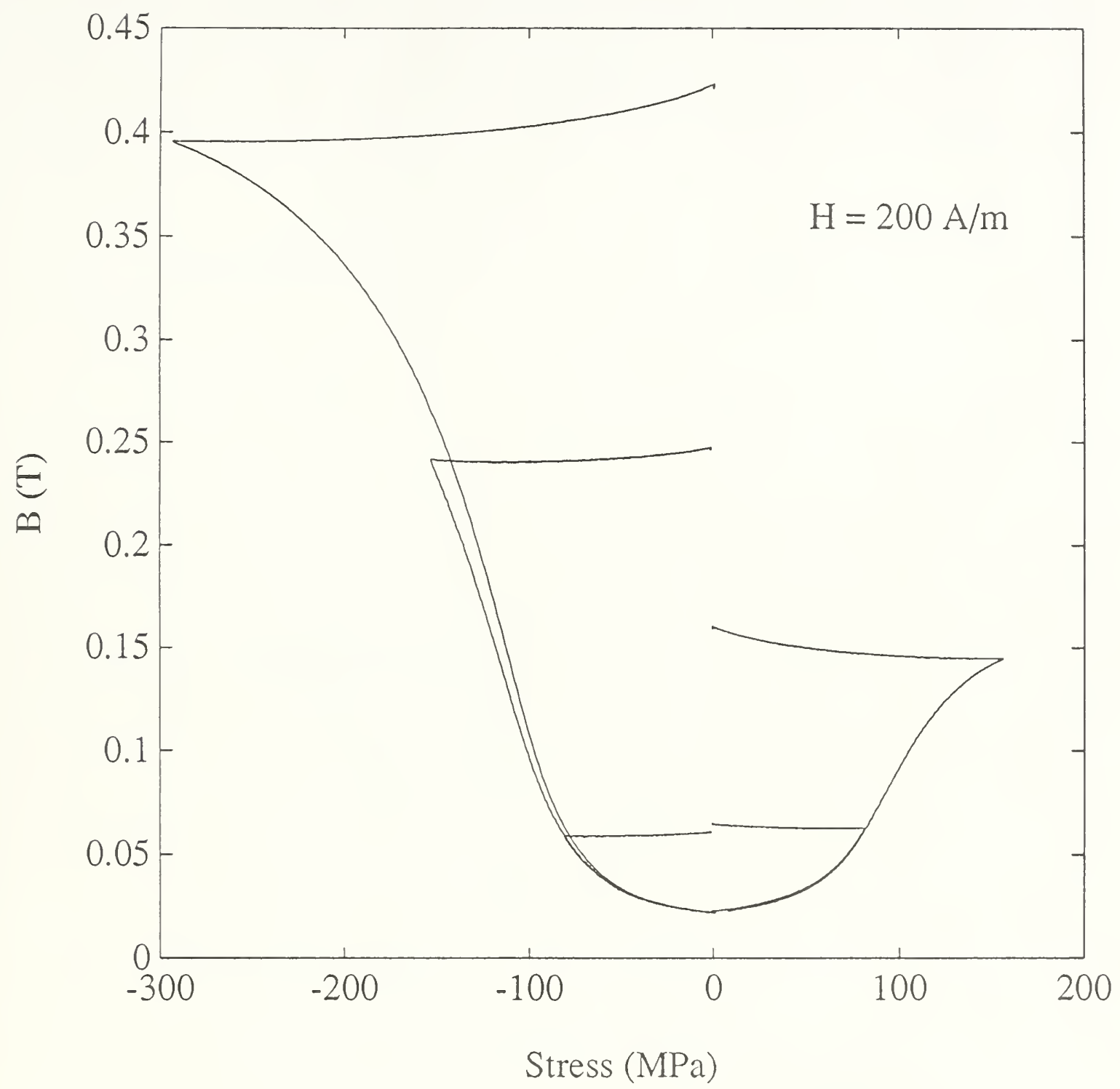

Figure A-10. Magnetic induction as a function of applied transverse stresses ranging from -300 to $300 \mathrm{MPa}$ as described by (6) in the test plan. The dc magnetic field was $200 \mathrm{~A} / \mathrm{m}$. 


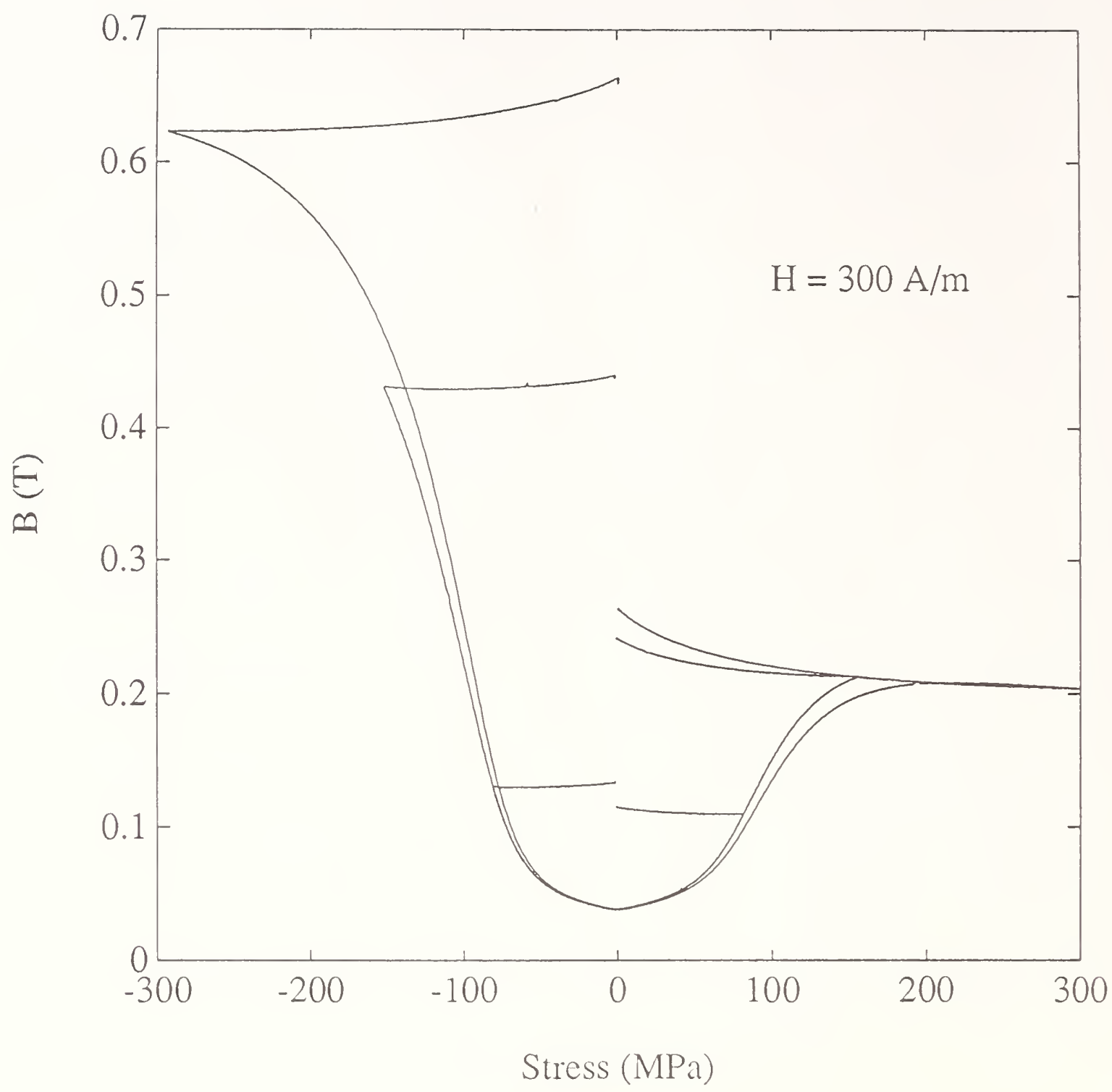

Figure A-11. Magnetic induction as a function of applied transverse stresses ranging from -300 to $300 \mathrm{MPa}$ as described by (6) in the test plan. The dc magnetic field was $300 \mathrm{~A} / \mathrm{m}$. 


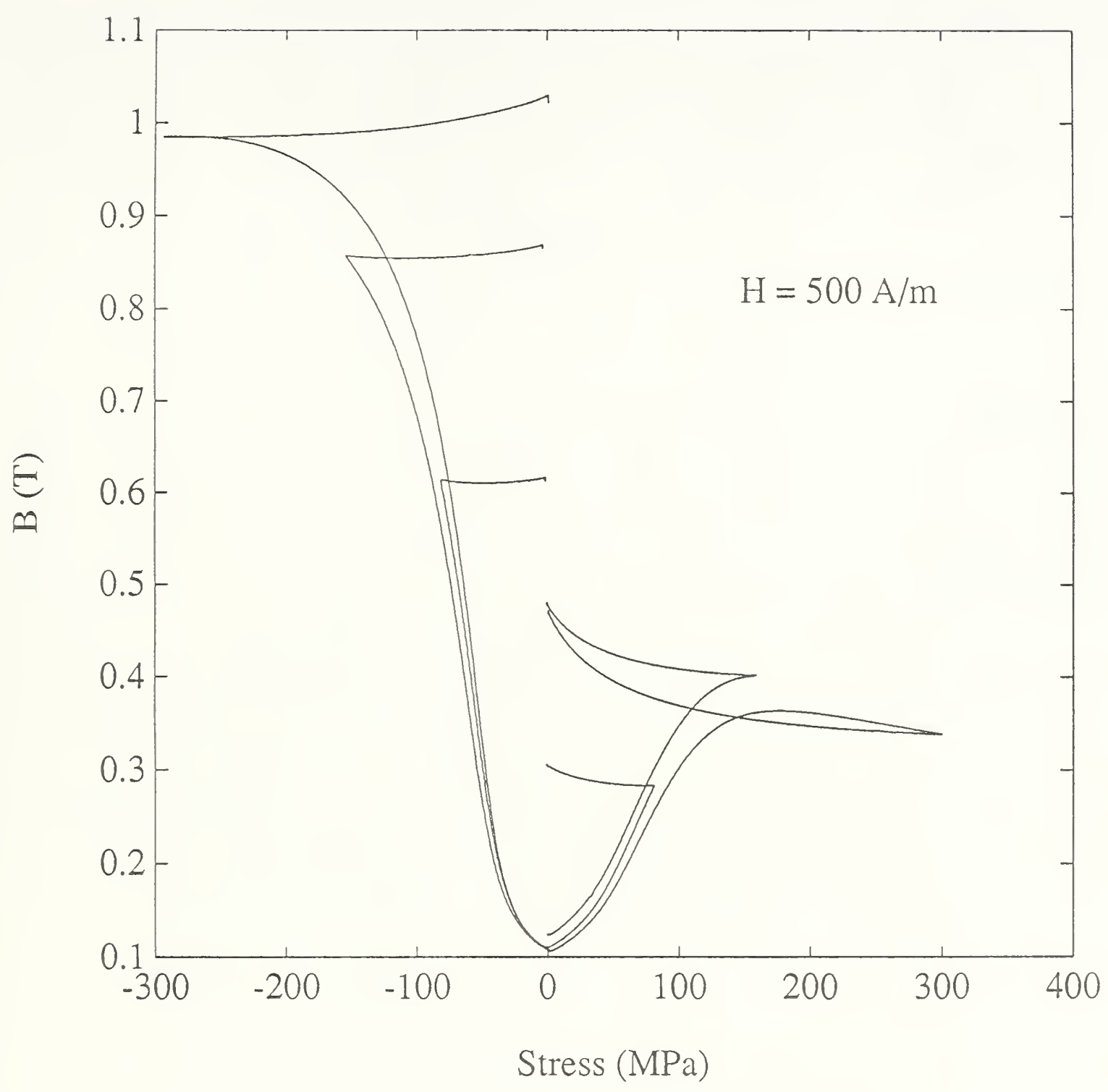

Figure A-12. Magnetic induction as a function of applied transverse stresses ranging from -300 to $300 \mathrm{MPa}$ as described by (6) in the test plan. The dc magnetic field was $500 \mathrm{~A} / \mathrm{m}$. 


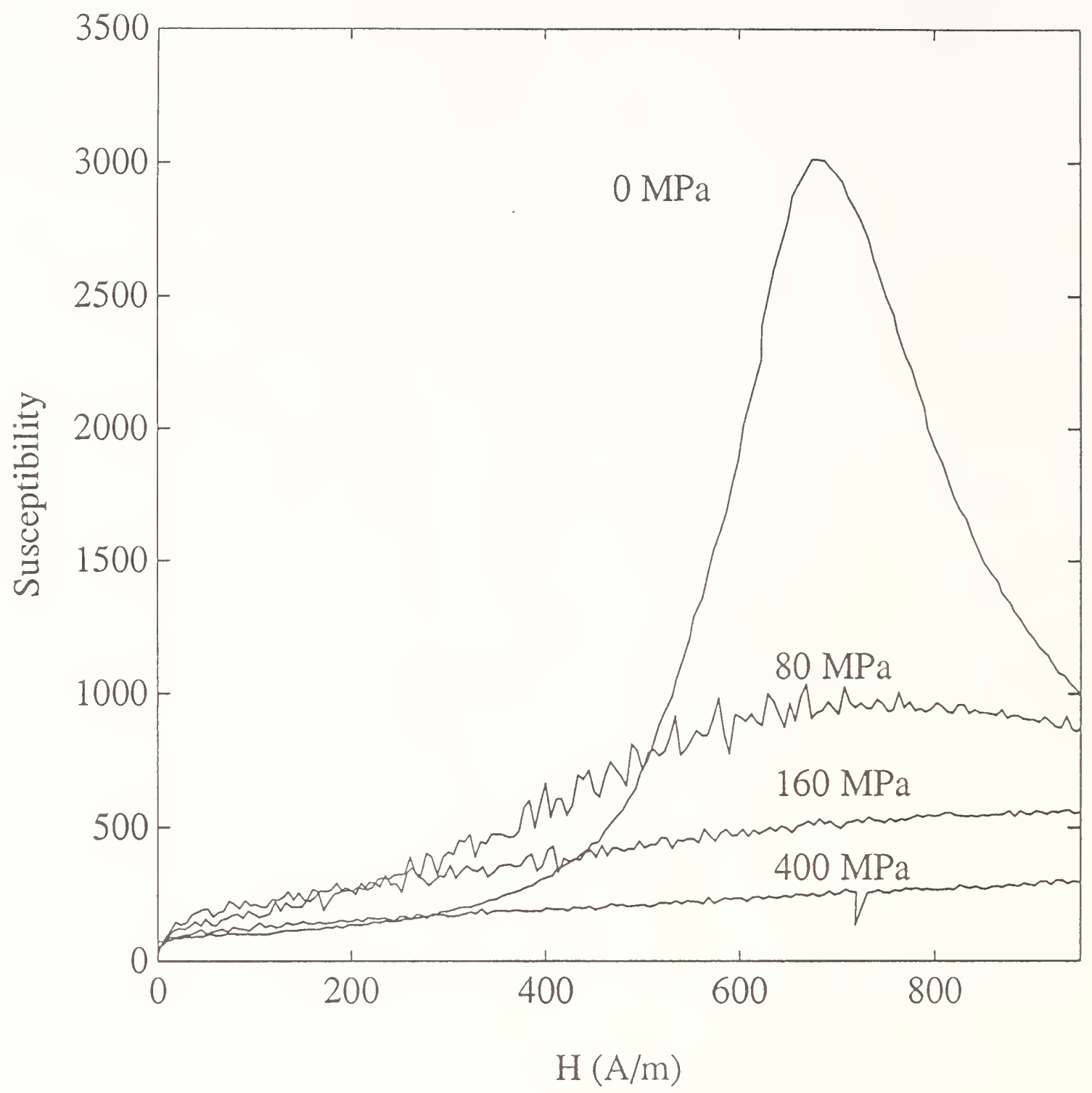

Figure A-13. Susceptibility as a function of applied magnetic field strength for transverse positive stresses (tension) ranging from 0 to $400 \mathrm{MPa}$ as described by (7) in the test plan. 


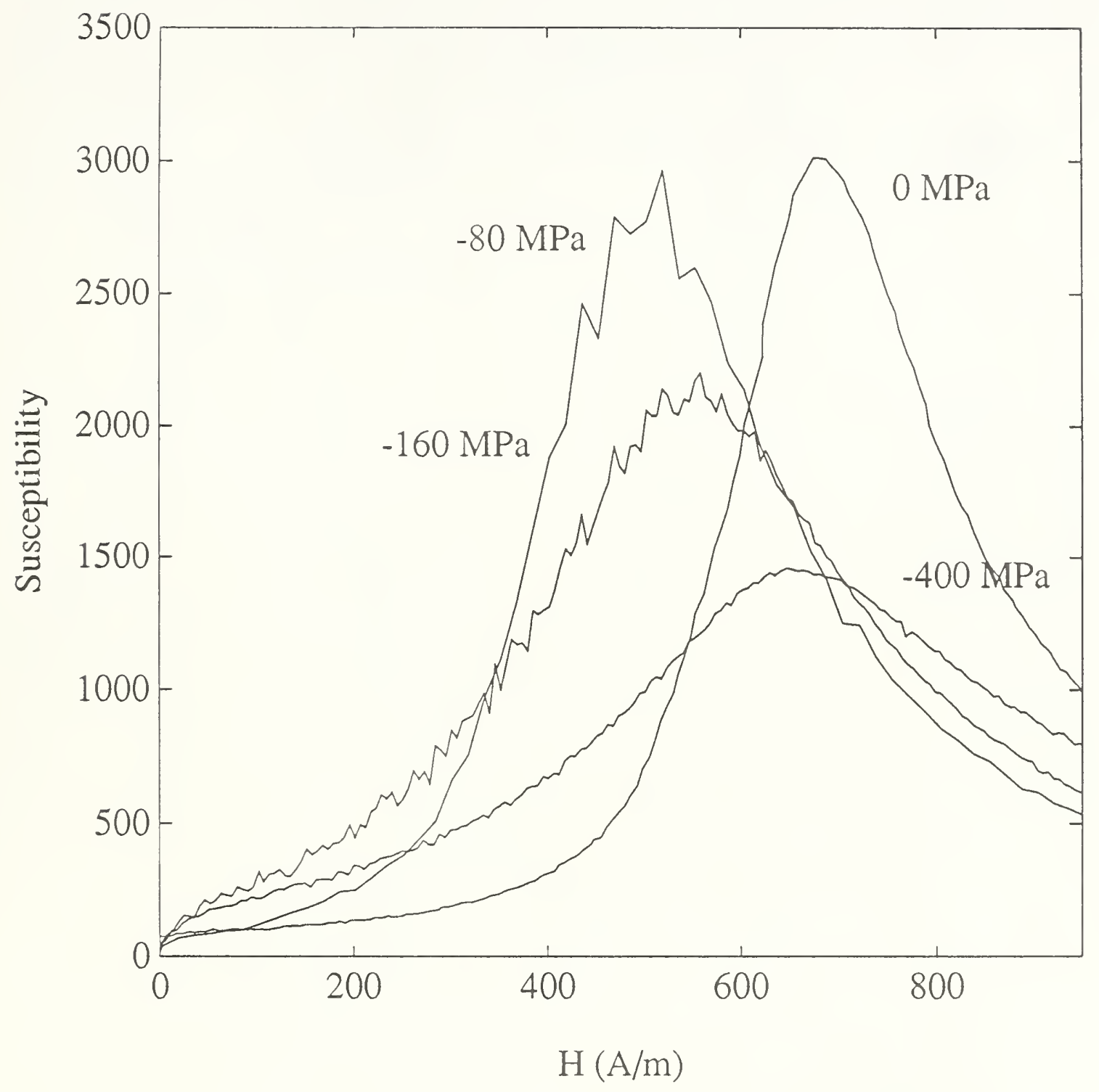

Figure A-14. Susceptibility as a function of applied magnetic field strength for transverse negative stresses (compression) ranging from 0 to $-400 \mathrm{MPa}$ as described by (7) in the test plan. 


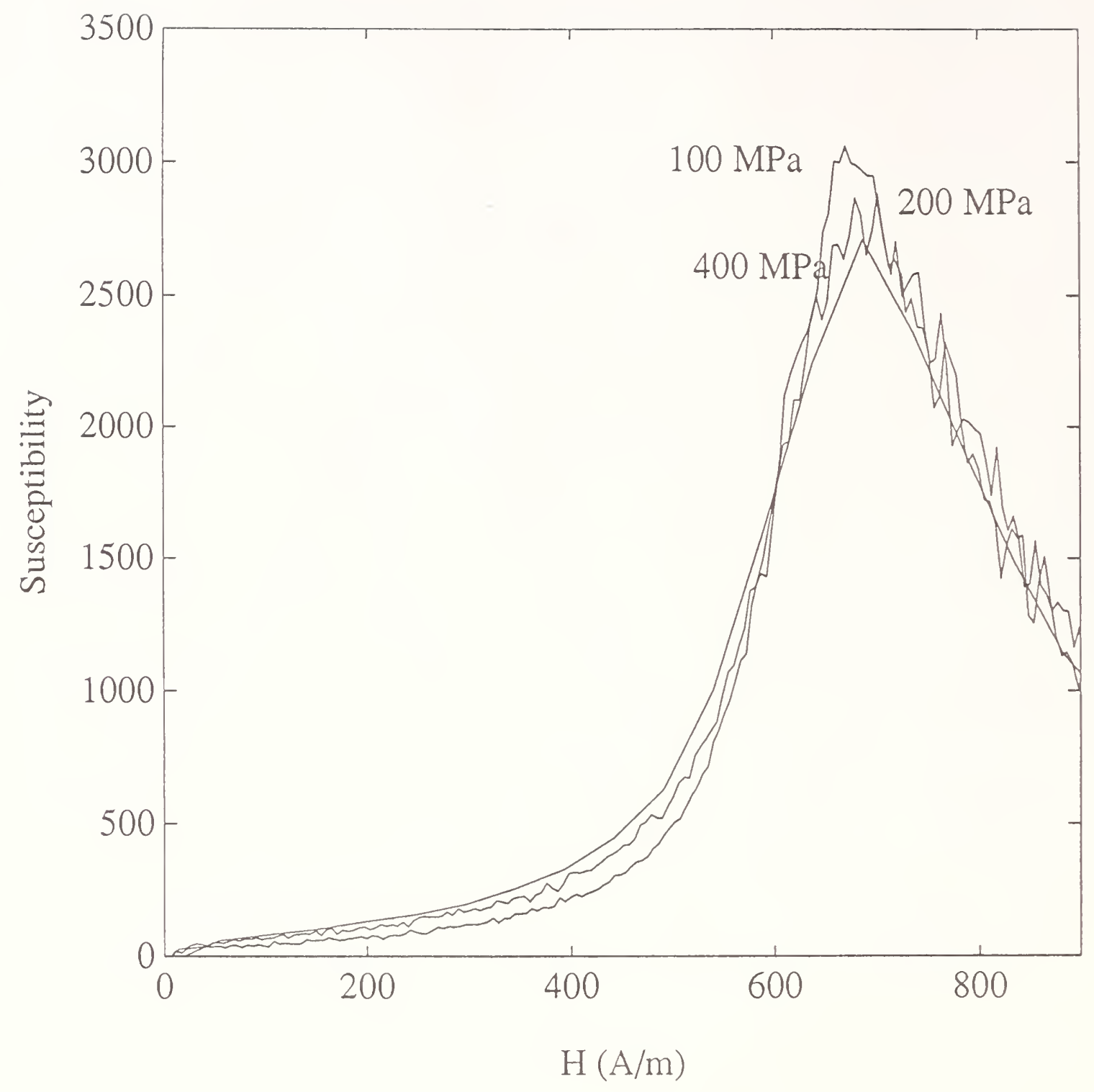

Figure A-15. Susceptibility as a function of applied magnetic field strength after the application and release of positive transverse stresses ranging from 50 to 400 MPa. The measurement is described by (8) in the test plan. 


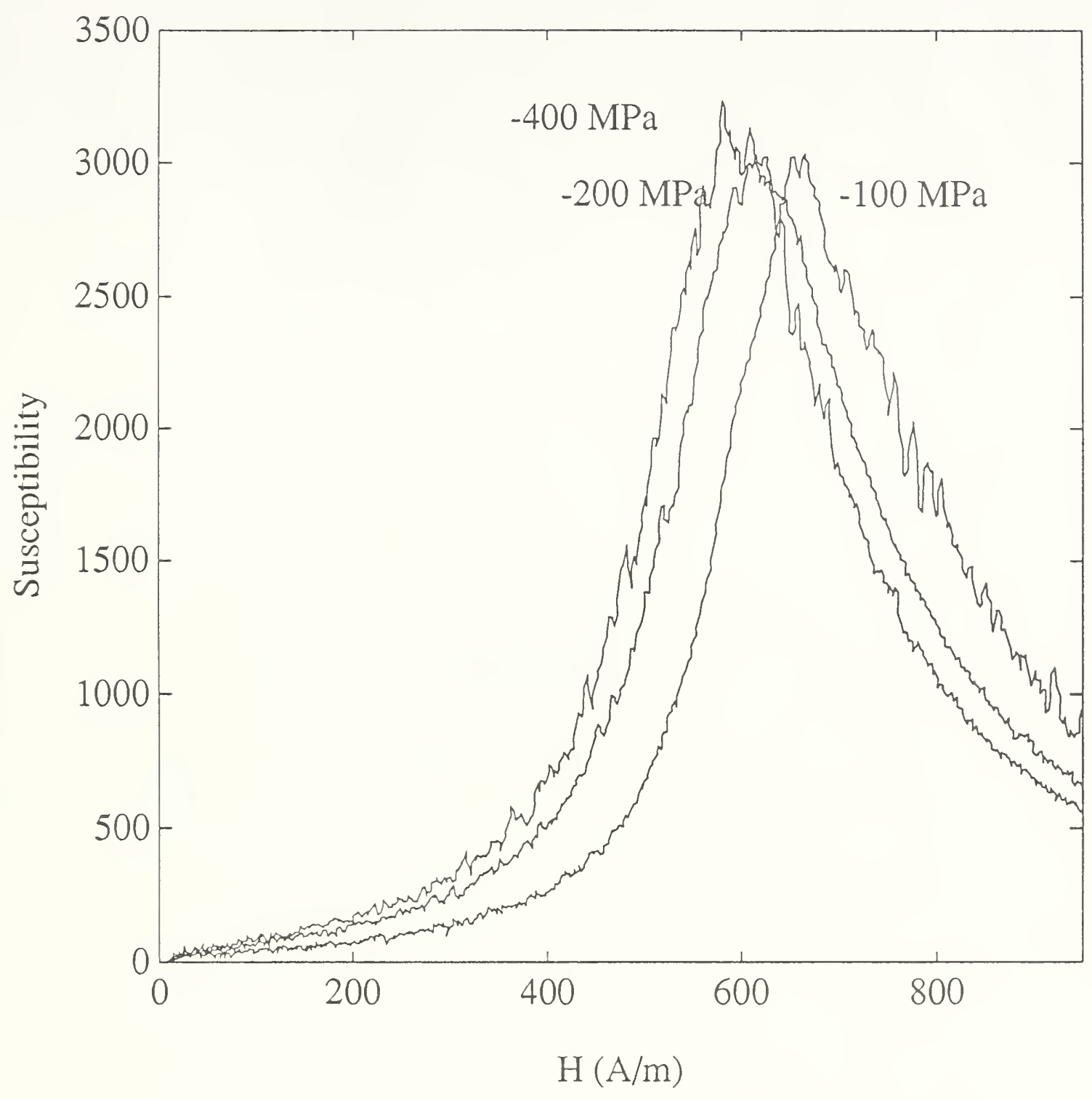

Figure A-16. Susceptibility as a function of applied magnetic field strength after the application and release of negative transverse stresses ranging from -50 to $-400 \mathrm{MPa}$. The measurement is described by (8) in the test plan. 

Appendix B 


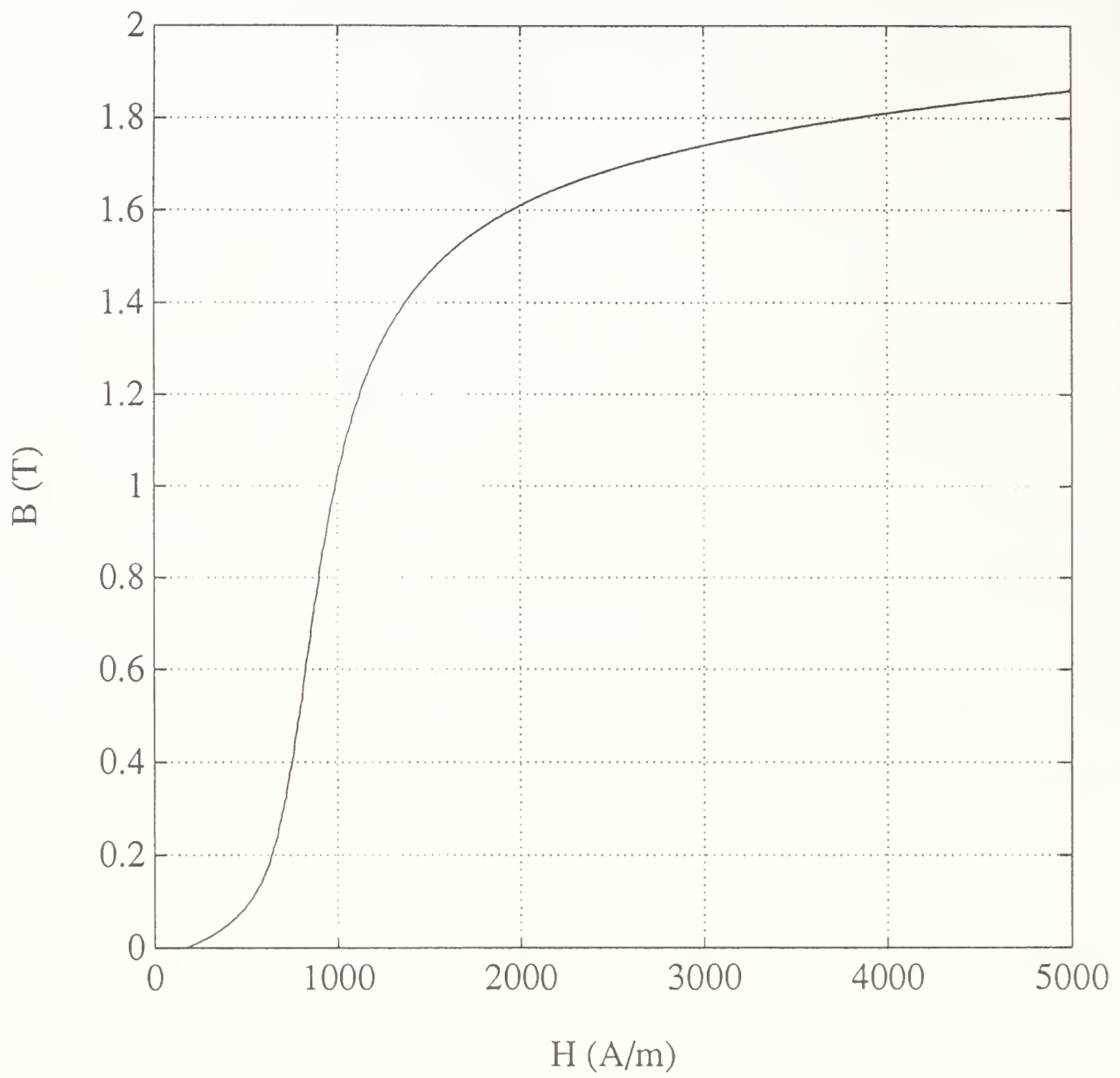

Figure B-1. Normal unstressed magnetization curve as described by (1) in the test plan. 


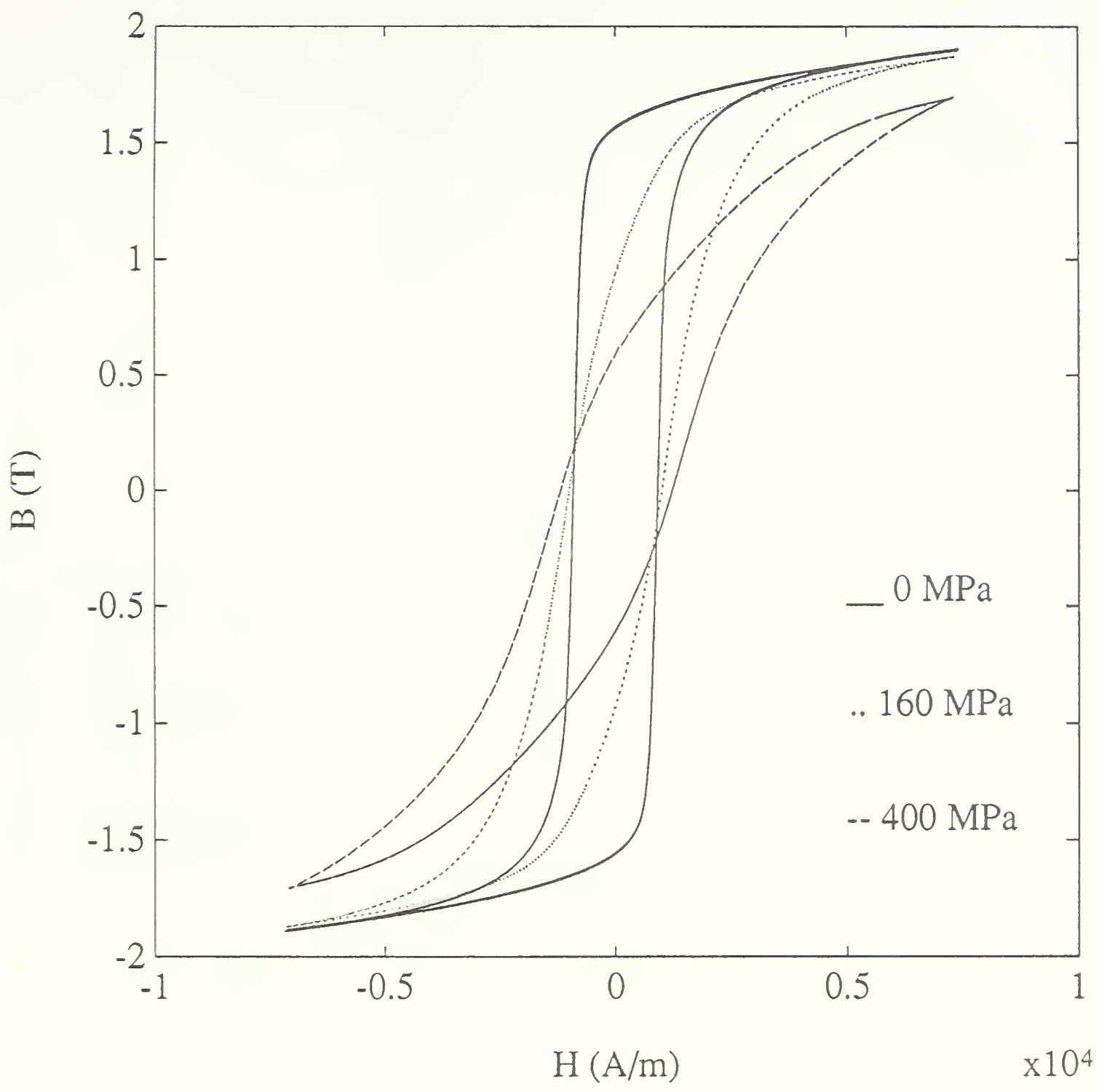

Figure B-2. Magnetic induction as a function of applied magnetic field strength for positive transverse stress (tension) ranging from 0 to $400 \mathrm{MPa}$ as described by (2) in the test plan. The stress results in an effective demagnetizing field which shears the hysteresis loop. 


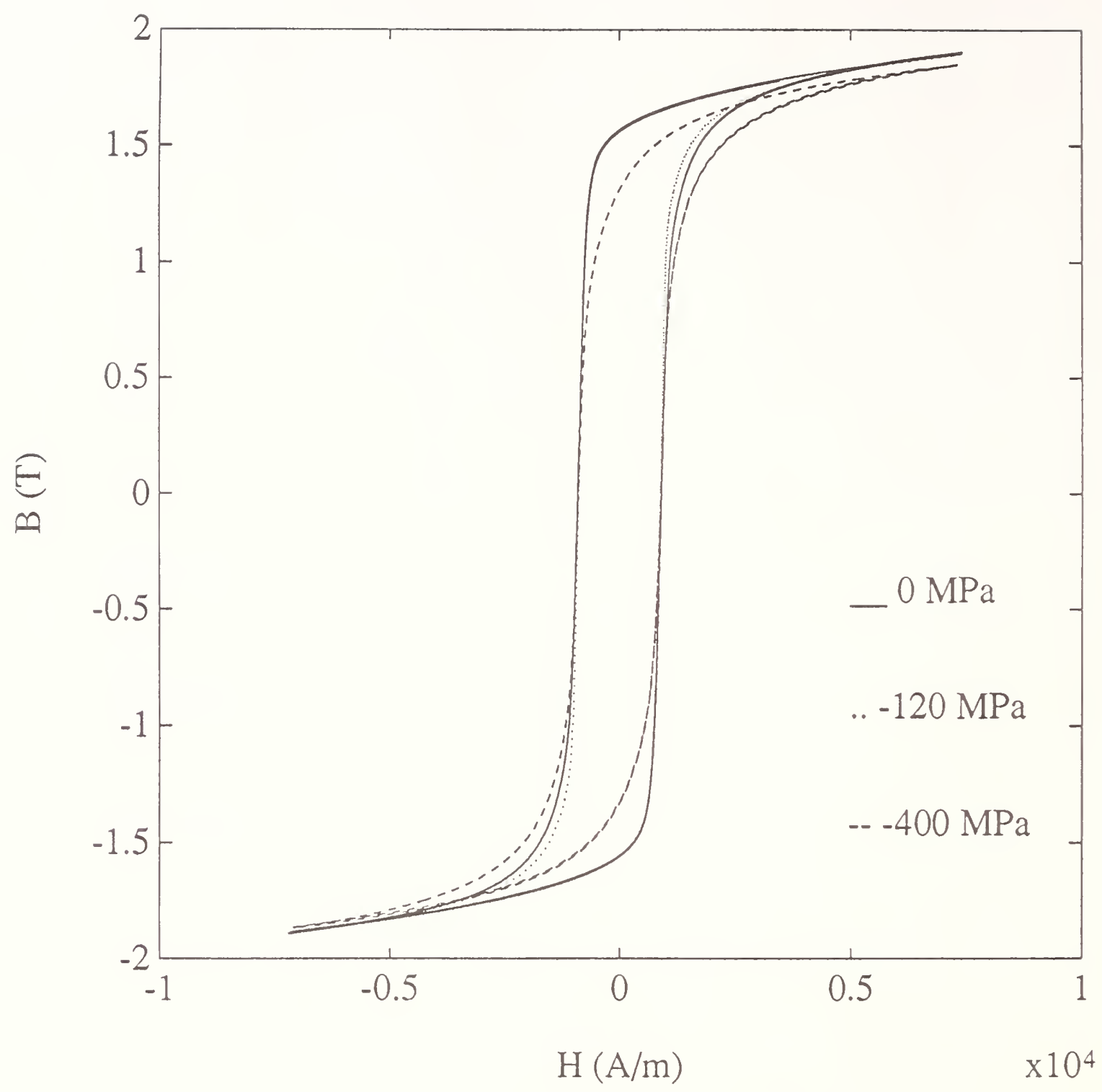

Figure B-3. Magnetic induction as a function of applied magnetic field strength for negative transverse stresses (compression) ranging from 0 to $-400 \mathrm{MPa}$ as described by (2) in the test plan. 


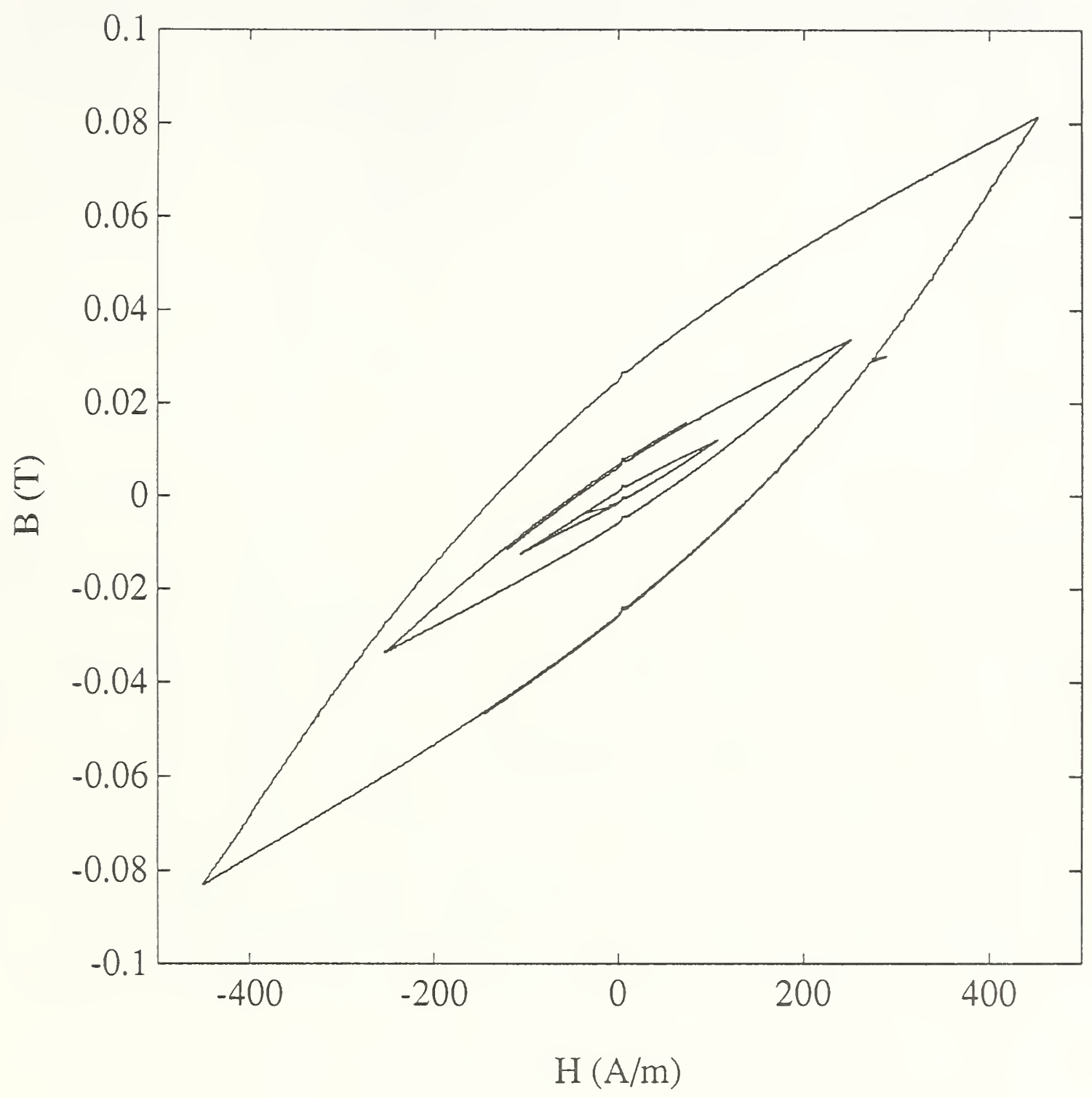

Figure B-4. Magnetic induction as a function of applied magnetic field strength for maximum fields of 100,200 , and $400 \mathrm{~A} / \mathrm{m}$ as described by (3) in the test plan. 


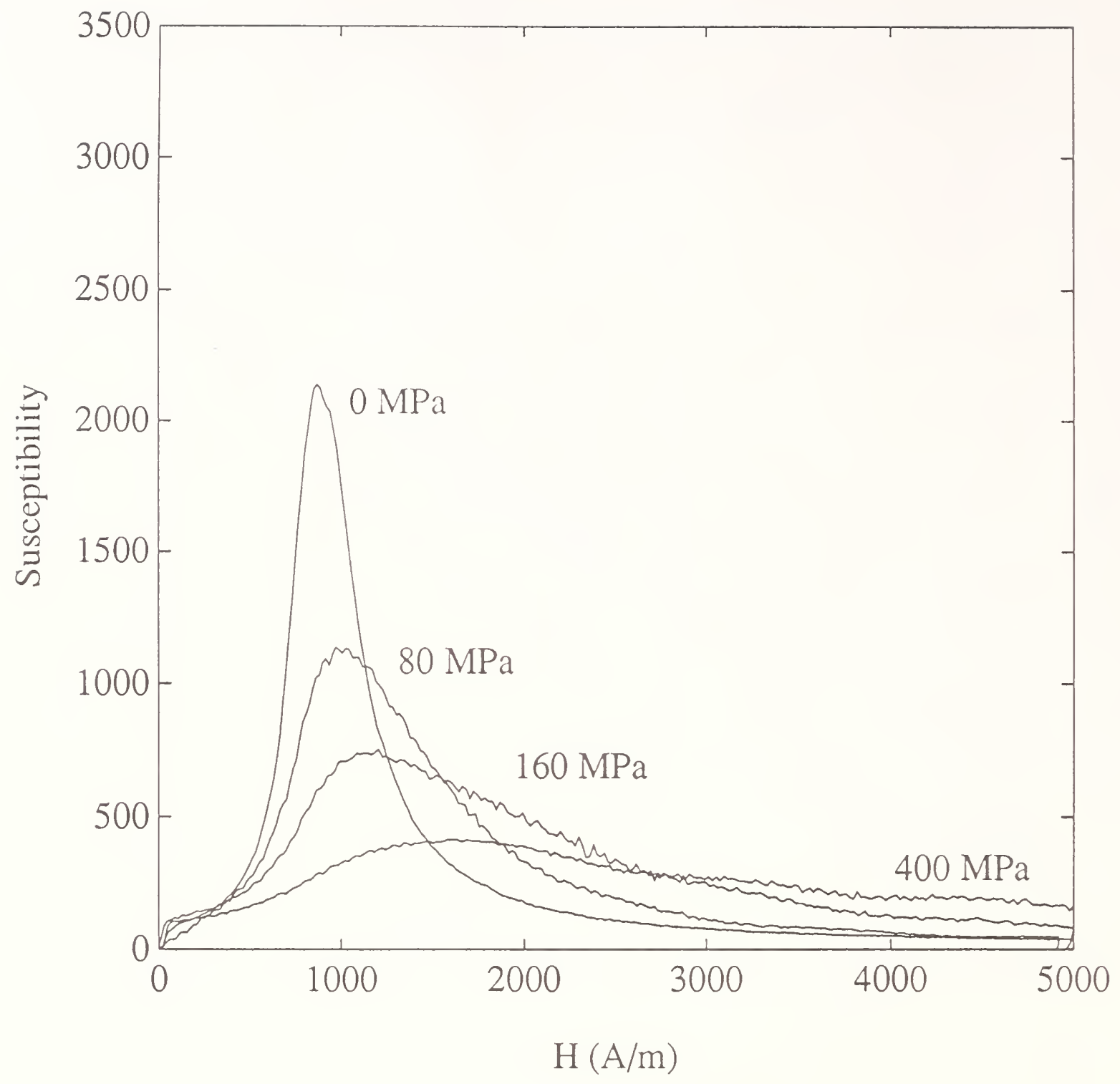

Figure B-5. Susceptibility as a function of applied magnetic field strength for positive transverse stresses (tension) ranging from 0 to $400 \mathrm{MPa}$ as described by (4) in the test plan. 


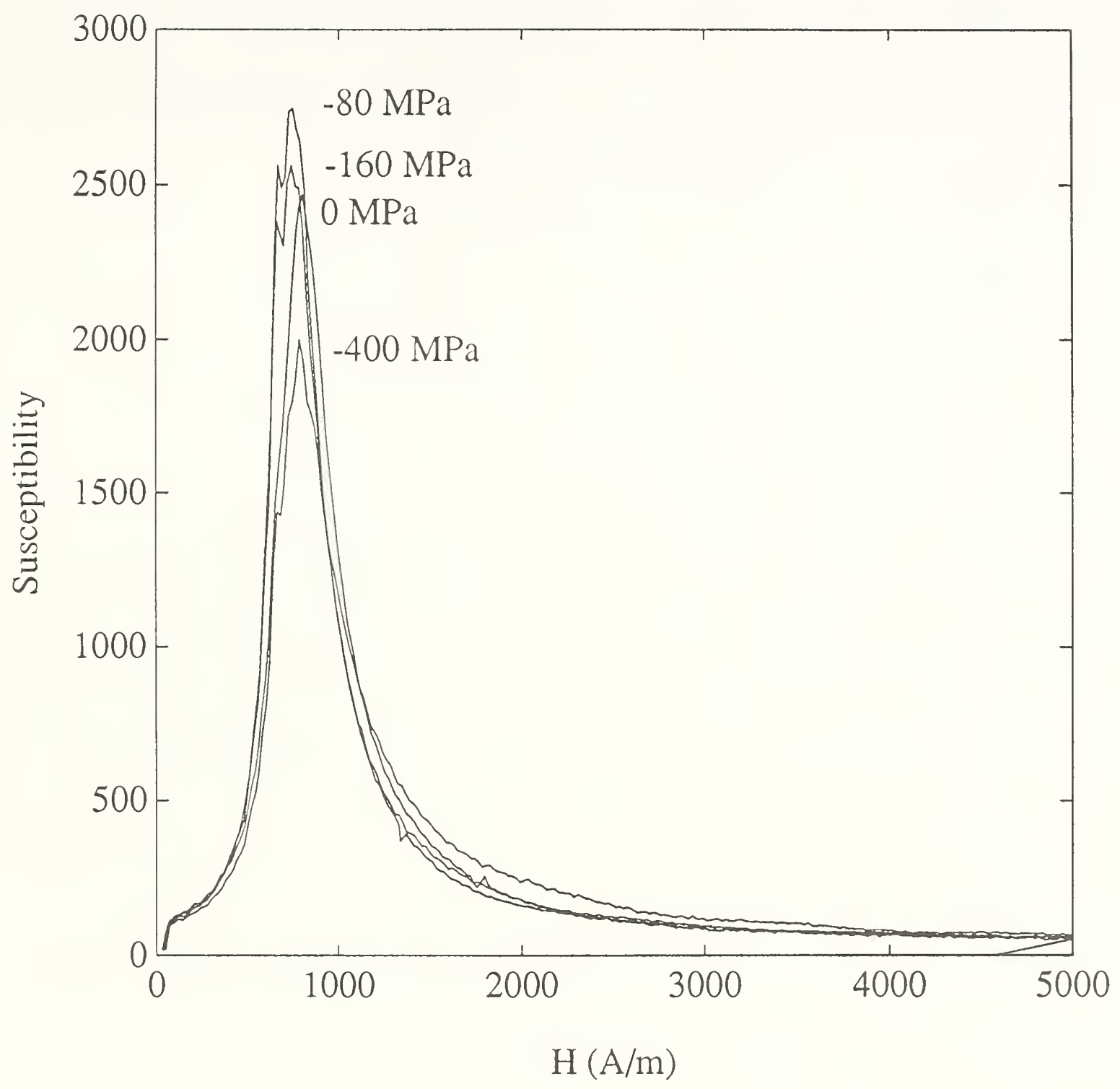

Figure B-6. Susceptibility as a function of applied magnetic field strength for negative transverse stresses (compression) ranging from 0 to $-400 \mathrm{MPa}$ as described by (4) in the test plan. 


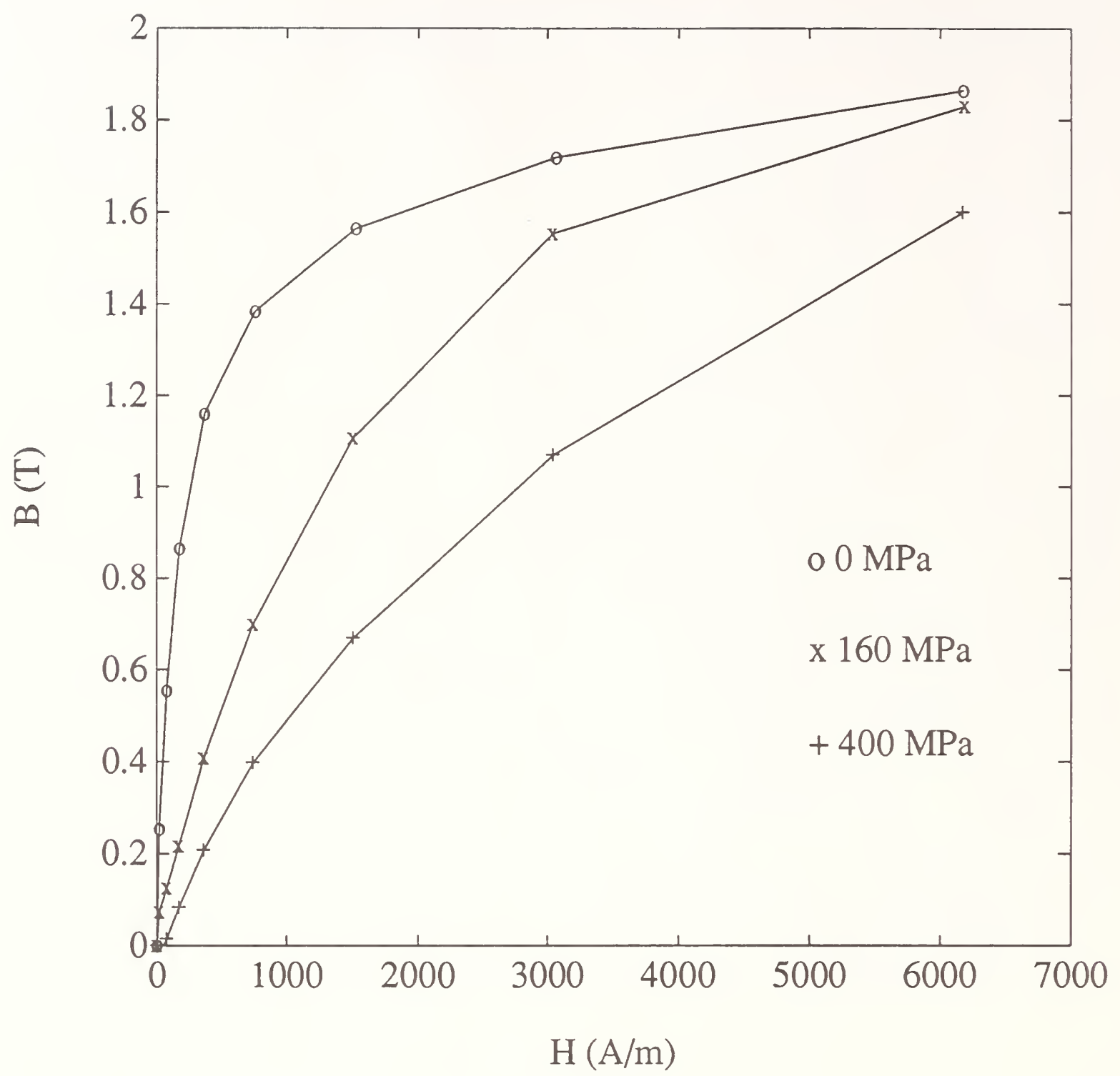

Figure B-7. Anhysteretic magnetization curves for positive transverse stresses (tension) ranging from 0 to $400 \mathrm{MPa}$ as described by (5) in the test plan. 


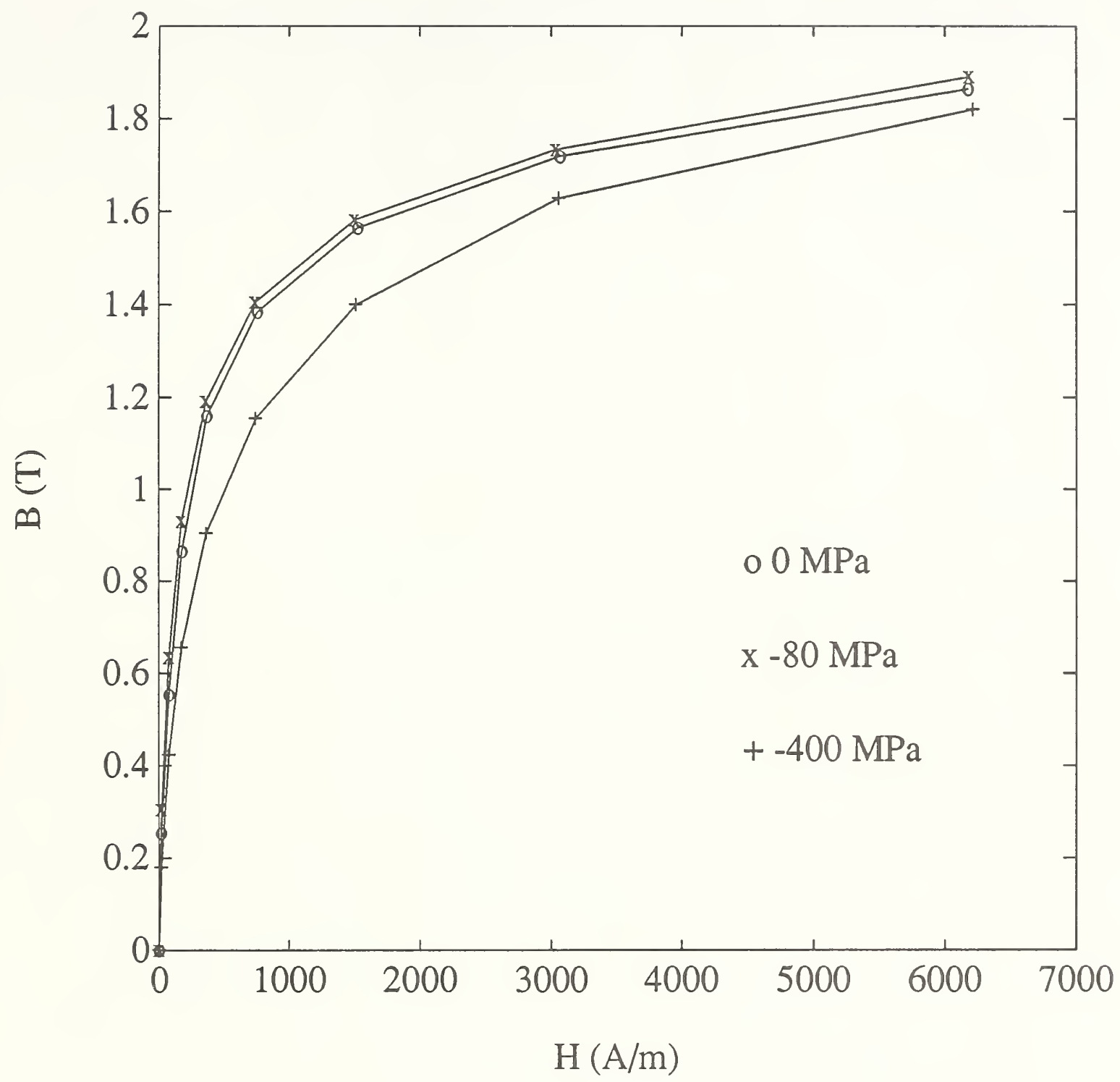

Figure B-8. Anhysteretic magnetization curves for negative transverse stresses (compression) ranging from 0 to $-400 \mathrm{MPa}$ as described by (5) in the test plan. 


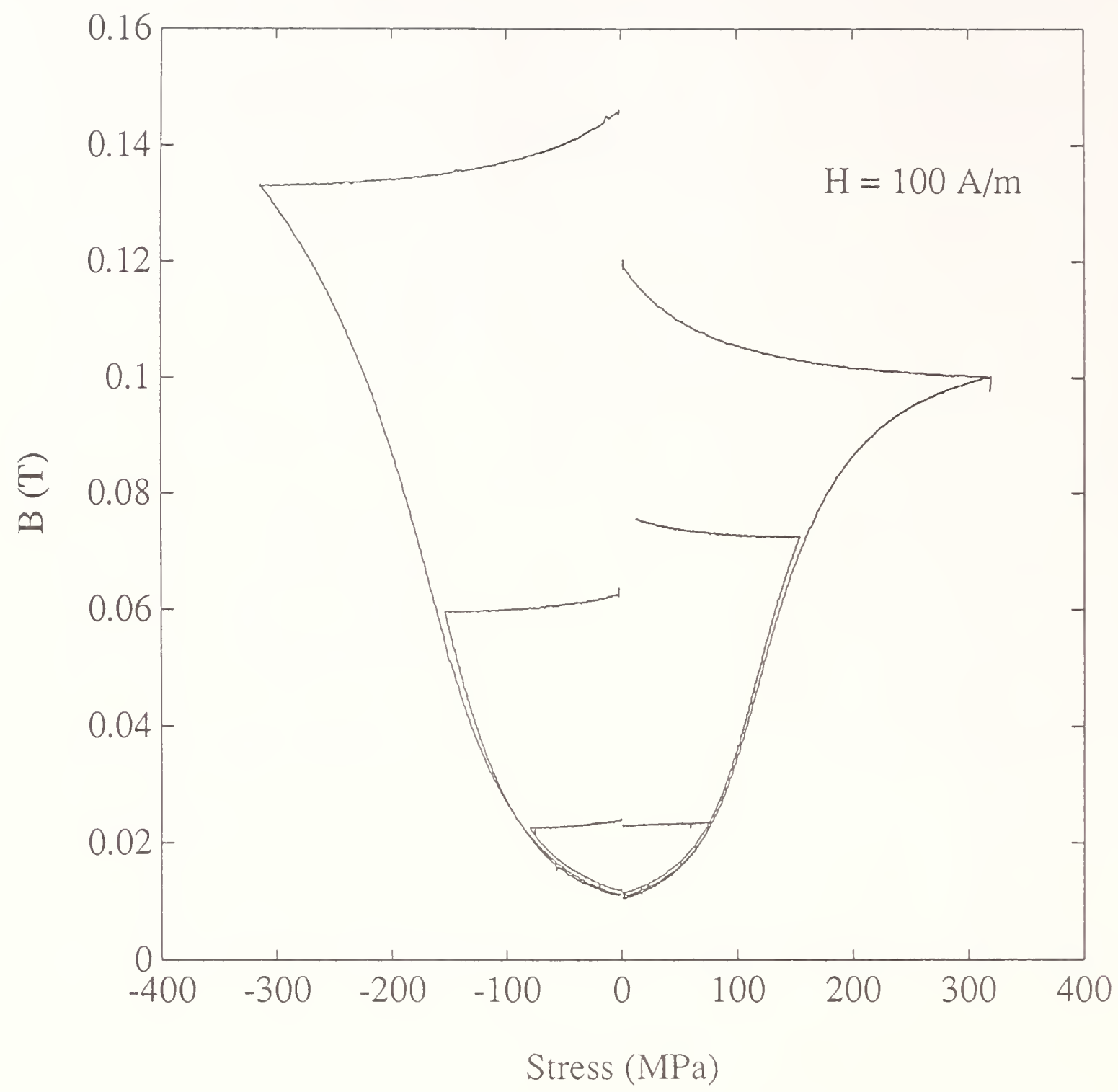

Figure B-9. Magnetic induction as a function of applied transverse stresses ranging from -300 to $300 \mathrm{MPa}$ as described by (6) in the test plan. The dc magnetic field was $100 \mathrm{~A} / \mathrm{m}$. 


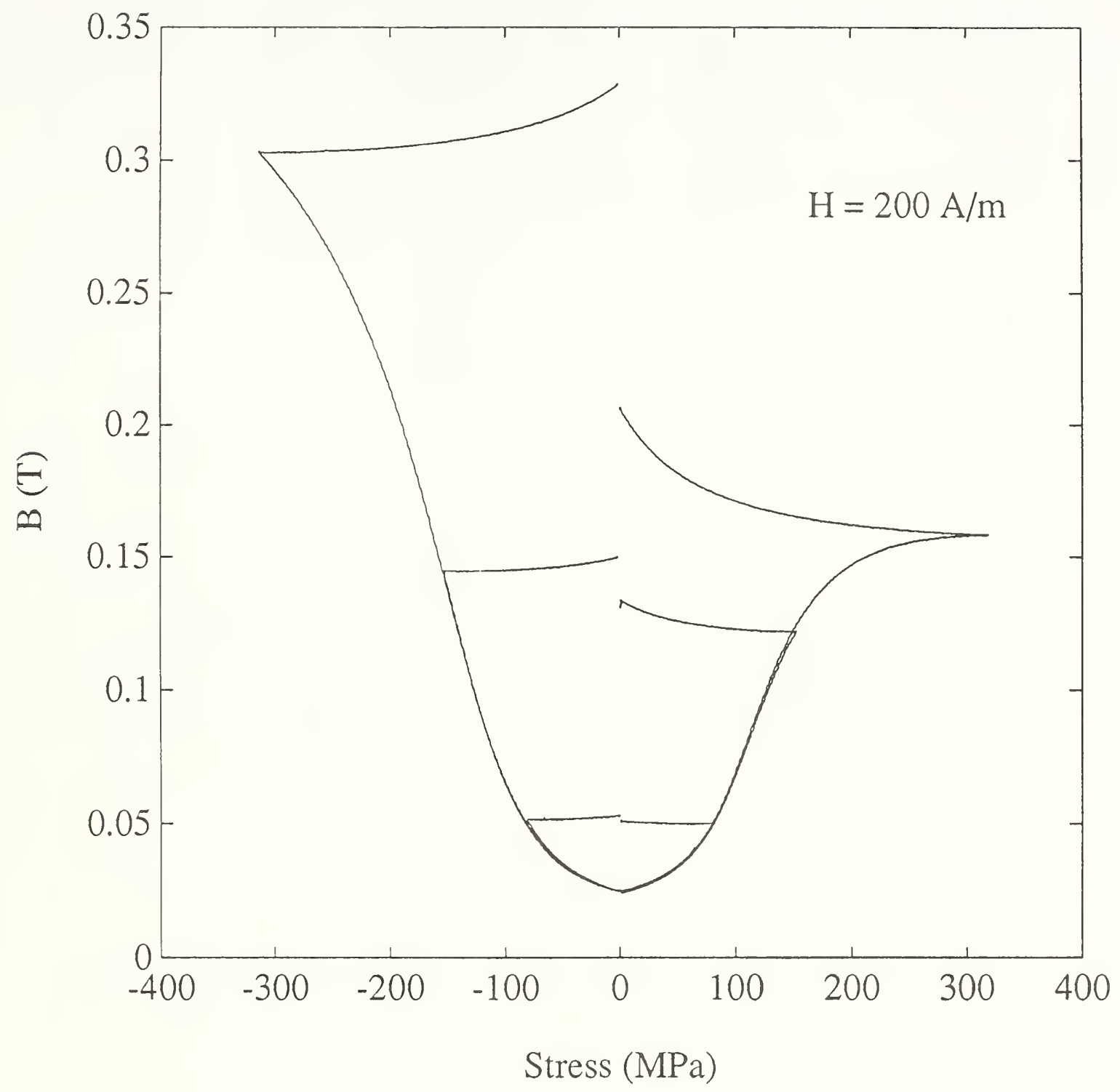

Figure B-10. Magnetic induction as a function of applied transverse stresses ranging from -300 to $300 \mathrm{MPa}$ as described by (6) in the test plan. The dc magnetic field was $200 \mathrm{~A} / \mathrm{m}$. 


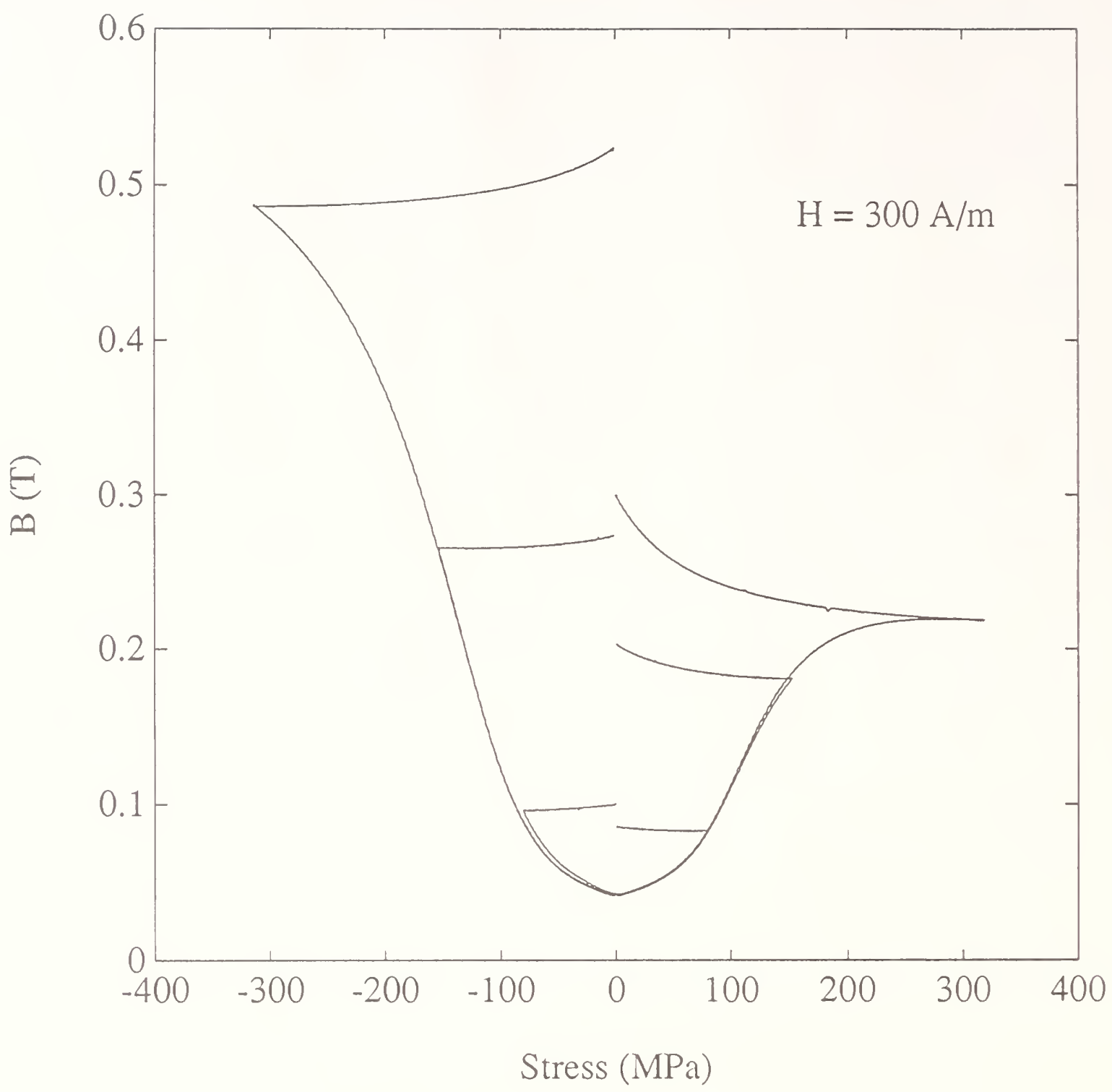

Figure B-11. Magnetic induction as a function of applied transverse stresses ranging from -300 to $300 \mathrm{MPa}$ as described by (6) in the test plan. The dc magnetic field was $300 \mathrm{~A} / \mathrm{m}$. 


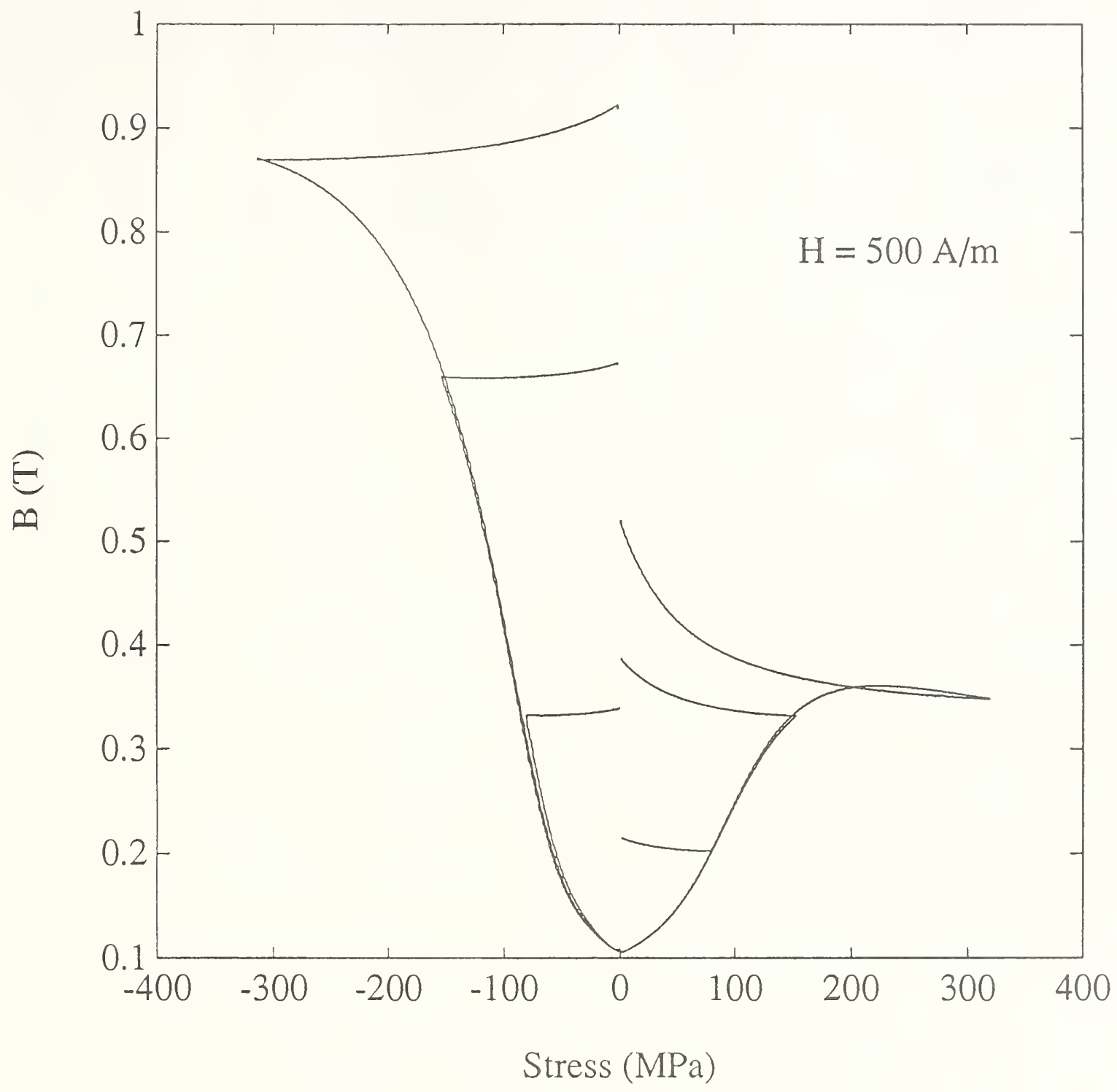

Figure B-12. Magnetic induction as a function of applied transverse stresses ranging from -300 to $300 \mathrm{MPa}$ as described by (6) in the test plan. The dc magnetic field was $500 \mathrm{~A} / \mathrm{m}$. 


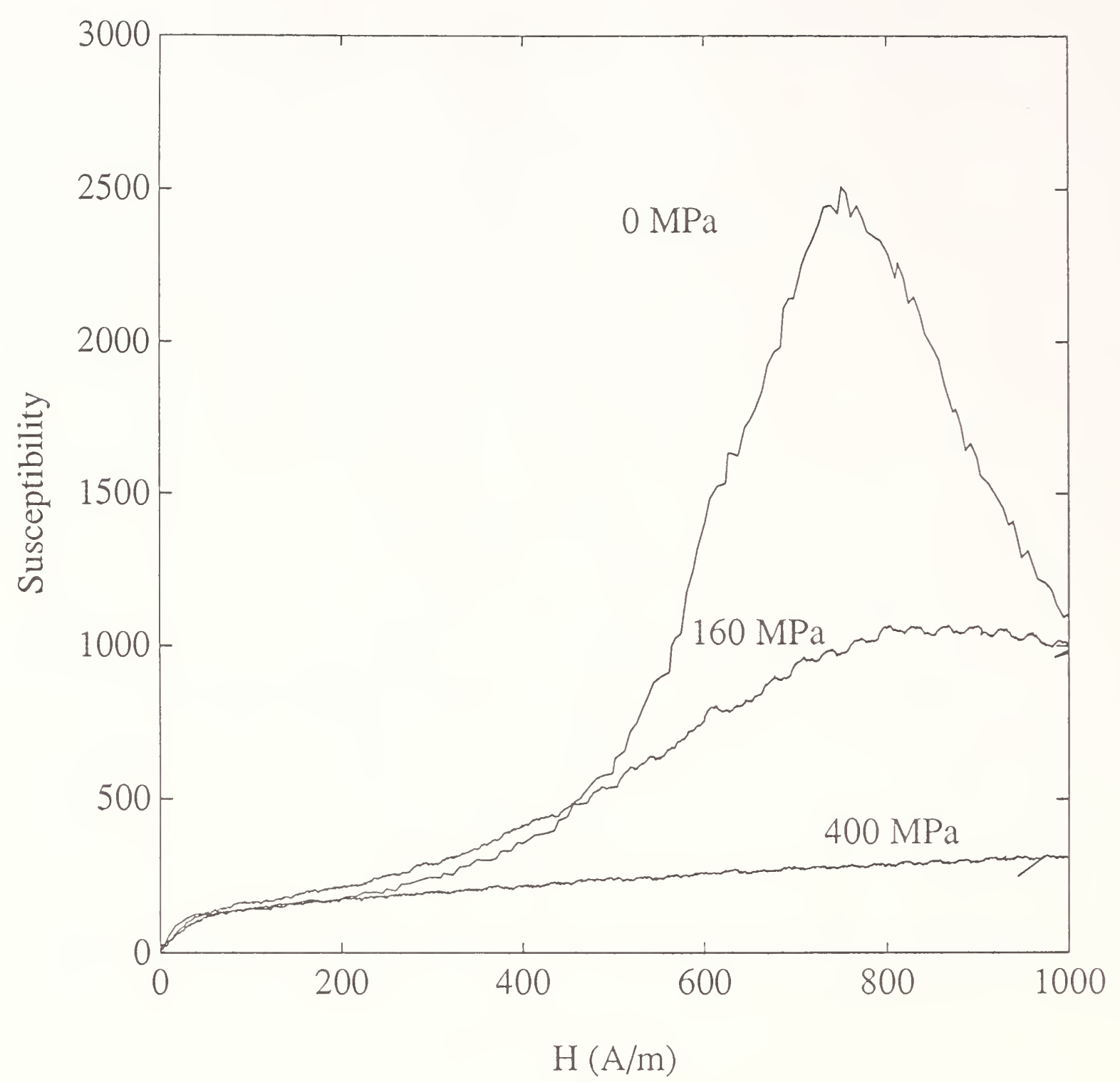

Figure B-13. Susceptibility as a function of applied magnetic field strength for transverse positive stresses (tension) ranging from 0 to $400 \mathrm{MPa}$ as described by (7) in the test plan. 


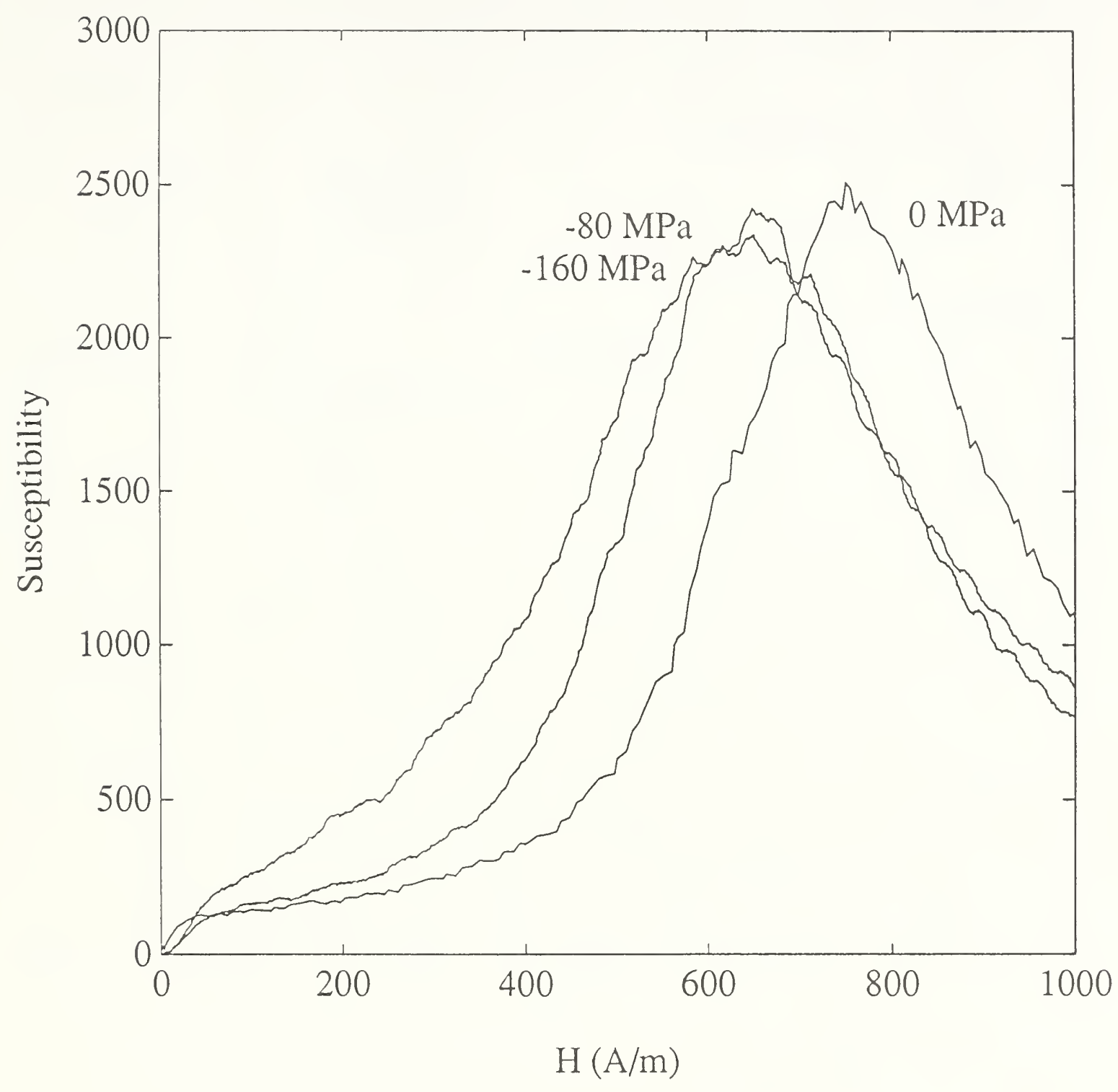

Figure B-14. Susceptibility as a function of applied magnetic field strength for transverse negative stresses (compression) ranging from 0 to $-400 \mathrm{MPa}$ as described by (7) in the test plan. 


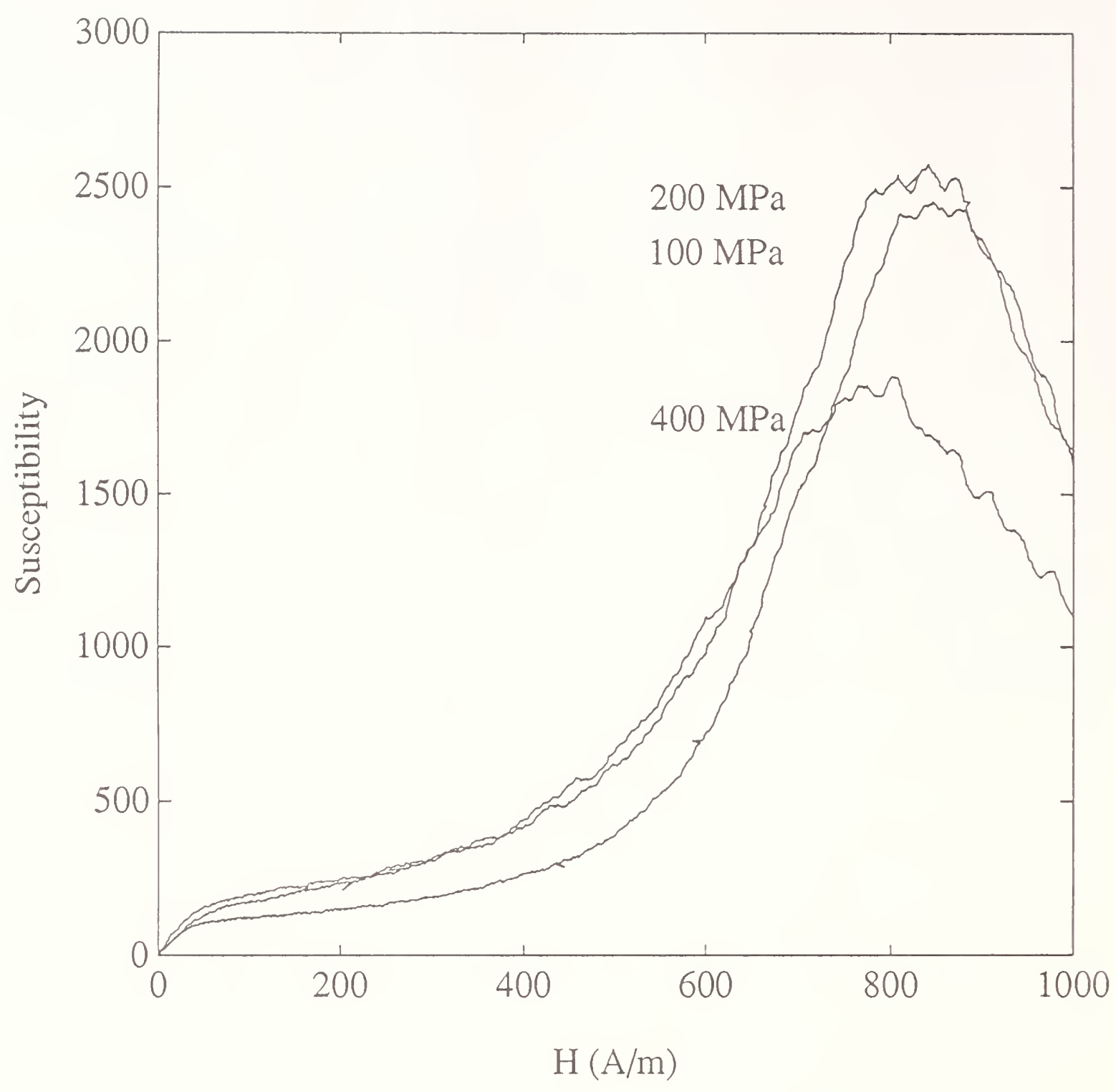

Figure B-15. Susceptibility as a function of applied magnetic field strength after the application and release of positive transverse stresses ranging from 50 to 400 $\mathrm{MPa}$. The measurement is described by (8) in the test plan. 


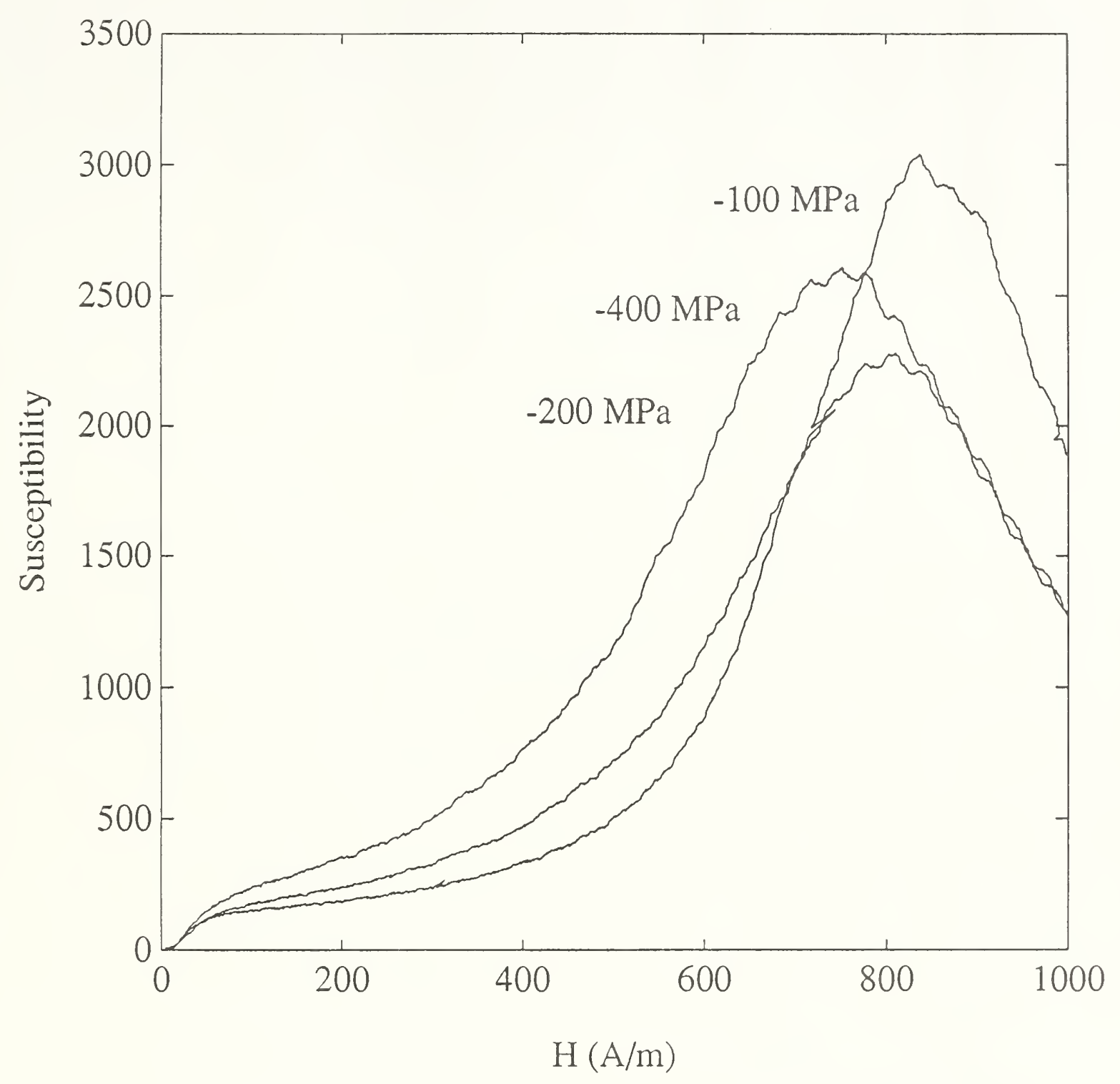

Figure B-16. Susceptibility as a function of applied magnetic field strength after the application and release of negative transverse stresses ranging from -50 to $-400 \mathrm{MPa}$. The measurement is described by (8) in the test plan. 

Appendix C 


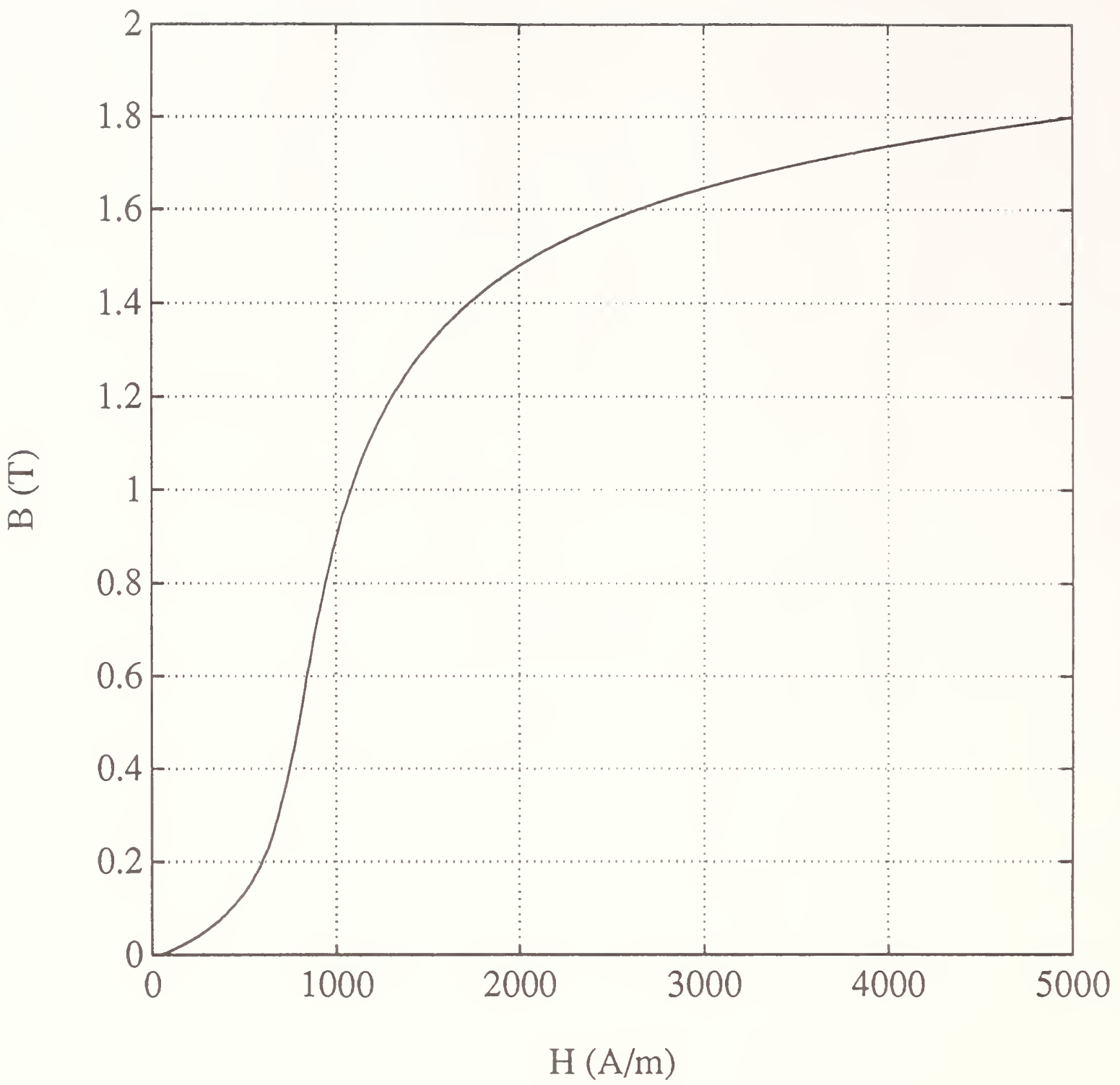

Figure C-1. Normal unstressed magnetization curve as described by (1) in the test plan. 


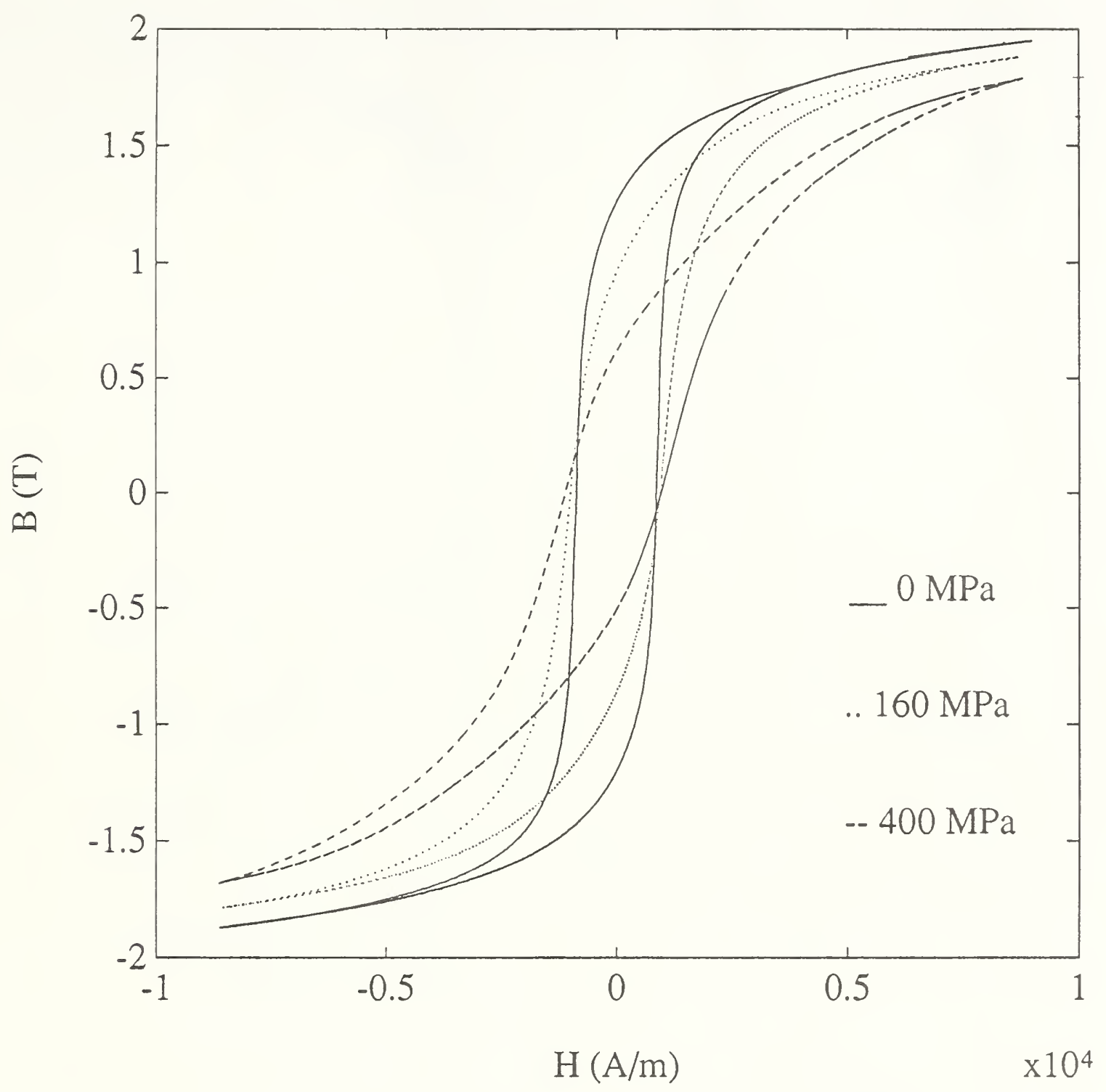

Figure C-2. Magnetic induction as a function of applied magnetic field strength for positive transverse stress (tension) ranging from 0 to $400 \mathrm{MPa}$ as described by (2) in the test plan. The stress results in an effective demagnetizing field which shears the hysteresis loop. 


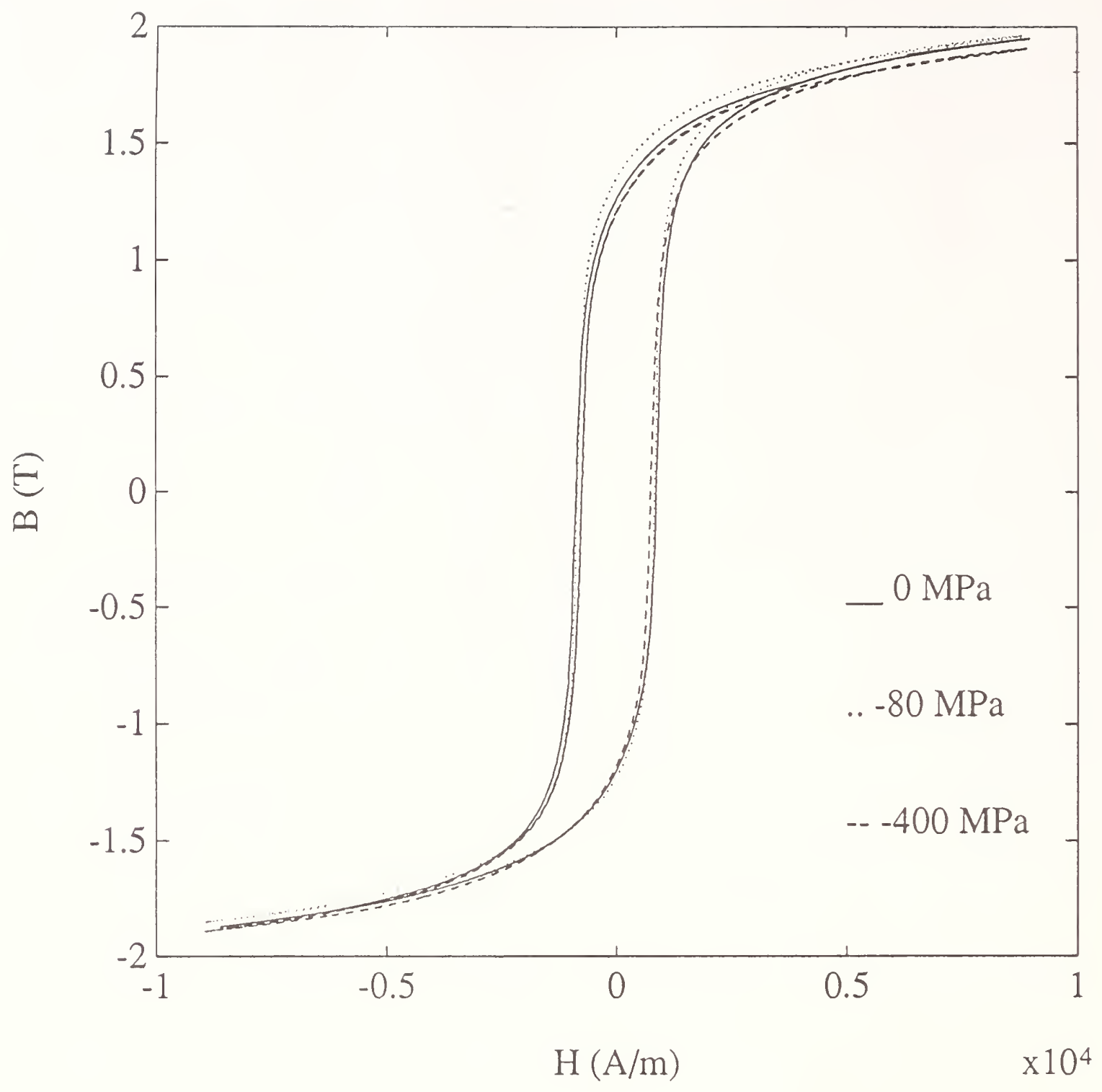

Figure C-3. Magnetic induction as a function of applied magnetic field strength for negative transverse stresses (compression) ranging from 0 to $-400 \mathrm{MPa}$ as described by (2) in the test plan. 


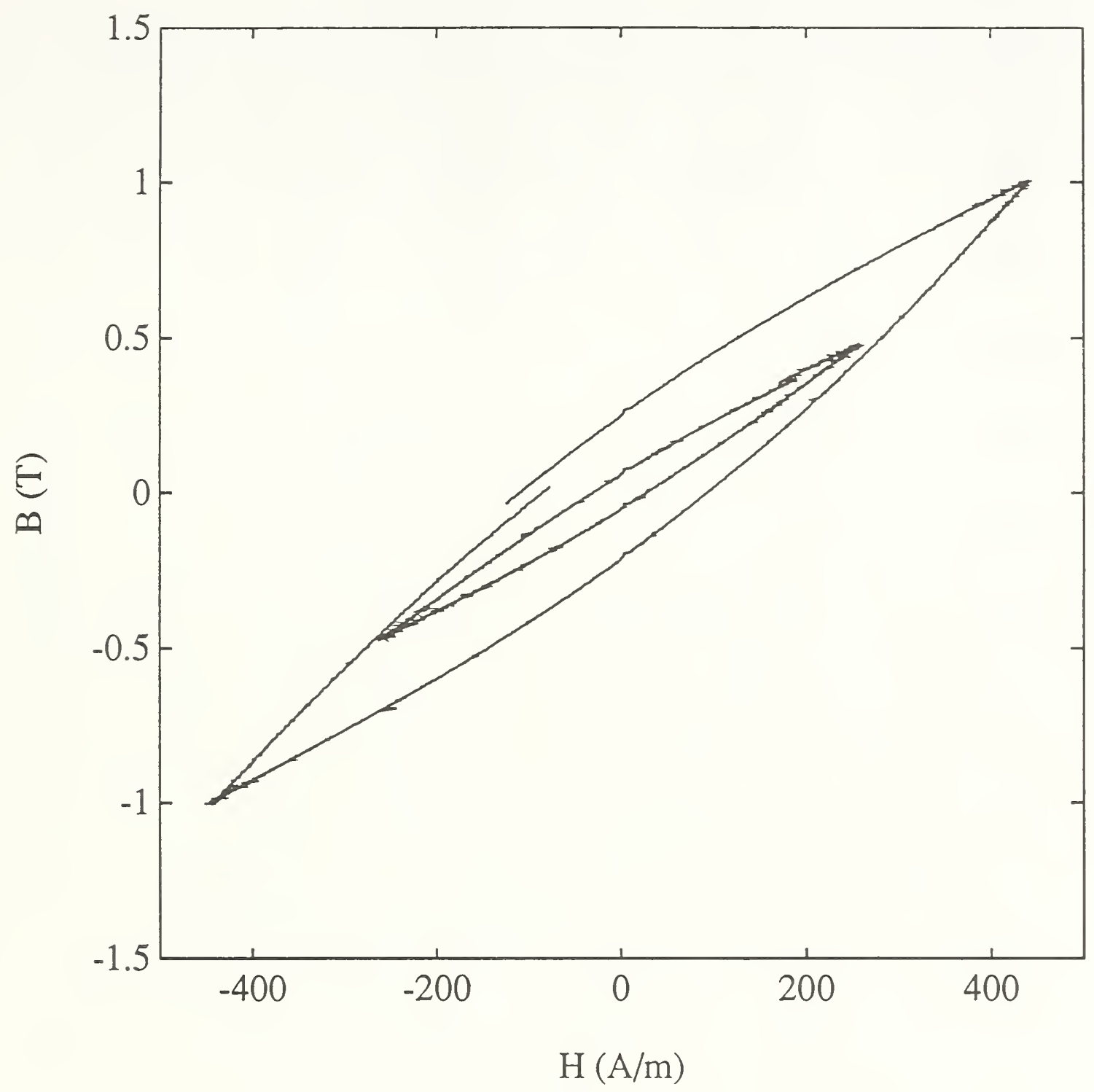

Figure C-4. Magnetic induction as a function of applied magnetic field strength for maximum fields of 200 and $400 \mathrm{~A} / \mathrm{m}$ as described by (3) in the test plan. 


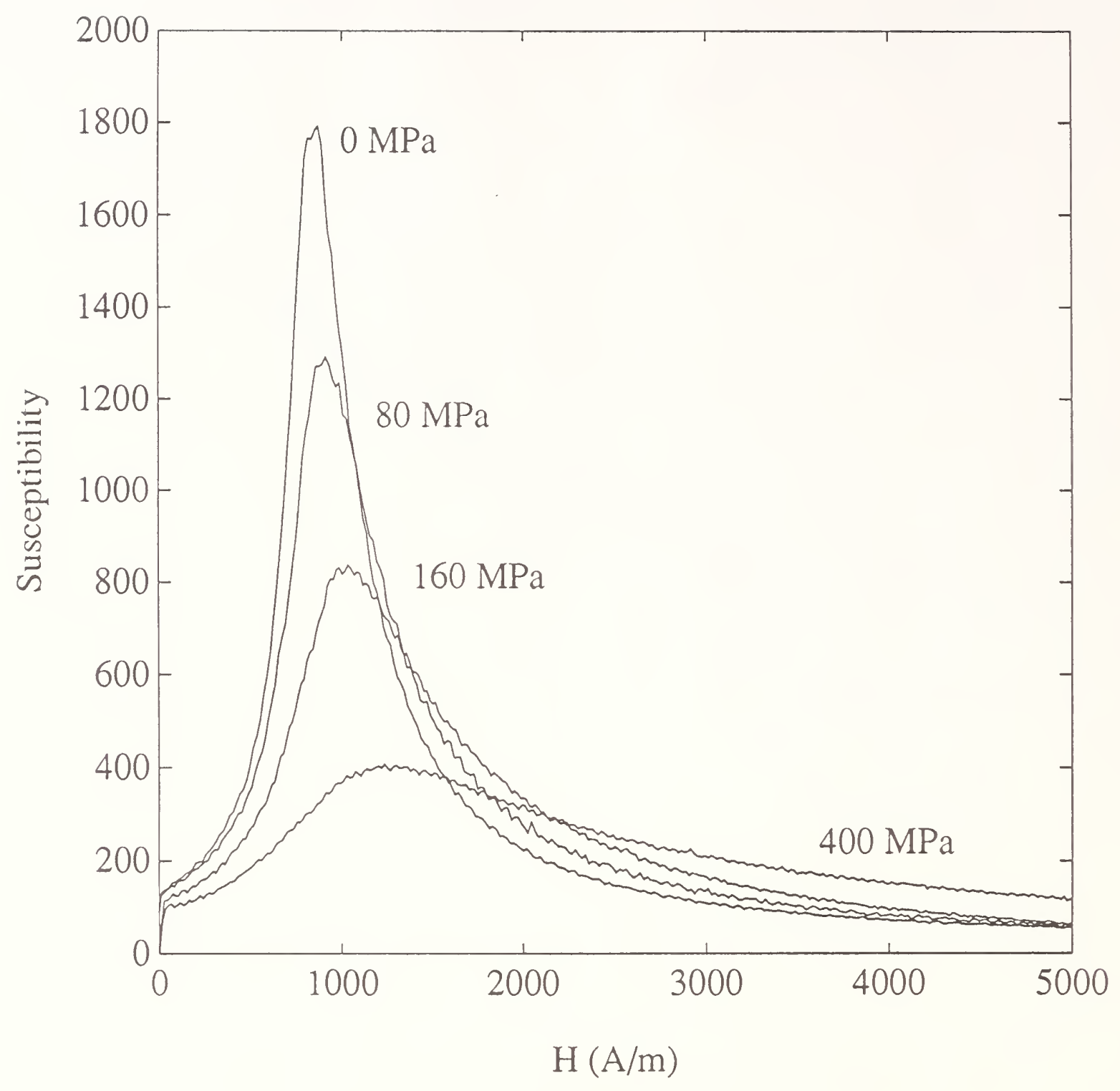

Figure C-5. Susceptibility as a function of applied magnetic field strength for positive transverse stresses (tension) ranging from 0 to $400 \mathrm{MPa}$ as described by (4) in the test plan. 


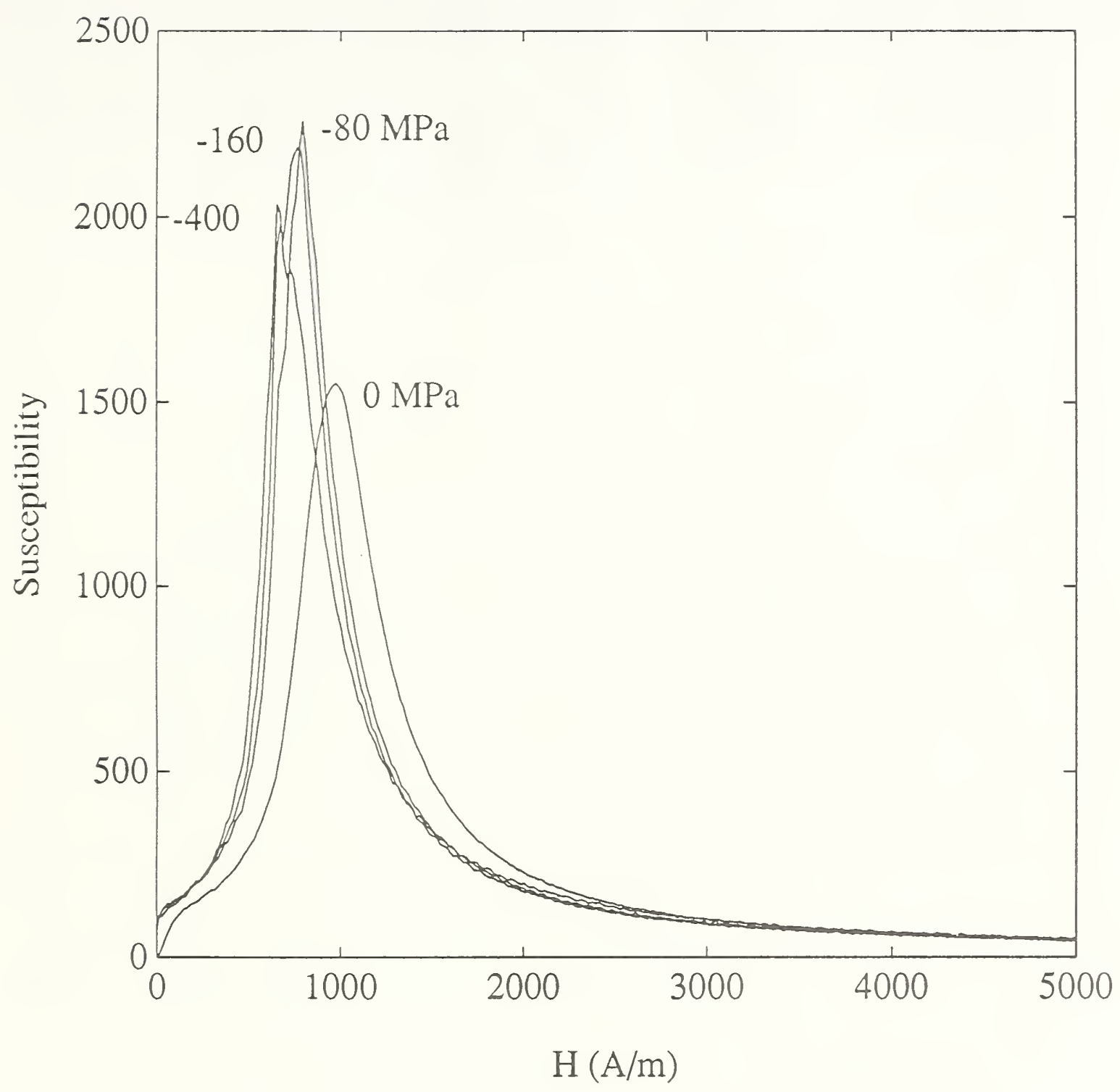

Figure C-6. Susceptibility as a function of applied magnetic field strength for negative transverse stresses (compression) ranging from 0 to $-400 \mathrm{MPa}$ as described by (4) in the test plan. 


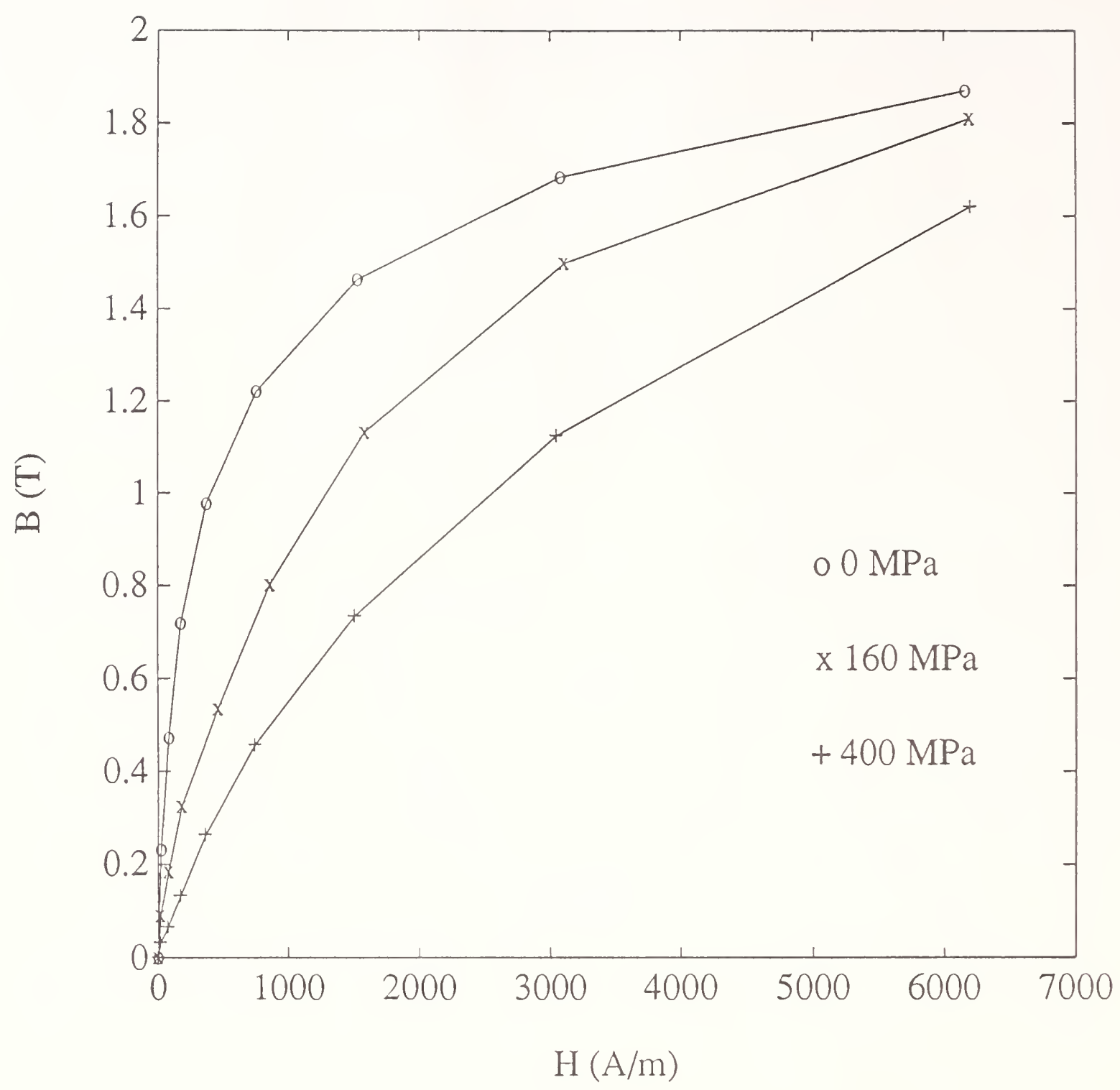

Figure C-7. Anhysteretic magnetization curves for positive transverse stresses (tension) ranging from 0 to $400 \mathrm{MPa}$ as described by (5) in the test plan. 


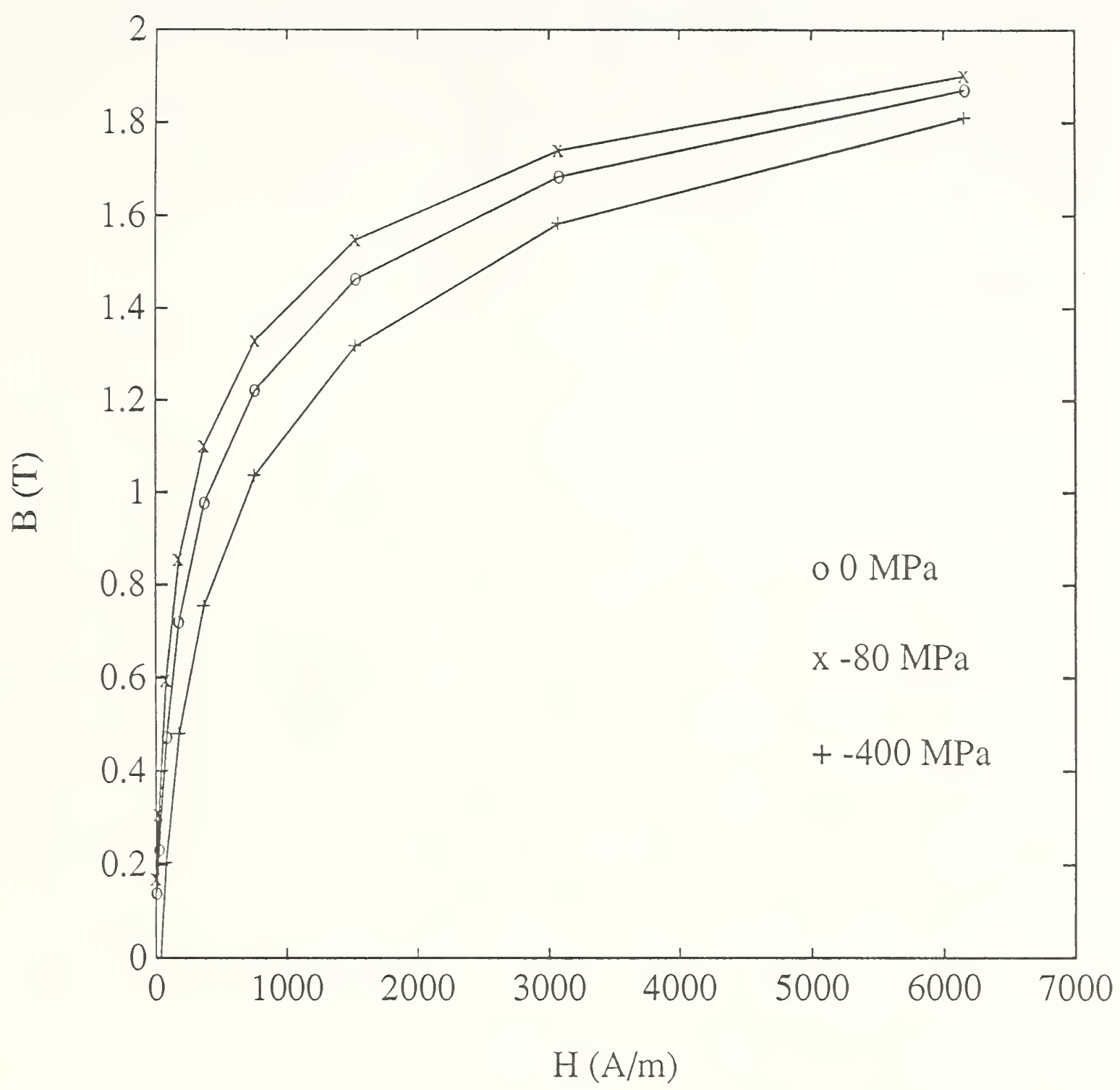

Figure C-8. Anhysteretic magnetization curves for negative transverse stresses (compression) ranging from 0 to $-400 \mathrm{MPa}$ as described by (5) in the test plan. 


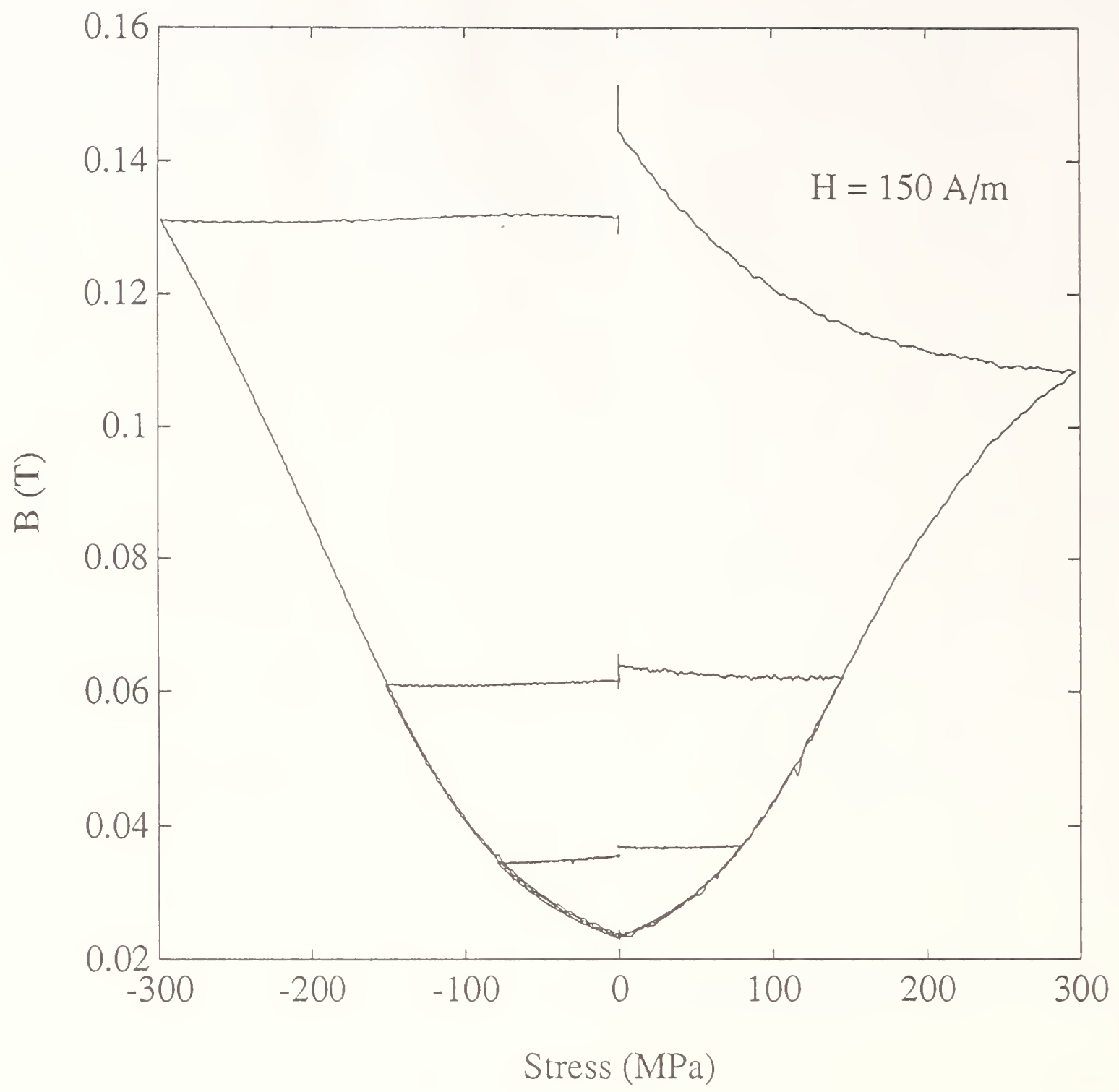

Figure C-9. Magnetic induction as a function of applied transverse stresses ranging from -300 to $300 \mathrm{MPa}$ as described by (6) in the test plan. The dc magnetic field was $150 \mathrm{~A} / \mathrm{m}$. 


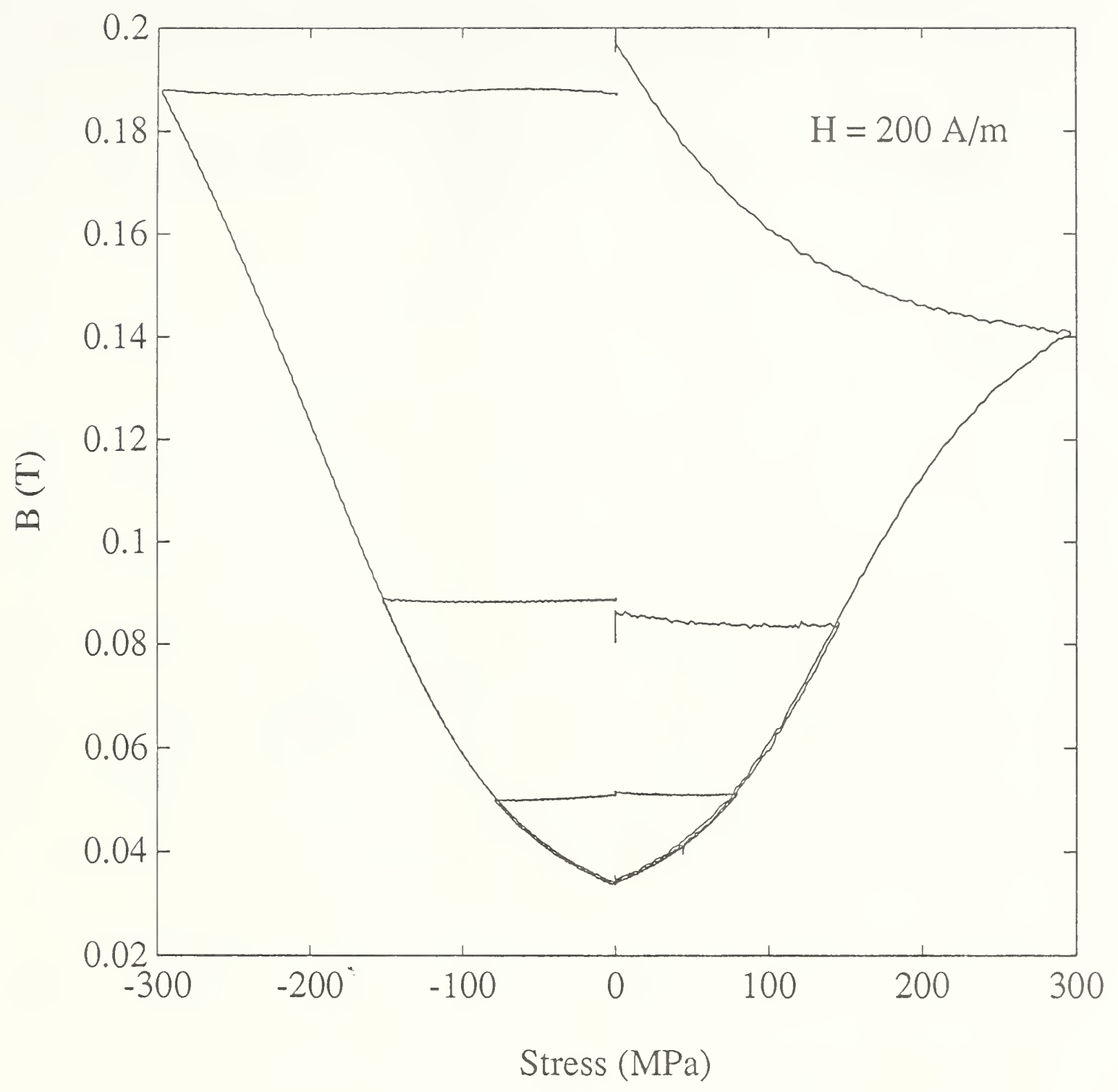

Figure C-10. Magnetic induction as a function of applied transverse stresses ranging from -300 to $300 \mathrm{MPa}$ as described by (6) in the test plan. The dc magnetic field was $200 \mathrm{~A} / \mathrm{m}$. 


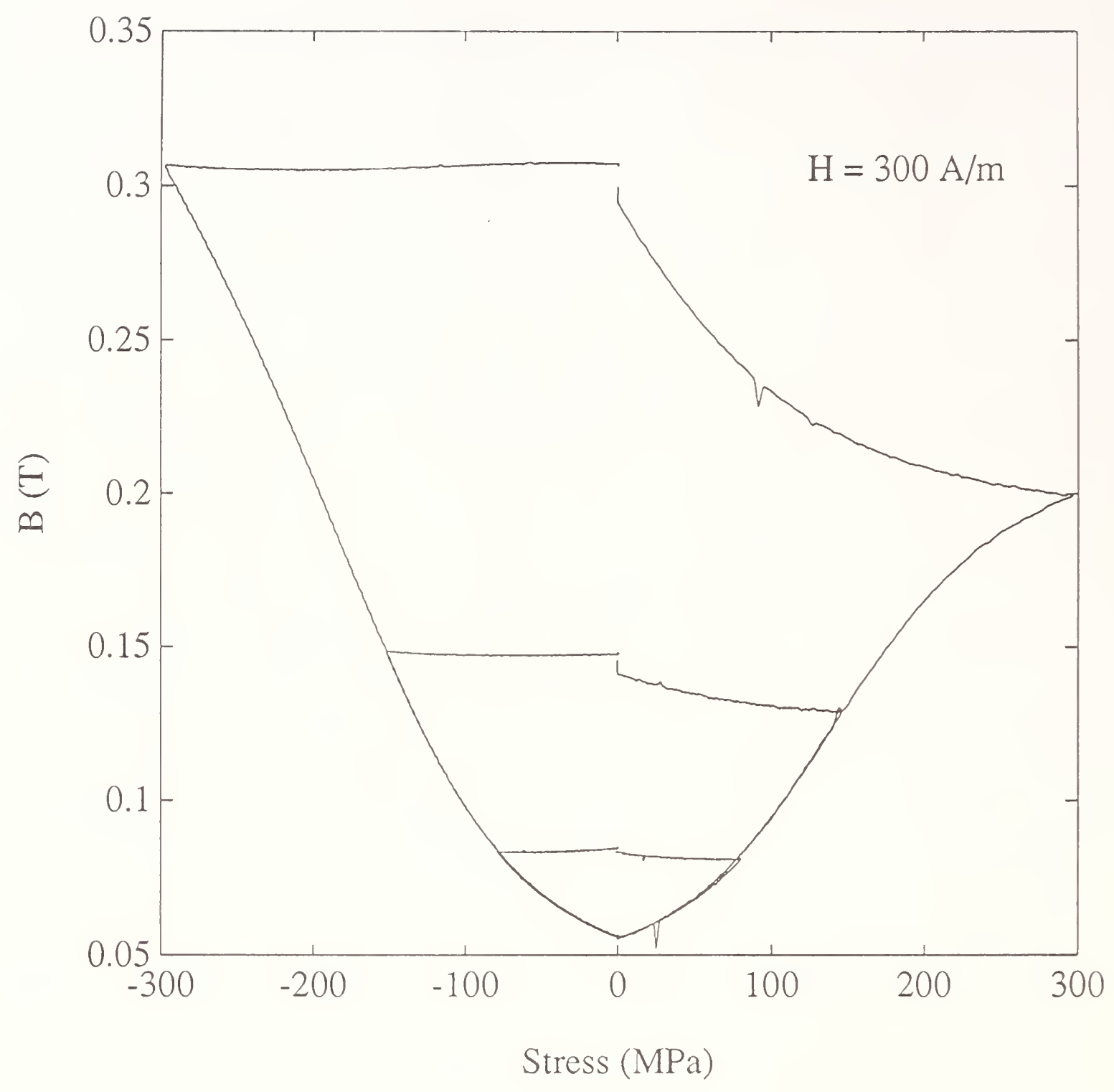

Figure C-11. Magnetic induction as a function of applied transverse stresses ranging from -300 to $300 \mathrm{MPa}$ as described by (6) in the test plan. The dc magnetic field was $300 \mathrm{~A} / \mathrm{m}$. 


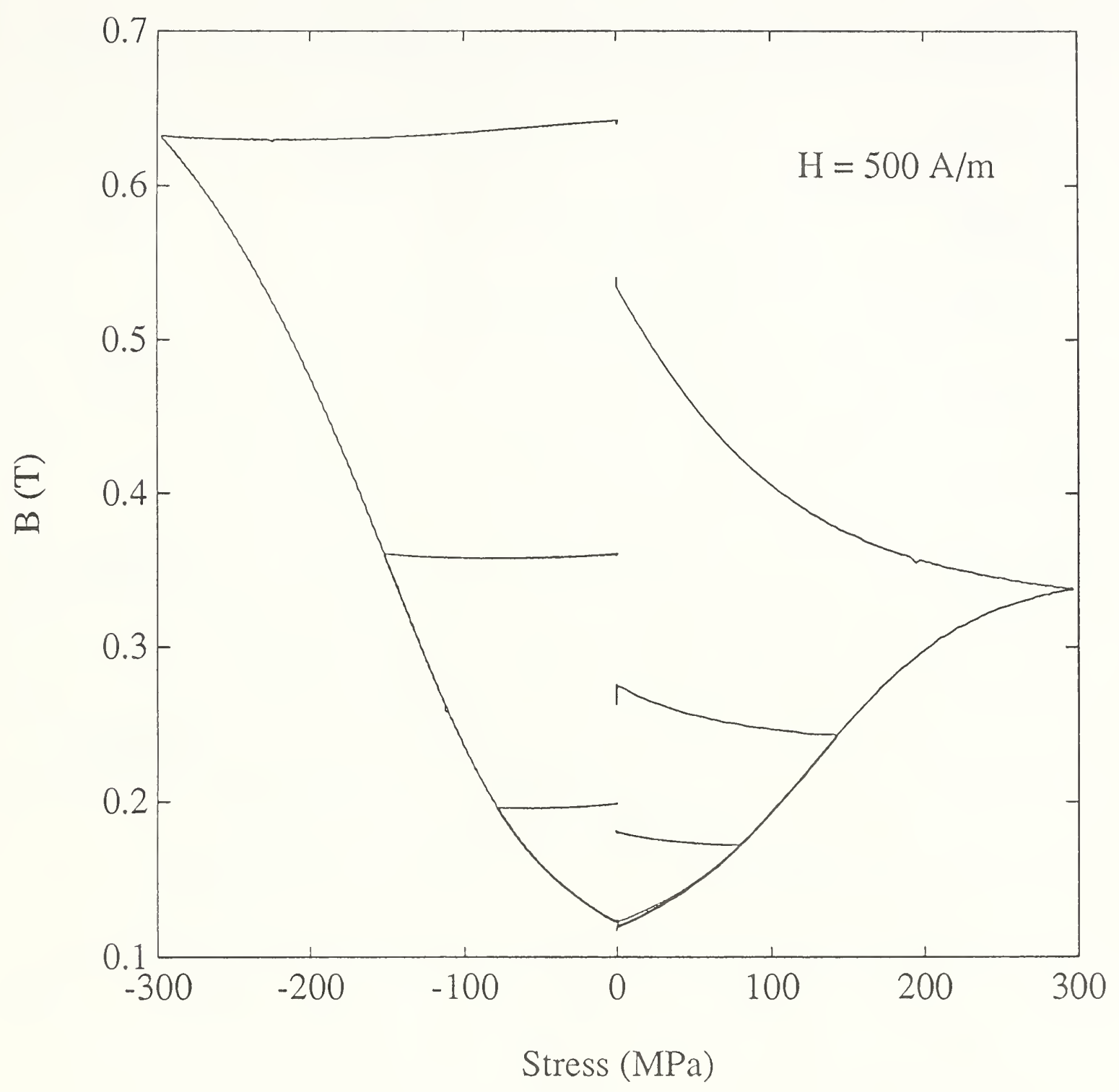

Figure C-12. Magnetic induction as a function of applied transverse stresses ranging from -300 to $300 \mathrm{MPa}$ as described by (6) in the test plan. The dc magnetic field was $500 \mathrm{~A} / \mathrm{m}$. 


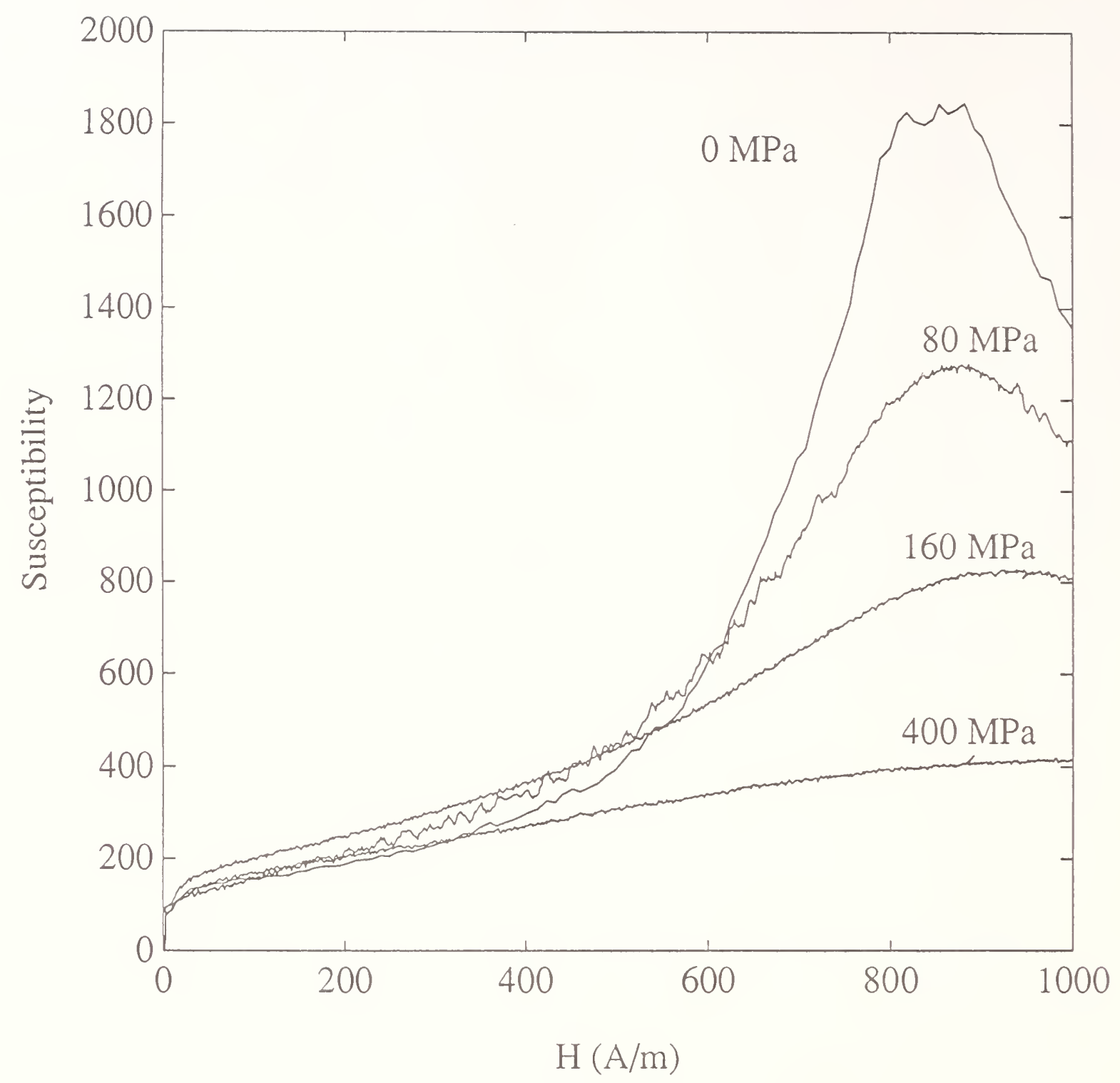

Figure C-13. Susceptibility as a function of applied magnetic field strength for transverse positive stresses (tension) ranging from 0 to $400 \mathrm{MPa}$ as described by (7) in the test plan. 


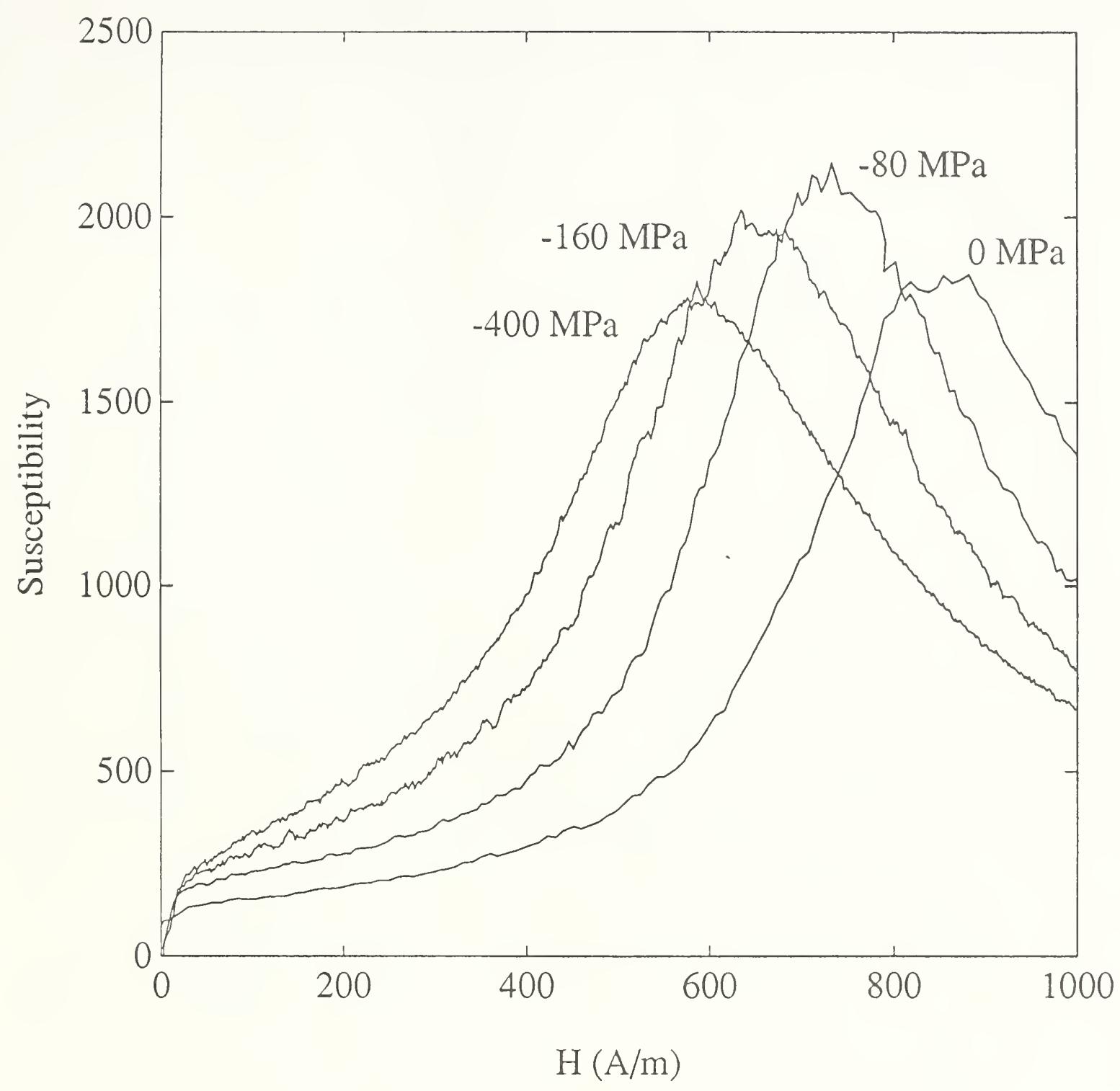

Figure C-14. Susceptibility as a function of applied magnetic field strength for transverse negative stresses (compression) ranging from 0 to $-400 \mathrm{MPa}$ as described by (7) in the test plan. 


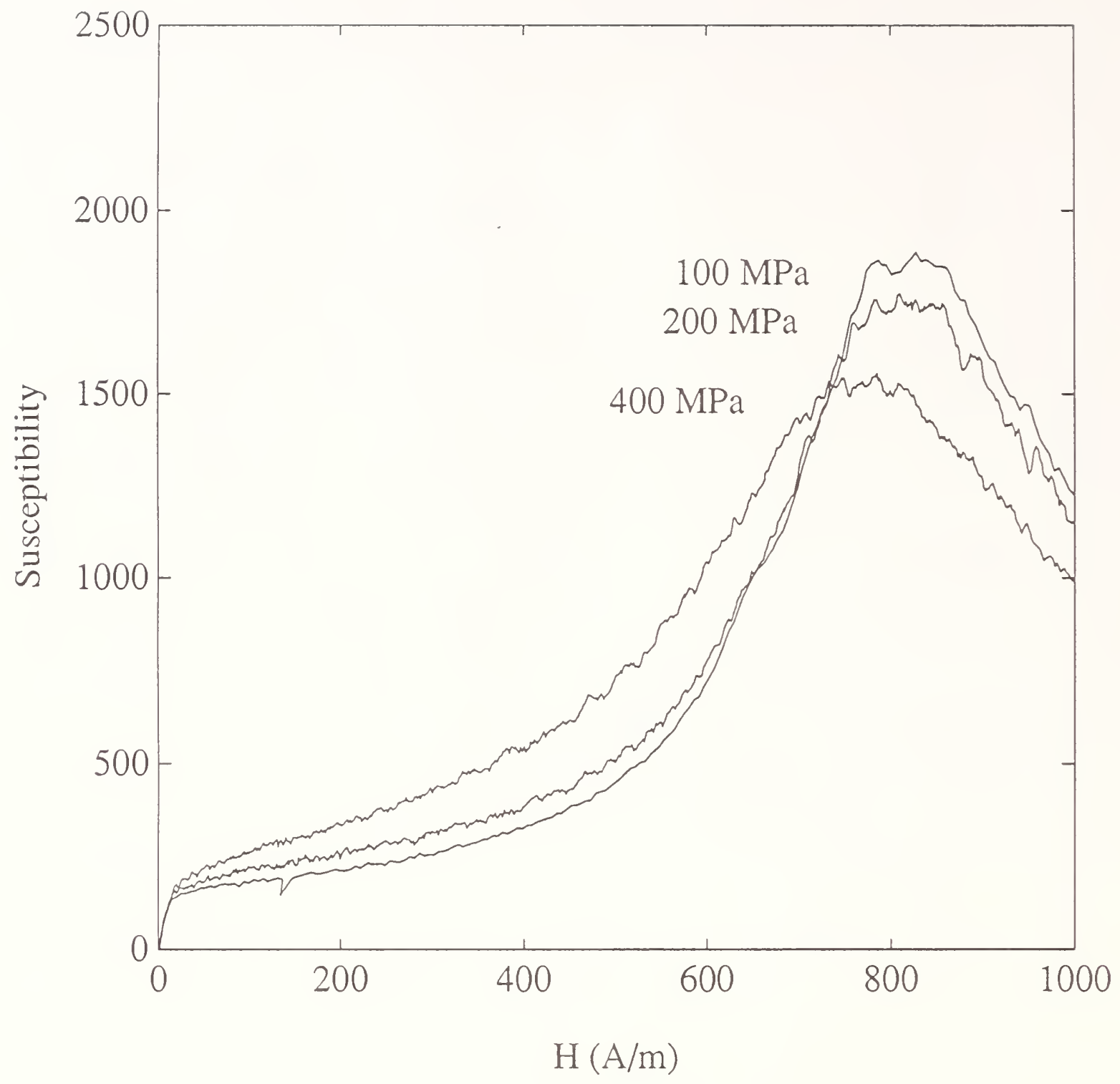

Figure C-15. Susceptibility as a function of applied magnetic field strength after the application and release of positive transverse stresses ranging from 50 to 400 $\mathrm{MPa}$. The measurement is described by (8) in the test plan. 


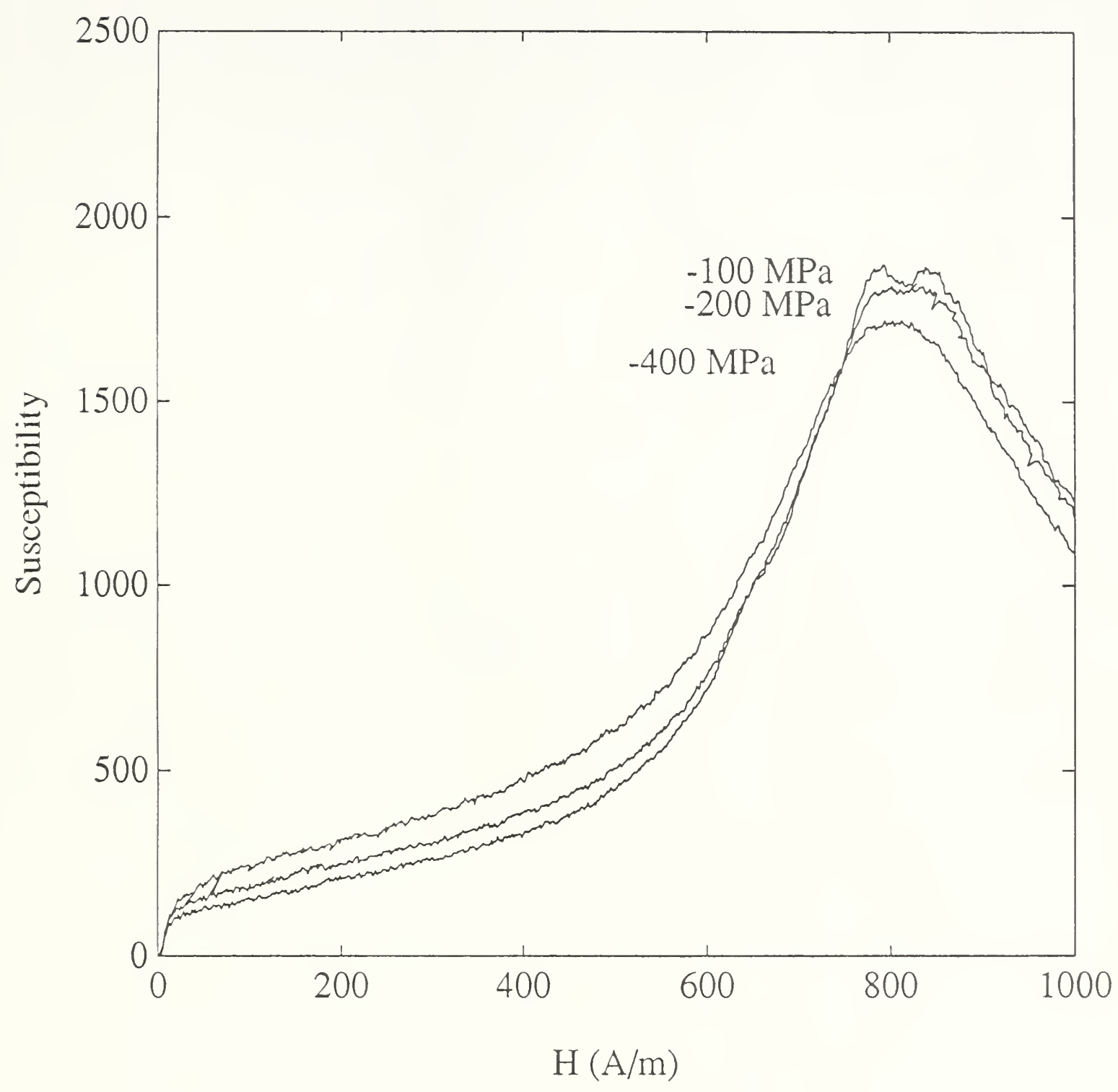

Figure C-16. Susceptibility as a function of applied magnetic field strength after the application and release of negative transverse stresses ranging from -50 to $-400 \mathrm{MPa}$. The measurement is described by (8) in the test plan. 

Appendix D 


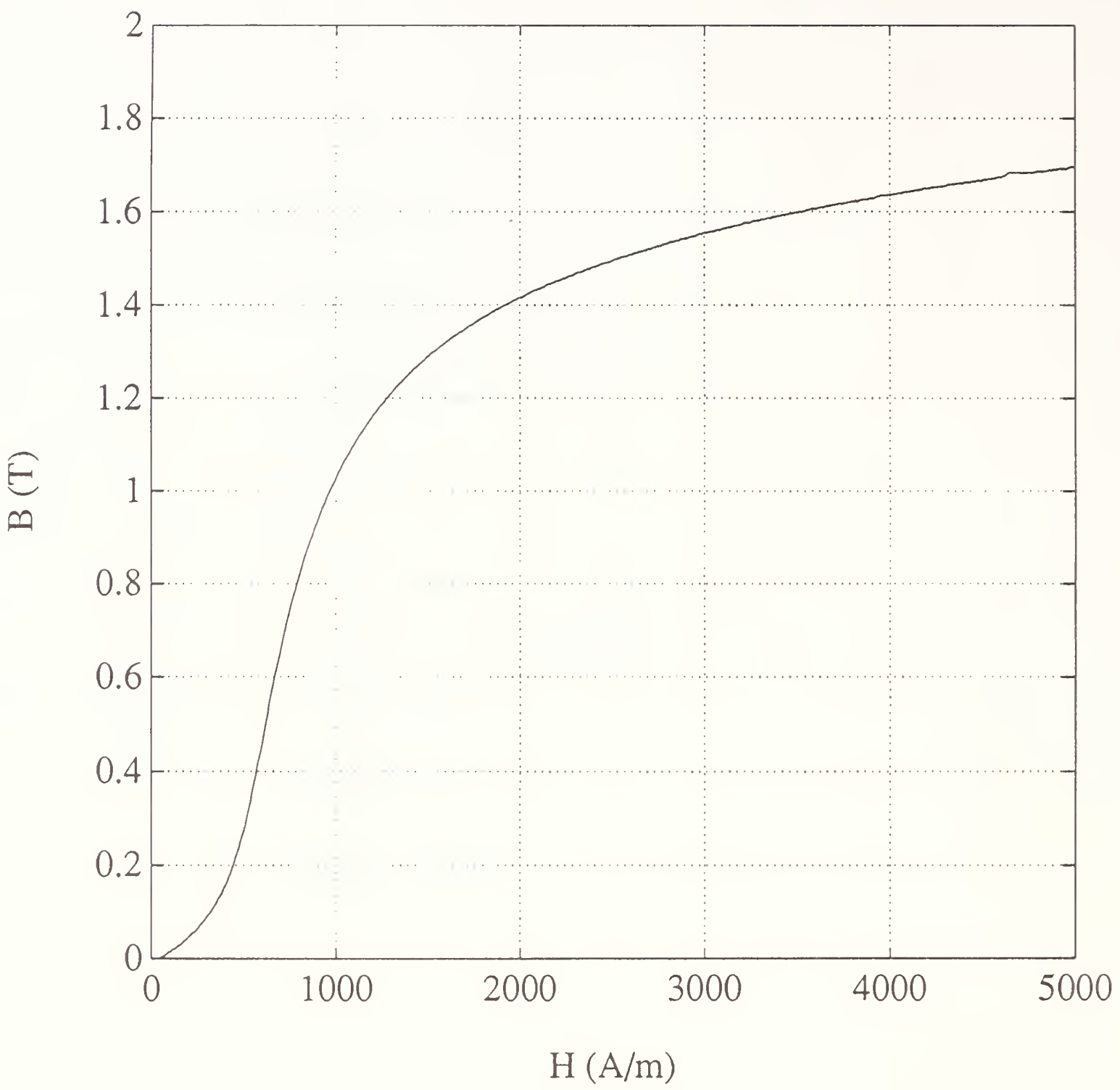

Figure D-1. Normal unstressed magnetization curve as described by (1) in the test plan. 


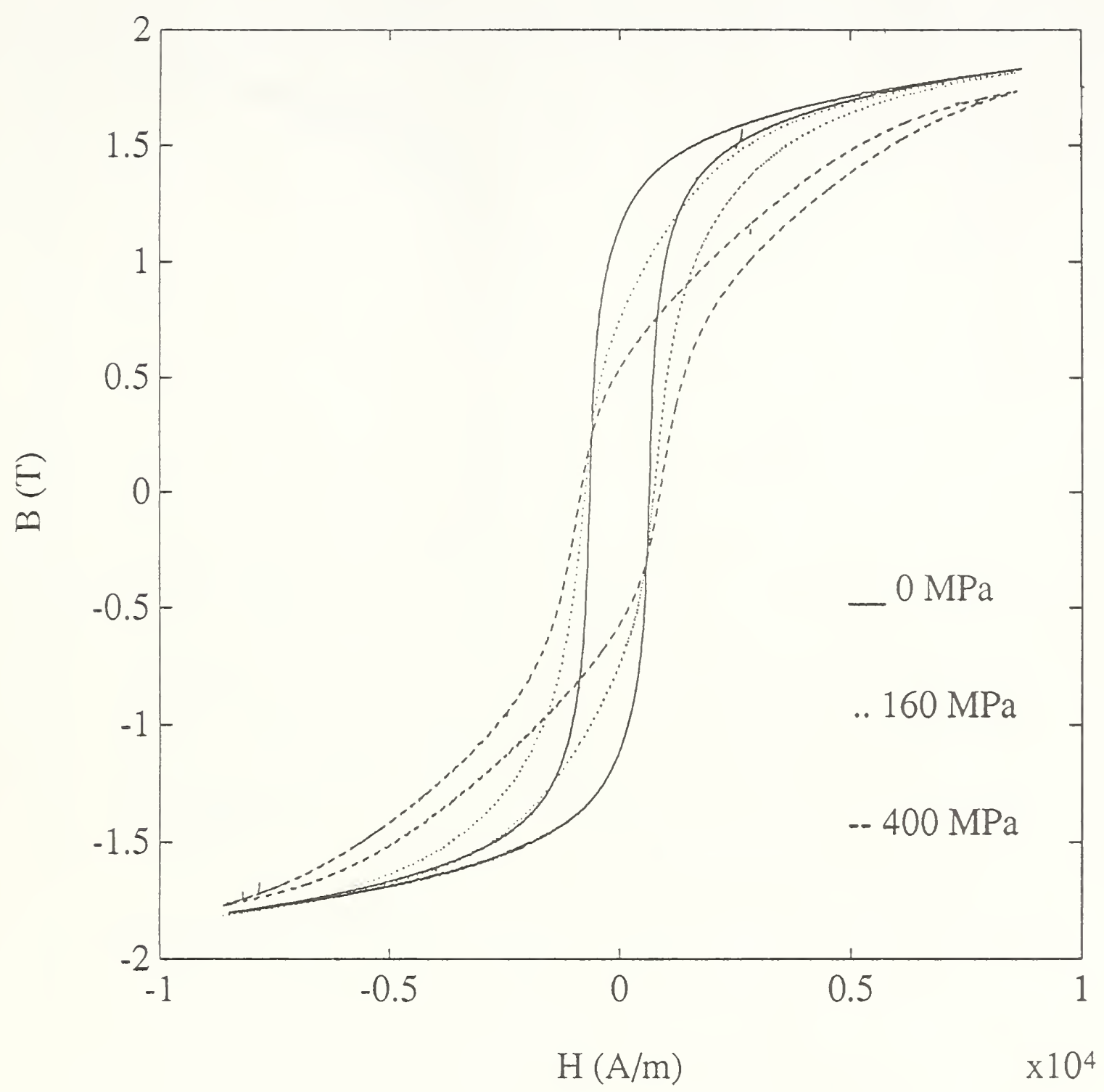

Figure D-2. Magnetic induction as a function of applied magnetic field strength for positive transverse stress (tension) ranging from 0 to $400 \mathrm{MPa}$ as described by (2) in the test plan. The stress results in an effective demagnetizing field which shears the hysteresis loop. 


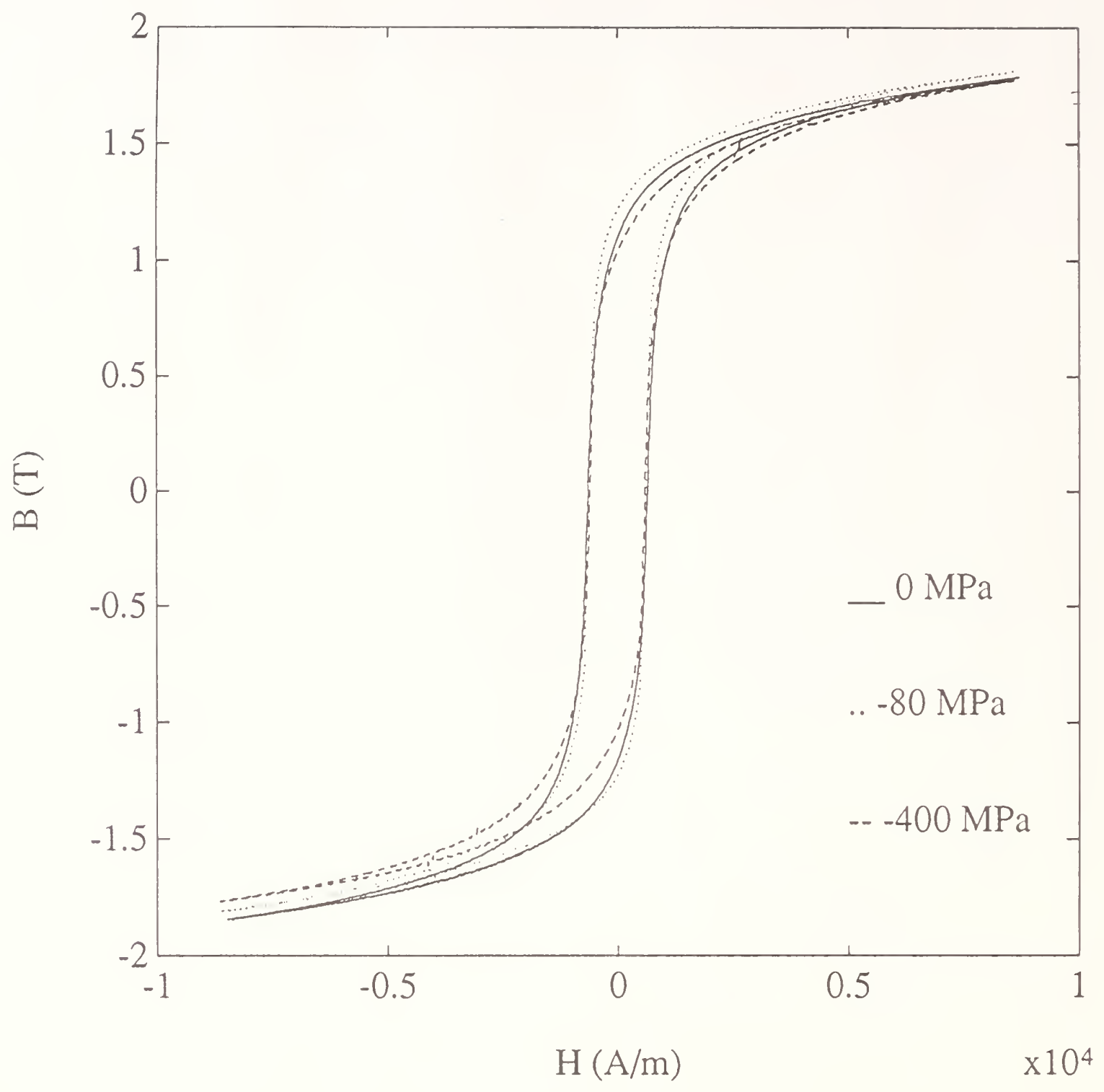

Figure D-3. Magnetic induction as a function of applied magnetic field strength for negative transverse stresses (compression) ranging from 0 to $-400 \mathrm{MPa}$ as described by (2) in the test plan. 


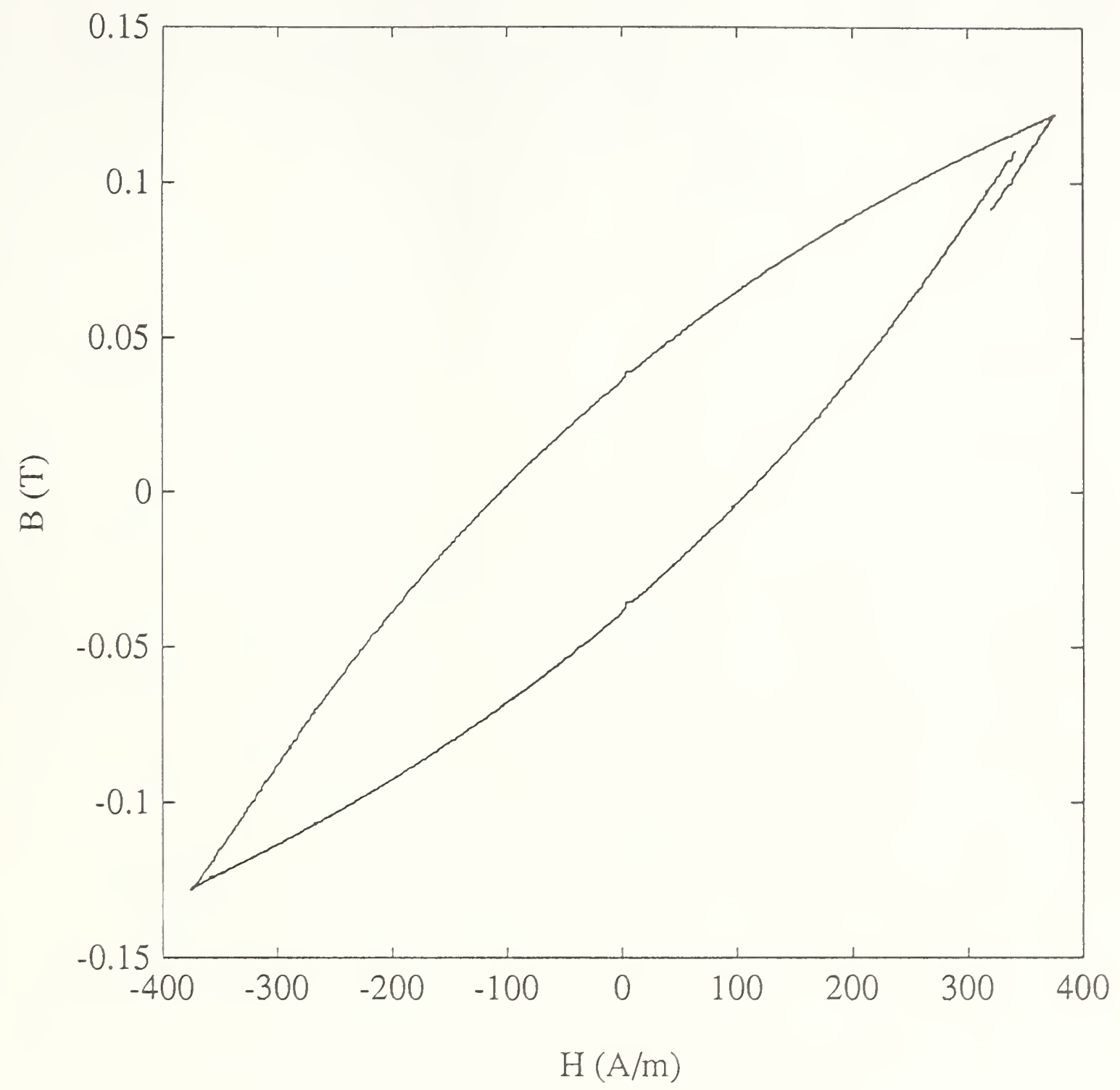

Figure D-4. Magnetic induction as a function of applied magnetic field strength for a maximum field of $400 \mathrm{~A} / \mathrm{m}$ as described by (3) in the test plan. 


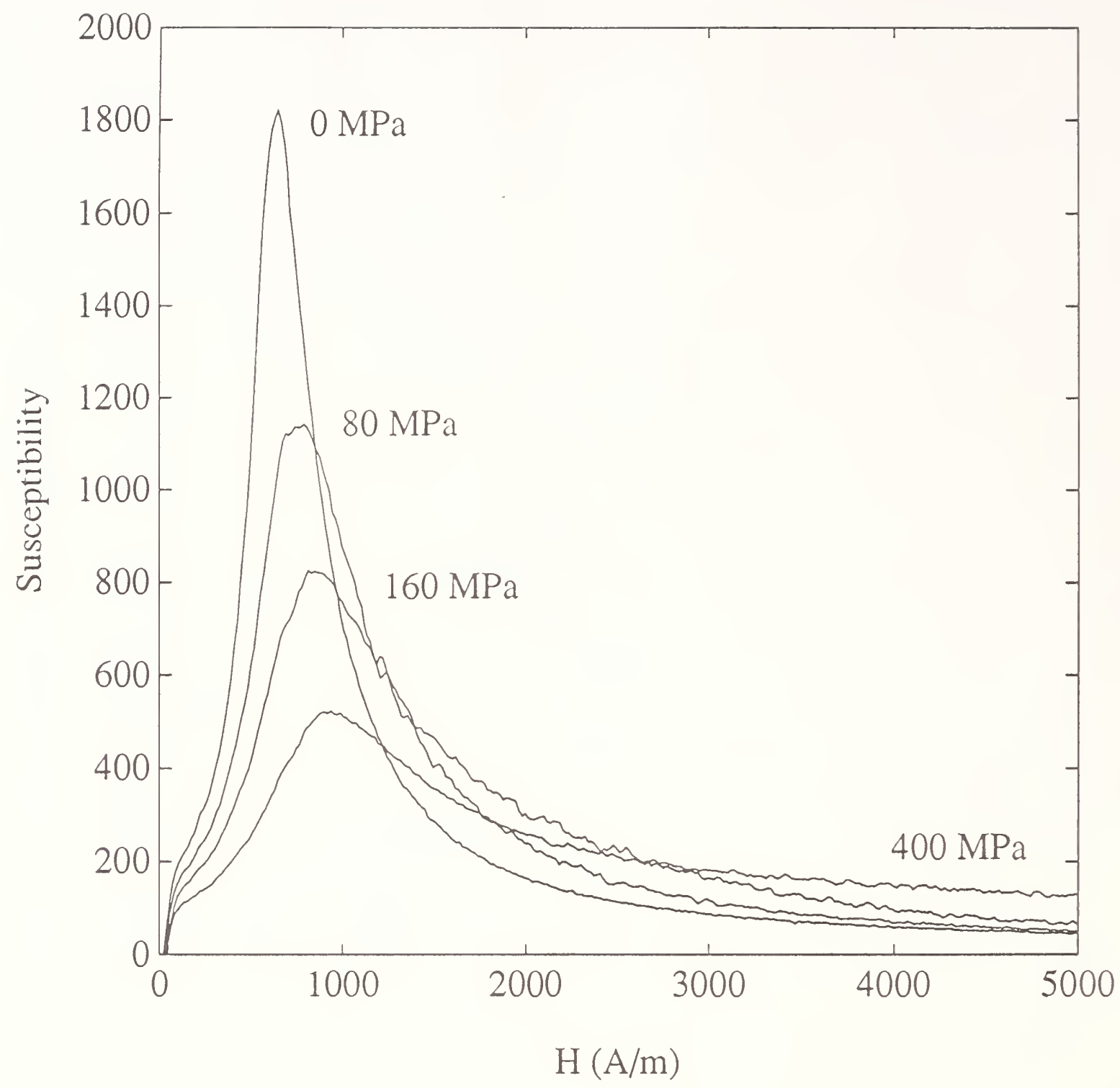

Figure D-5. Susceptibility as a function of applied magnetic field strength for positive transverse stresses (tension) ranging from 0 to $400 \mathrm{MPa}$ as described by (4) in the test plan. 


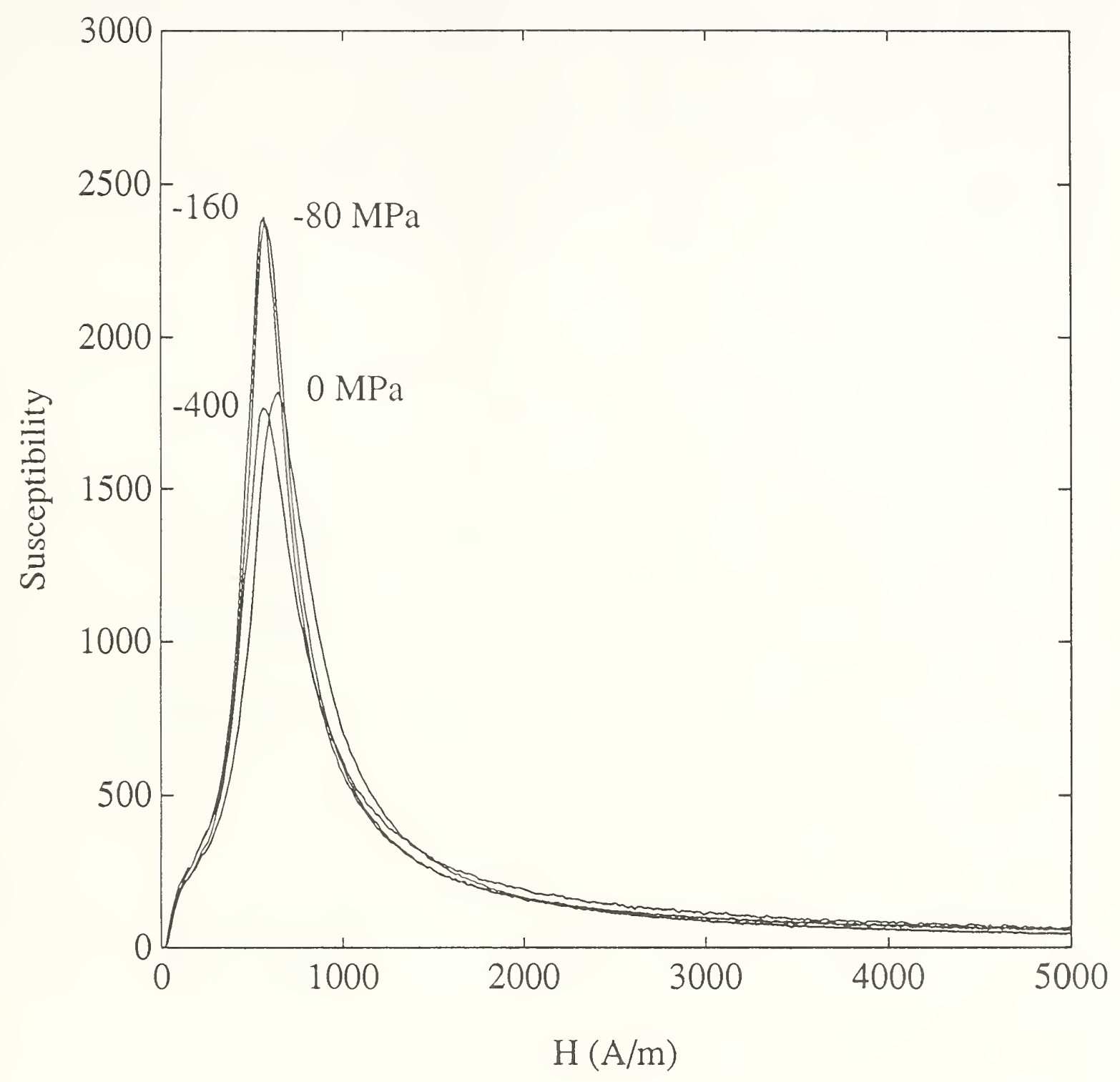

Figure D-6. Susceptibility as a function of applied magnetic field strength for negative transverse stresses (compression) ranging from 0 to $-400 \mathrm{MPa}$ as described by (4) in the test plan. 


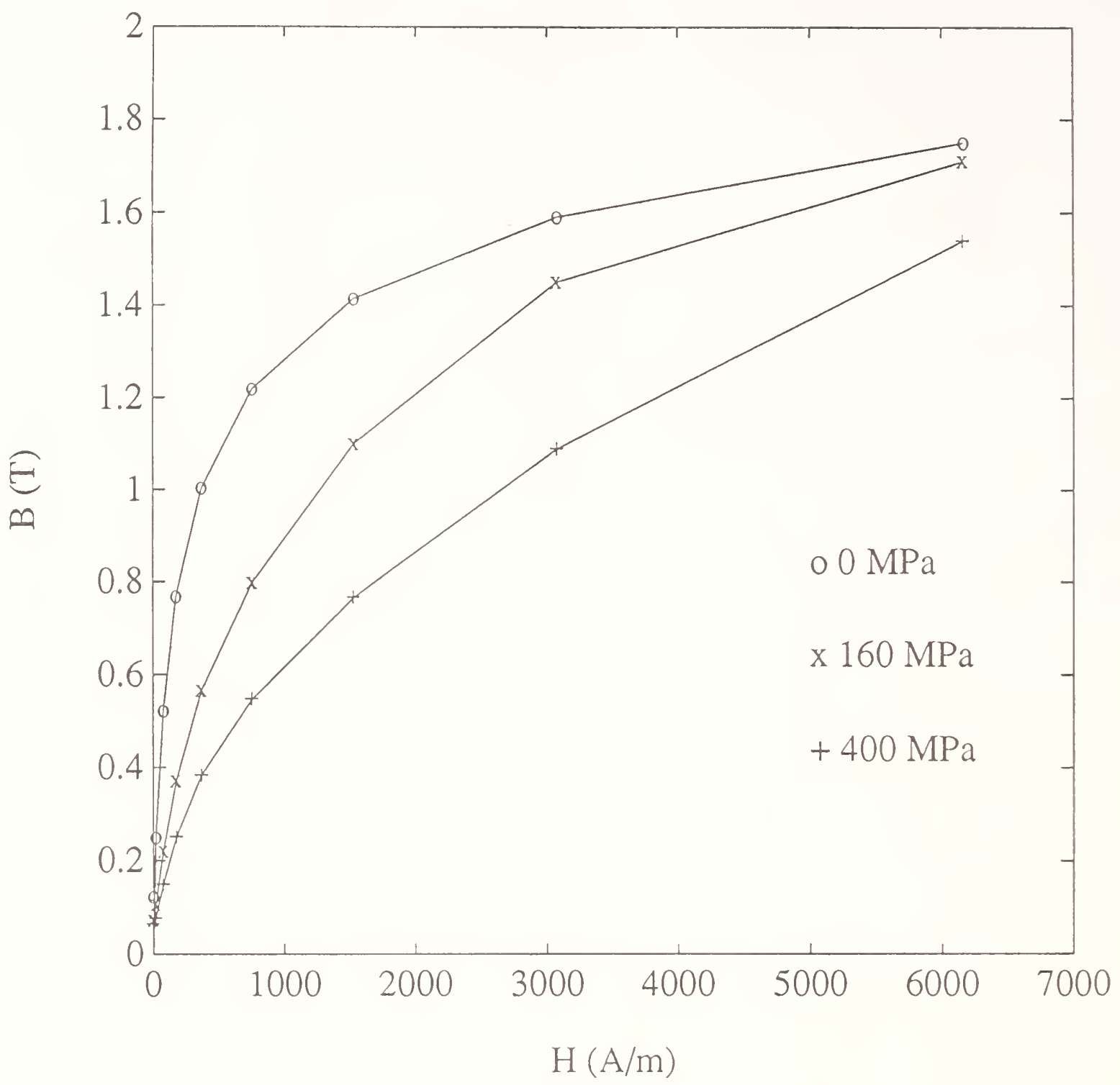

Figure D-7. Anhysteretic magnetization curves for positive transverse stresses (tension) ranging from 0 to $400 \mathrm{MPa}$ as described by (5) in the test plan. 


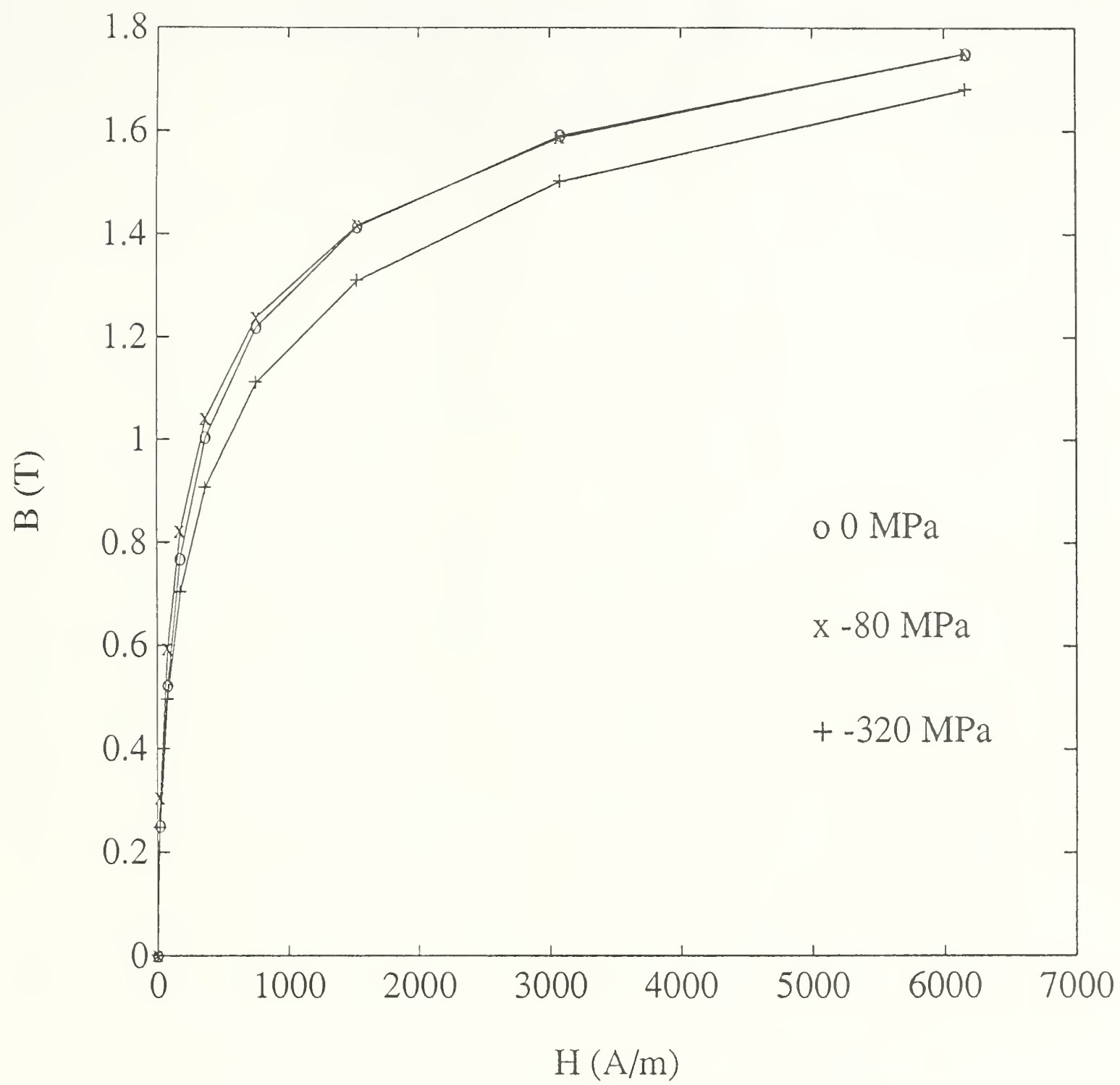

Figure D-8. Anhysteretic magnetization curves for negative transverse stresses (compression) ranging from 0 to $-400 \mathrm{MPa}$ as described by (5) in the test plan. 


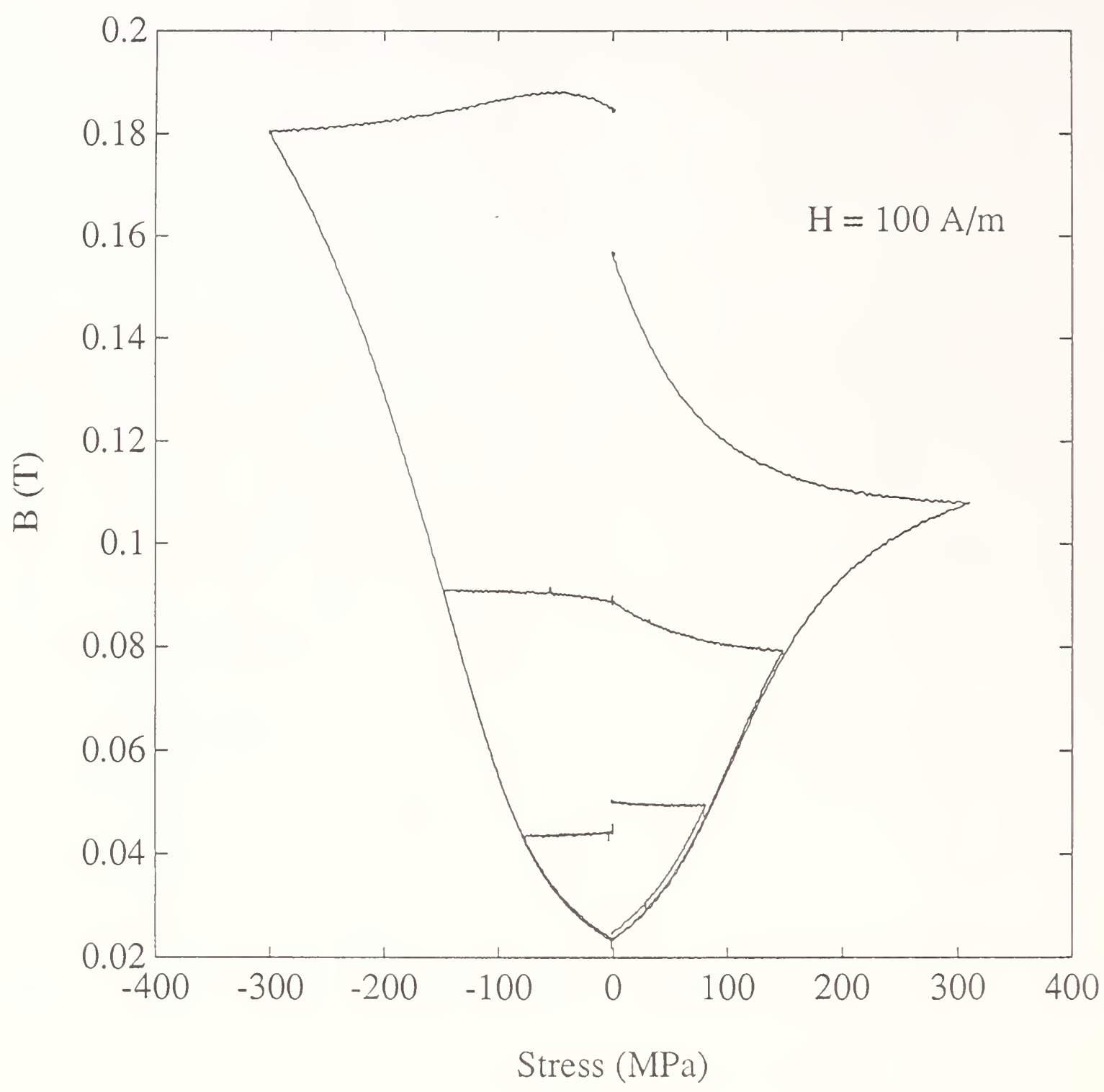

Figure D-9. Magnetic induction as a function of applied transverse stresses ranging from -300 to $300 \mathrm{MPa}$ as described by (6) in the test plan. The dc magnetic field was $100 \mathrm{~A} / \mathrm{m}$. 


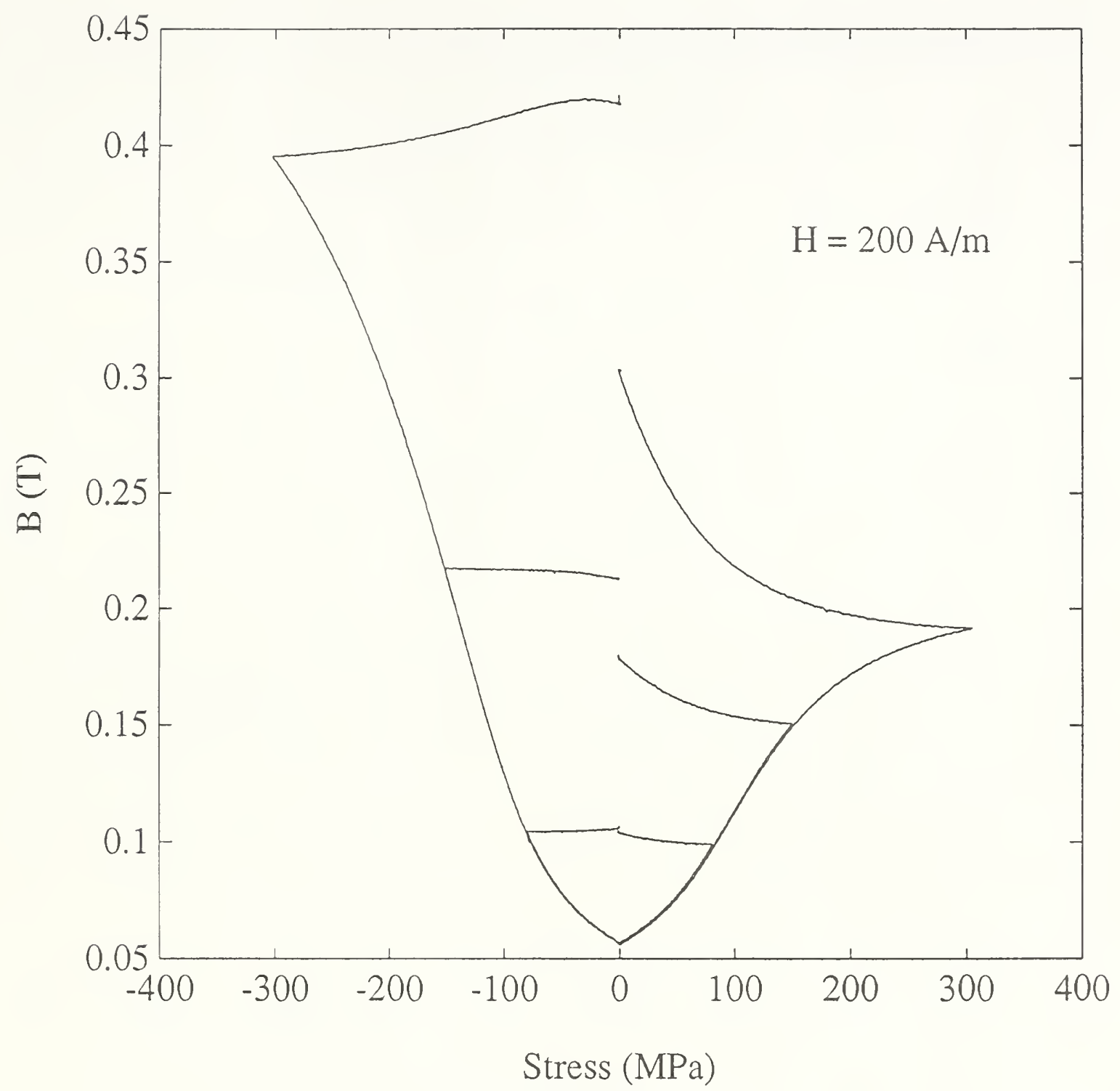

Figure D-10. Magnetic induction as a function of applied transverse stresses ranging from -300 to $300 \mathrm{MPa}$ as described by (6) in the test plan. The dc magnetic field was $200 \mathrm{~A} / \mathrm{m}$. 


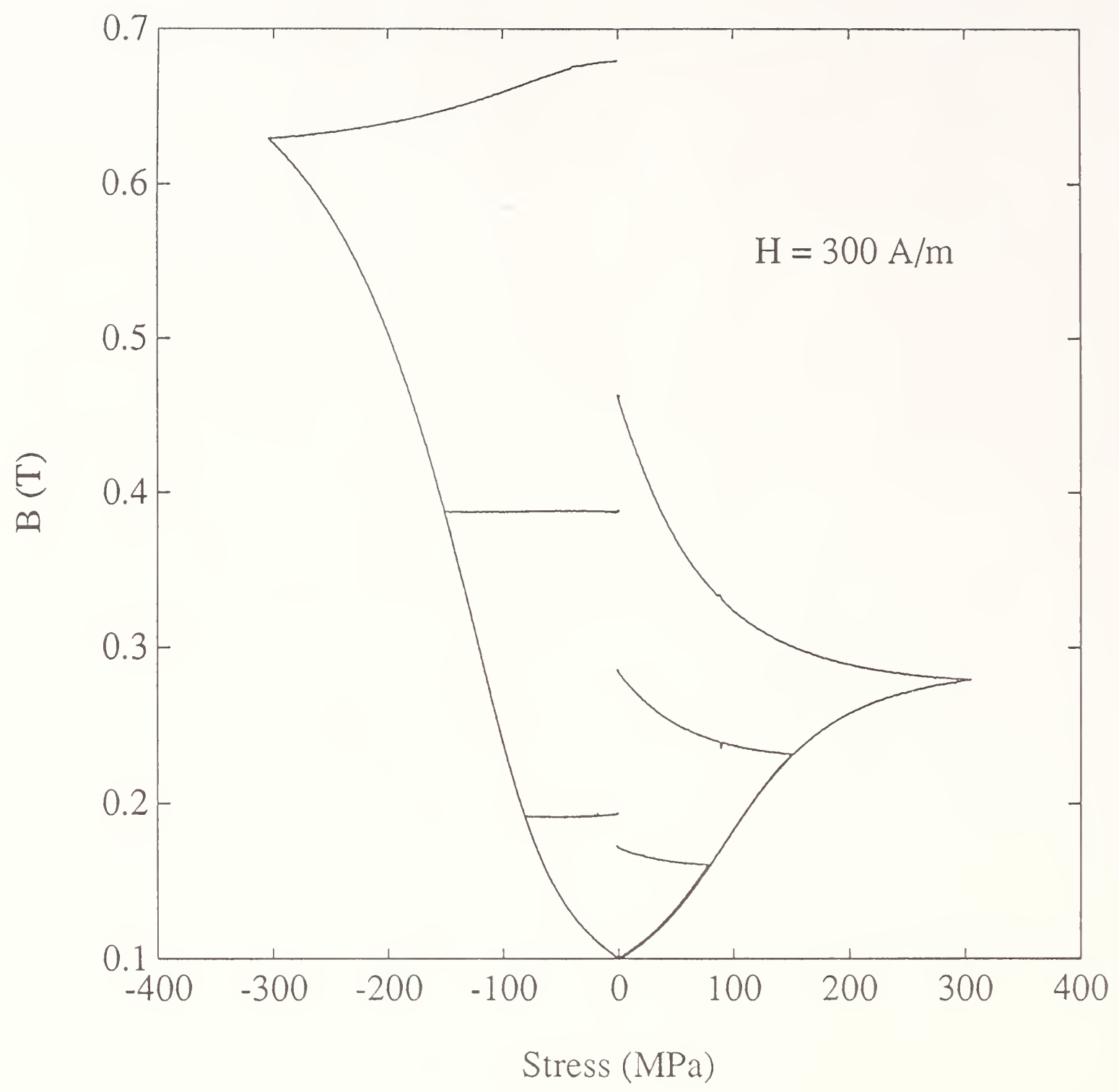

Figure D-11. Magnetic induction as a function of applied transverse stresses ranging from -300 to $300 \mathrm{MPa}$ as described by (6) in the test plan. The dc magnetic field was $300 \mathrm{~A} / \mathrm{m}$. 


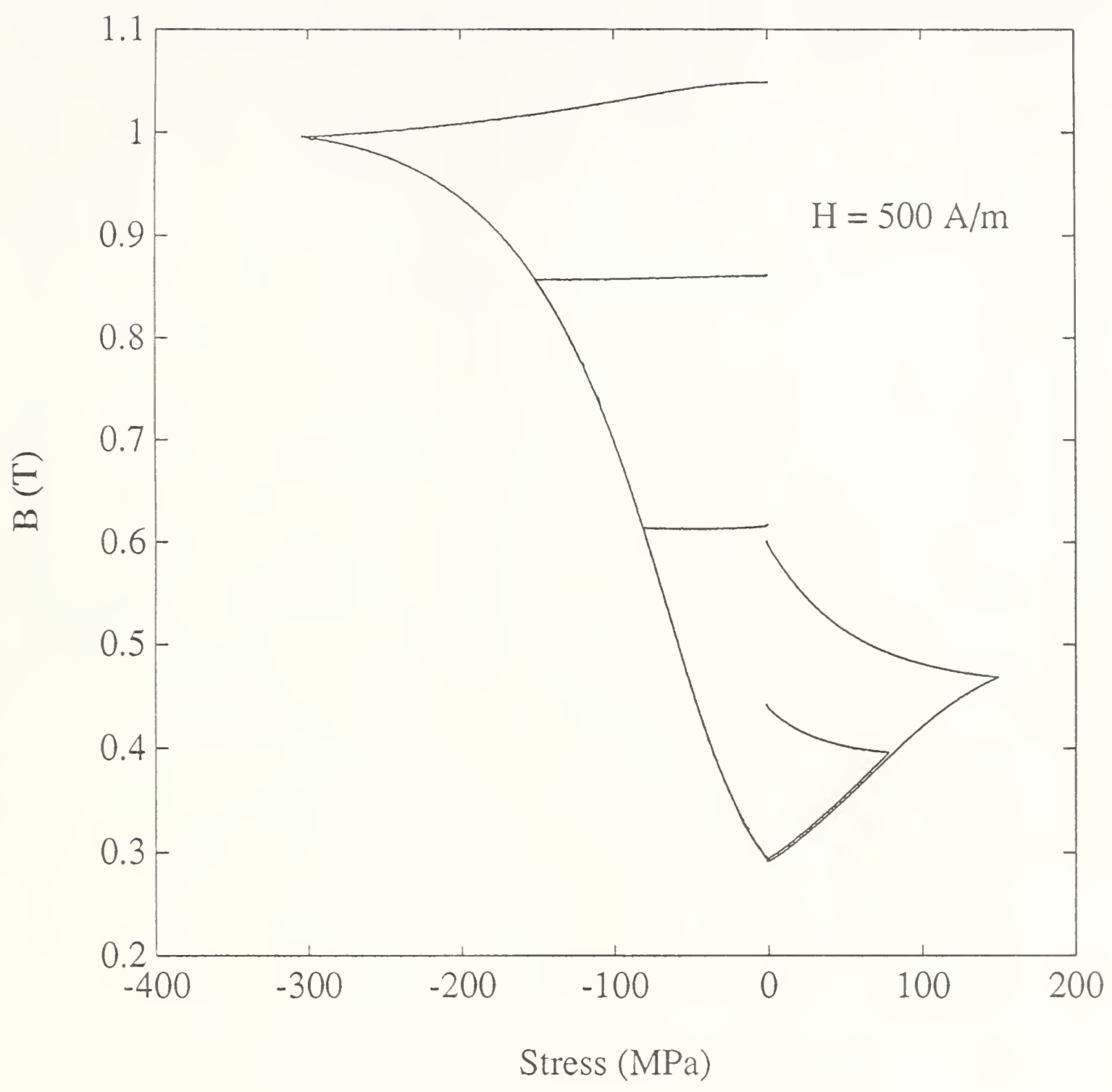

Figure D-12. Magnetic induction as a function of applied transverse stresses ranging from -300 to $300 \mathrm{MPa}$ as described by (6) in the test plan. The dc magnetic field was $500 \mathrm{~A} / \mathrm{m}$. 


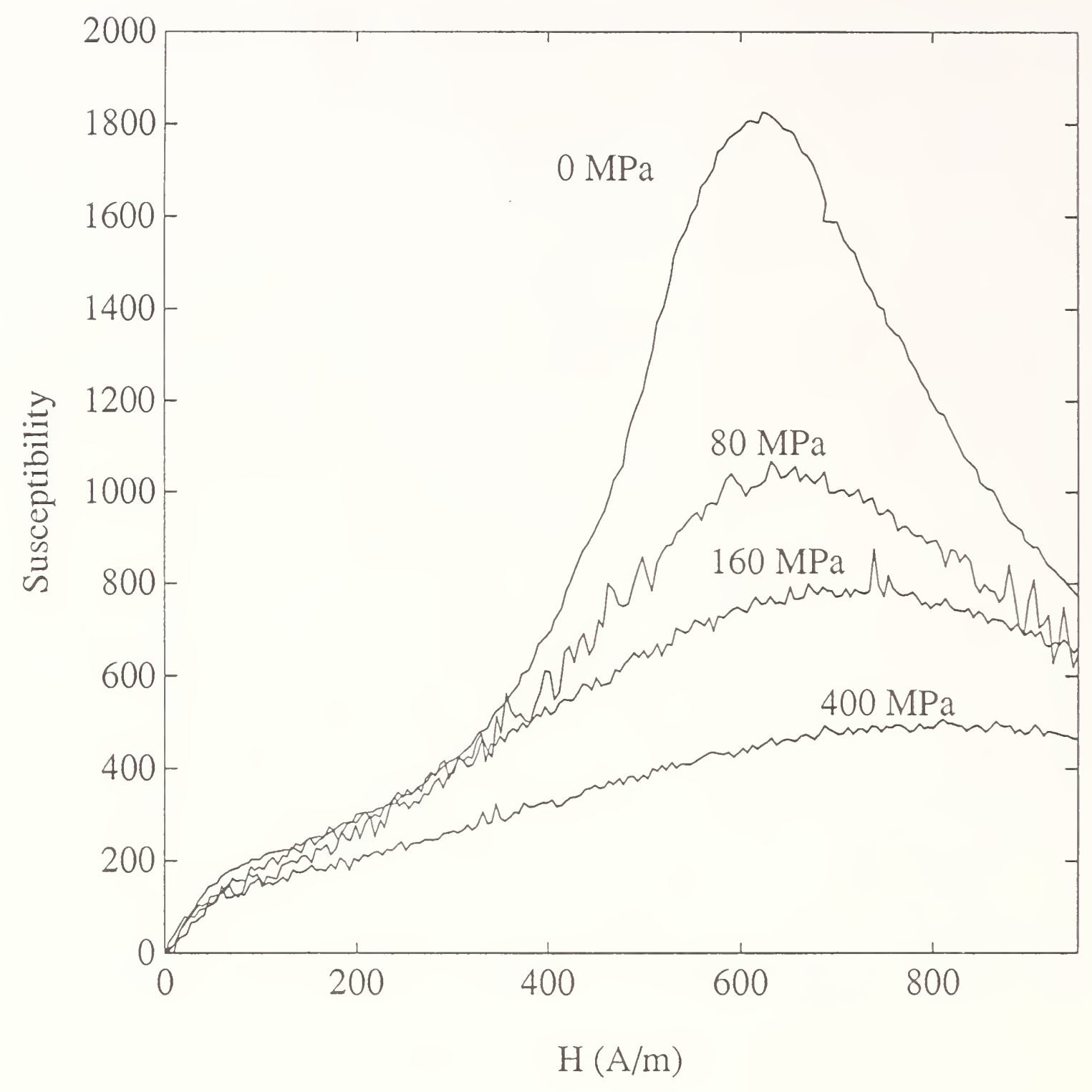

Figure D-13. Susceptibility as a function of applied magnetic field strength for transverse positive stresses (tension) ranging from 0 to $400 \mathrm{MPa}$ as described by (7) in the test plan. 


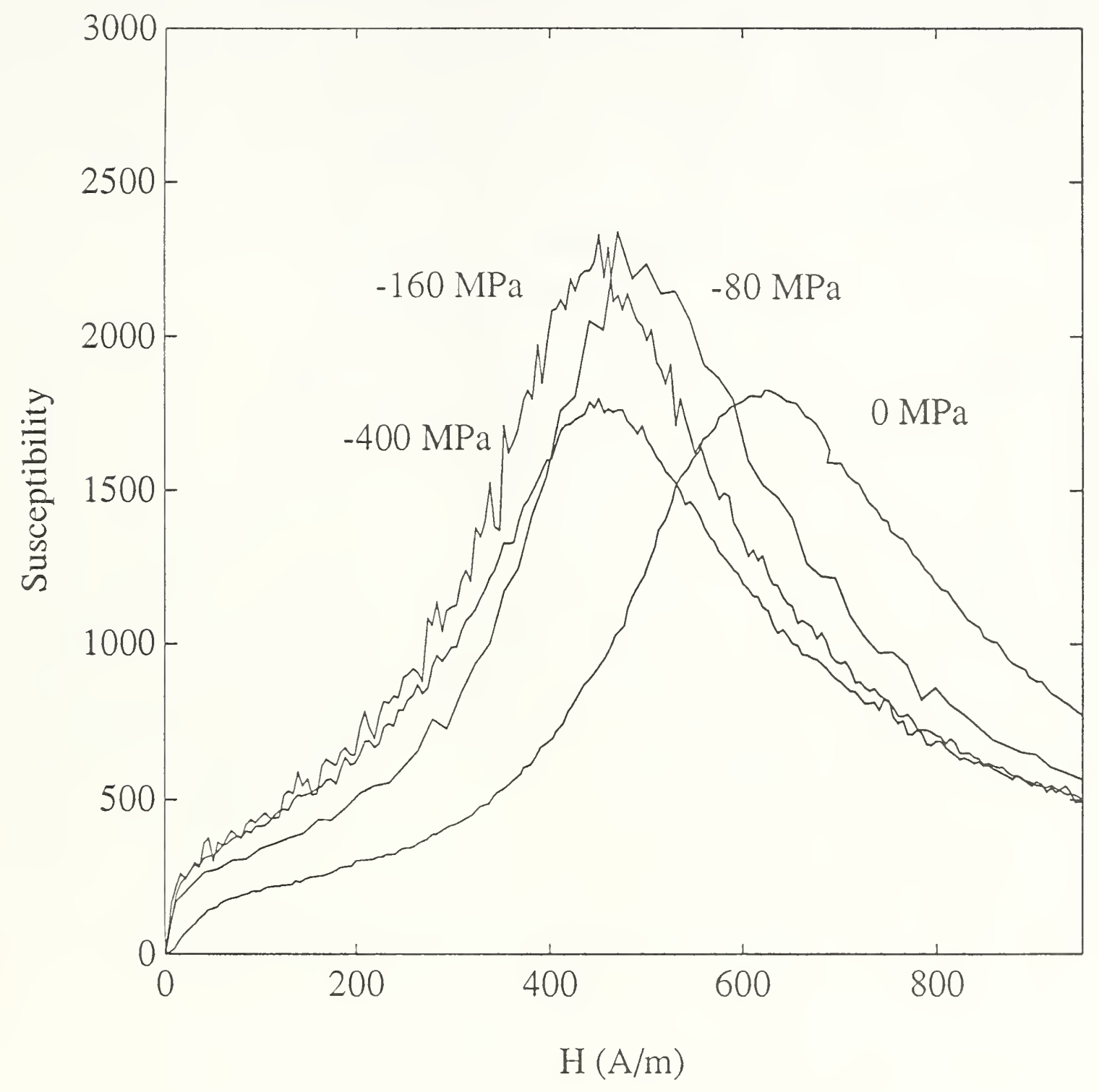

Figure D-14. Susceptibility as a function of applied magnetic field strength for transverse negative stresses (compression) ranging from 0 to $-400 \mathrm{MPa}$ as described by (7) in the test plan. 


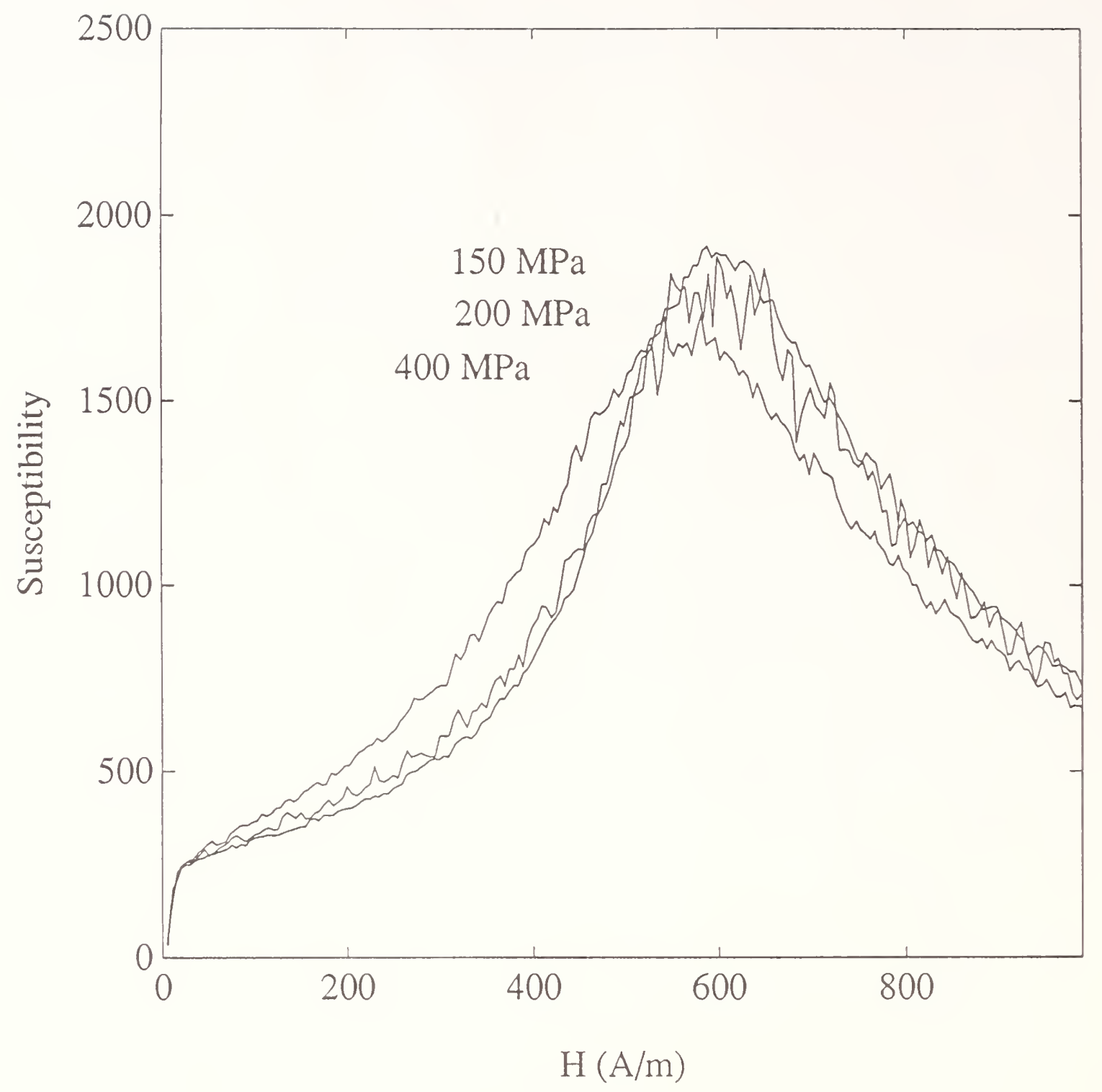

Figure D-15. Susceptibility as a function of applied magnetic field strength after the application and release of positive transverse stresses ranging from 50 to 400 $\mathrm{MPa}$. The measurement is described by (8) in the test plan. 


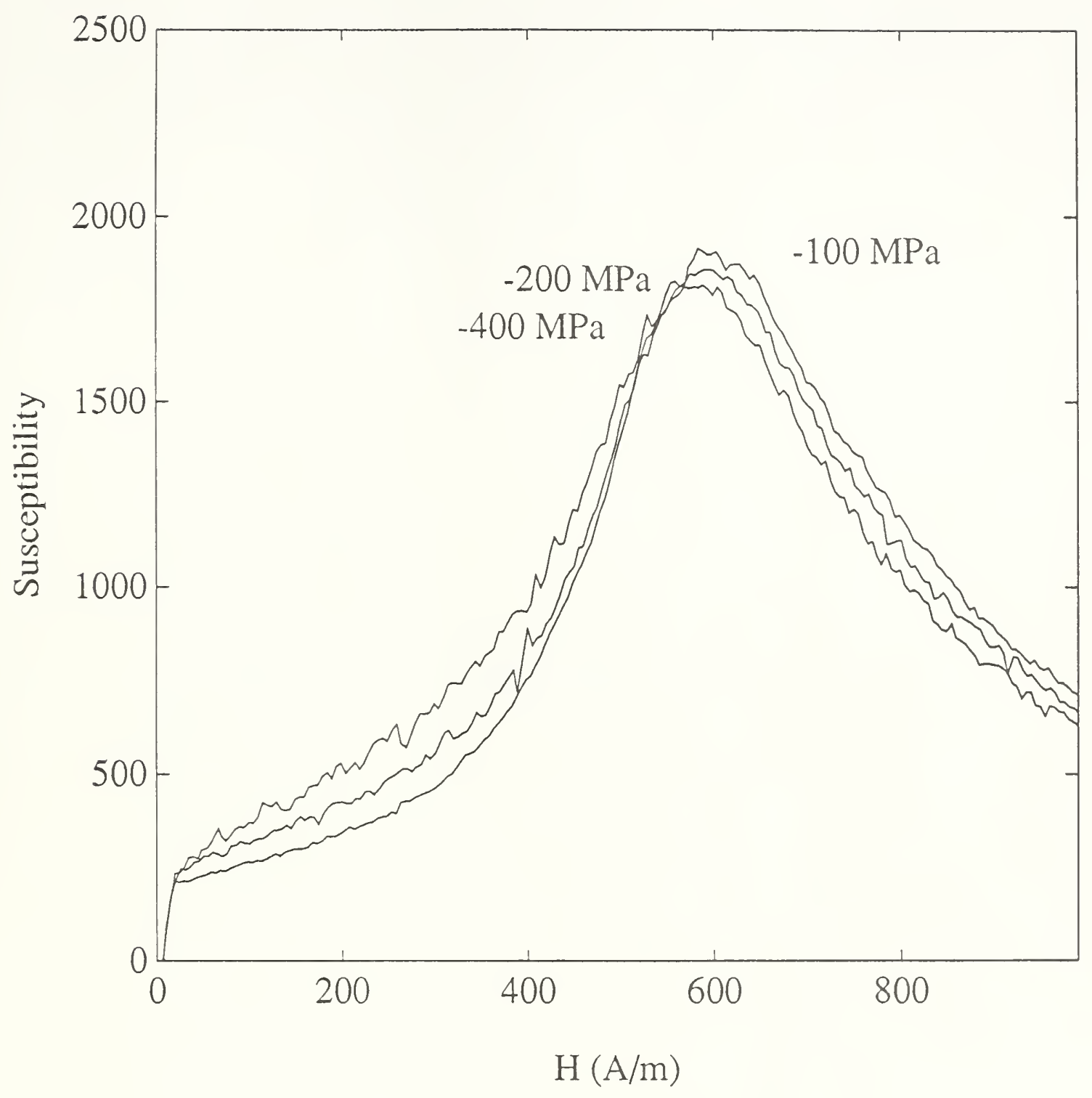

Figure D-16. Susceptibility as a function of applied magnetic field strength after the application and release of negative transverse stresses ranging from -50 to $-400 \mathrm{MPa}$. The measurement is described by (8) in the test plan. 


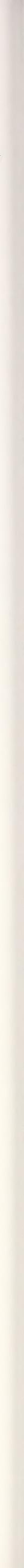


Appendix E 


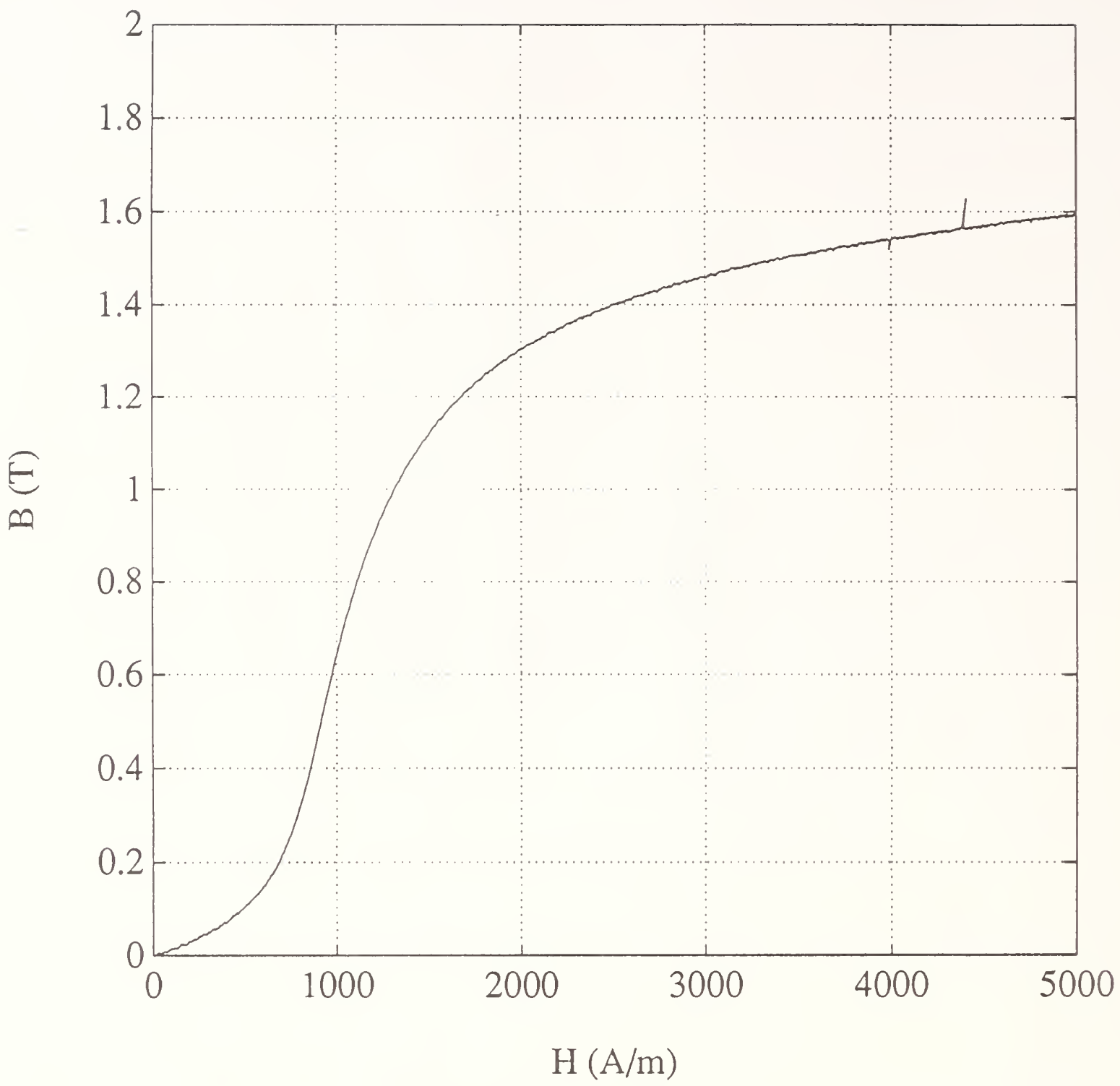

Figure E-1. Normal unstressed magnetization curve as described by (1) in the test plan. 


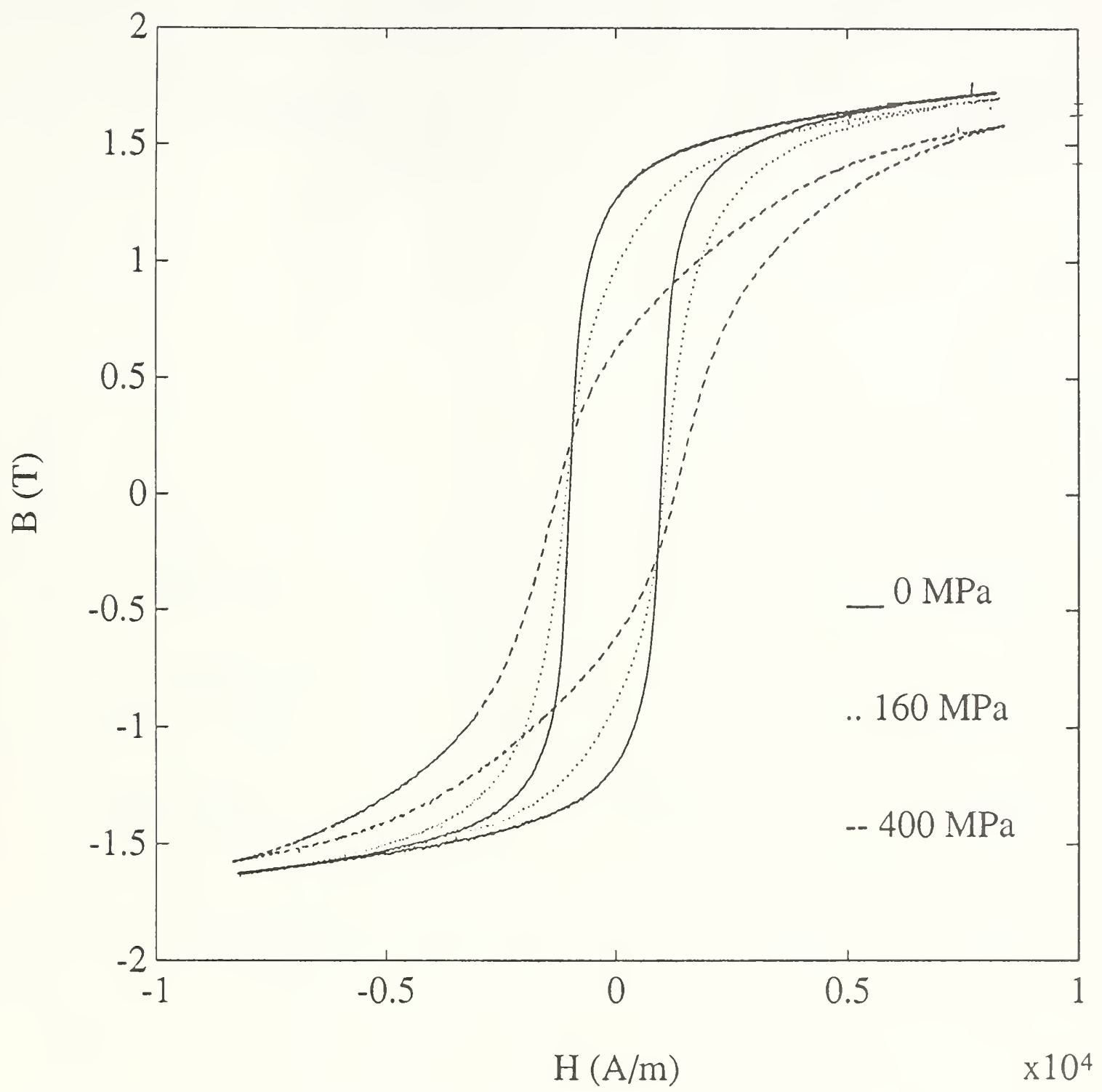

Figure E-2. Magnetic induction as a function of applied magnetic field strength for positive transverse stress (tension) ranging from 0 to $400 \mathrm{MPa}$ as described by (2) in the test plan. The stress results in an effective demagnetizing field which shears the hysteresis loop. 


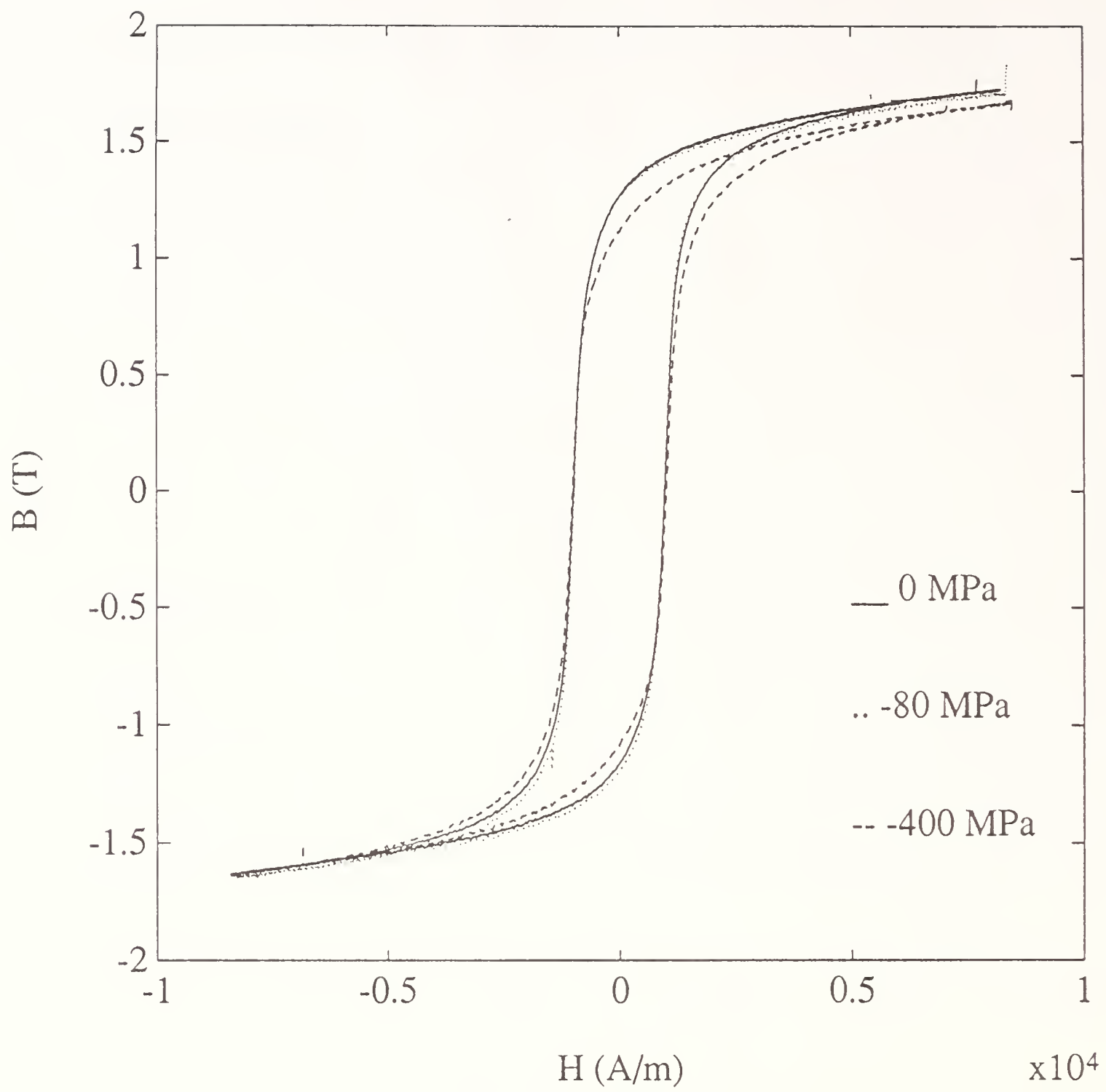

Figure E-3. Magnetic induction as a function of applied magnetic field strength for negative transverse stresses (compression) ranging from 0 to $-400 \mathrm{MPa}$ as described by (2) in the test plan. 


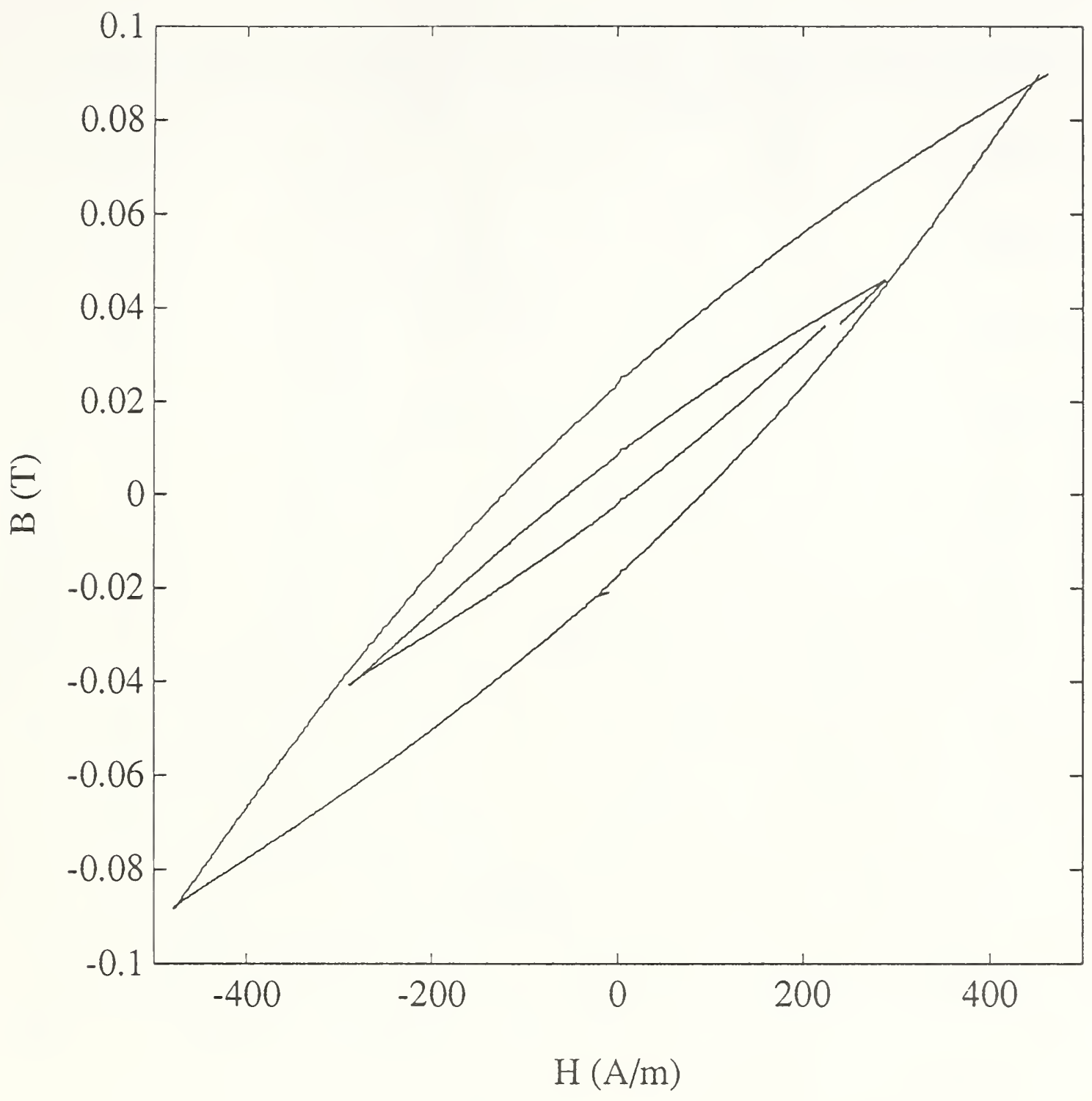

Figure E-4. Magnetic induction as a function of applied magnetic field strength for maximum fields of 200 and $400 \mathrm{~A} / \mathrm{m}$ as described by (3) in the test plan. 


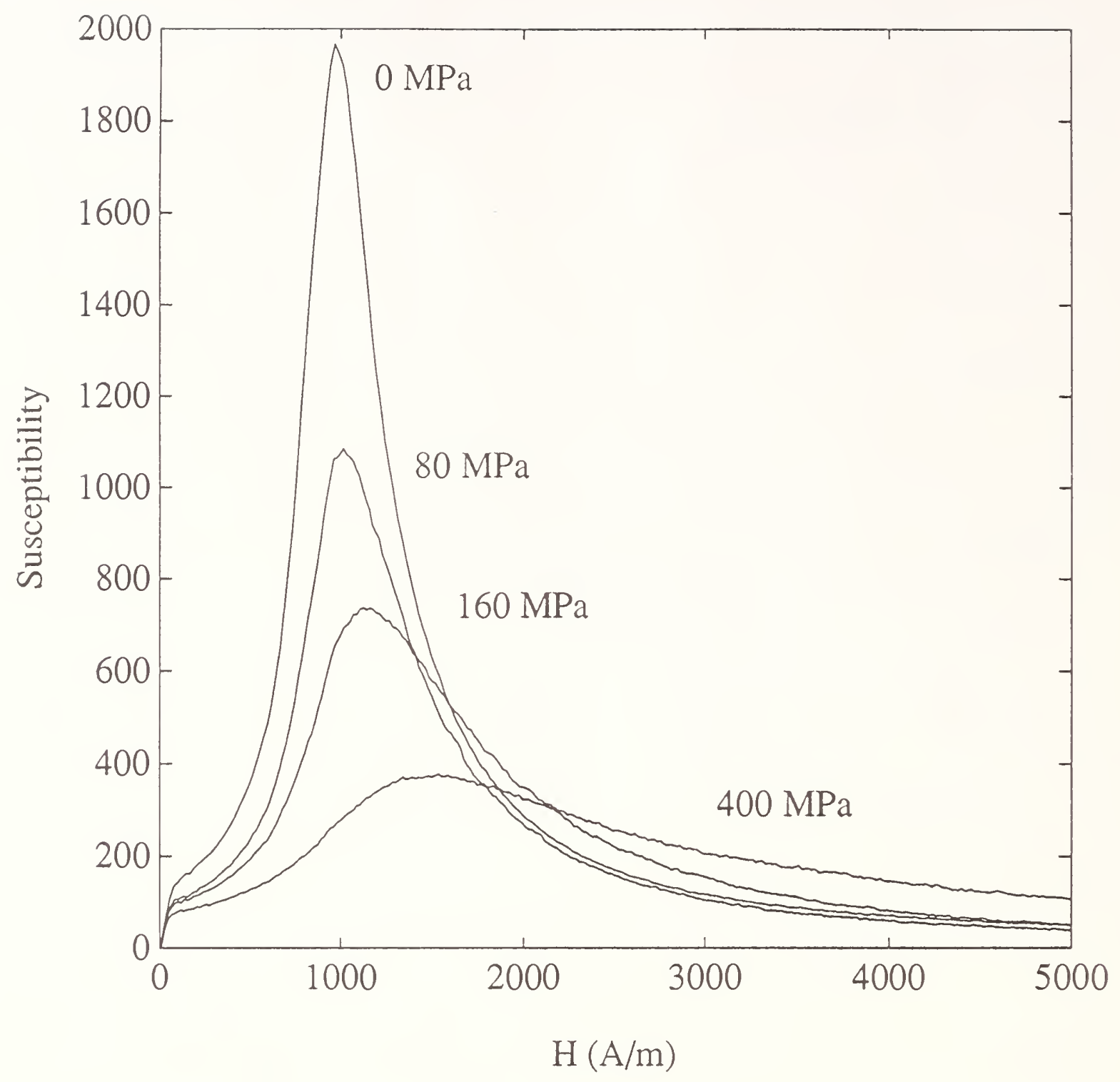

Figure E-5. Susceptibility as a function of applied magnetic field strength for positive transverse stresses (tension) ranging from 0 to $400 \mathrm{MPa}$ as described by (4) in the test plan. 


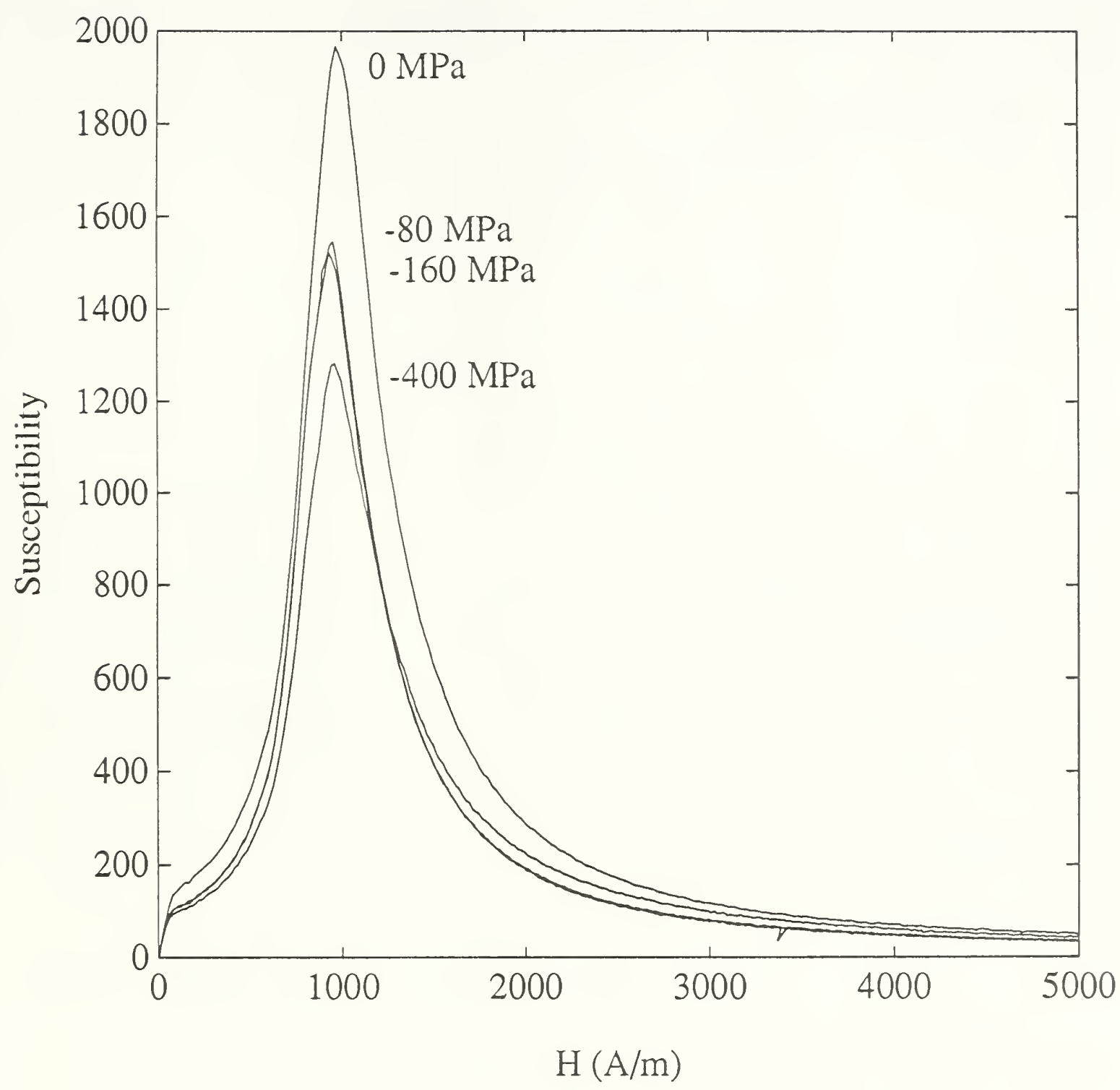

Figure E-6. Susceptibility as a function of applied magnetic field strength for negative transverse stresses (compression) ranging from 0 to $-400 \mathrm{MPa}$ as described by (4) in the test plan. 


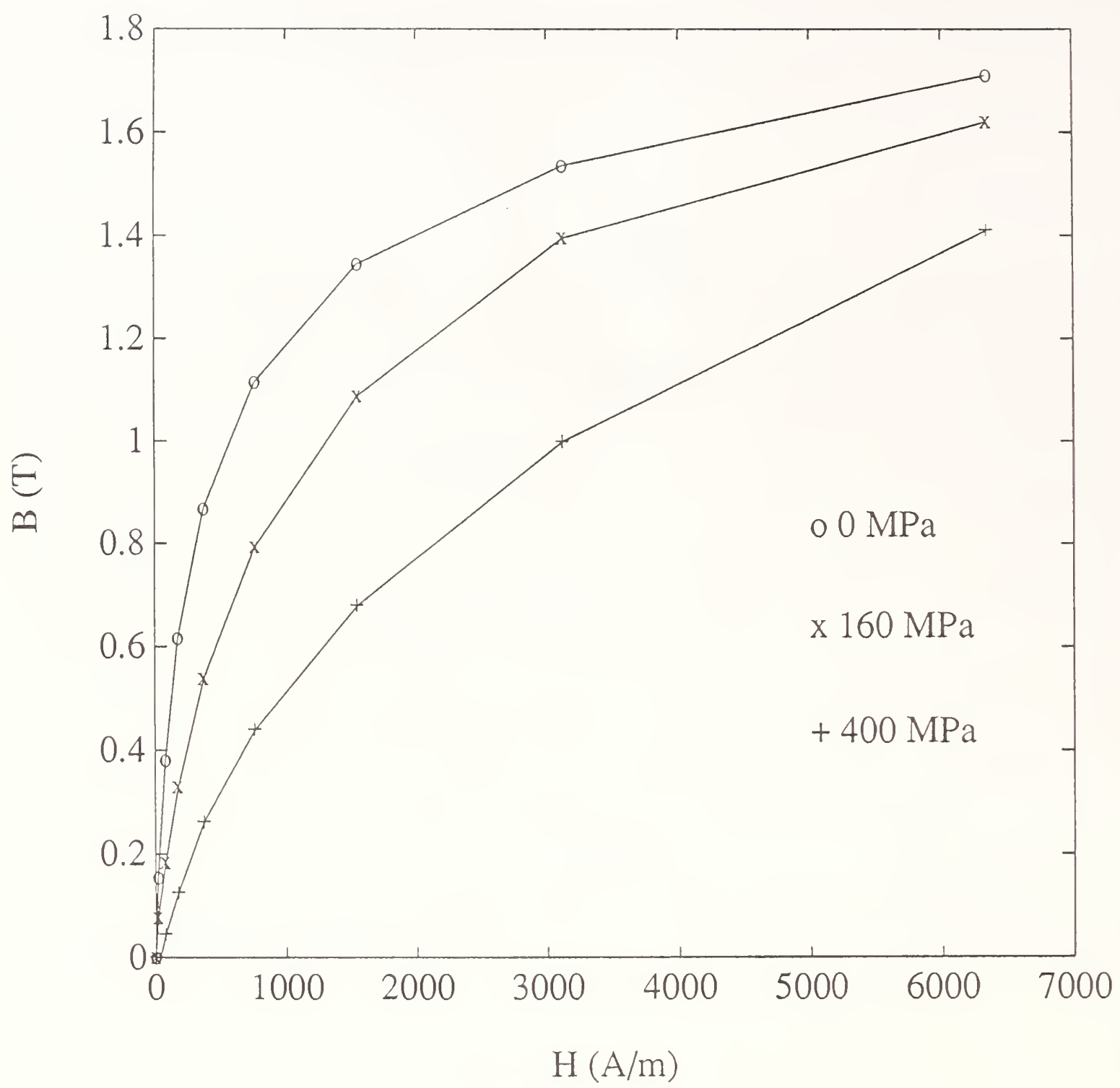

Figure E-7. Anhysteretic magnetization curves for positive transverse stresses (tension) ranging from 0 to $400 \mathrm{MPa}$ as described by (5) in the test plan. 


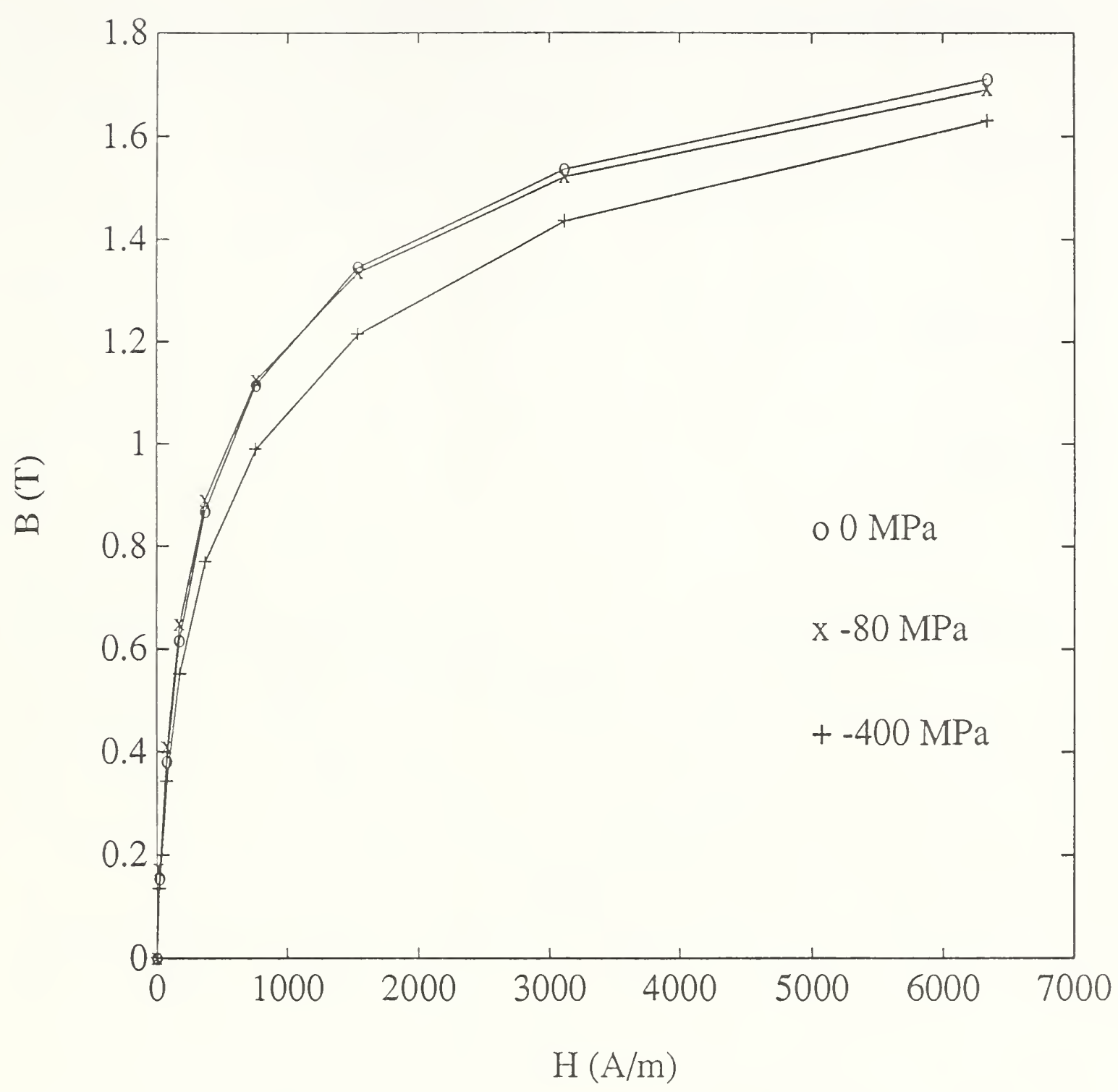

Figure E-8. Anhysteretic magnetization curves for negative transverse stresses (compression) ranging from 0 to $-400 \mathrm{MPa}$ as described by (5) in the test plan. 


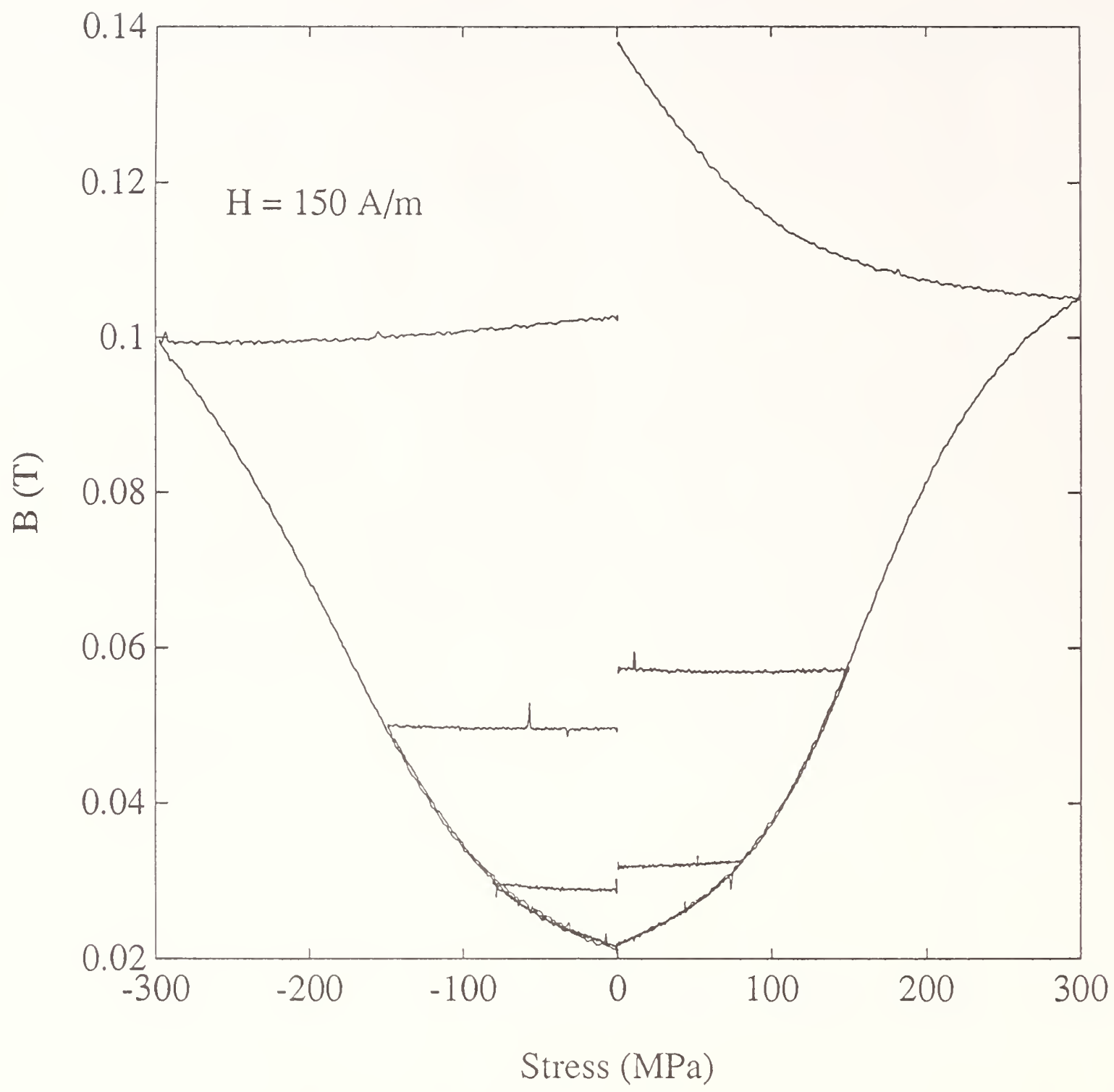

Figure E-9. Magnetic induction as a function of applied transverse stresses ranging from -300 to $300 \mathrm{MPa}$ as described by (6) in the test plan. The dc magnetic field was $150 \mathrm{~A} / \mathrm{m}$. 


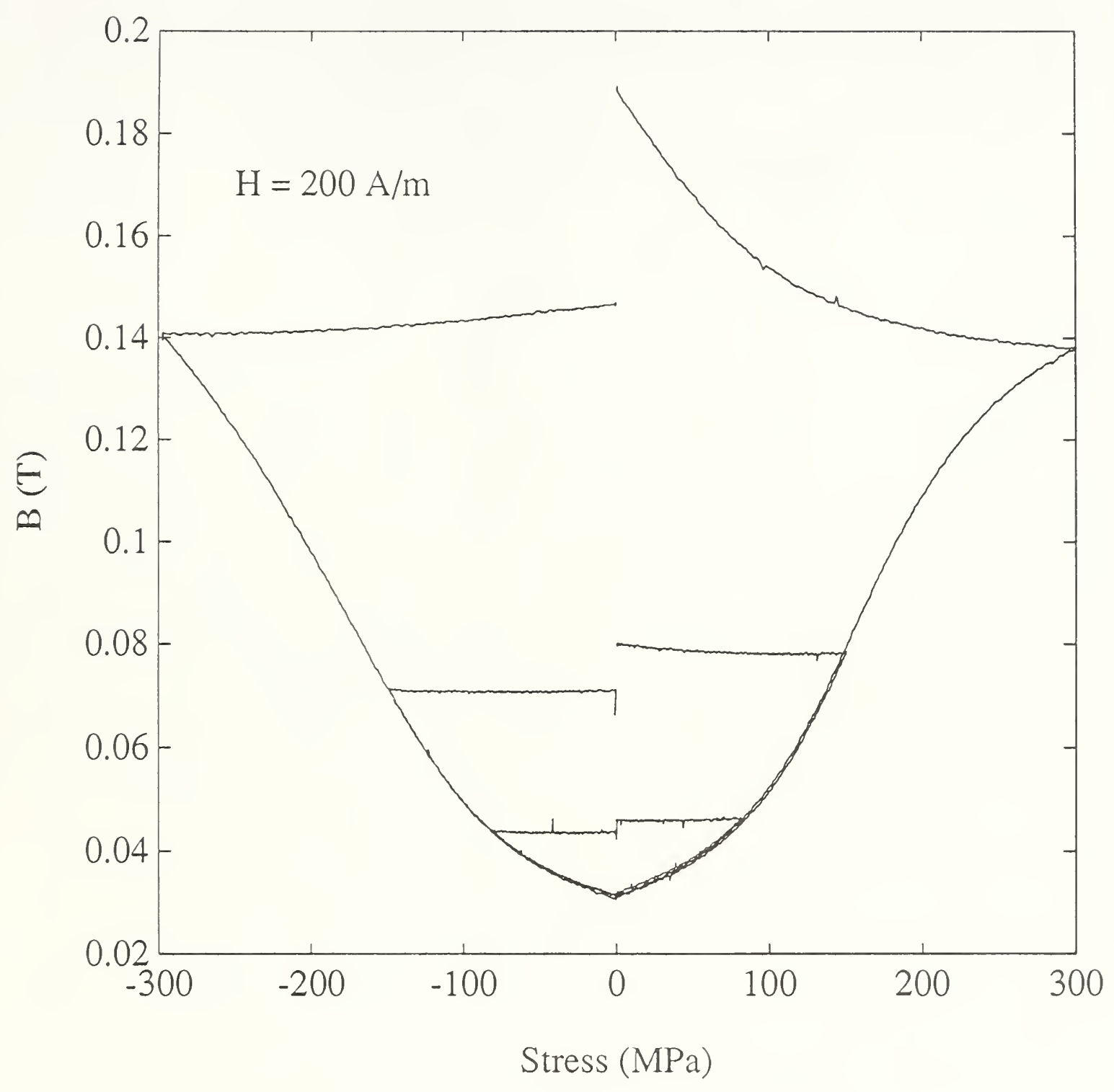

Figure E-10. Magnetic induction as a function of applied transverse stresses ranging from -300 to $300 \mathrm{MPa}$ as described by (6) in the test plan. The dc magnetic field was $200 \mathrm{~A} / \mathrm{m}$. 


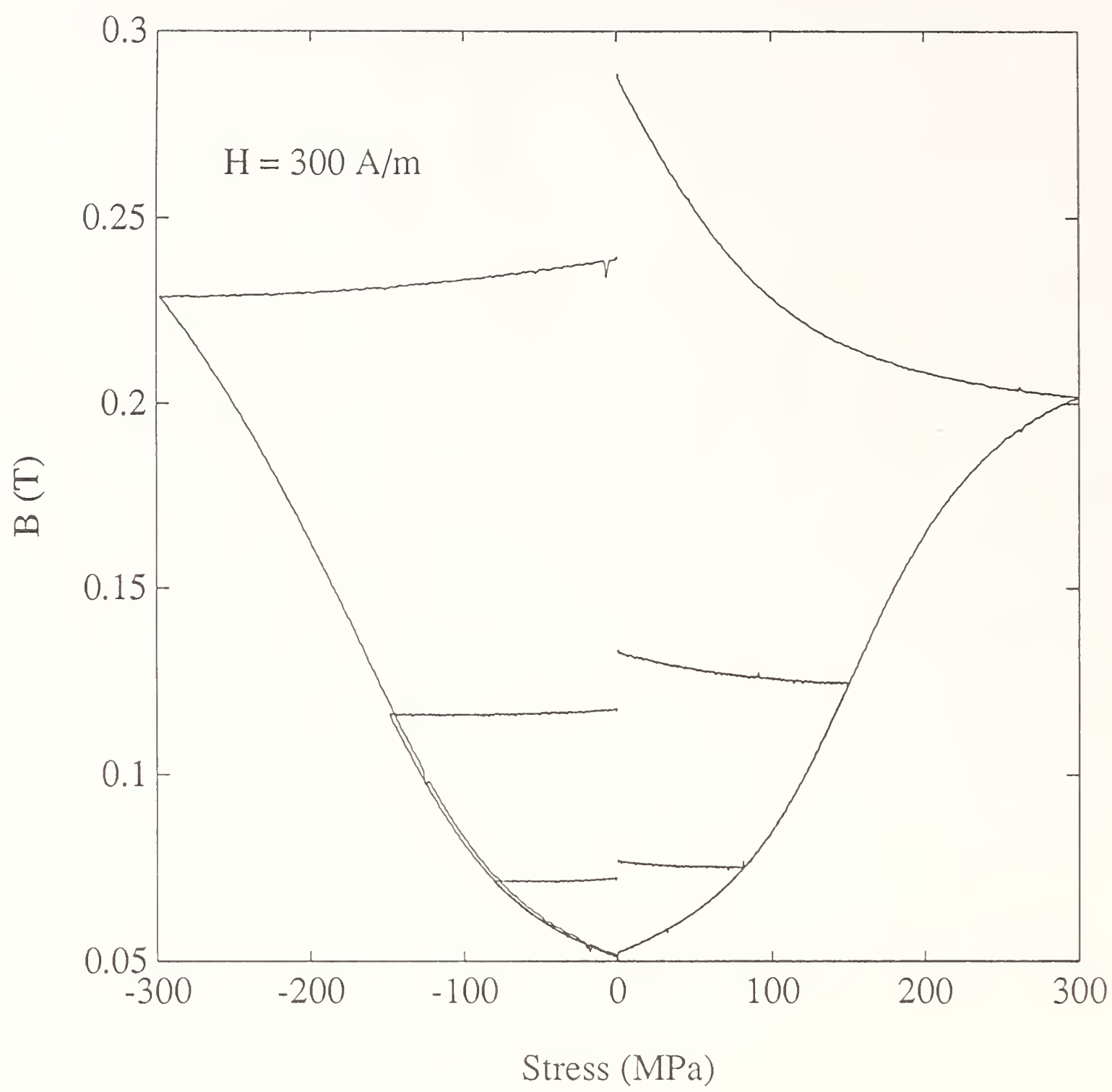

Figure E-11. Magnetic induction as a function of applied transverse stresses ranging from -300 to $300 \mathrm{MPa}$ as described by (6) in the test plan. The dc magnetic field was $300 \mathrm{~A} / \mathrm{m}$. 


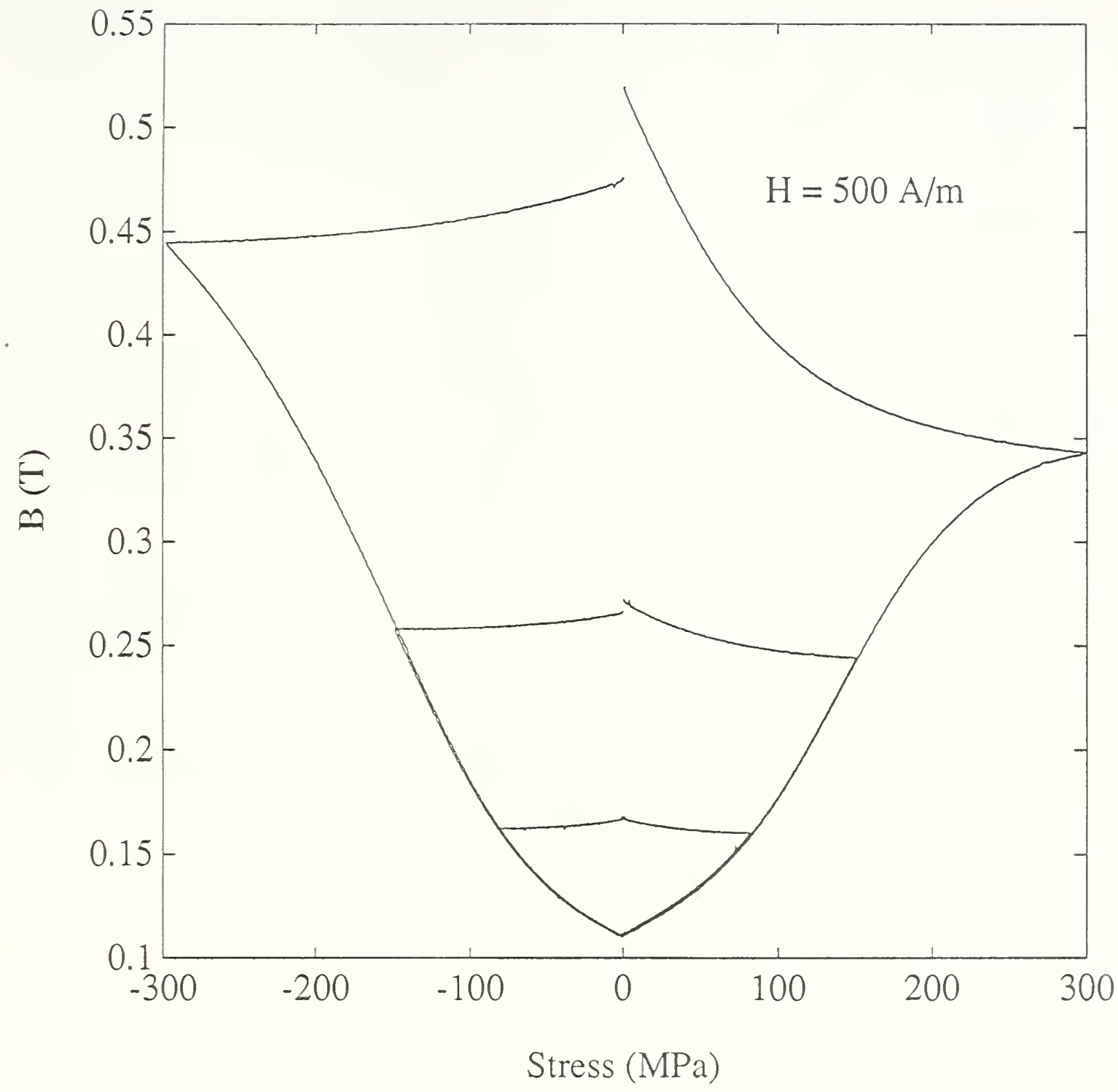

Figure E-12. Magnetic induction as a function of applied transverse stresses ranging from -300 to $300 \mathrm{MPa}$ as described by (6) in the test plan. The dc magnetic field was $500 \mathrm{~A} / \mathrm{m}$. 


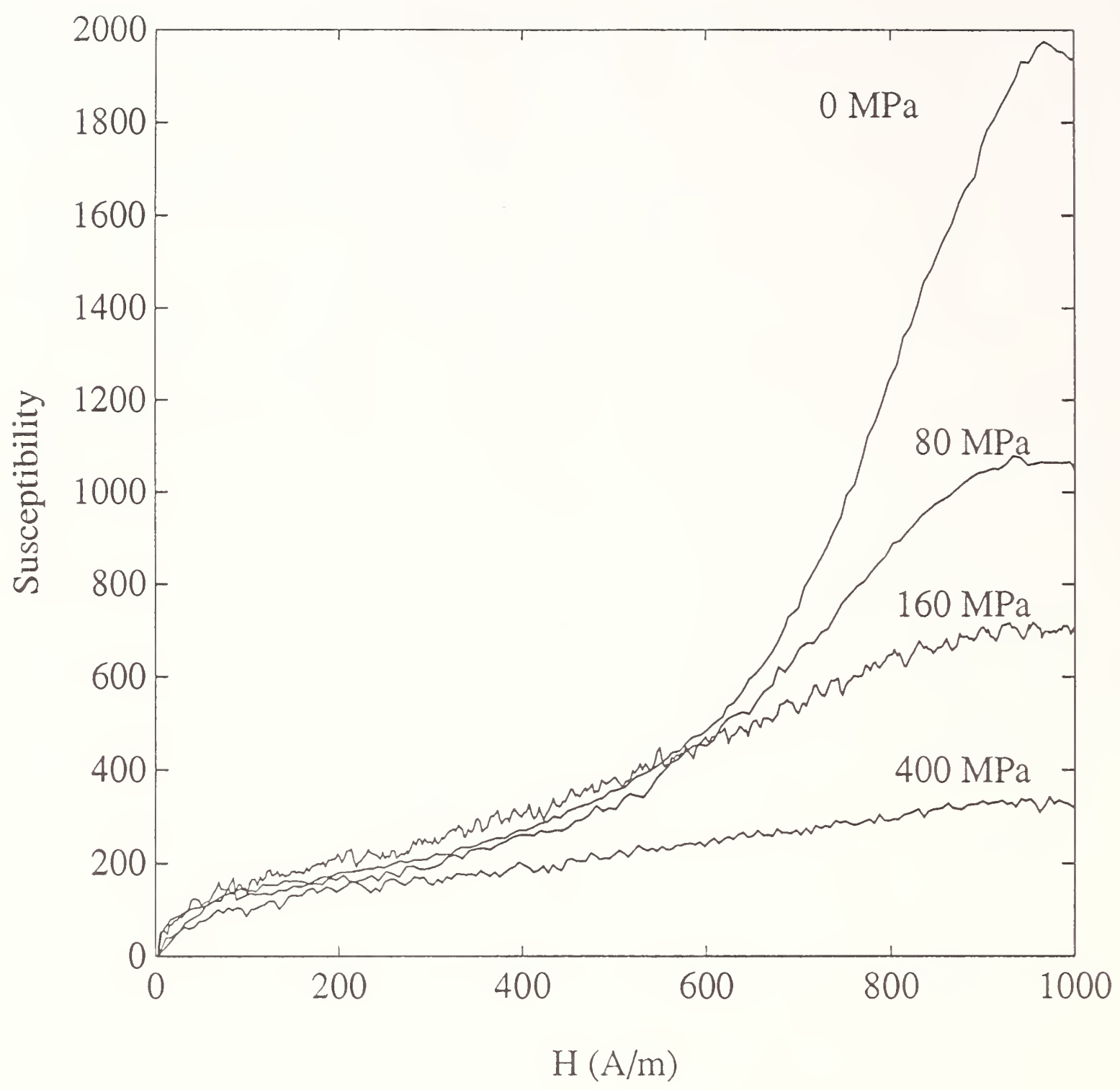

Figure E-13. Susceptibility as a function of applied magnetic field strength for transverse positive stresses (tension) ranging from 0 to $400 \mathrm{MPa}$ as described by (7) in the test plan. 


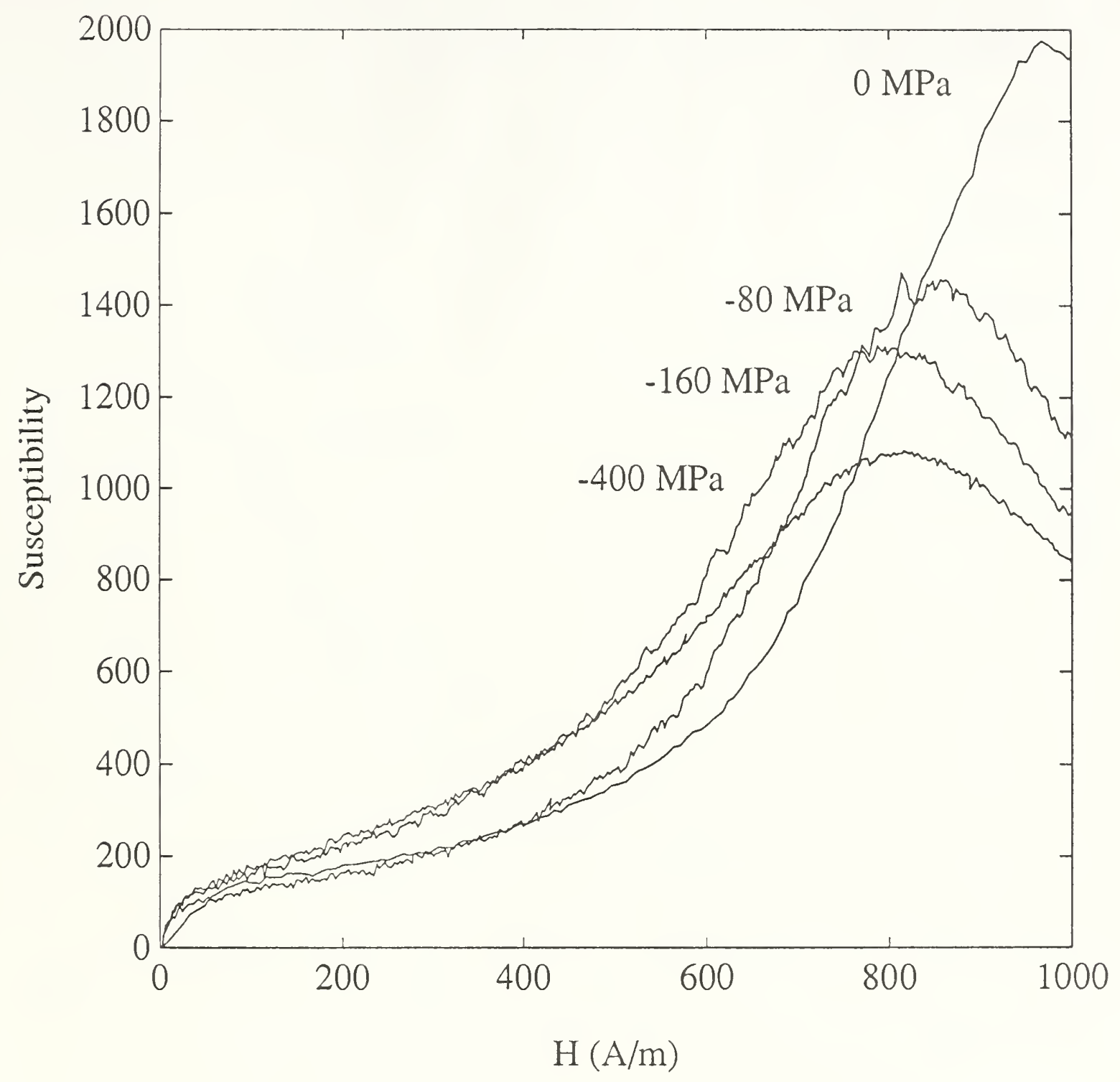

Figure E-14. Susceptibility as a function of applied magnetic field strength for transverse negative stresses (compression) ranging from 0 to $-400 \mathrm{MPa}$ as described by (7) in the test plan. 


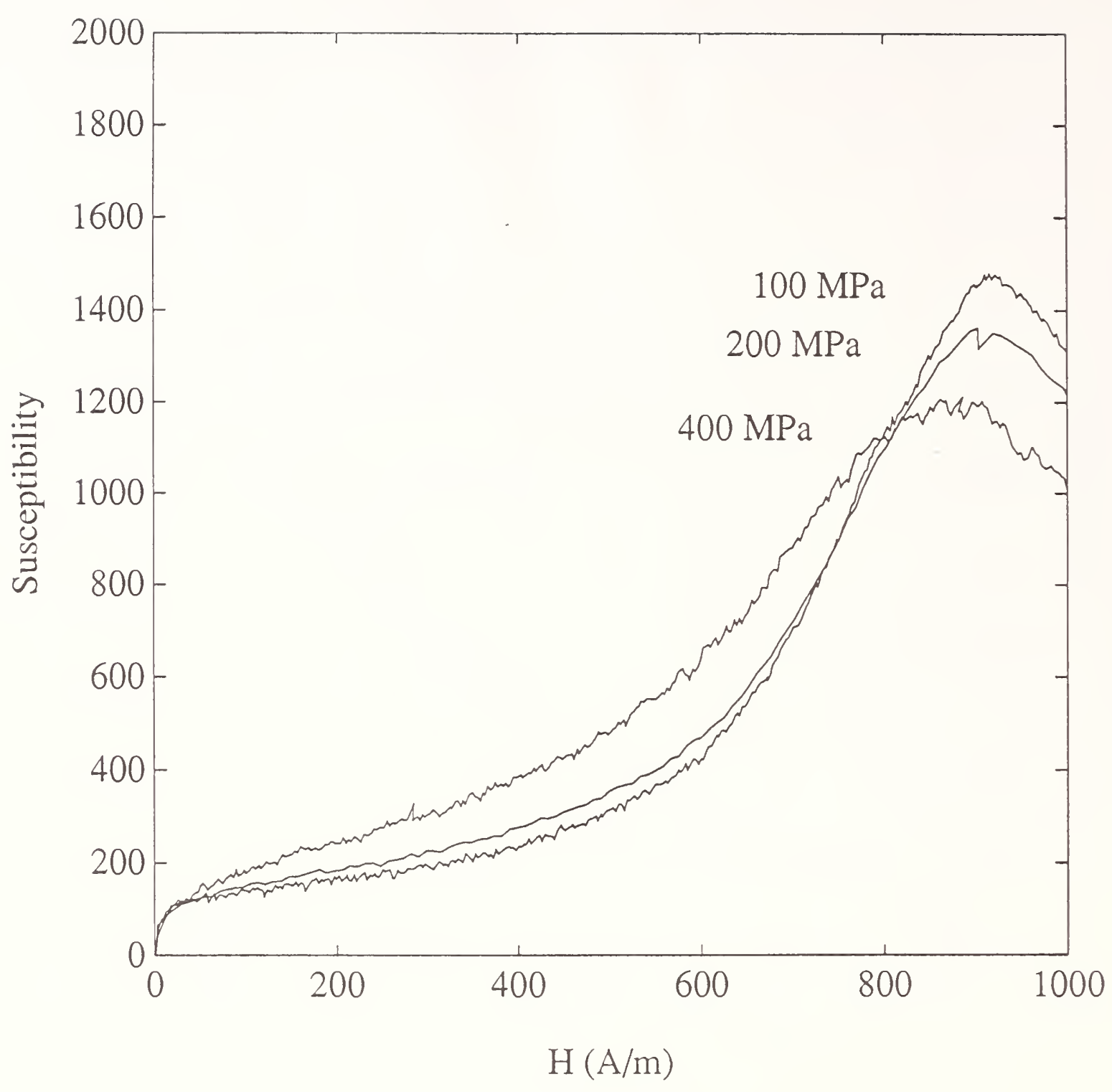

Figure E-15. Susceptibility as a function of applied magnetic field strength after the application and release of positive transverse stresses ranging from 50 to 400 $\mathrm{MPa}$. The measurement is described by (8) in the test plan. 


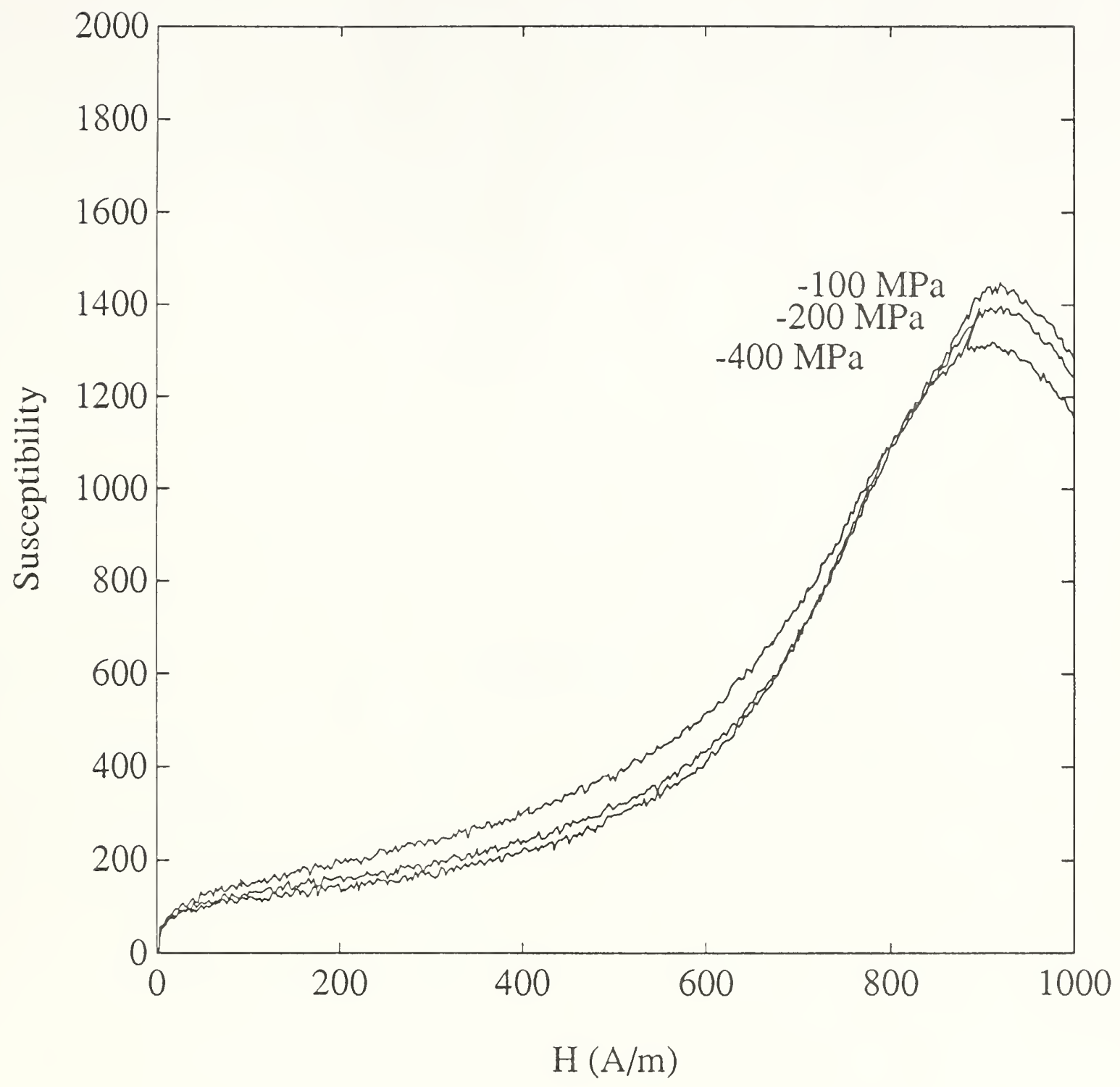

Figure E-16. Susceptibility as a function of applied magnetic field strength after the application and release of negative transverse stresses ranging from -50 to $-400 \mathrm{MPa}$. The measurement is described by (8) in the test plan. 


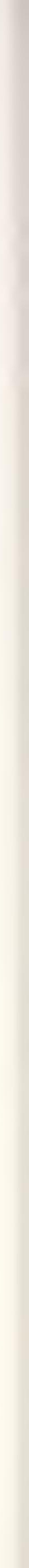


Appendix $\mathbf{F}$ 


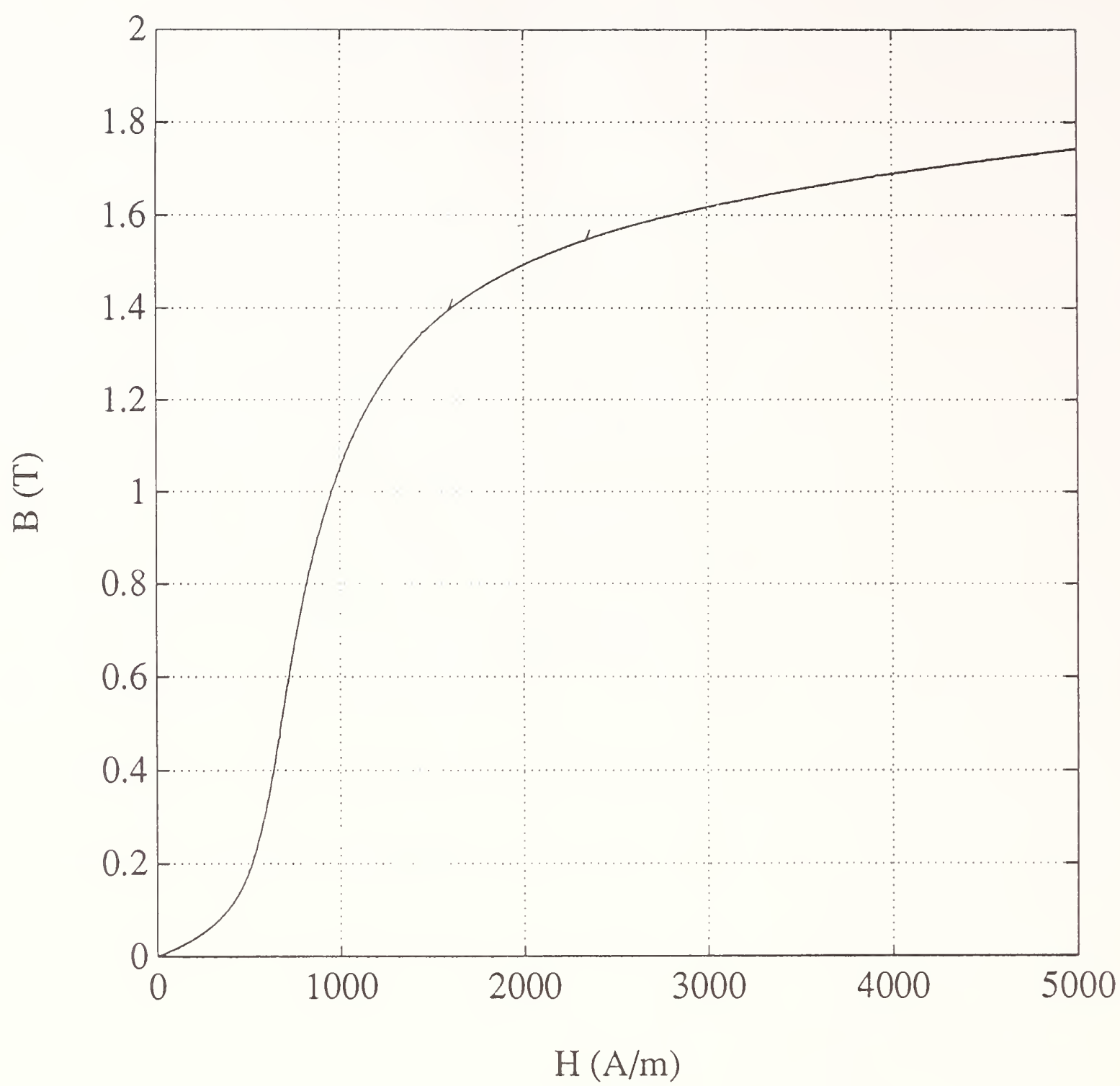

Figure F-1. Normal unstressed magnetization curve as described by (1) in the test plan. 


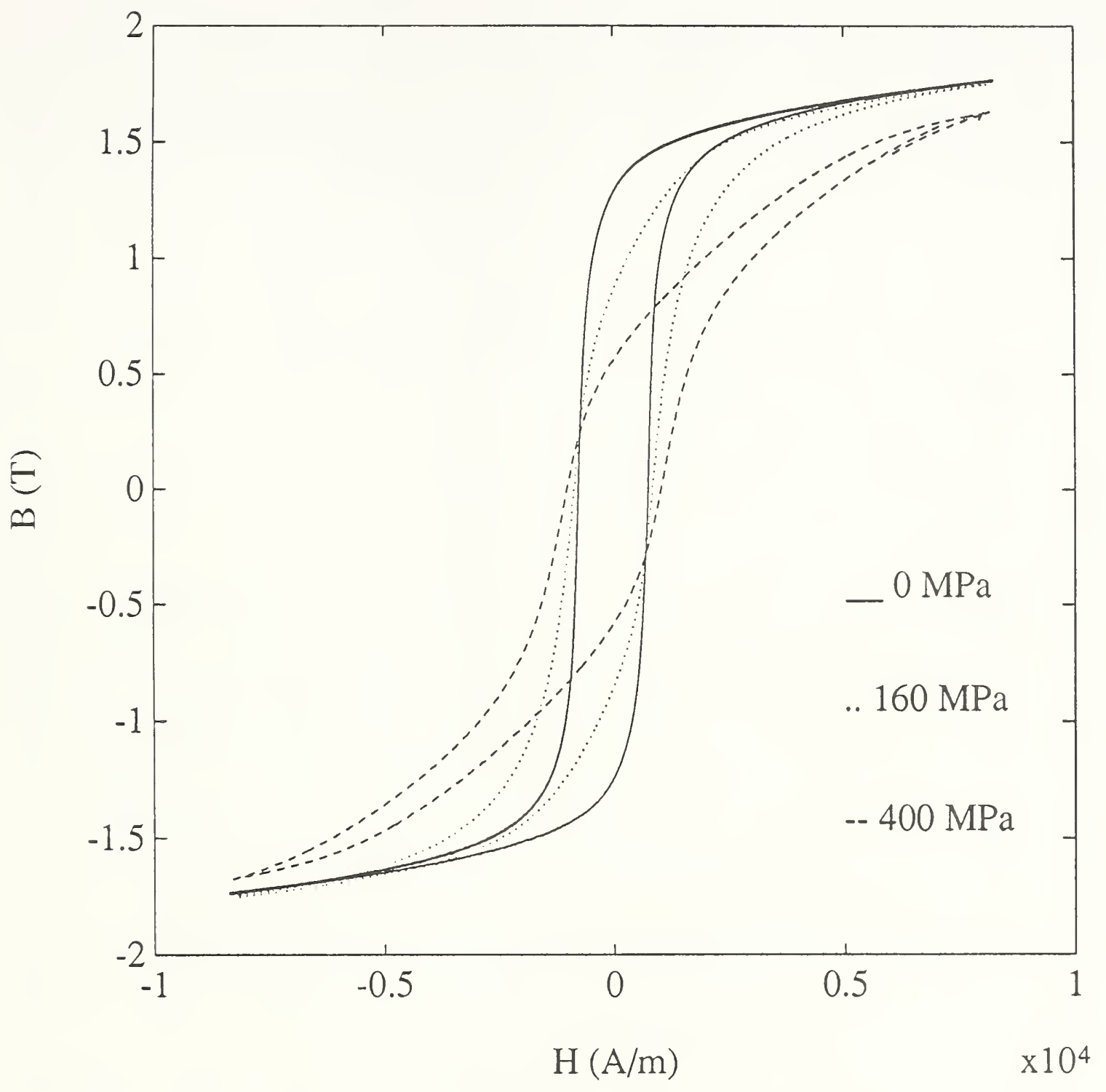

Figure F-2. Magnetic induction as a function of applied magnetic field strength for positive transverse stress (tension) ranging from 0 to $400 \mathrm{MPa}$ as described by (2) in the test plan. The stress results in an effective demagnetizing field which shears the hysteresis loop. 


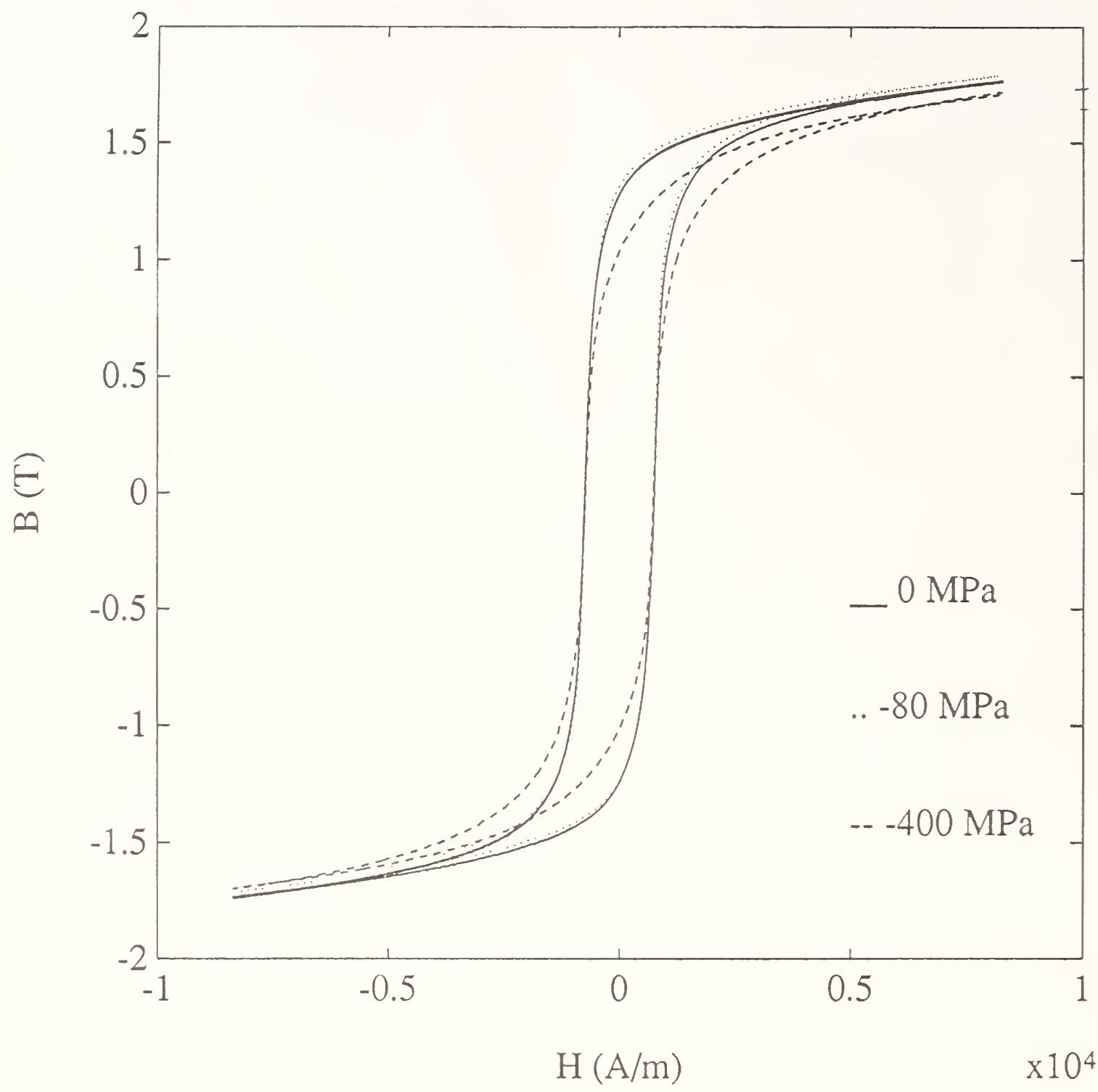

Figure F-3. Magnetic induction as a function of applied magnetic field strength for negative transverse stresses (compression) ranging from 0 to $-400 \mathrm{MPa}$ as described by (2) in the test plan. 


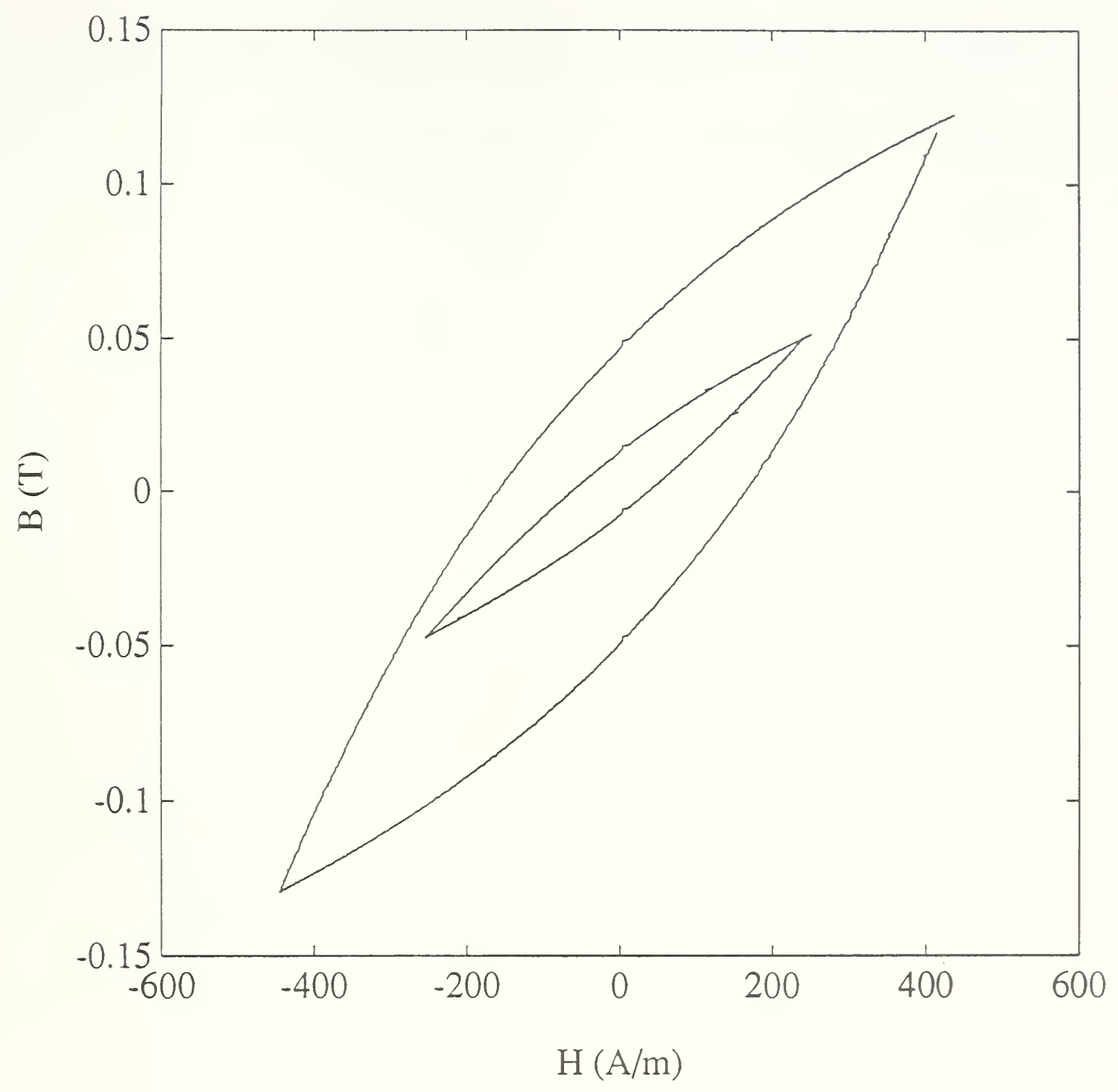

Figure F-4. Magnetic induction as a function of applied magnetic field strength for maximum fields of 200 and $400 \mathrm{~A} / \mathrm{m}$ as described by (3) in the test plan. 


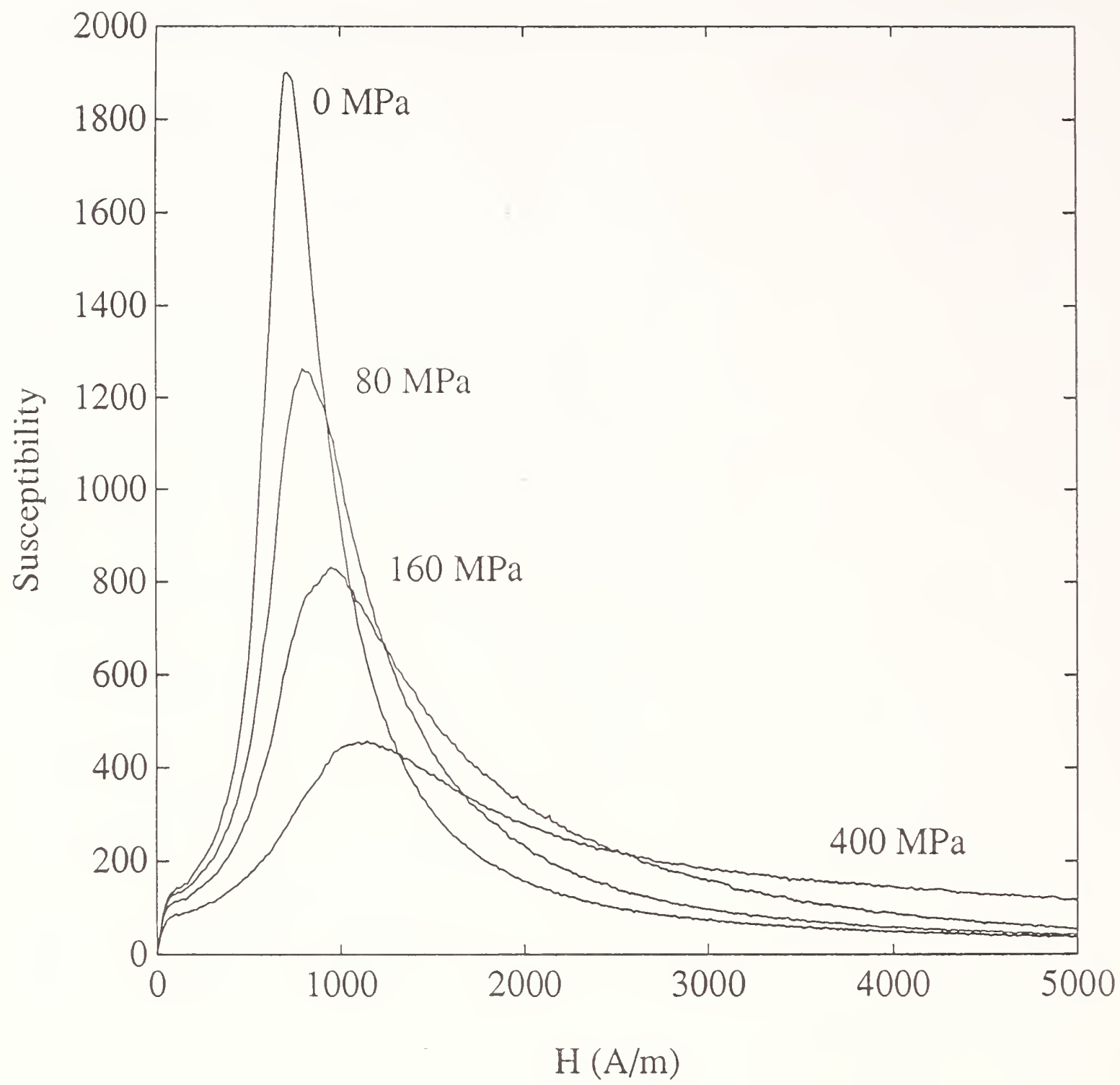

Figure F-5. Susceptibility as a function of applied magnetic field strength for positive transverse stresses (tension) ranging from 0 to $400 \mathrm{MPa}$ as described by (4) in the test plan. 


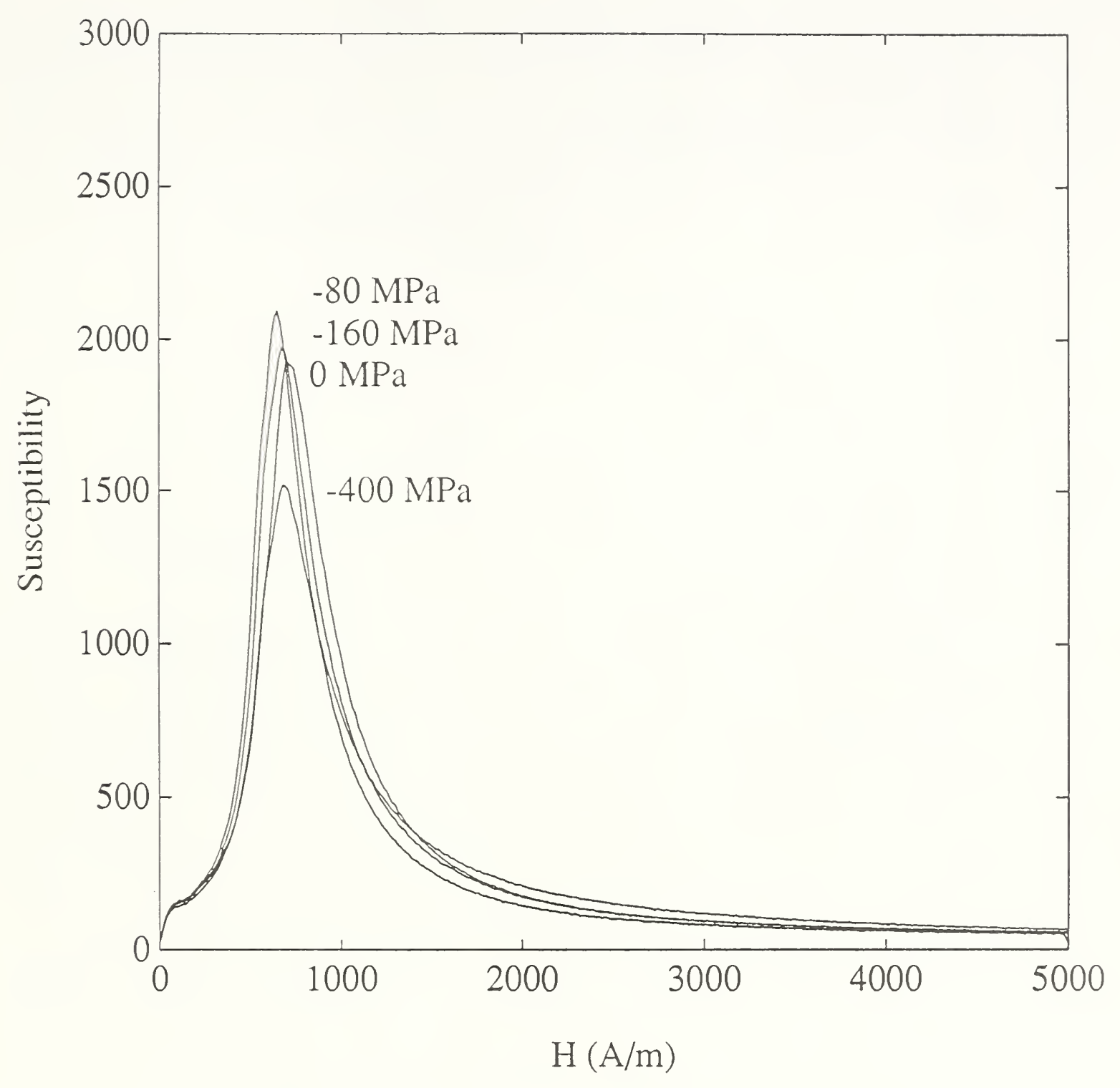

Figure F-6. Susceptibility as a function of applied magnetic field strength for negative transverse stresses (compression) ranging from 0 to $-400 \mathrm{MPa}$ as described by (4) in the test plan. 


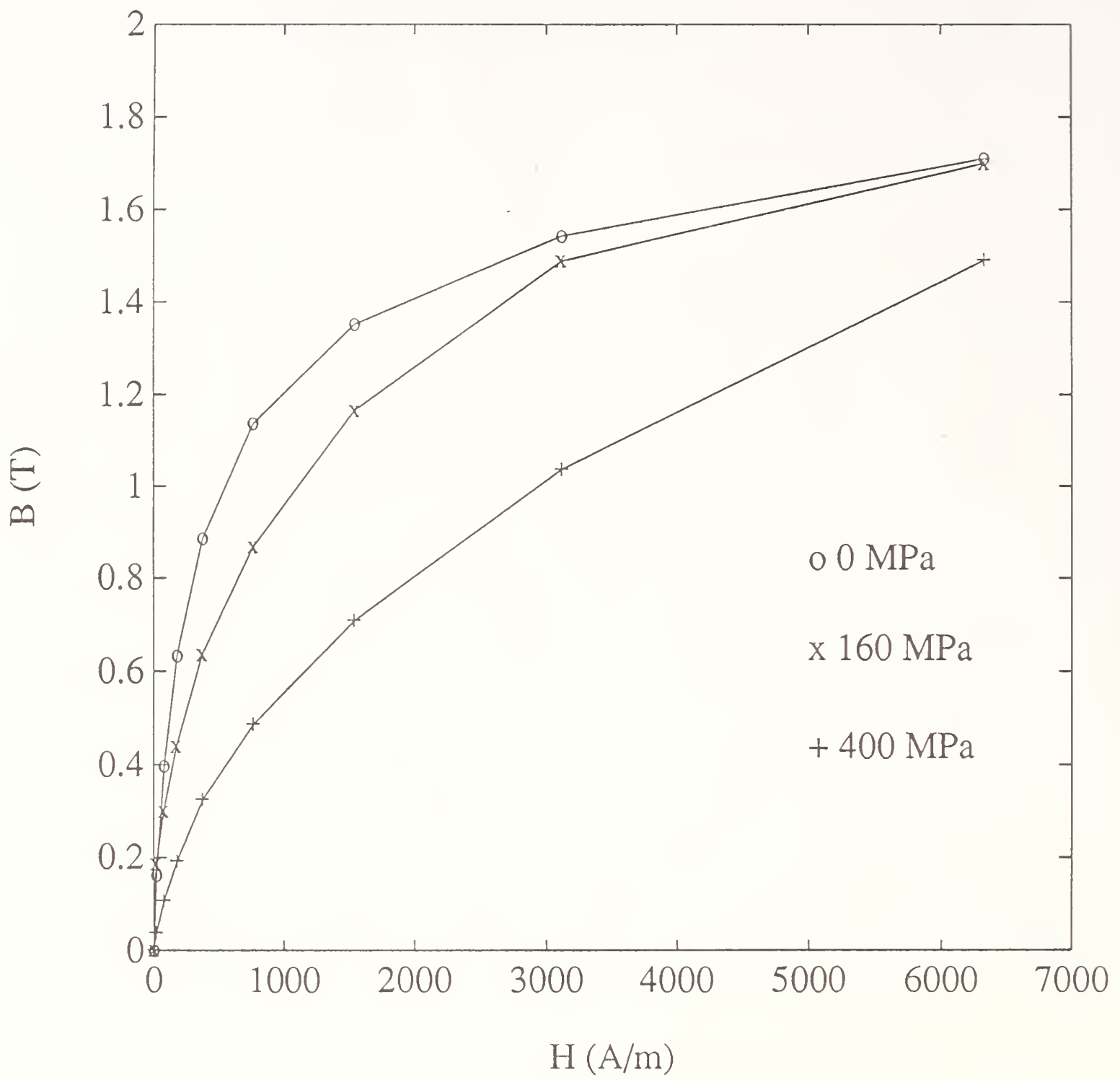

Figure F-7. Anhysteretic magnetization curves for positive transverse stresses (tension) ranging from 0 to $400 \mathrm{MPa}$ as described by (5) in the test plan. 


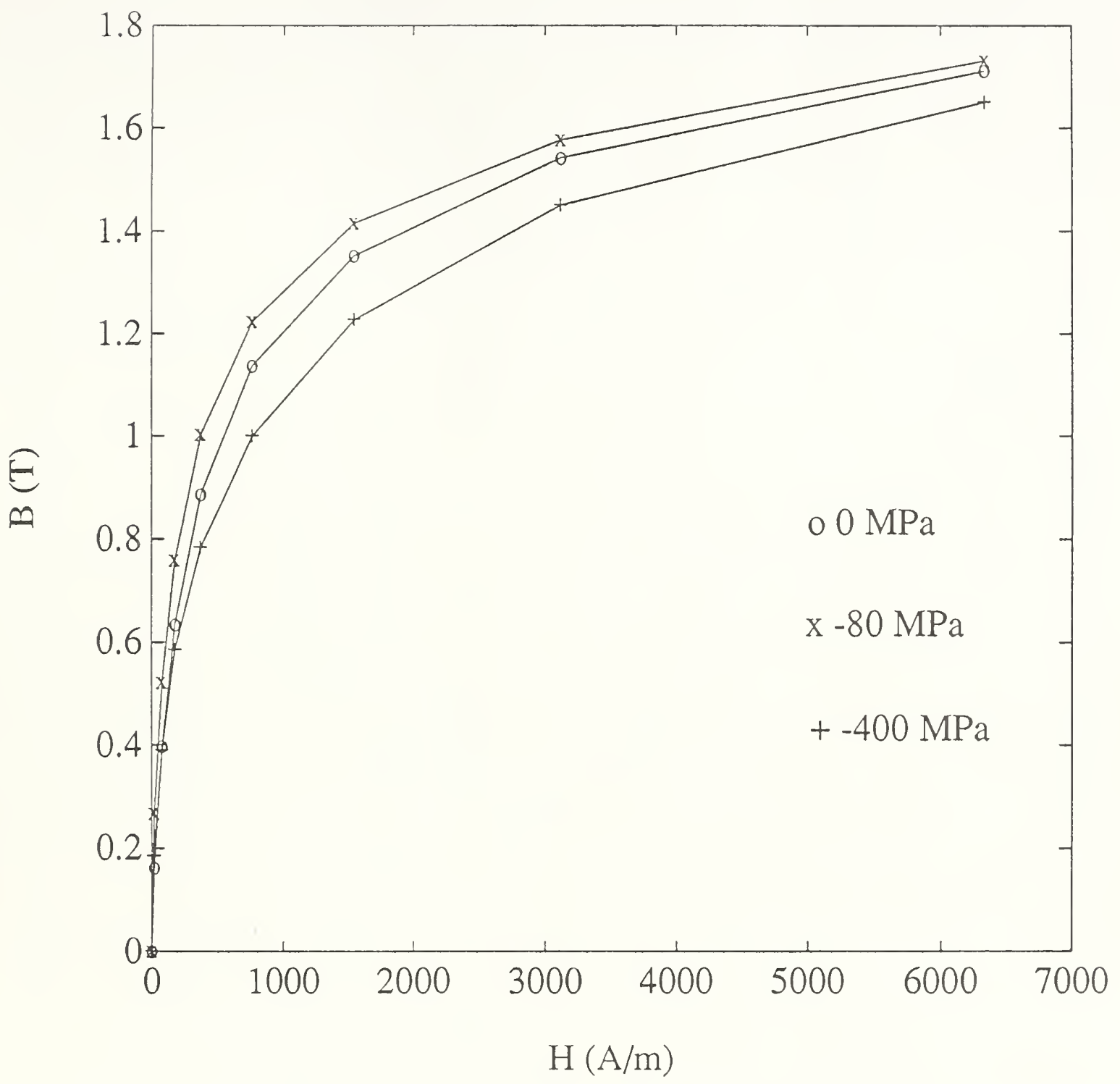

Figure F-8. Anhysteretic magnetization curves for negative transverse stresses (compression) ranging from 0 to $-400 \mathrm{MPa}$ as described by (5) in the test plan. 


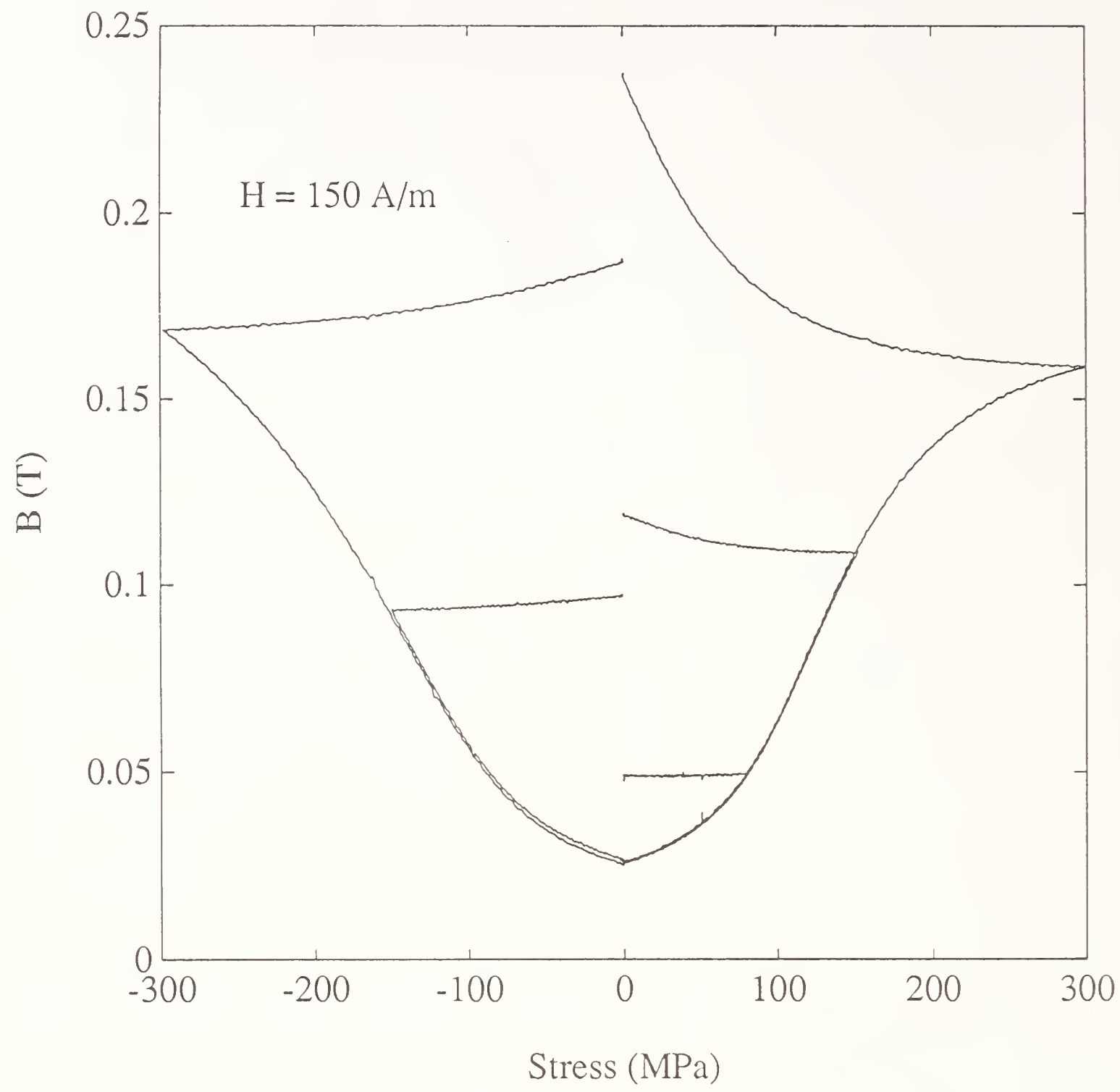

Figure F-9. Magnetic induction as a function of applied transverse stresses ranging from -300 to $300 \mathrm{MPa}$ as described by (6) in the test plan. The de magnetic field was $150 \mathrm{~A} / \mathrm{m}$. 


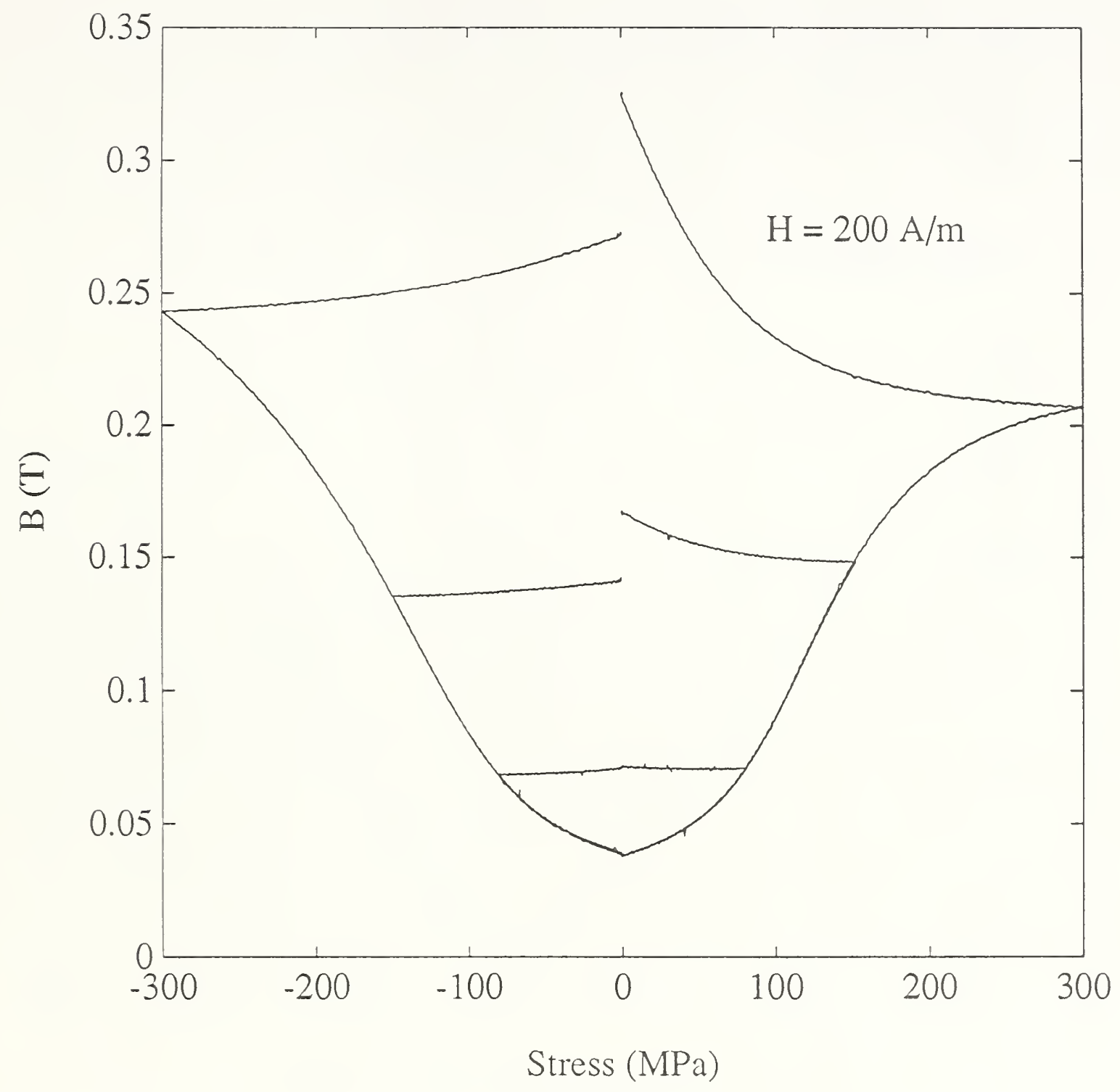

Figure F-10. Magnetic induction as a function of applied transverse stresses ranging from -300 to $300 \mathrm{MPa}$ as described by (6) in the test plan. The dc magnetic field was $200 \mathrm{~A} / \mathrm{m}$. 


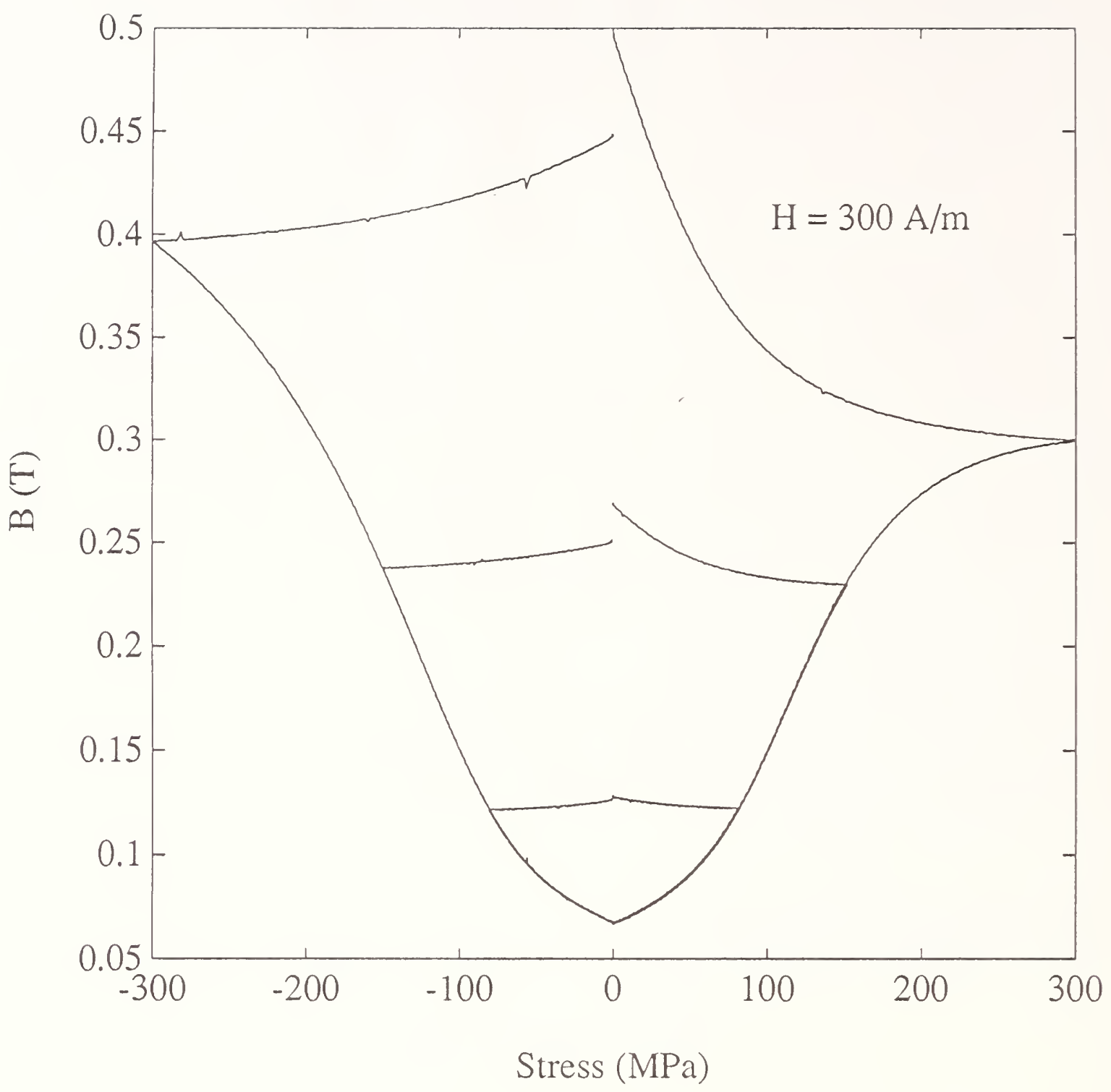

Figure F-11. Magnetic induction as a function of applied transverse stresses ranging from -300 to $300 \mathrm{MPa}$ as described by (6) in the test plan. The dc magnetic field was $300 \mathrm{~A} / \mathrm{m}$. 


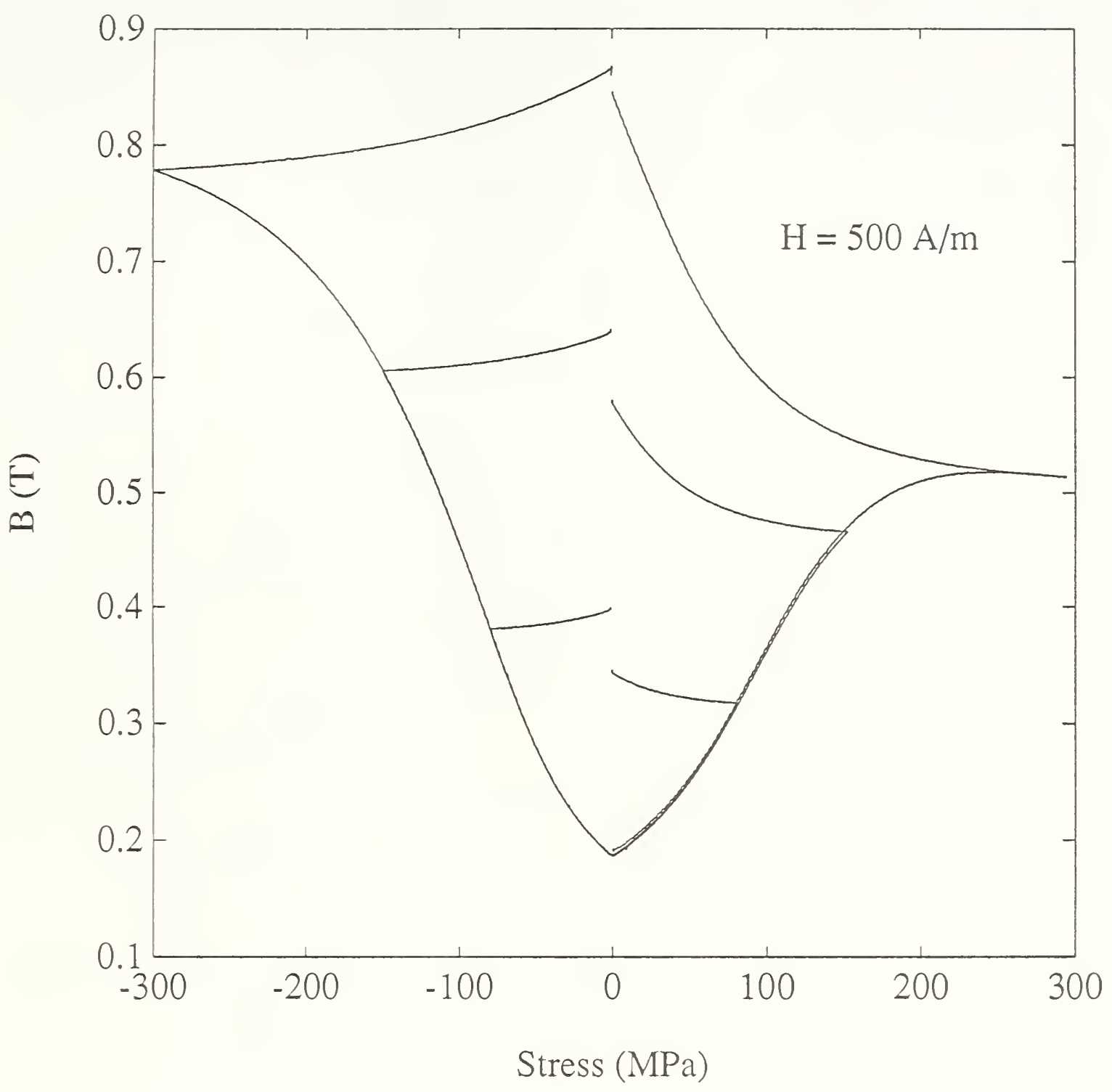

Figure F-12. Magnetic induction as a function of applied transverse stresses ranging from -300 to $300 \mathrm{MPa}$ as described by (6) in the test plan. The dc magnetic field was $500 \mathrm{~A} / \mathrm{m}$. 


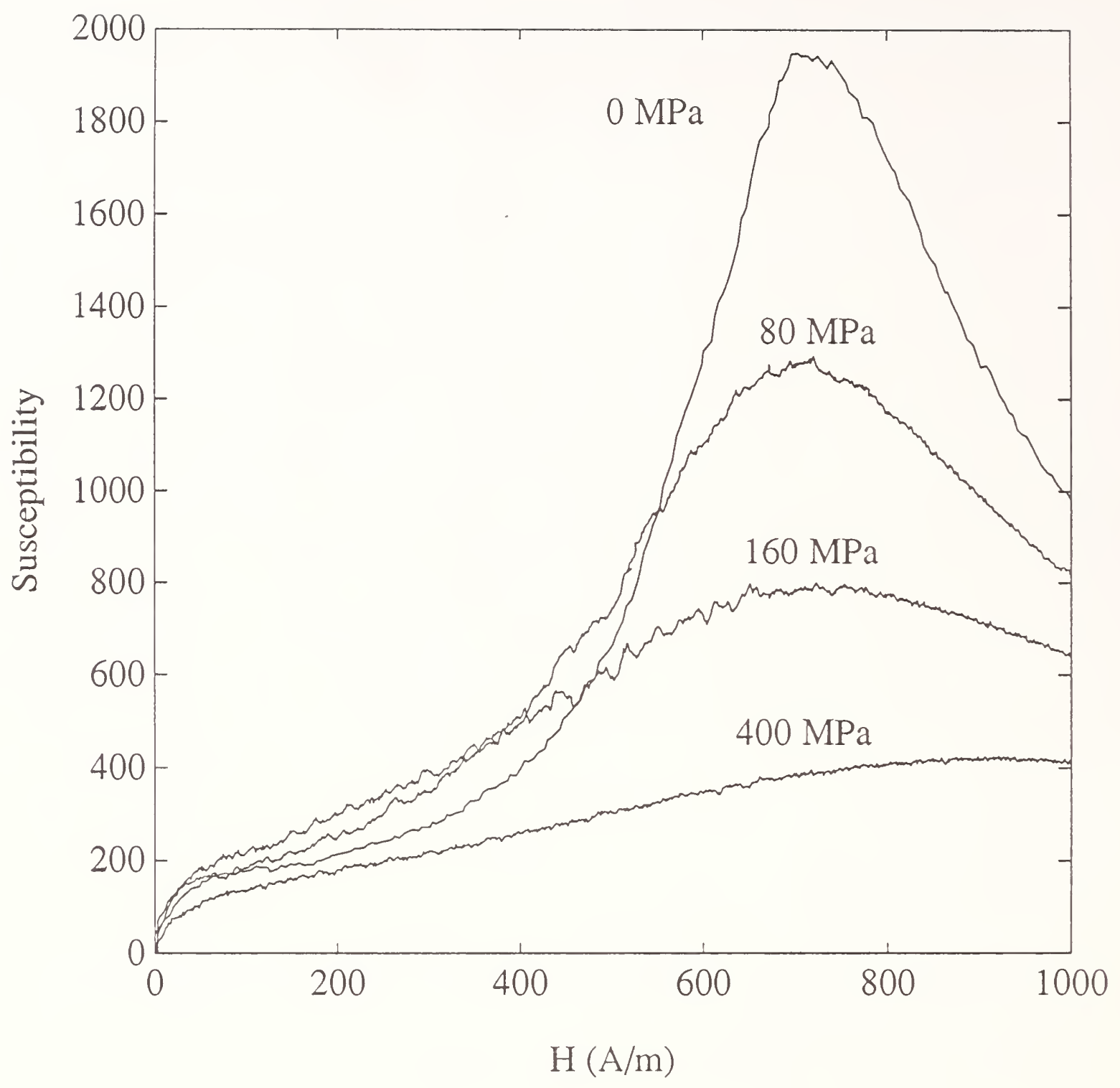

Figure F-13. Susceptibility as a function of applied magnetic field strength for transverse positive stresses (tension) ranging from 0 to $400 \mathrm{MPa}$ as described by (7) in the test plan. 


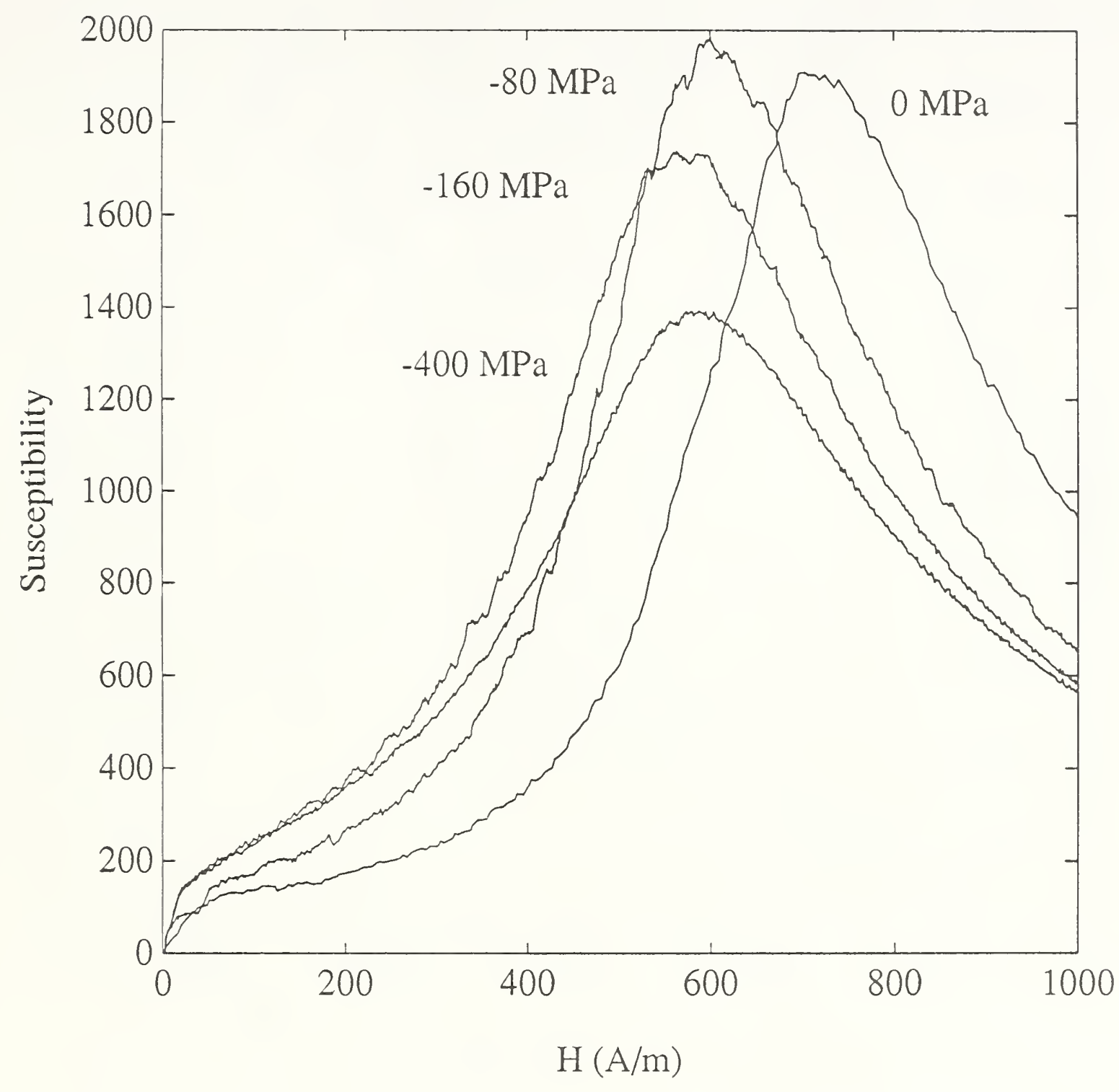

Figure F-14. Susceptibility as a function of applied magnetic field strength for transverse negative stresses (compression) ranging from 0 to $-400 \mathrm{MPa}$ as described by (7) in the test plan. 


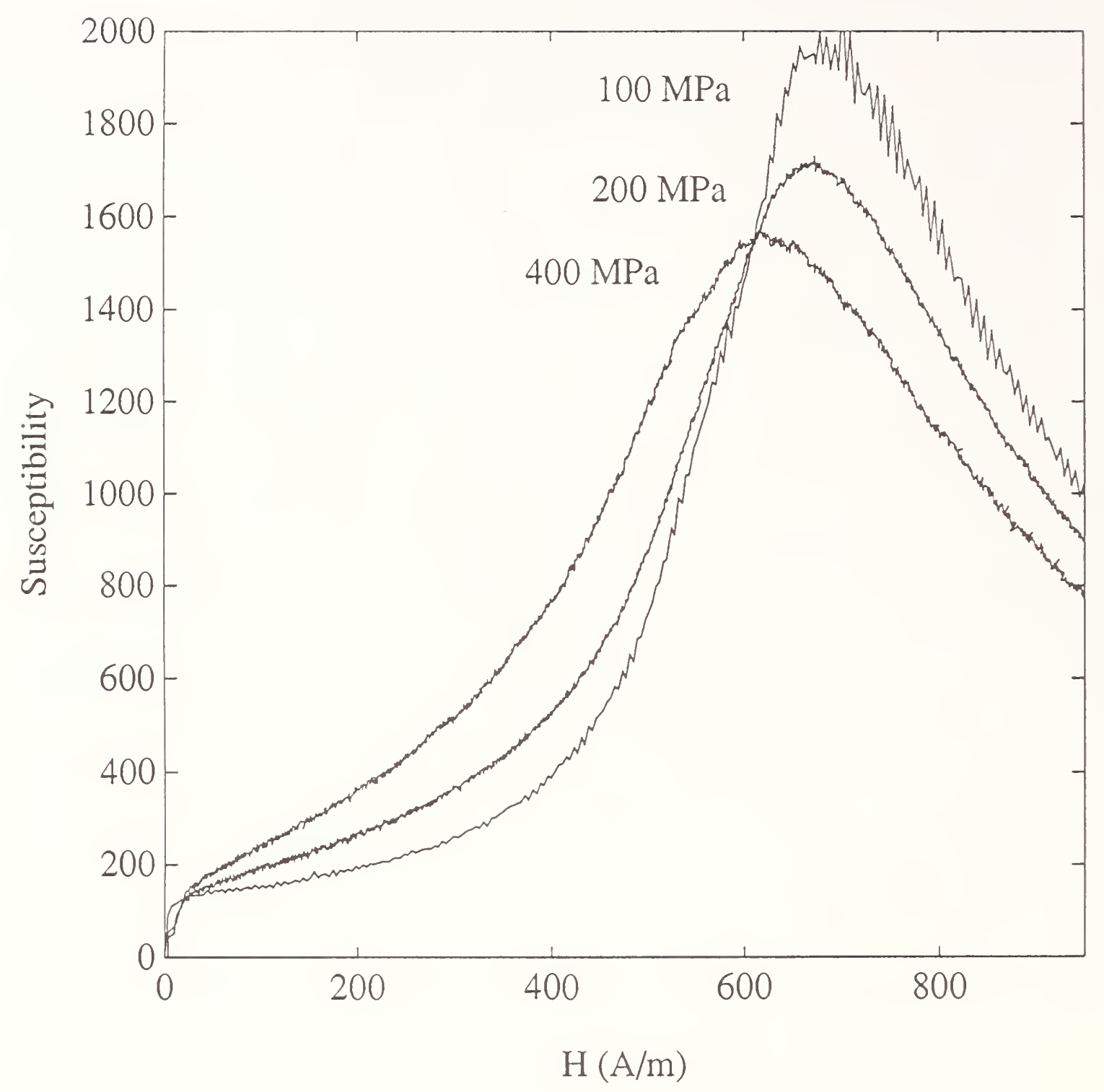

Figure F-15. Susceptibility as a function of applied magnetic field strength after the application and release of positive transverse stresses ranging from 50 to 400 $\mathrm{MPa}$. The measurement is described by (8) in the test plan. 


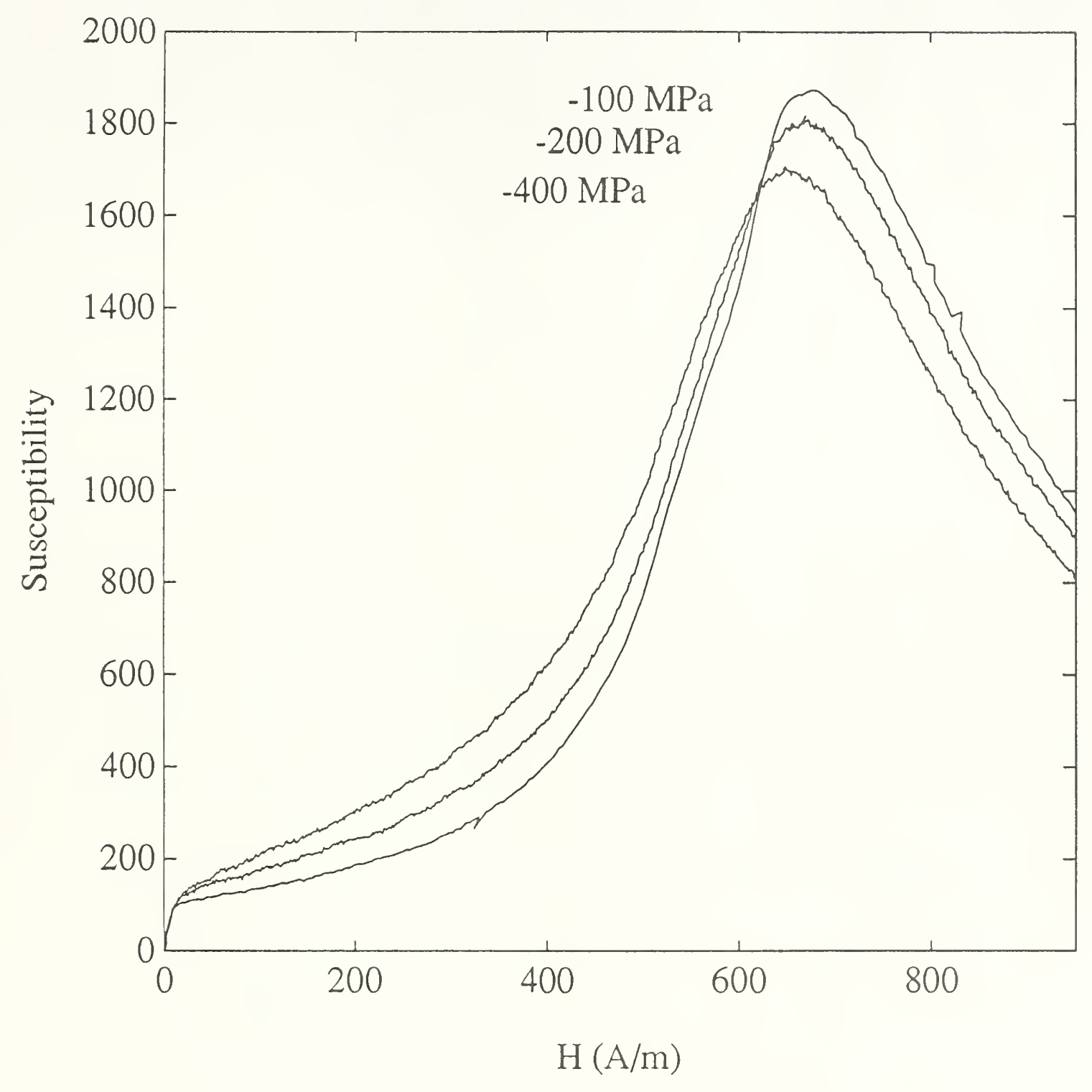

Figure F-16. Susceptibility as a function of applied magnetic field strength after the application and release of negative transverse stresses ranging from -50 to $-400 \mathrm{MPa}$. The measurement is described by (8) in the test plan. 

Appendix G 


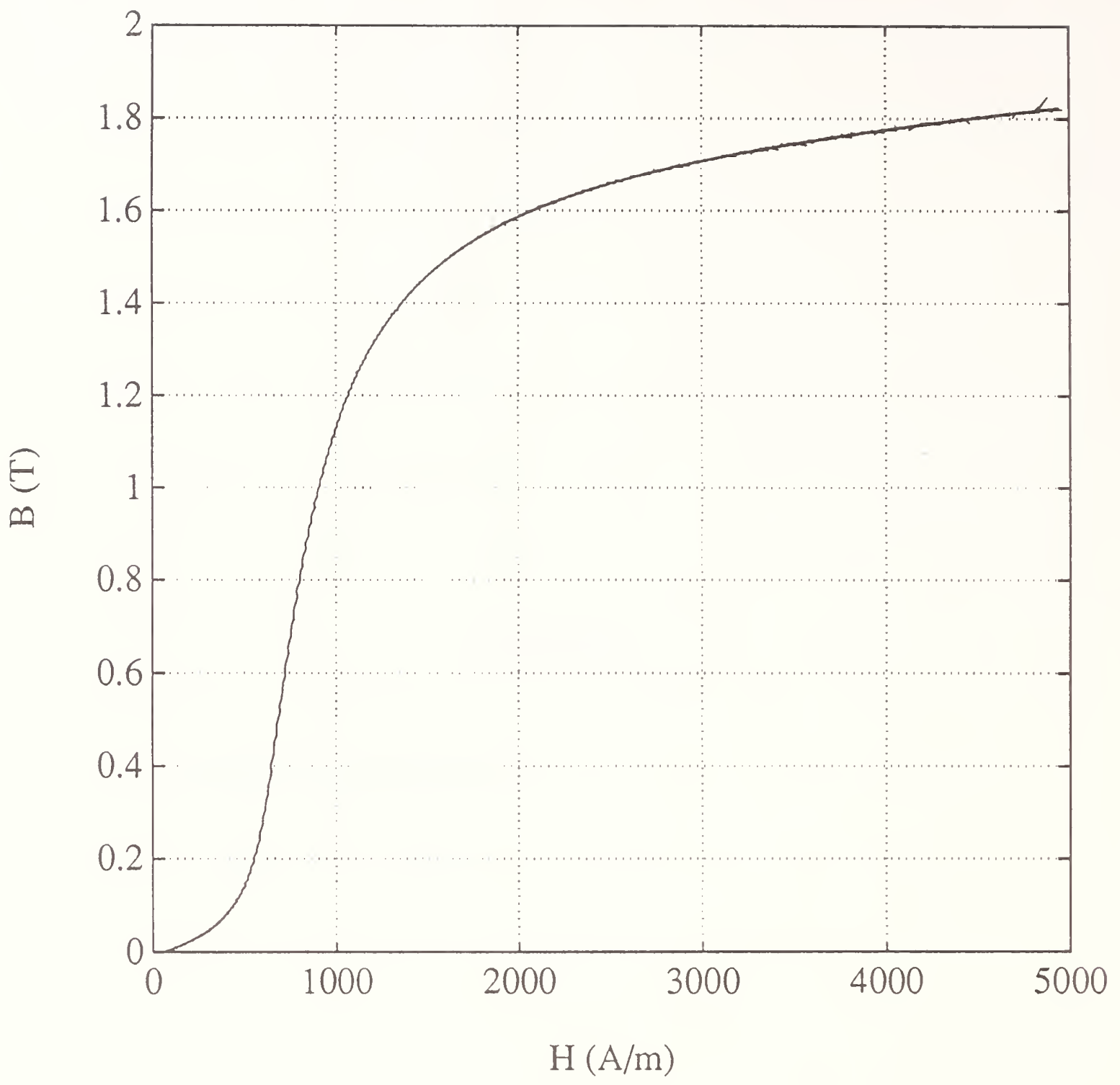

Figure G-1. Normal unstressed magnetization curve as described by (1) in the test plan. 


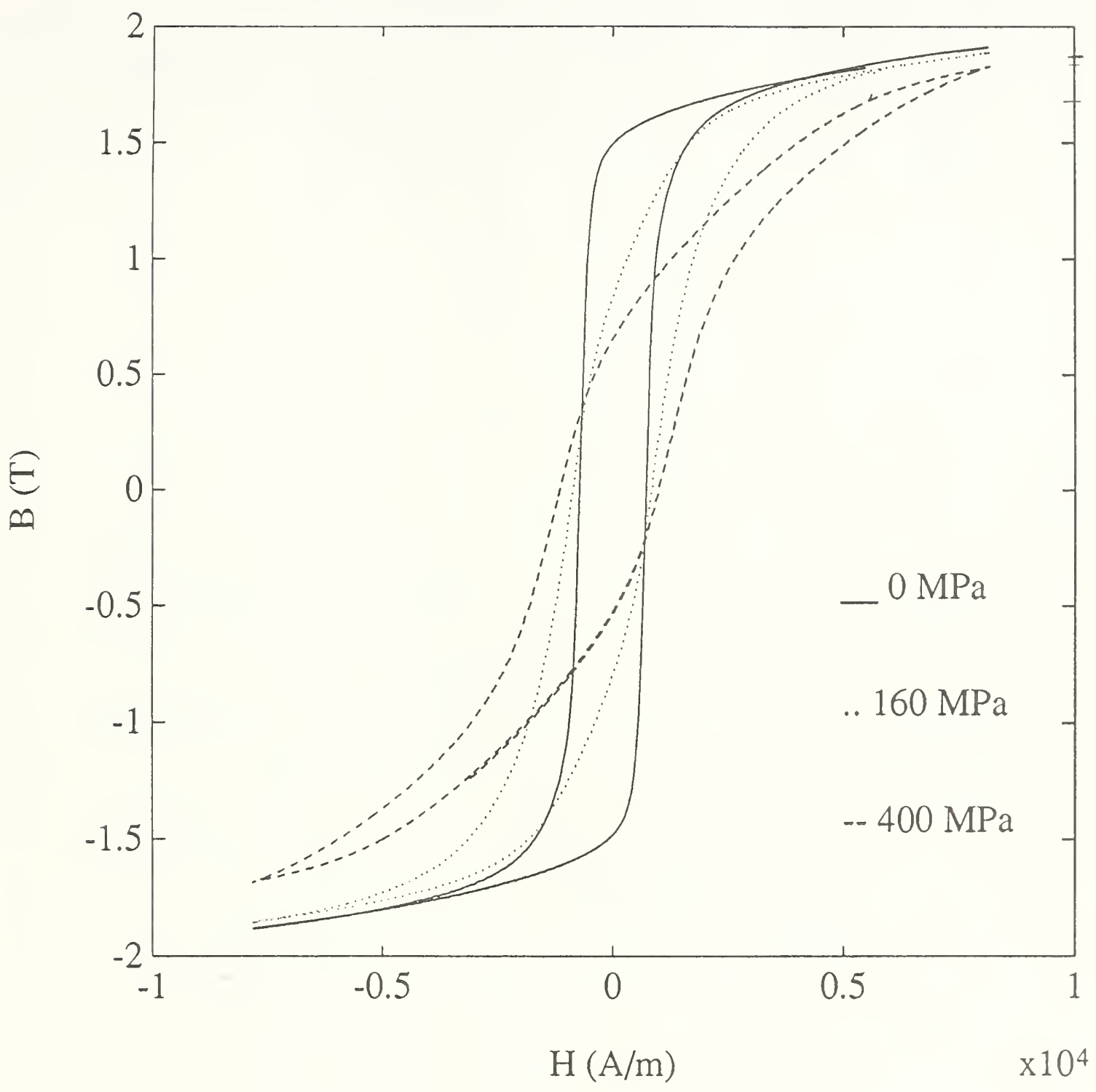

Figure G-2. Magnetic induction as a function of applied magnetic field strength for positive transverse stress (tension) ranging from 0 to $400 \mathrm{MPa}$ as described by (2) in the test plan. The stress results in an effective demagnetizing field which shears the hysteresis loop. 


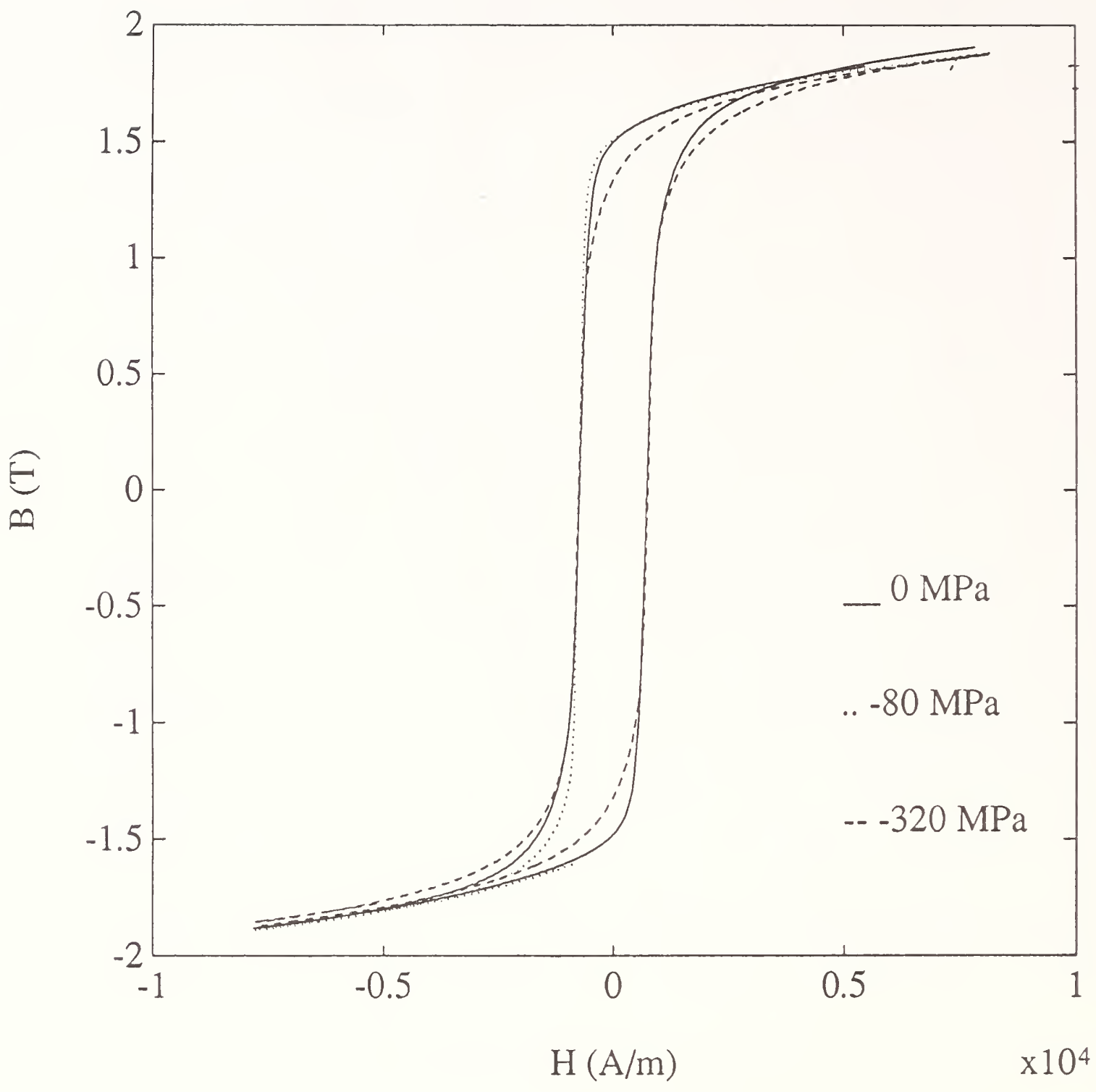

Figure G-3. Magnetic induction as a function of applied magnetic field strength for negative transverse stresses (compression) ranging from 0 to $-400 \mathrm{MPa}$ as described by (2) in the test plan. 


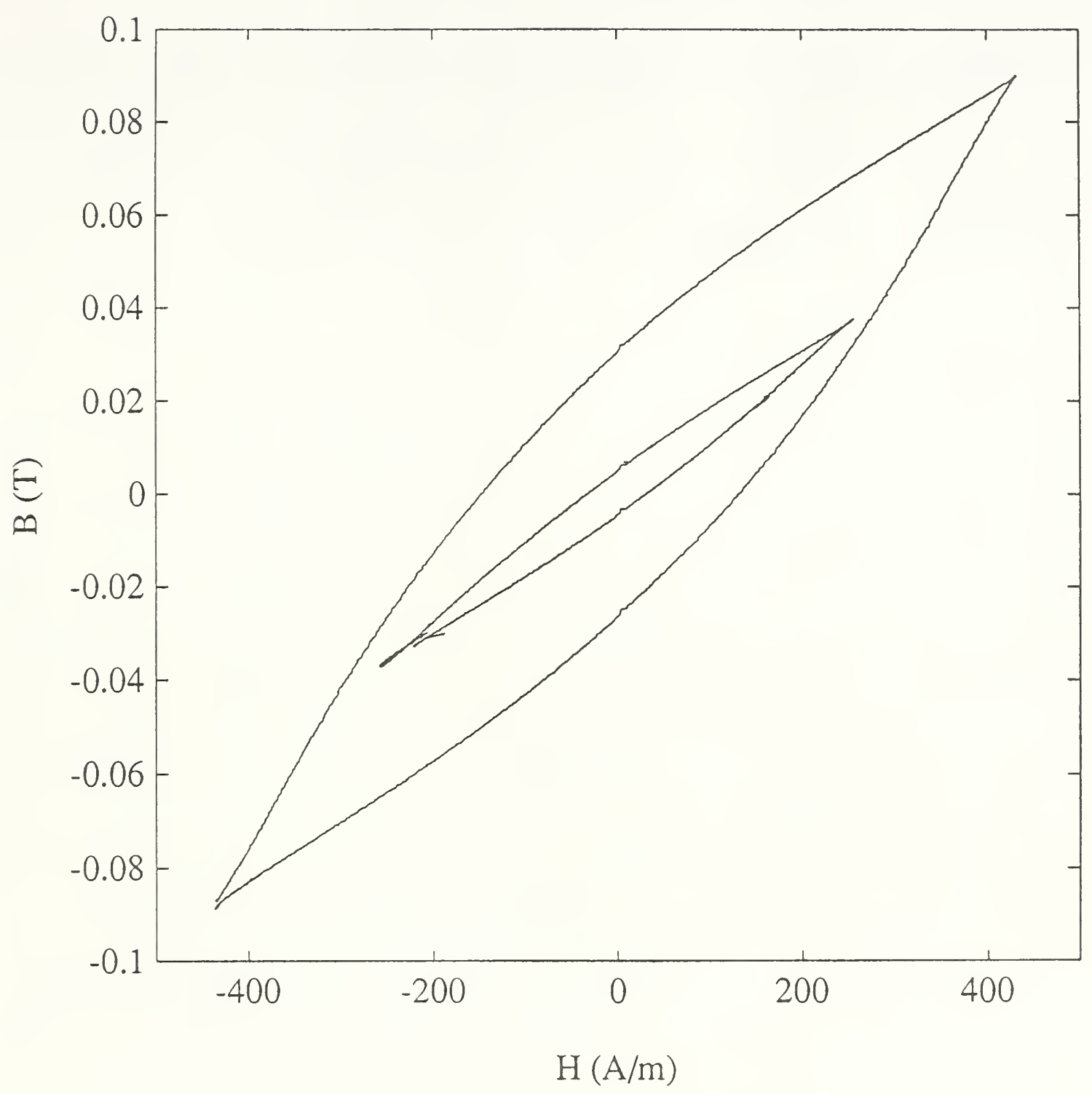

Figure G-4. Magnetic induction as a function of applied magnetic field strength for maximum fields of 200 and $400 \mathrm{~A} / \mathrm{m}$ as described by (3) in the test plan. 


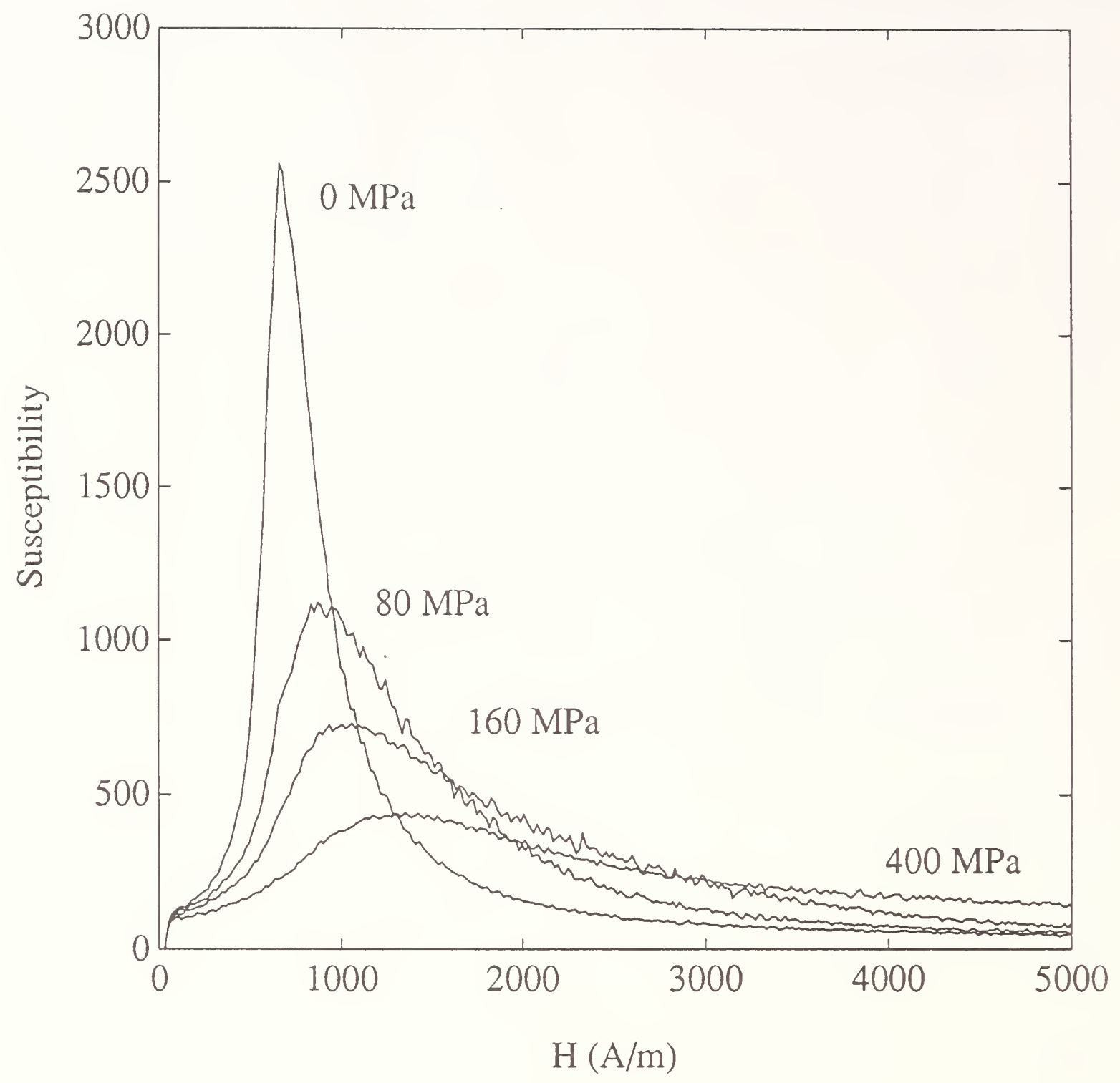

Figure G-5. Susceptibility as a function of applied magnetic field strength for positive transverse stresses (tension) ranging from 0 to $400 \mathrm{MPa}$ as described by (4) in the test plan. 


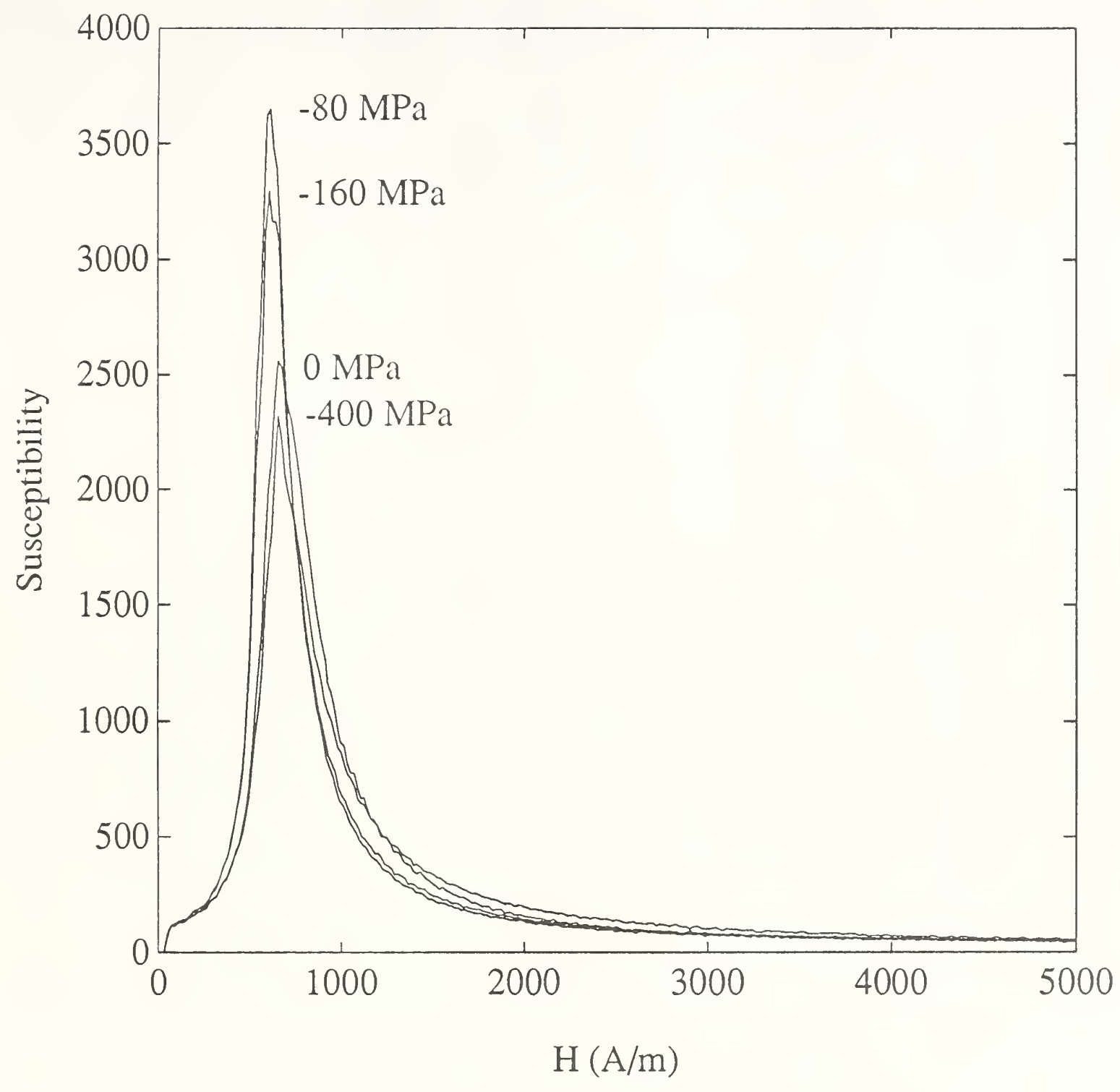

Figure G-6. Susceptibility as a function of applied magnetic field strength for negative transverse stresses (compression) ranging from 0 to $-400 \mathrm{MPa}$ as described by (4) in the test plan. 


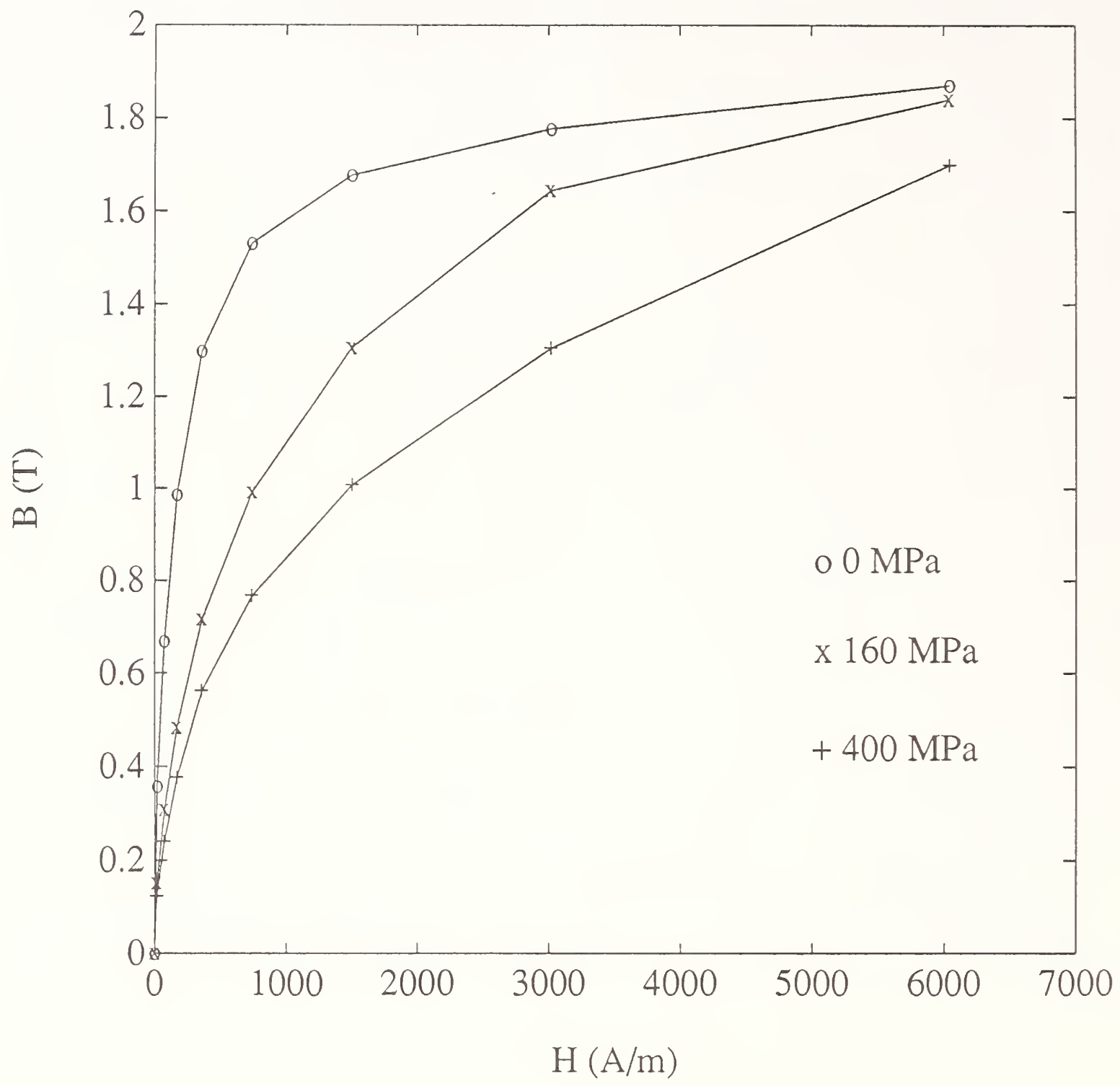

Figure G-7. Anhysteretic magnetization curves for positive transverse stresses (tension) ranging from 0 to $400 \mathrm{MPa}$ as described by (5) in the test plan. 


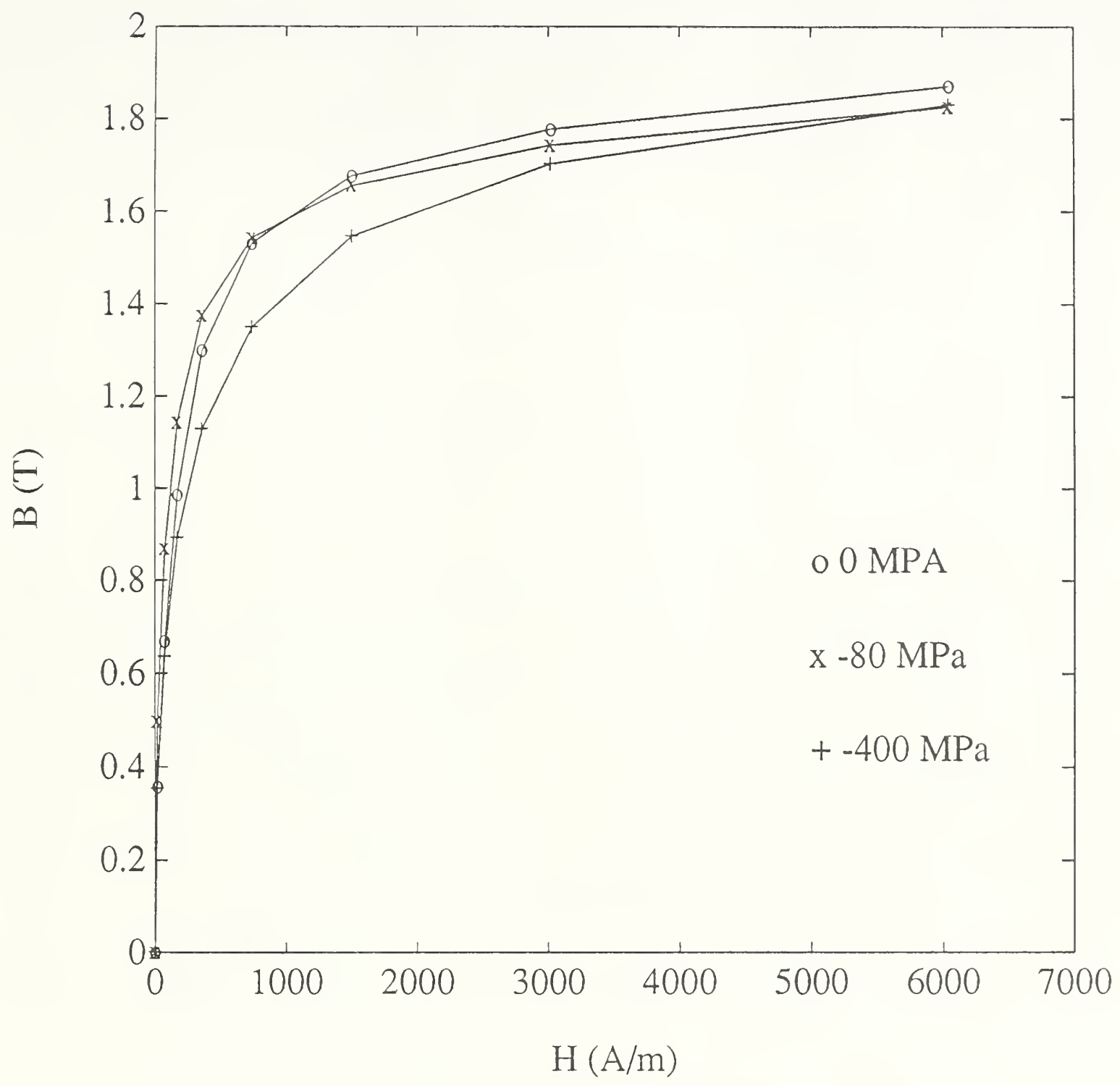

Figure G-8. Anhysteretic magnetization curves for negative transverse stresses (compression) ranging from 0 to $-400 \mathrm{MPa}$ as described by (5) in the test plan. 


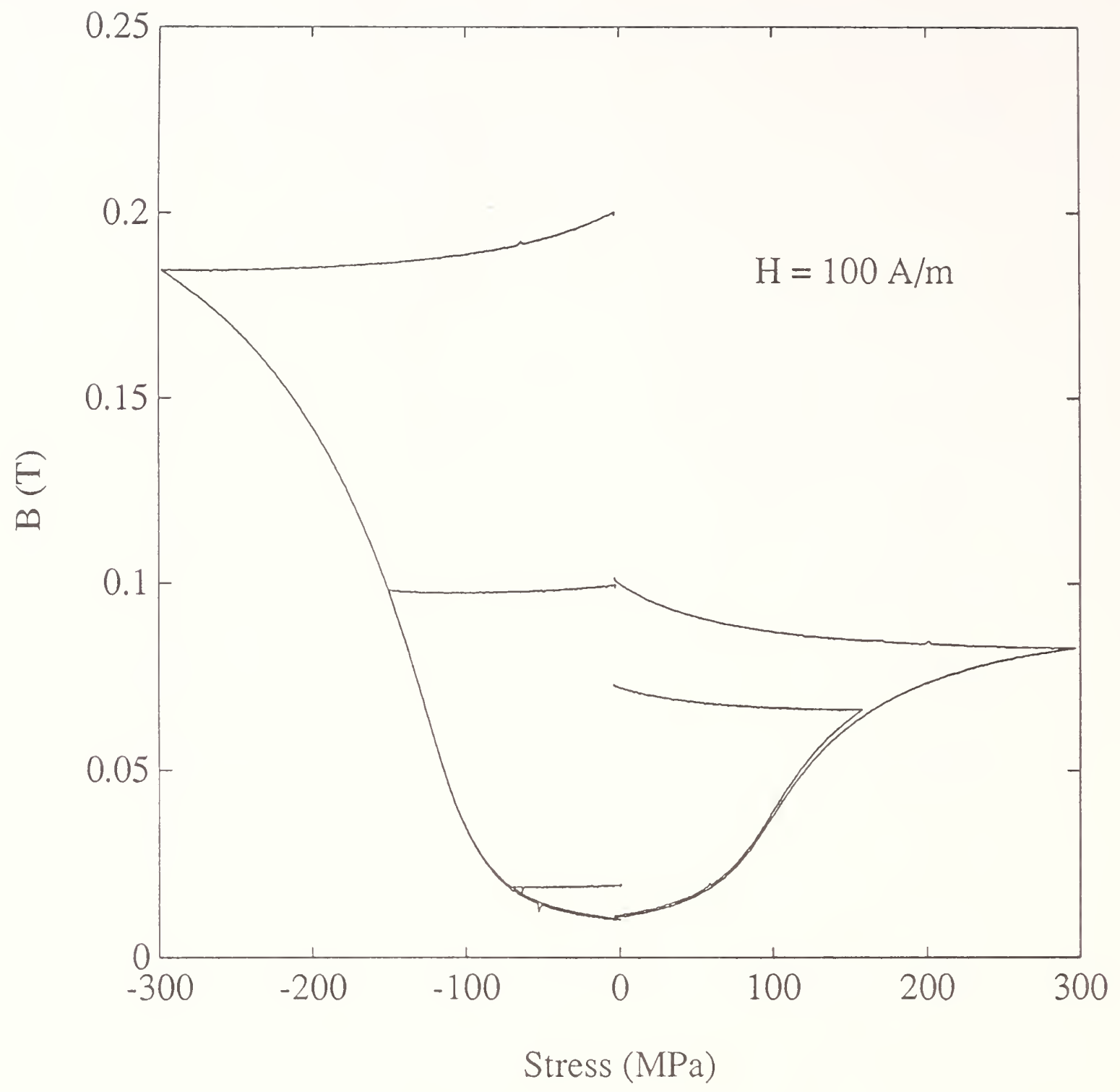

Figure G-9. Magnetic induction as a function of applied transverse stresses ranging from -300 to $300 \mathrm{MPa}$ as described by (6) in the test plan. The dc magnetic field was $100 \mathrm{~A} / \mathrm{m}$. 


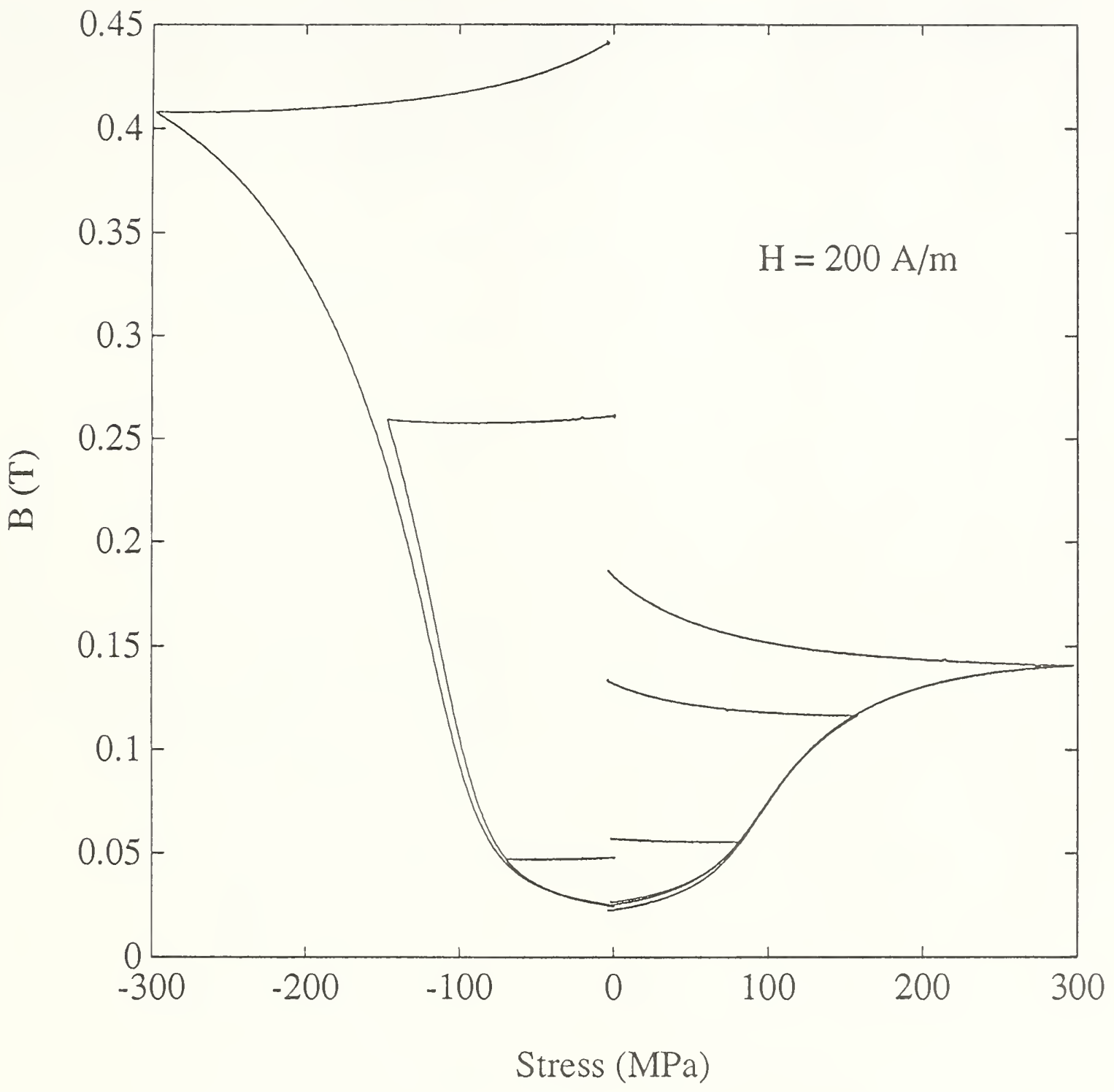

Figure G-10. Magnetic induction as a function of applied transverse stresses ranging from -300 to $300 \mathrm{MPa}$ as described by (6) in the test plan. The dc magnetic field was $200 \mathrm{~A} / \mathrm{m}$. 


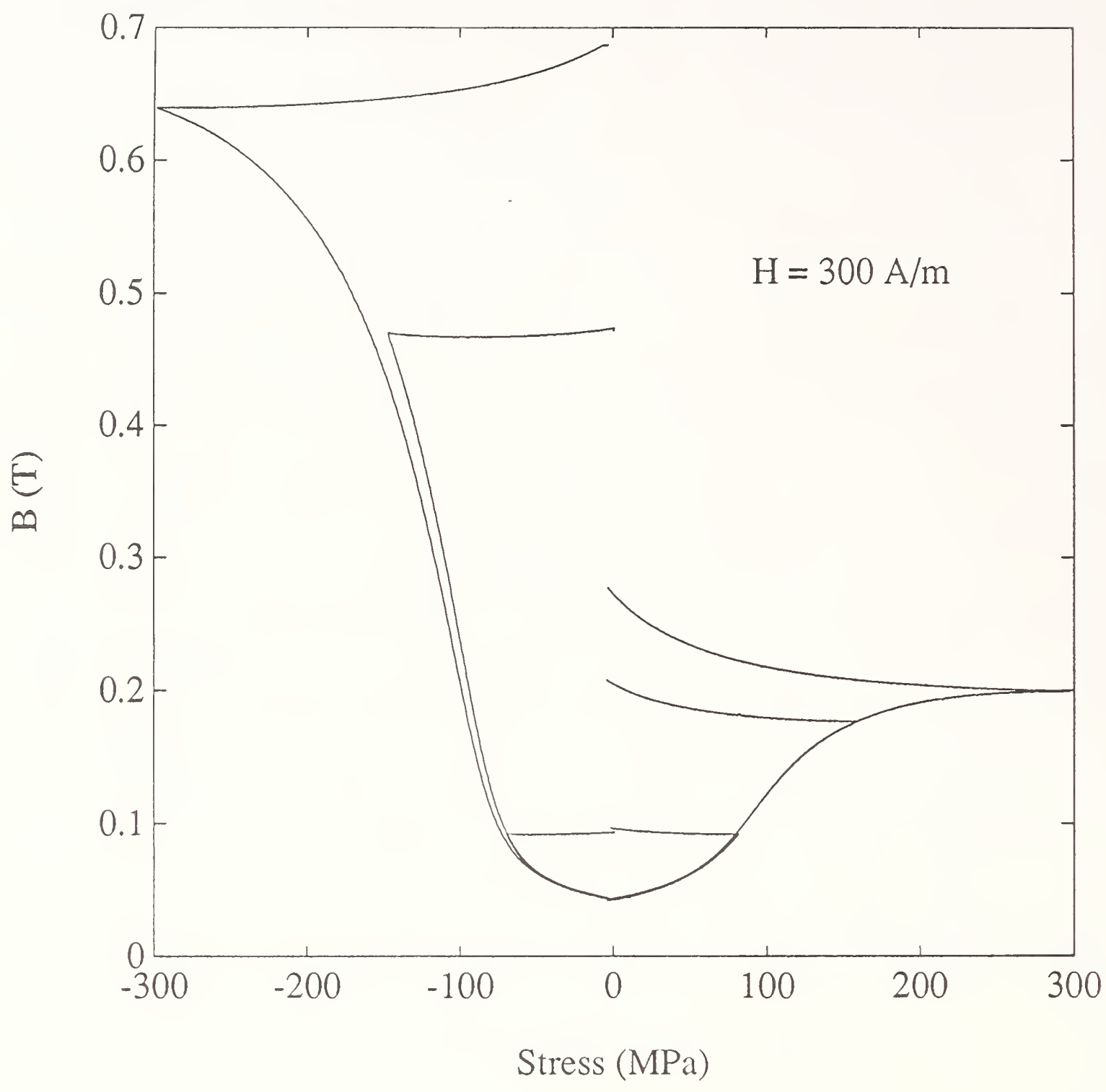

Figure G-11. Magnetic induction as a function of applied transverse stresses ranging from -300 to $300 \mathrm{MPa}$ as described by (6) in the test plan. The dc magnetic field was $300 \mathrm{~A} / \mathrm{m}$. 


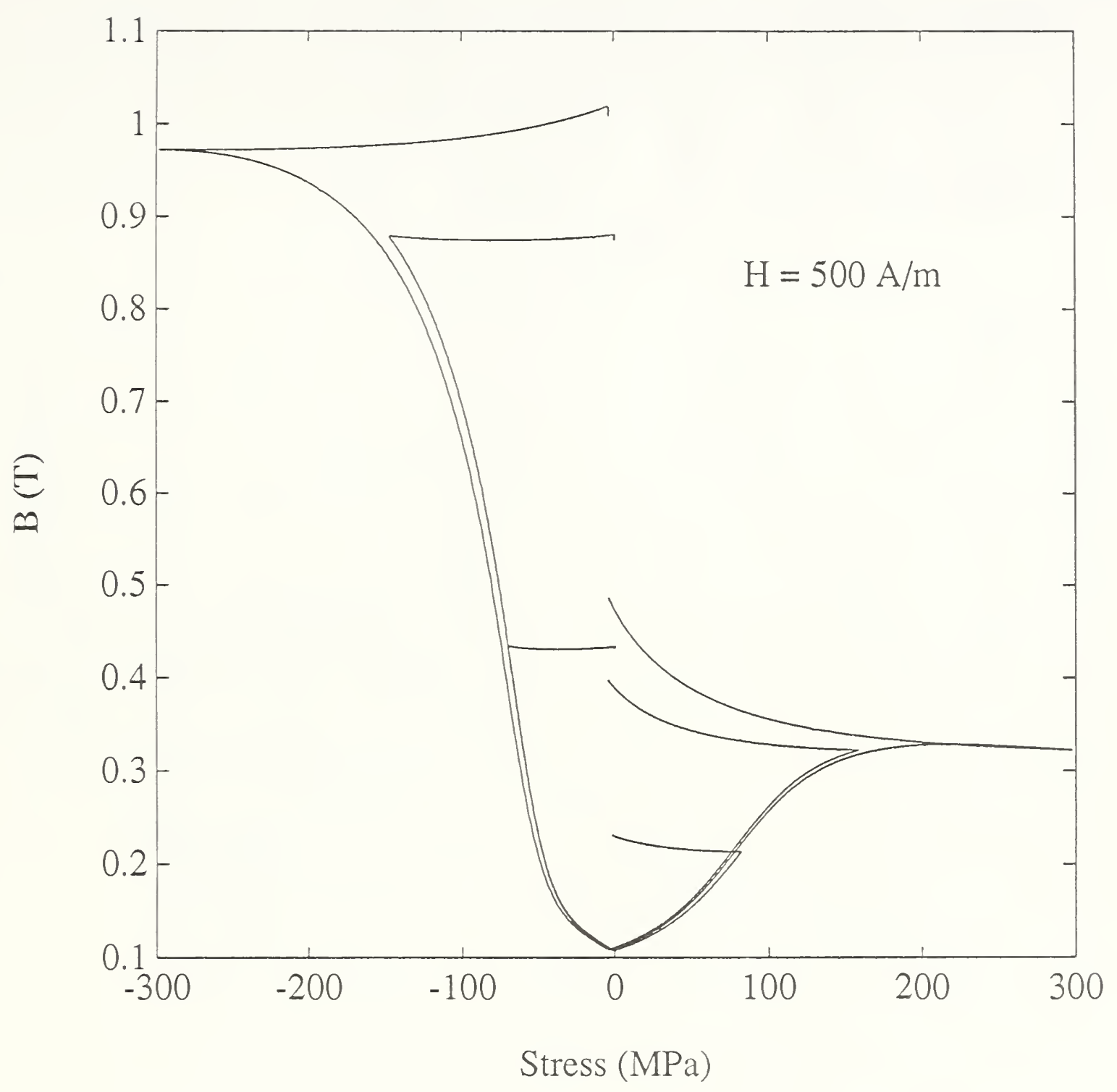

Figure G-12. Magnetic induction as a function of applied transverse stresses ranging from -300 to $300 \mathrm{MPa}$ as described by (6) in the test plan. The dc magnetic field was $500 \mathrm{~A} / \mathrm{m}$. 


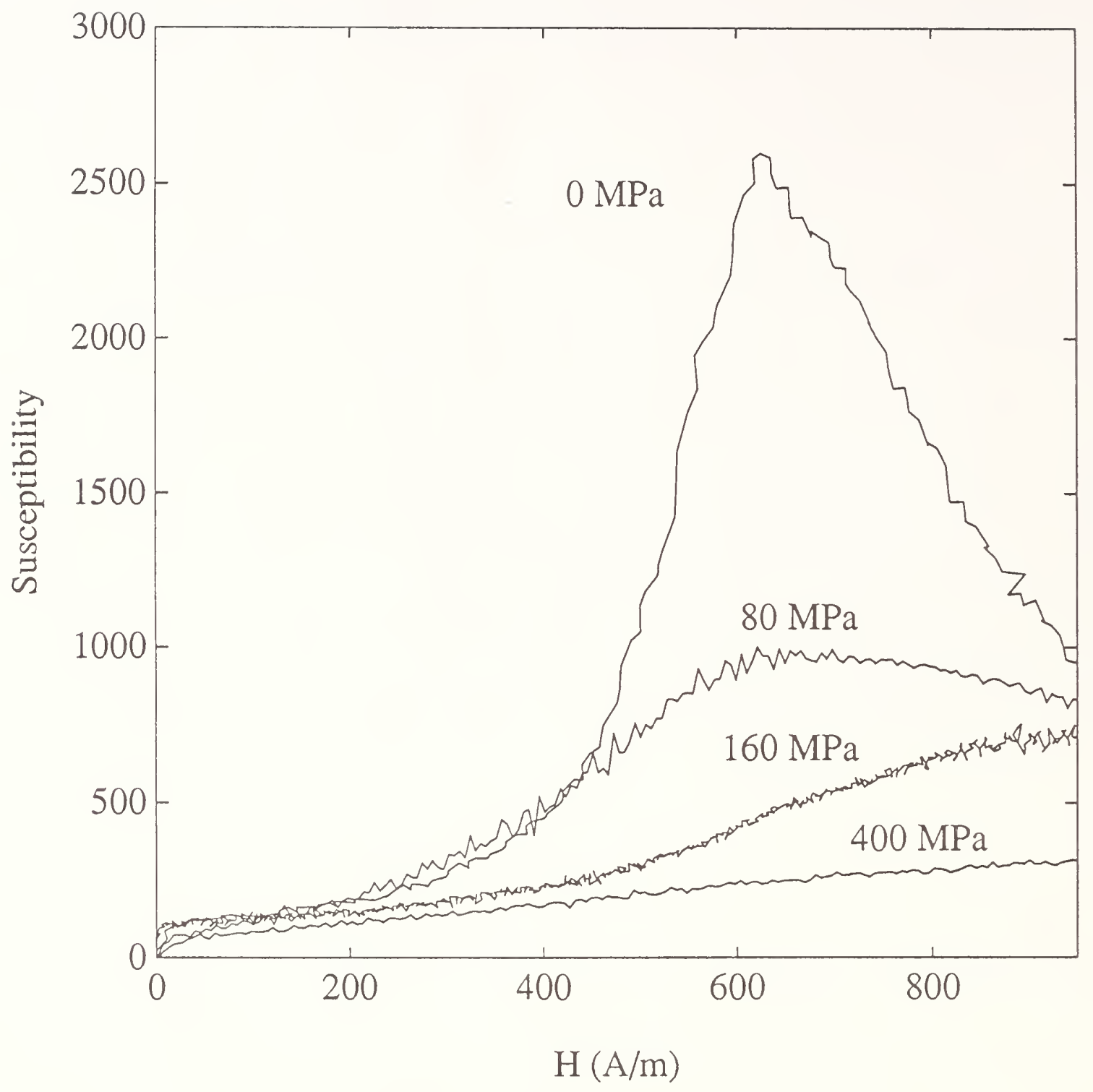

Figure G-13. Susceptibility as a function of applied magnetic field strength for transverse positive stresses (tension) ranging from 0 to $400 \mathrm{MPa}$ as described by (7) in the test plan. 


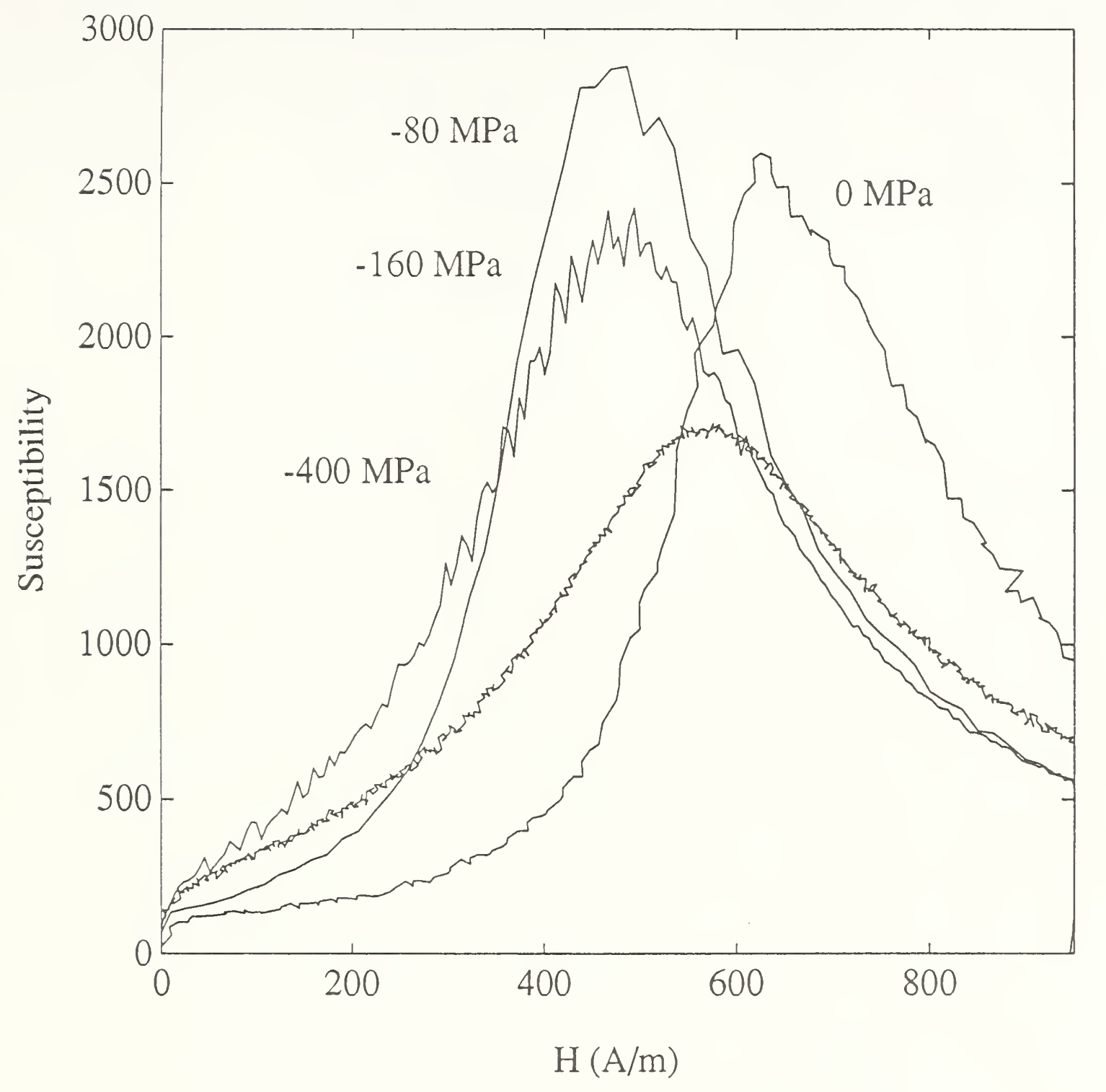

Figure G-14. Susceptibility as a function of applied magnetic field strength for transverse negative stresses (compression) ranging from 0 to $-400 \mathrm{MPa}$ as described by (7) in the test plan. 


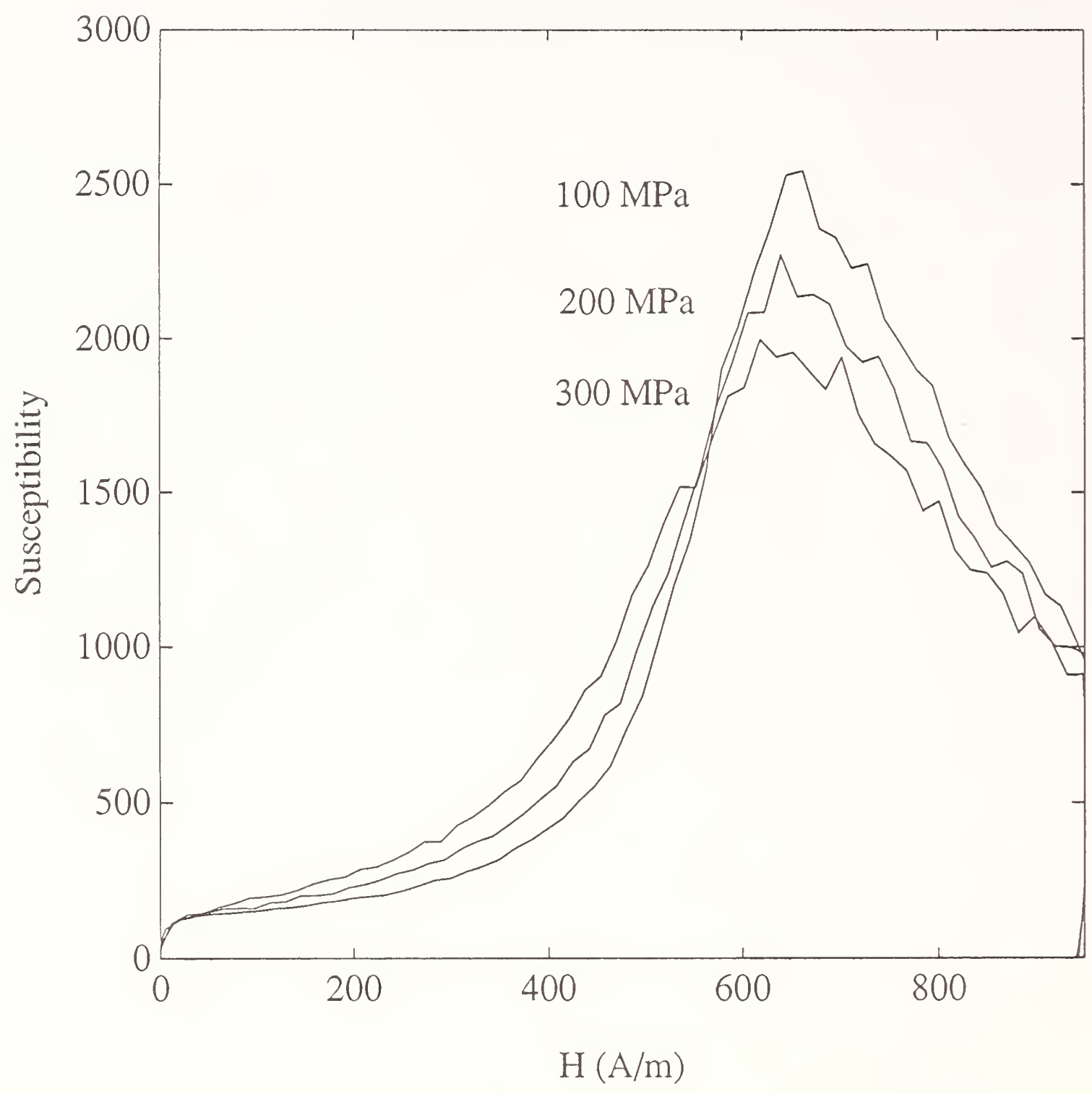

Figure G-15. Susceptibility as a function of applied magnetic field strength after the application and release of positive transverse stresses ranging from 50 to 400 MPa. The measurement is described by (8) in the test plan. 


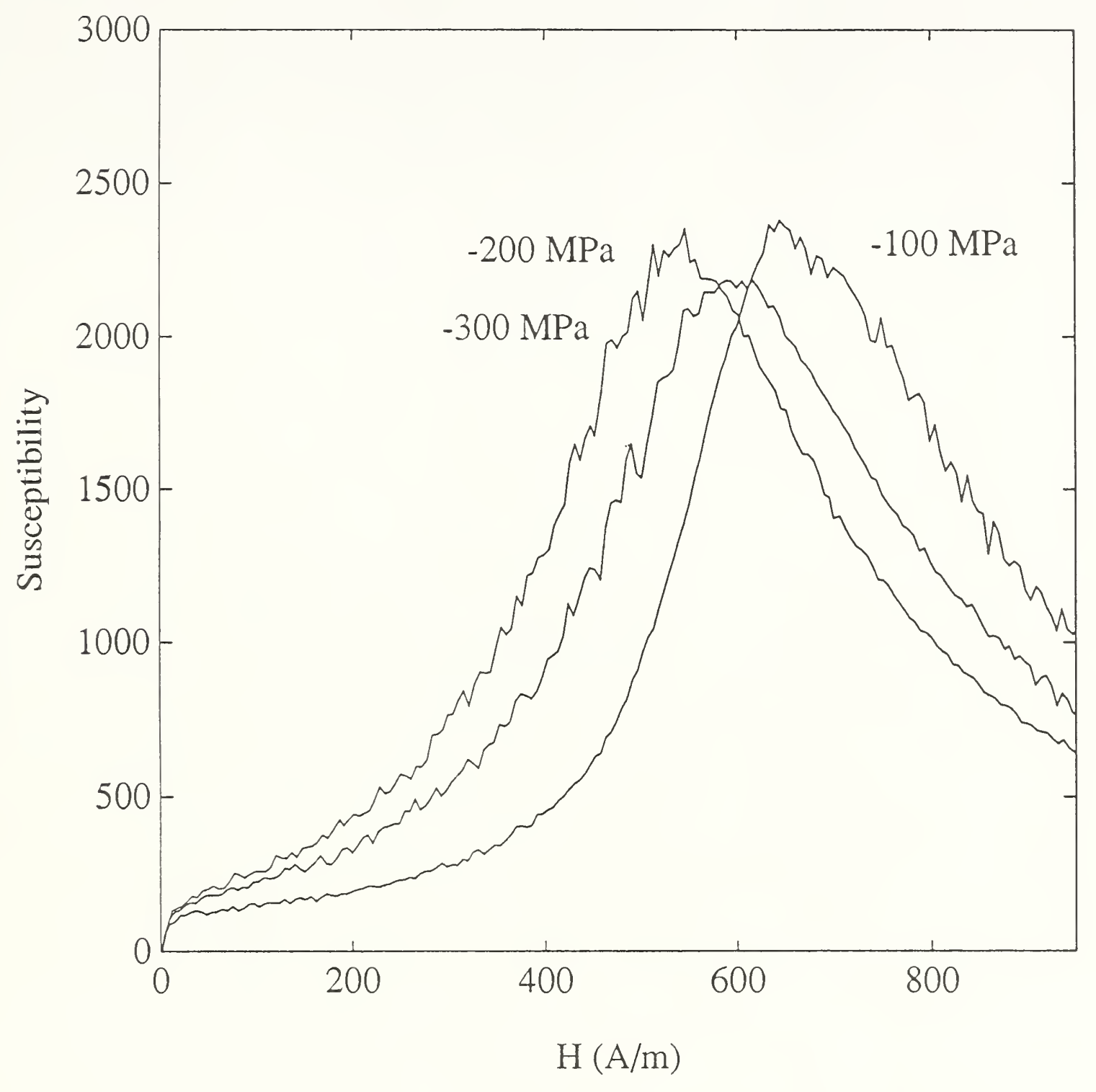

Figure G-16. Susceptibility as a function of applied magnetic field strength after the application and release of negative transverse stresses ranging from -50 to $-400 \mathrm{MPa}$. The measurement is described by (8) in the test plan. 
Appendix $\mathrm{H}$ 


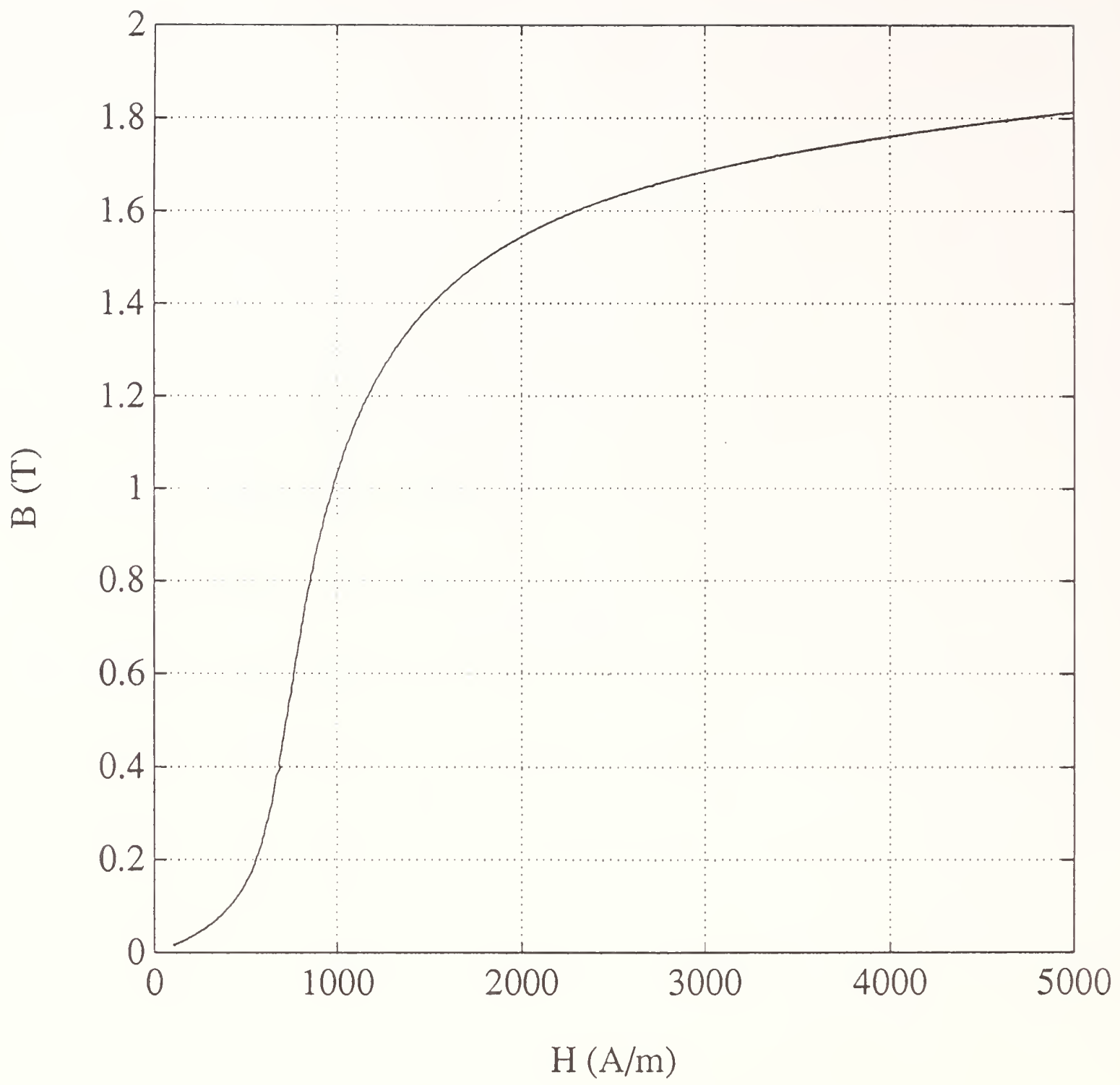

Figure H-1. Normal unstressed magnetization curve as described by (1) in the test plan. 


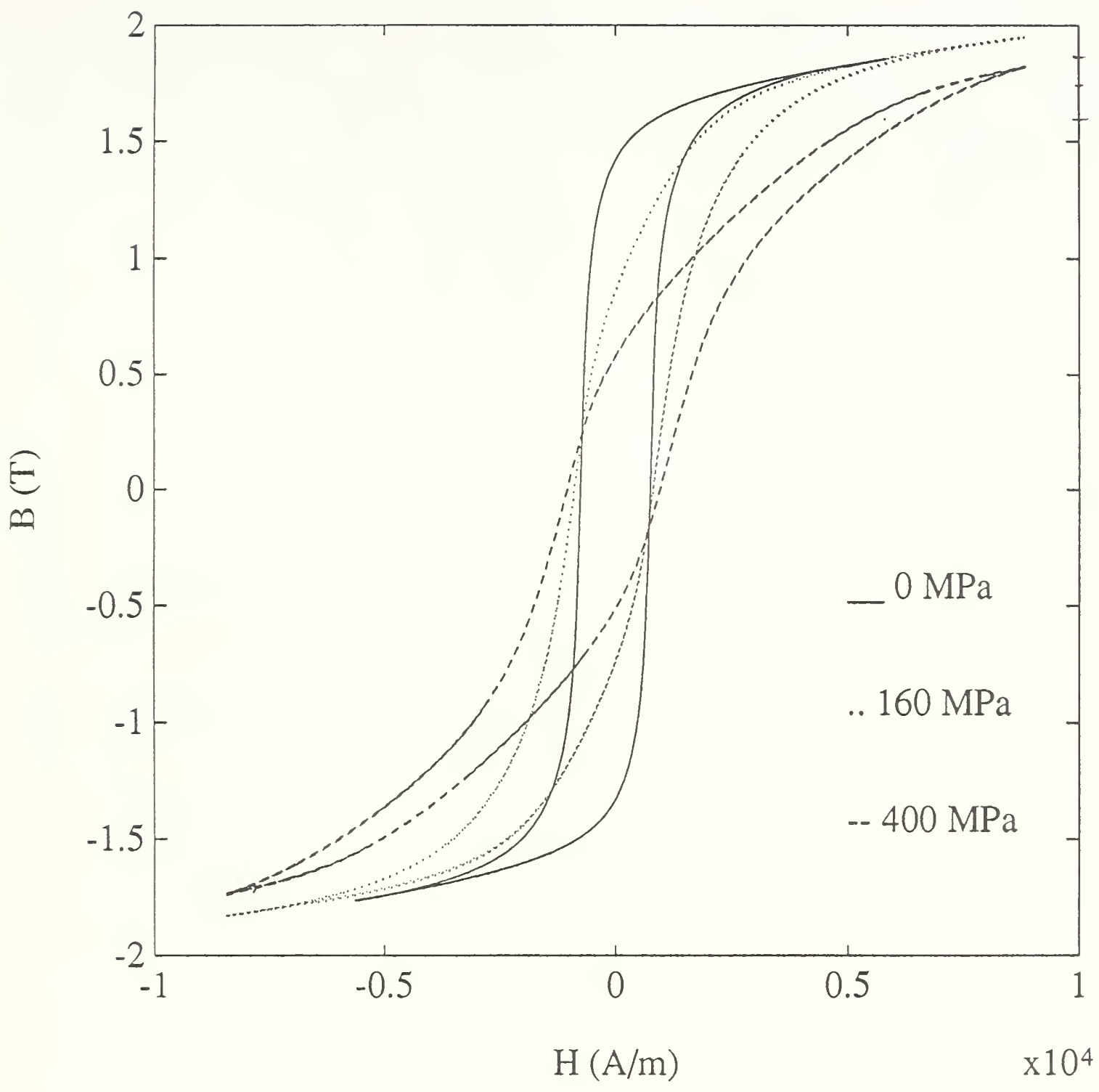

Figure H-2. Magnetic induction as a function of applied magnetic field strength for positive transverse stress (tension) ranging from 0 to $400 \mathrm{MPa}$ as described by (2) in the test plan. The stress results in an effective demagnetizing field which shears the hysteresis loop. 


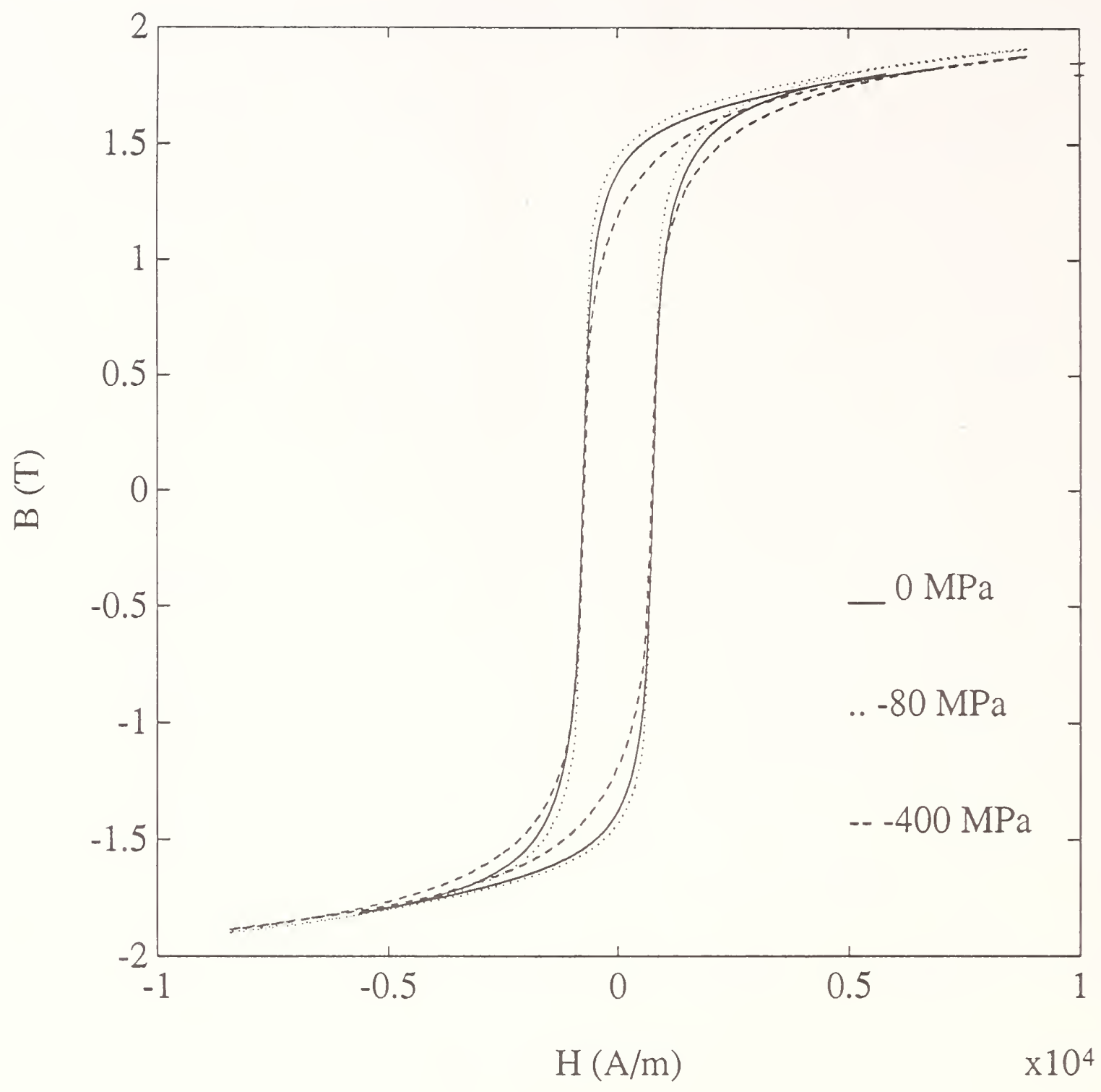

Figure H-3. Magnetic induction as a function of applied magnetic field strength for negative transverse stresses (compression) ranging from 0 to $-400 \mathrm{MPa}$ as described by (2) in the test plan. 


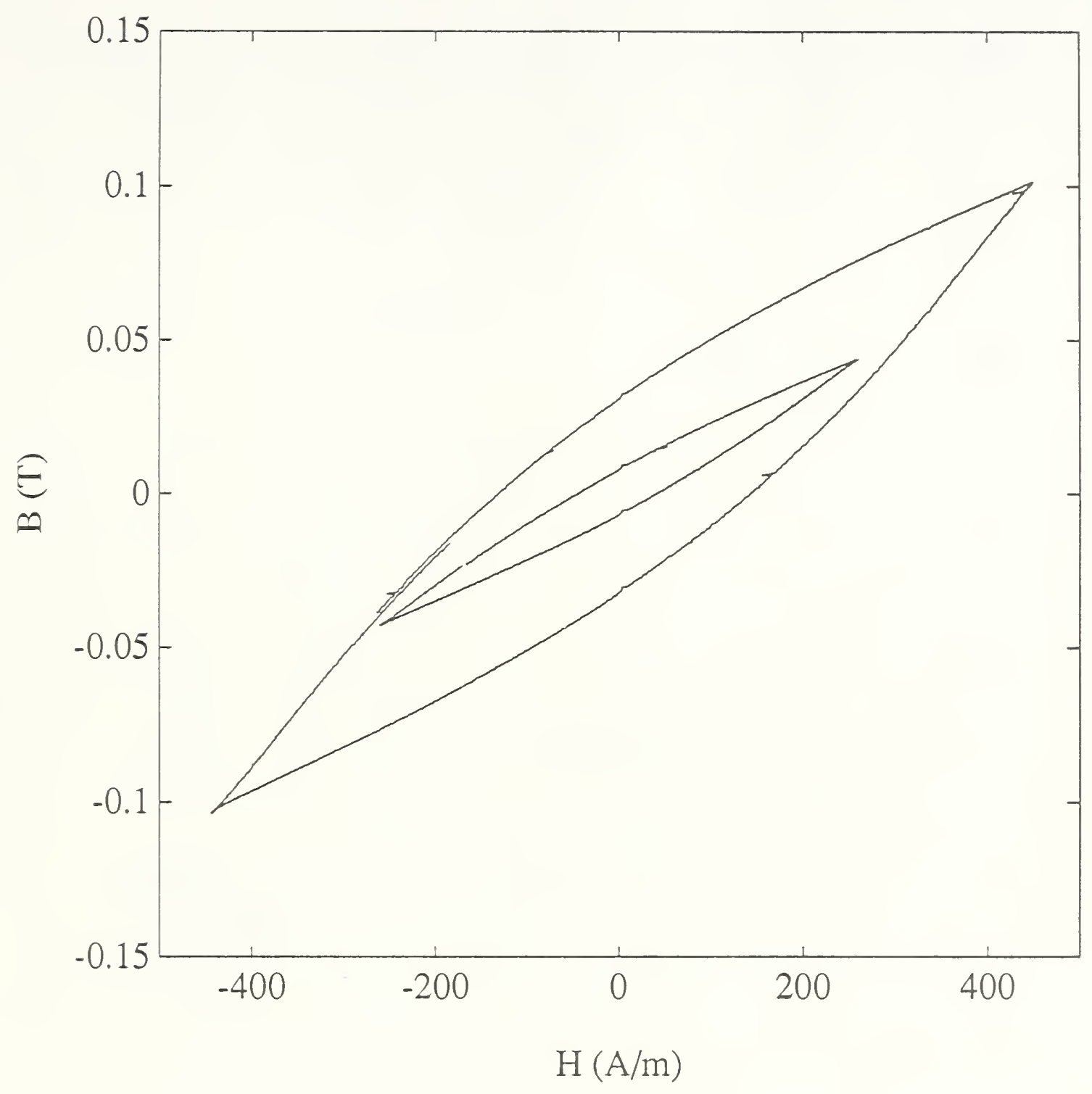

Figure H-4. Magnetic induction as a function of applied magnetic field strength for maximum fields of 200 and $400 \mathrm{~A} / \mathrm{m}$ as described by (3) in the test plan. 


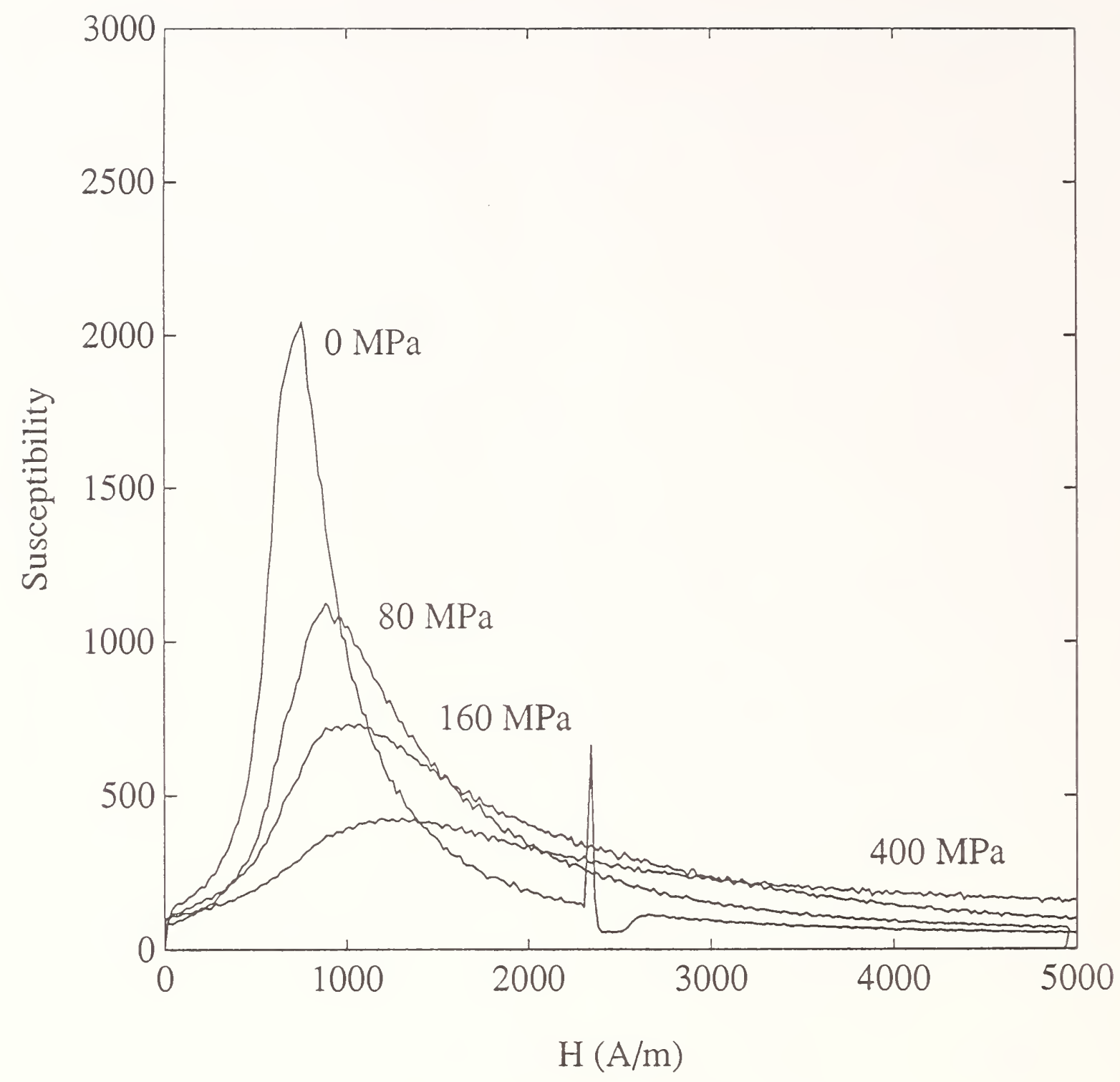

Figure H-5. Susceptibility as a function of applied magnetic field strength for positive transverse stresses (tension) ranging from 0 to $400 \mathrm{MPa}$ as described by (4) in the test plan. 


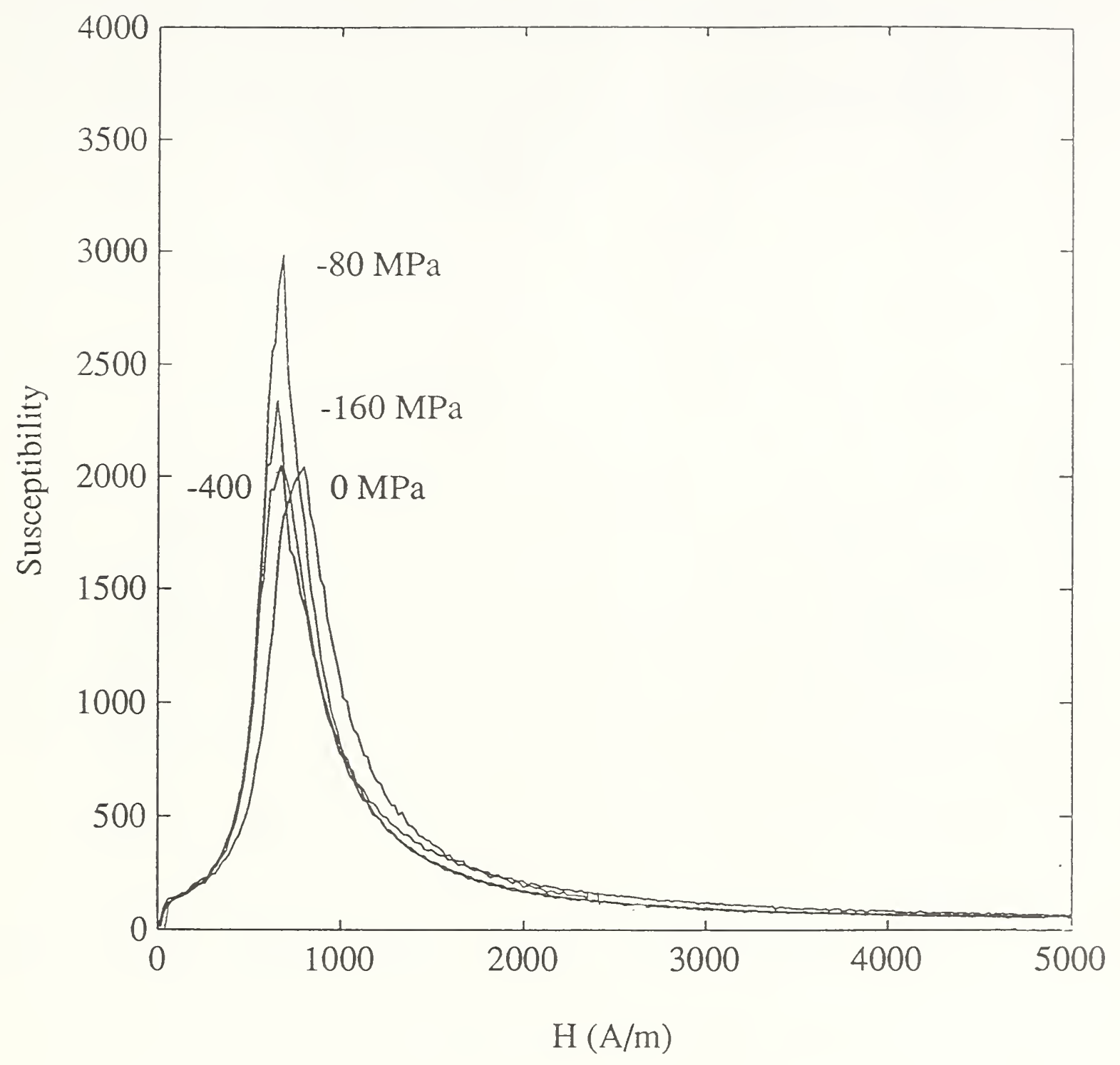

Figure H-6. Susceptibility as a function of applied magnetic field strength for negative transverse stresses (compression) ranging from 0 to $-400 \mathrm{MPa}$ as described by (4) in the test plan. 


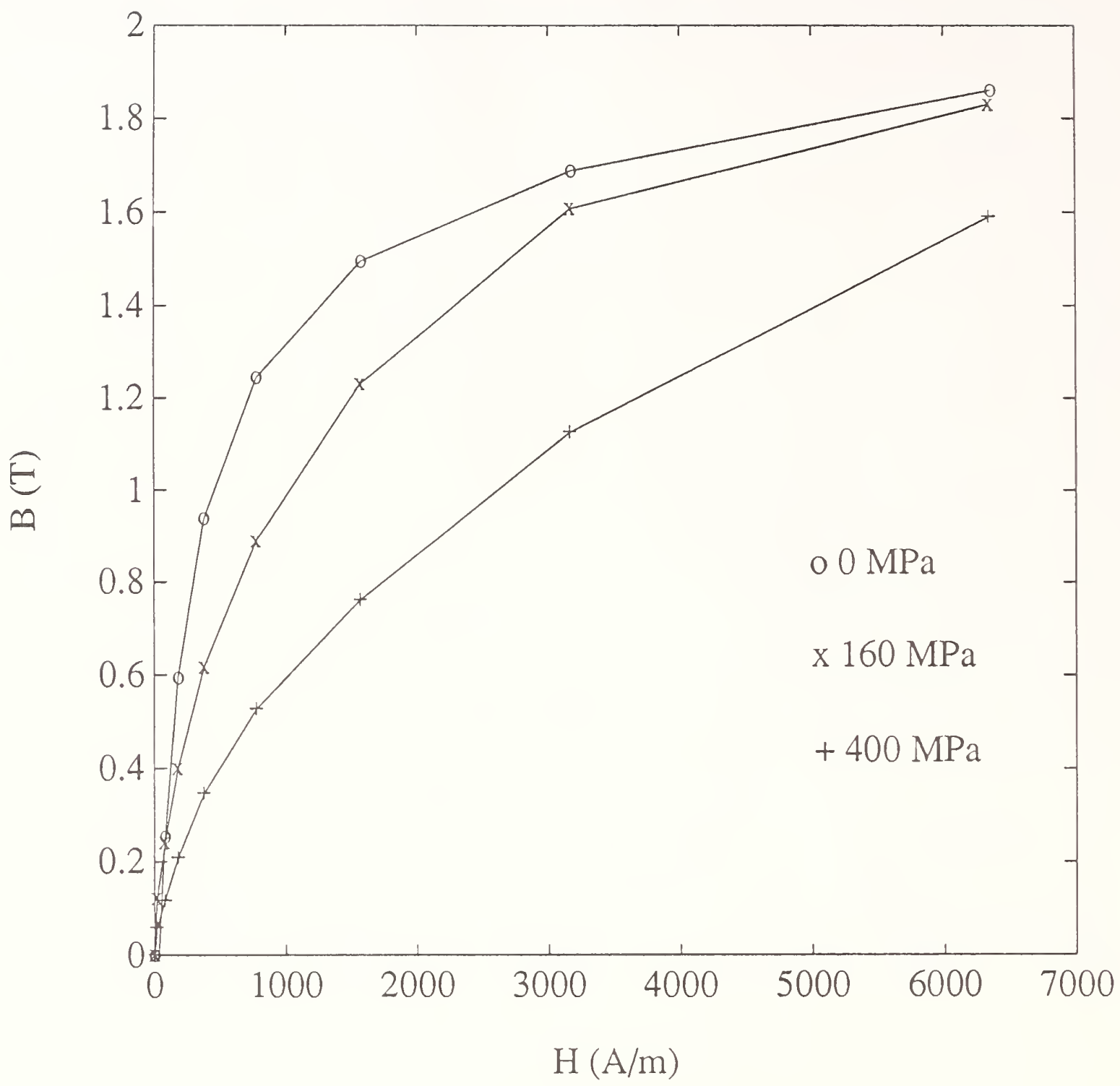

Figure H-7. Anhysteretic magnetization curves for positive transverse stresses (tension) ranging from 0 to $400 \mathrm{MPa}$ as described by (5) in the test plan. 


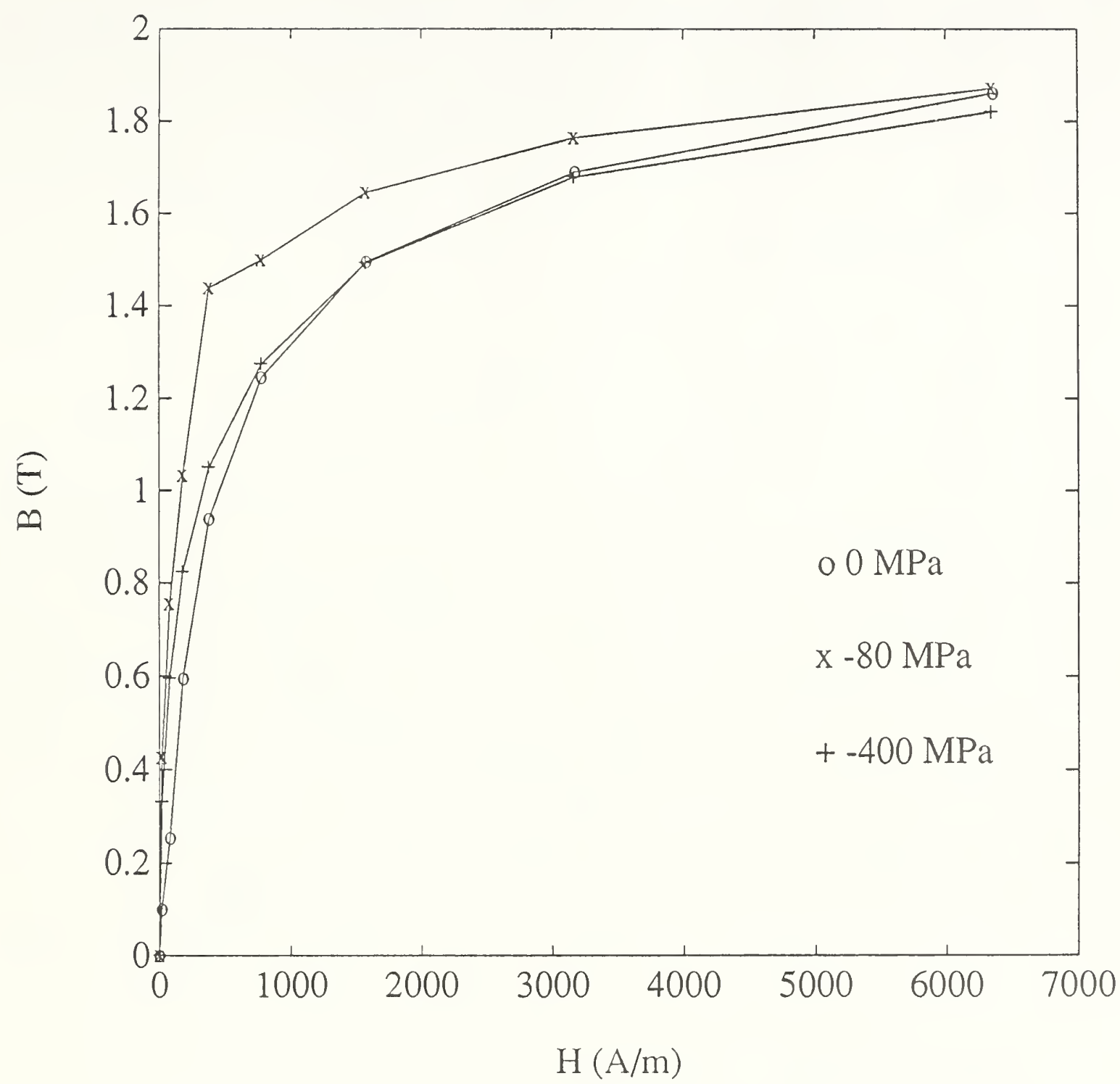

Figure H-8. Anhysteretic magnetization curves for negative transverse stresses (compression) ranging from 0 to $-400 \mathrm{MPa}$ as described by (5) in the test plan. 


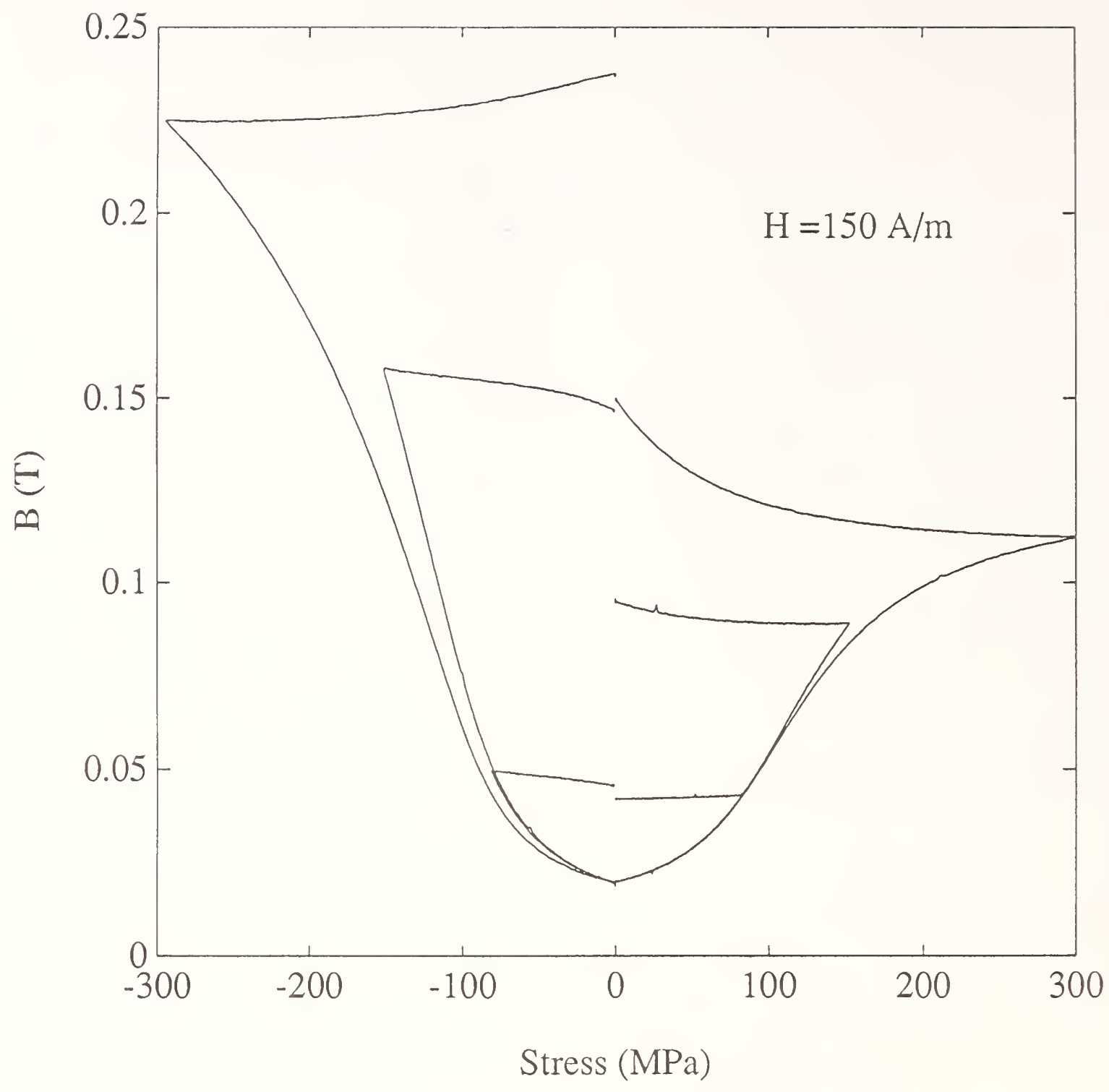

Figure H-9. Magnetic induction as a function of applied transverse stresses ranging from -300 to $300 \mathrm{MPa}$ as described by (6) in the test plan. The dc magnetic field was $150 \mathrm{~A} / \mathrm{m}$. 


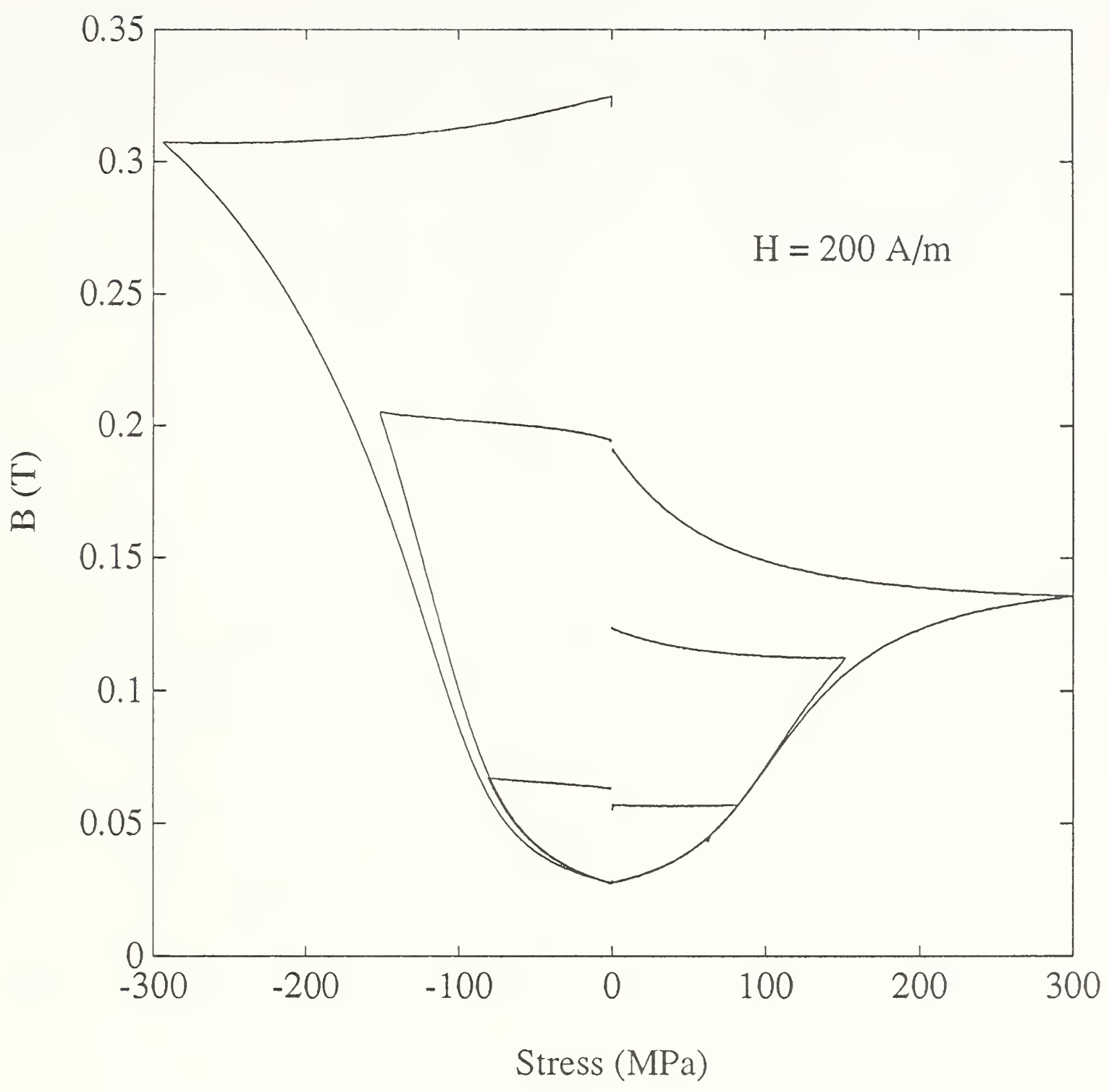

Figure $\mathrm{H}-10$. Magnetic induction as a function of applied transverse stresses ranging from -300 to $300 \mathrm{MPa}$ as described by (6) in the test plan. The dc magnetic field was $200 \mathrm{~A} / \mathrm{m}$. 


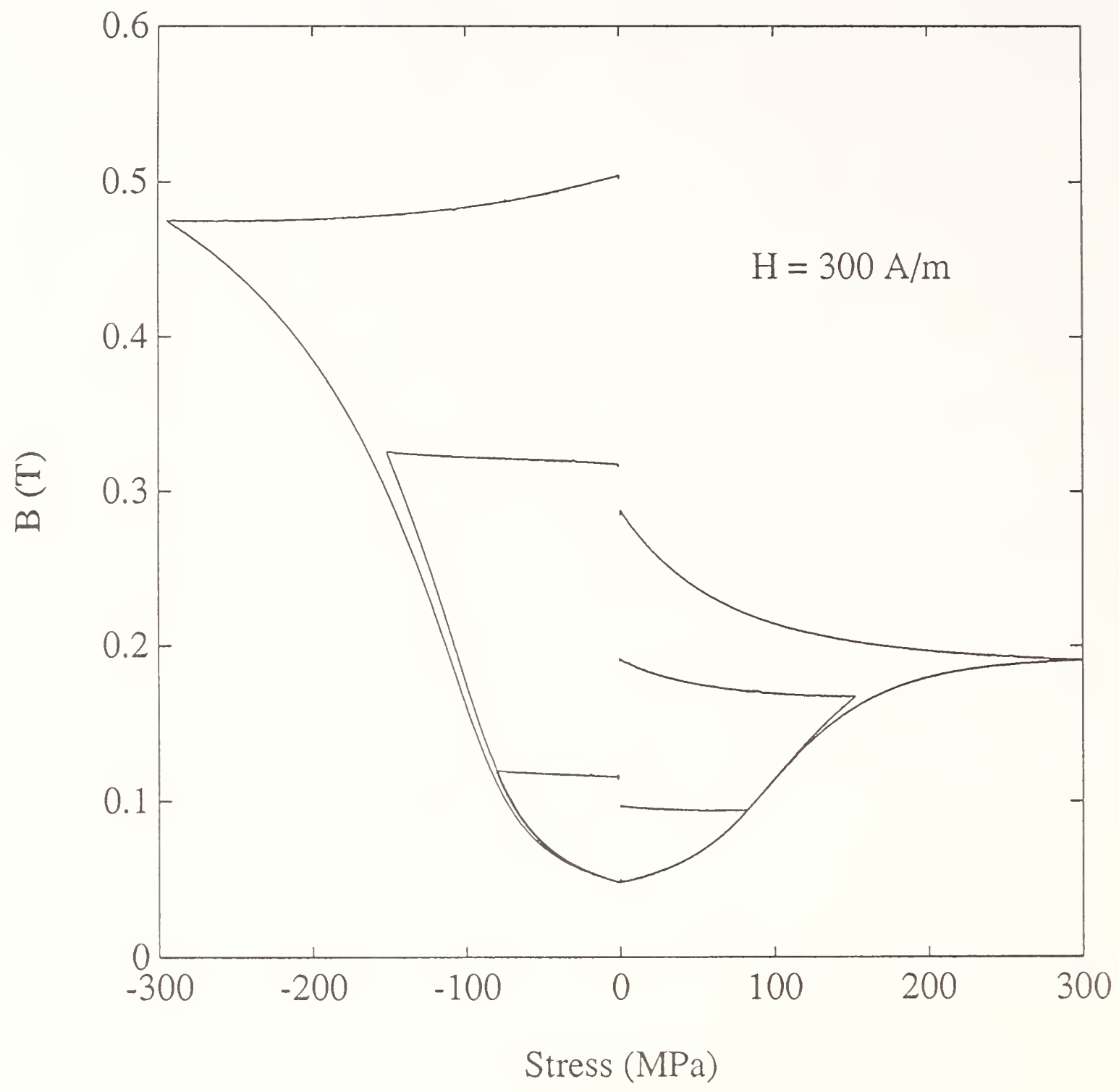

Figure H-11. Magnetic induction as a function of applied transverse stresses ranging from -300 to $300 \mathrm{MPa}$ as described by (6) in the test plan. The dc magnetic field was $300 \mathrm{~A} / \mathrm{m}$. 


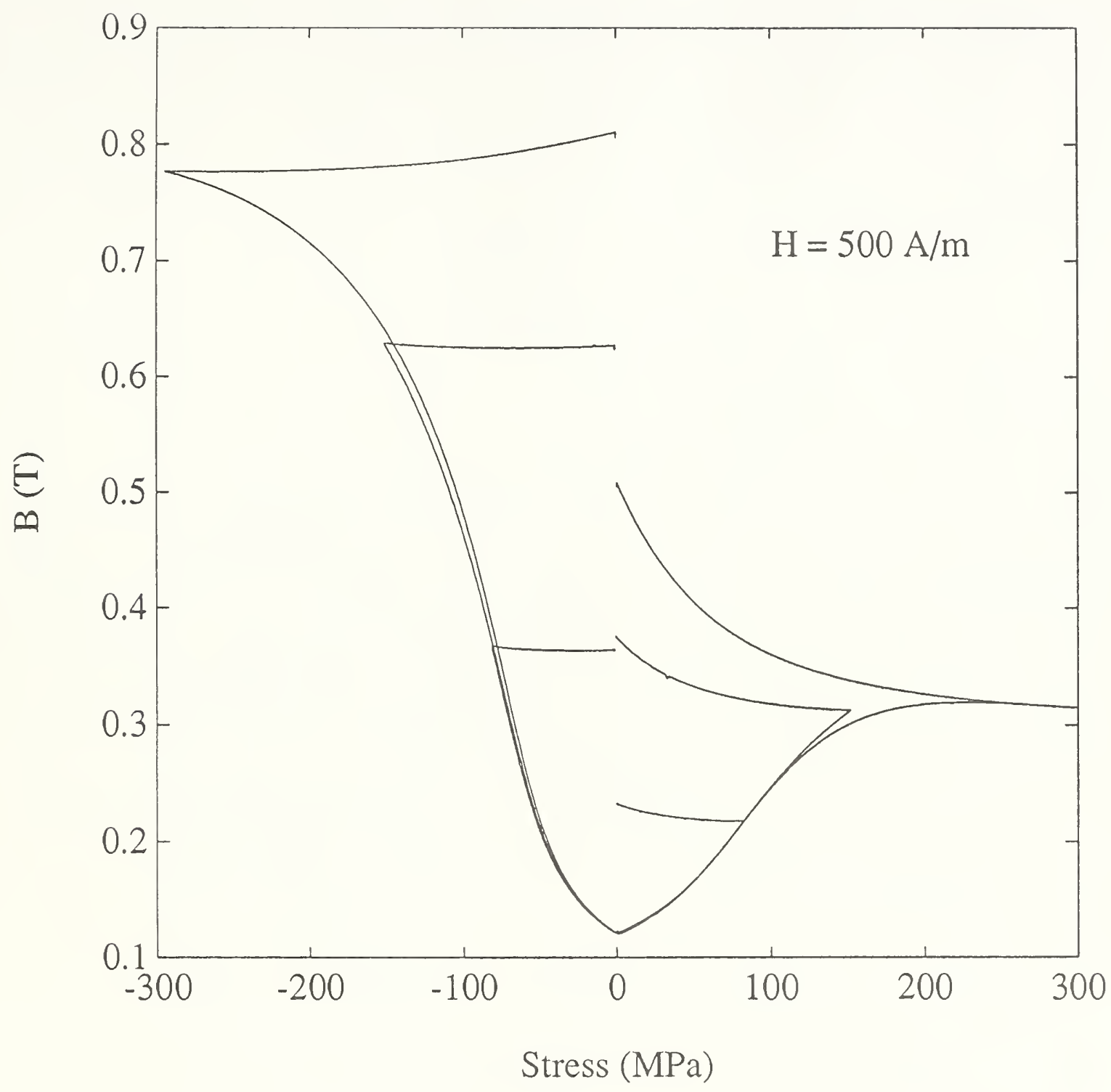

Figure H-12. Magnetic induction as a function of applied transverse stresses ranging from -300 to $300 \mathrm{MPa}$ as described by (6) in the test plan. The dc magnetic field was $500 \mathrm{~A} / \mathrm{m}$. 


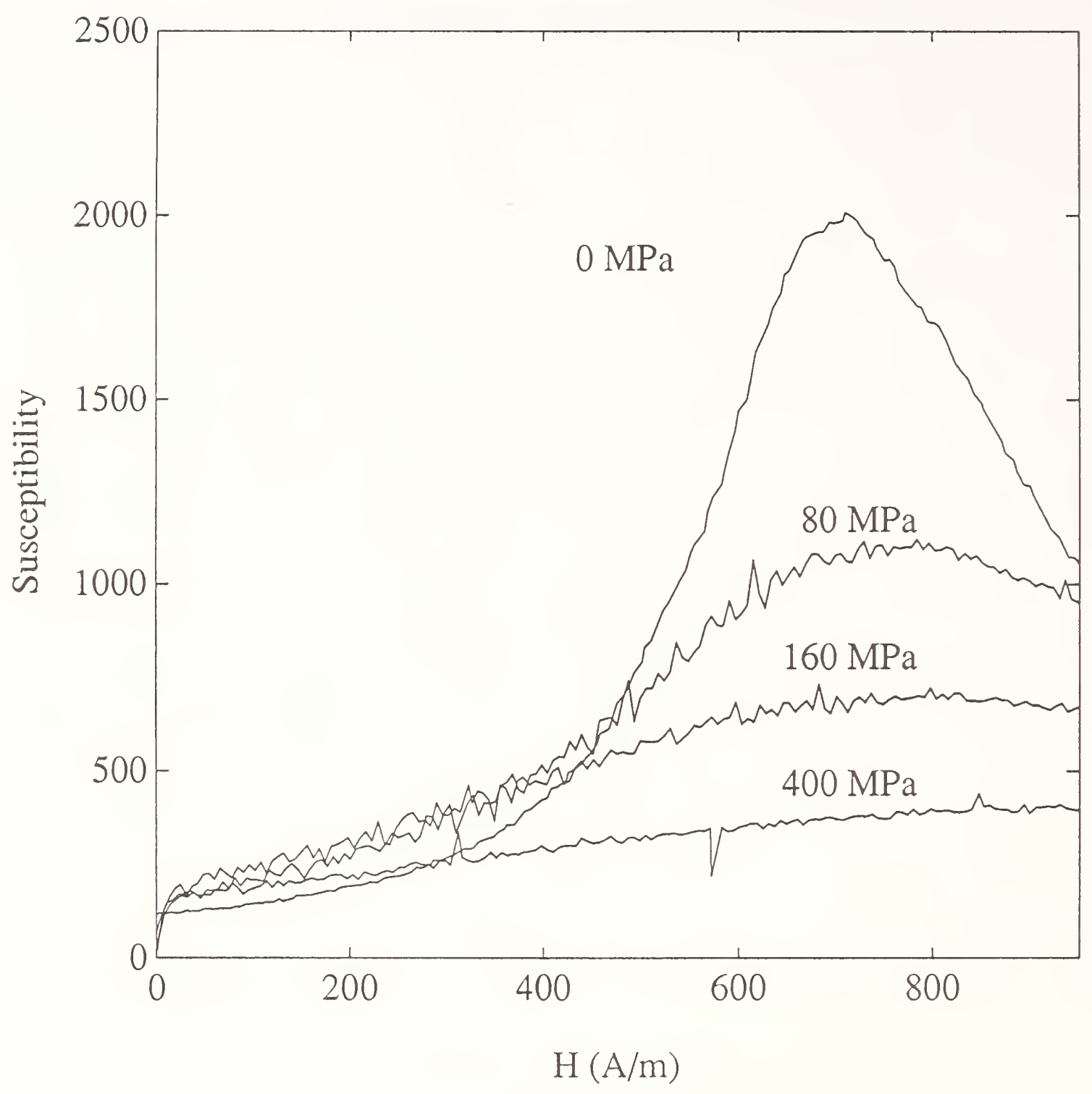

Figure H-13. Susceptibility as a function of applied magnetic field strength for transverse positive stresses (tension) ranging from 0 to $400 \mathrm{MPa}$ as described by (7) in the test plan. 


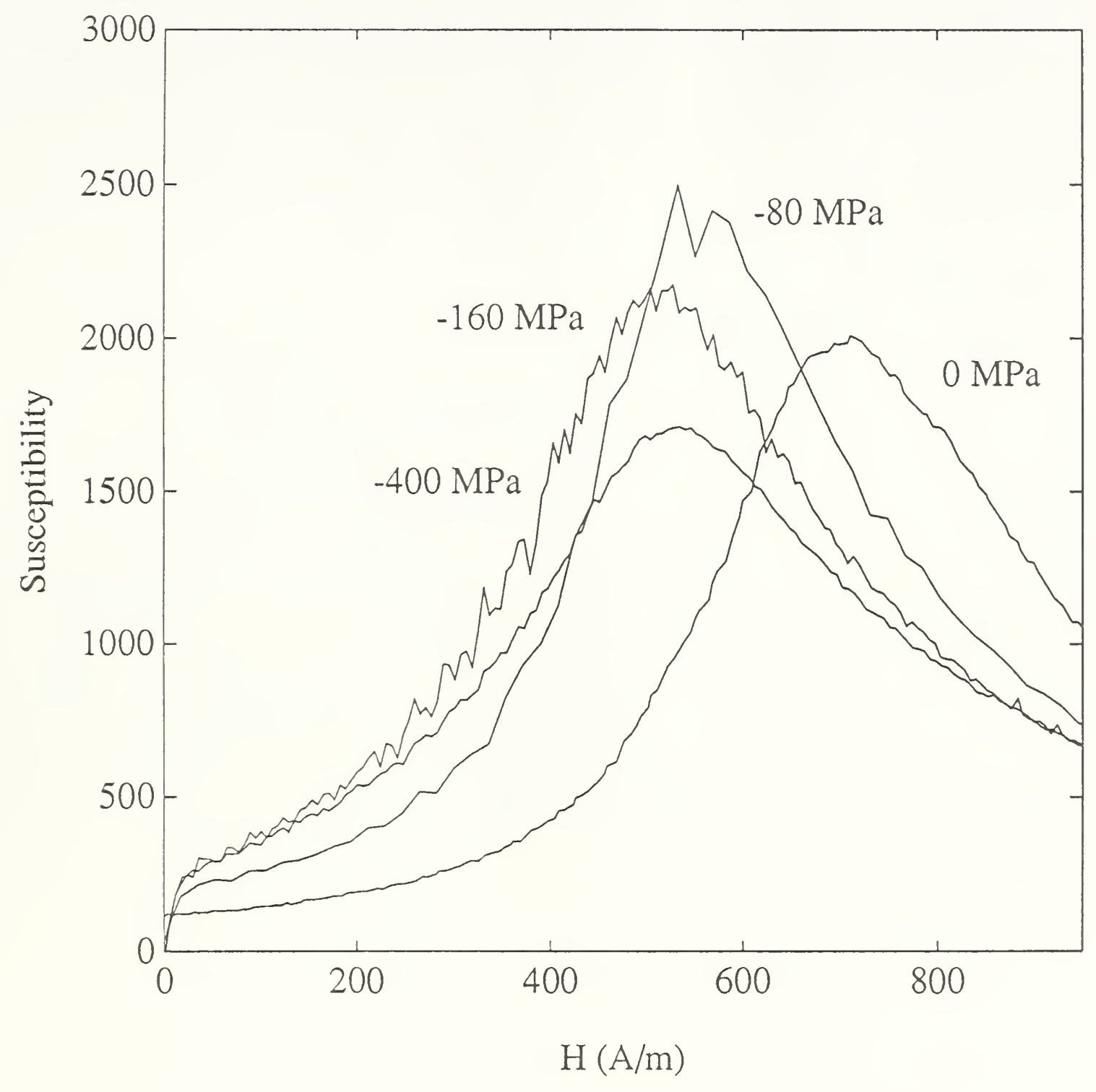

Figure H-14. Susceptibility as a function of applied magnetic field strength for transverse negative stresses (compression) ranging from 0 to $-400 \mathrm{MPa}$ as described by (7) in the test plan. 


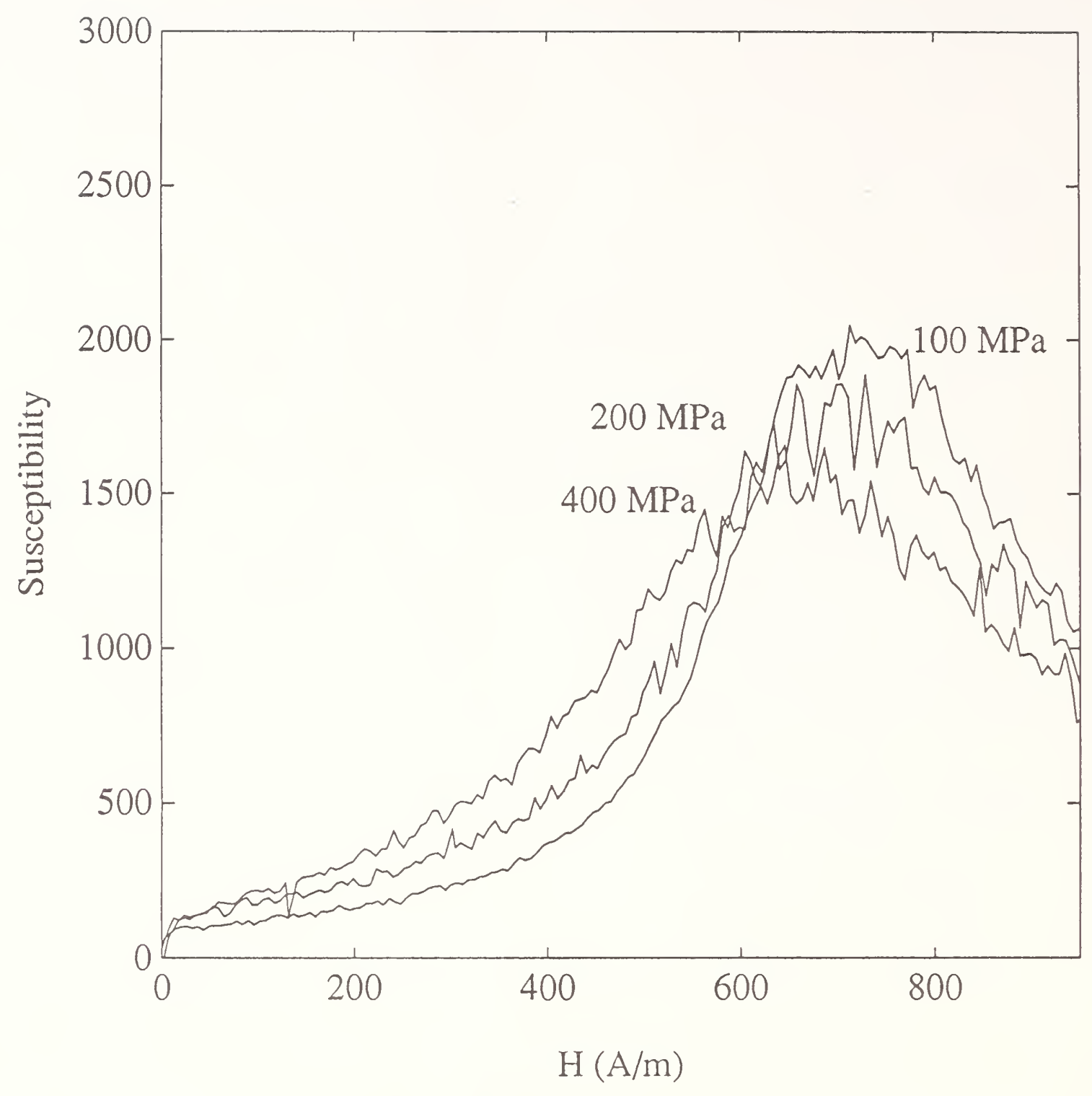

Figure H-15. Susceptibility as a function of applied magnetic field strength after the application and release of positive transverse stresses ranging from 50 to 400 $\mathrm{MPa}$. The measurement is described by (8) in the test plan. 


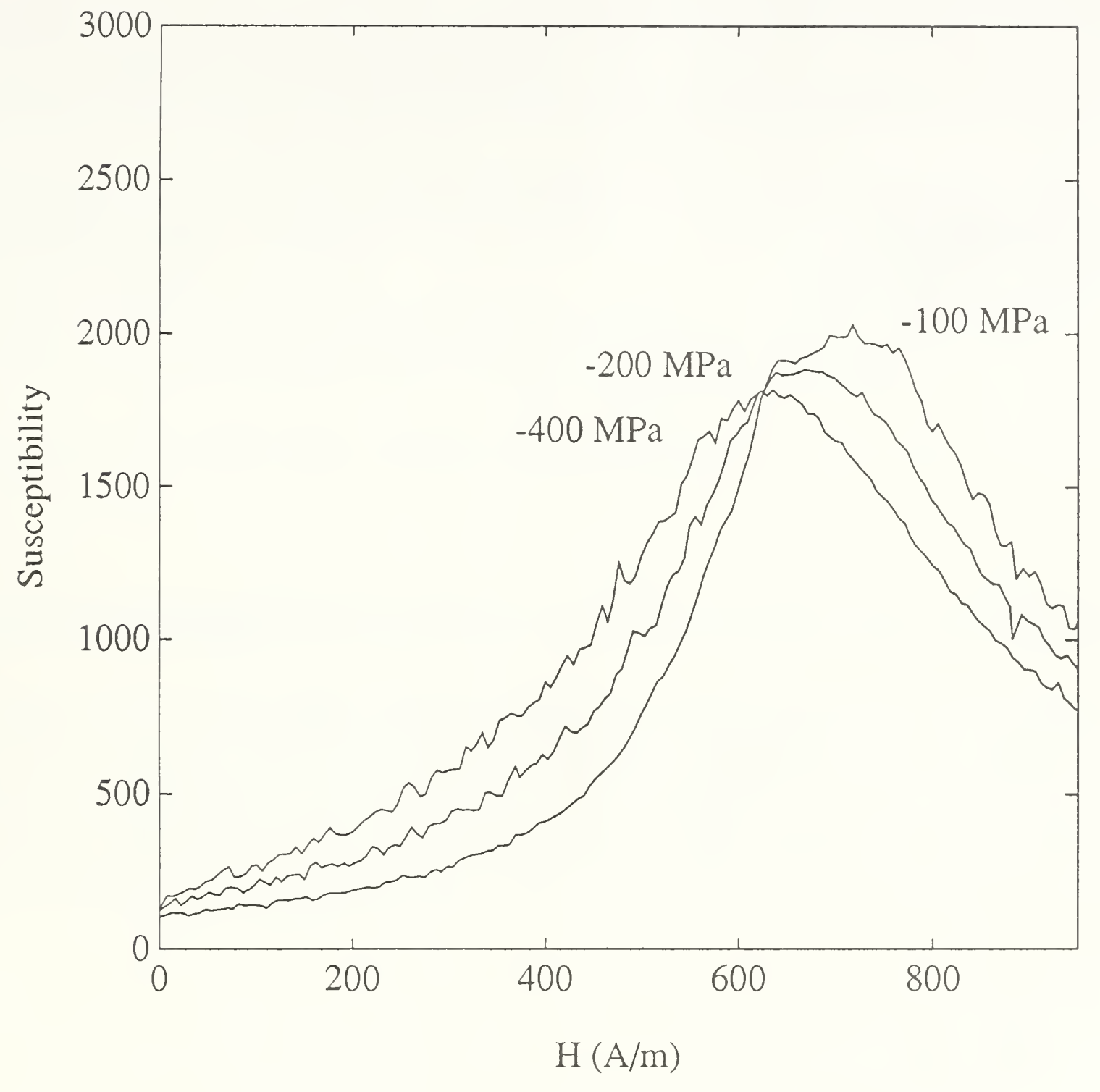

Figure H-16. Susceptibility as a function of applied magnetic field strength after the application and release of negative transverse stresses ranging from -50 to $-400 \mathrm{MPa}$. The measurement is described by (8) in the test plan. 

\begin{tabular}{ll}
\hline BL-114A & U.S. DEPARTMENT OF COMMERCE \\
$(5-\infty)$ & NATIONAL INSTITUTE OF STANDARDS AND TECHNOLOGY
\end{tabular}

BIBLIOGRAPHIC DATA SHEET
1. PUUUCATION ON REPONT NUMBEA

NISTIR 3962

2. PERFOAMINO ORQMIIZATION REPORT MUMBEA

3. PULUCATIOM DATE

September 1991

4. TITLE AND SUBTITLE

Magnetization Changes in Low-Carbon, Ni-Cr-Mo and

High-Strength-Low-Alloy Steels as a Function of Stress

5. AUTHOR(3)

T. W. Petersen

6. PERFORMING ORQANIZATION (FF JOINT OA OTHER THAN MIST, SEE INSTRUCTIONS)

U.S. DEPARTMENT OF COMMEACE

MATIONAL INSTITUTE OF STANDAMDS AND TECHMOLOOY

BOULER, COLORADO $80303-3320$

7. CONTRACT/ORANT NUMBEA

N00167-90MP-00227, -00420

2. TYPE OF AEPORT AND PEAIOD COVERED

Final Report, 12/1/89 - 9/30/91

9. SPONSORING ORGANIZATION MWE AND COMPLETE ADDRESS (STRETT, CTY, STATE, ZIP)

U.S. Department of the Navy, David Taylor Research Center, Annapolis, MD 21402

and

Defense Advanced Research Projects Agency, Arlington, VA 22209

10. SUPPIEMENTARY NOTES

11. ABSTRACT (A 200-WORD OR LESS FACTUAL SUMMARY OF MOST SIOMIFICANT INFOAMATION. IF DOCUMENT INCLUDES A SIONIFICANT BIBLOGRAPHY OA LTERATURE SURVEY, MENTION IT HERE.)

The magnetic properties of eight steel alloys and the effect of tensile and compressive stresses on these properties were measured. Experimental samples were designed to allow the application of stress in a direction transverse to that of the applied magnetic field and the measured induction. The measured properties include the differential susceptibility, the normal magnetization curve, symmetric major and minor hysteresis loops, and the anhysteretic magnetization curve for varying stress levels. In addition, the magnetic induction as a function of applied transverse stress was measured for various dc magnetic fields. This report describes the experimental apparatus, the experimental design, and the results of the measurements.

12. KEY WOADS (6 TO 12 ENTRIES; NPHAEETICAL OADER; CAPTALZE OMLY PROPEA MUMES; NDD SEPARATE KEY WOADS DY SEMICOLONS)

anhysteretic magnetization; compressive stress; ferromagnetism; hysteresis; magnetic induction; magnetic susceptibility; magnetization; magnetoelastic processes; magnetomechanical effects; magnetostriction; steel alloys; stress-induced magnetization; tensile stress.

\begin{tabular}{|c|c|c|}
\hline \multicolumn{2}{|c|}{ 13. AVALARIUTY } & 14. NUMBER OF PRINTED PAGES \\
\hline \multirow[t]{2}{*}{$x$} & UNUMITED & 168 \\
\hline & $\begin{array}{l}\text { ORDER FAOM SUPERINTENDENT OF DOCUMENTS, U.S. COVERMLENT PAINTHM OFFICE, } \\
\text { WASHIMOTON, DC } 20402 .\end{array}$ & \multirow[t]{2}{*}{ 15. PRICE } \\
\hline$\underline{x}$ & ORDER FAOM MATIOMAL TECHMICAL IMFORMATION SERVICE (NTIS), SPRIMOFIELD, VA 22161. & \\
\hline
\end{tabular}




